\title{
Ambivalent Constructions of Nature and Region in Lynn Coady's Fiction: An Ecocritical Reading
}

\author{
By \\ Peter Thompson
}

A dissertation submitted to the Faculty of Graduate Studies and Research

In partial fulfilment of the requirements for the degree of

Doctor of Philosophy

School of Canadian Studies

Carleton University

Ottawa, Ontario

June 9, 2009

(C) Peter Thompson, 2009 
Library and Archives Canada

Published Heritage

Branch

395 Wellington Street

Ottawa ON K1A ON4

Canada
Bibliothèque et

Archives Canada

Direction du

Patrimoine de l'édition

395 , rue Wellington

Ottawa ON K1A ON4

Canada
Your file Votre référence

ISBN: 978-0-494-60124-2

Our file Notre référence

ISBN: 978-0-494-60124-2
NOTICE:

The author has granted a nonexclusive license allowing Library and Archives Canada to reproduce, publish, archive, preserve, conserve, communicate to the public by telecommunication or on the Internet, loan, distribute and sell theses worldwide, for commercial or noncommercial purposes, in microform, paper, electronic and/or any other formats.

The author retains copyright ownership and moral rights in this thesis. Neither the thesis nor substantial extracts from it may be printed or otherwise reproduced without the author's permission.
AVIS:

L'auteur a accordé une licence non exclusive permettant à la Bibliothèque et Archives Canada de reproduire, publier, archiver, sauvegarder, conserver, transmettre au public par télécommunication ou par l'Internet, prêter, distribuer et vendre des thèses partout dans le monde, à des fins commerciales ou autres, sur support microforme, papier, électronique et/ou autres formats.

L'auteur conserve la propriété du droit d'auteur et des droits moraux qui protège cette thèse. $\mathrm{Ni}$ la thèse ni des extraits substantiels de celle-ci ne doivent être imprimés ou autrement reproduits sans son autorisation.
In compliance with the Canadian Privacy Act some supporting forms may have been removed from this thesis.

While these forms may be included in the document page count, their removal does not represent any loss of content from the thesis.
Conformément à la loi canadienne sur la protection de la vie privée, quelques formulaires secondaires ont étè enlevés de cette thèse.

Bien que ces formulaires aient inclus dans la pagination, il n'y aura aucun contenu manquant.

\section{Canadä}




\begin{abstract}
This thesis examines Canadian author Lynn Coady's representation of nature in her four published works of fiction, Strange Heaven (1998), Play the Monster Blind (2000), Saints of Big Harbour (2003), and Mean Boy (2006). Using post-structuralist ecocriticism as a model, I argue that Coady presents nature as a cultural construction and undermines efforts by the state, the tourism industry, and previous generations of writers to portray idealized depictions of the Maritimes and its landscape as permanent, essential, and arising spontaneously. While early ecocritics mainly considered literature that dramatizes a search for redemption or enlightenment through nature, in this thesis I demonstrate that Coady presents a historicized account of constructions of the natural environment. My ecocritical approach identifies three potentially deconstructive sites with which Coady engages: the feminine and masculine body, idyllic portrayals of nature, and toxic landscapes. I focus on the way in which her ironic treatment of these concepts challenges romanticized portraits of the region.
\end{abstract}

In Coady's fiction, conventional definitions of nature are based on three interrelated and socially constructed truths: that women are close to nature, while men possess the ability to control it; that the region is quaint and welcoming to outsiders looking for dramatic yet accessible scenery; and that the natural world exists primarily as pristine wilderness. Coady uses images of the abject to dispute the idea that women are connected to nature through mothering and illustrates the harmful personal and environmental effects of the process by which adult males indoctrinate adolescents into a violent masculine culture that advocates control over the land. By juxtaposing outsiders' expectations of the Maritimes with the impoverished communities they encounter once 
there, Coady contests the serene and therapeutic version of the region promoted by the tourism industry. Finally, Coady's fiction complicates the definition of nature as untouched wilderness through her emphasis on the permanence of the pollution and waste products that dominate rural Cape Breton's post-industrial landscape. 


\section{ACKNOWLEDGEMENTS}

I apologize in advance if this runs a little long, and if it simply reads like a series of lists, but many people played an instrumental role in me completing this dissertation. My supervisor, Michèle Lacombe, could not have been more generous with her time and effort, even during her sabbatical, and provided incisive comments and meticulous readings of my drafts. Her sense of humour and constant reminder that I should "have fun with it" made writing my thesis a very enjoyable experience. Parker Duchemin, who came out of retirement to be on my committee, provided invaluable observations on early drafts, fortified me with tea and fiddle tunes during meetings, and ensured that I keep a copy of Strunk and White within reach at all times. Peter Hodgins was there always to discuss the most important issue, the ups and downs of the Toronto Raptors, and to help me conceptualize this project. Gwen Davies and Brenda Carr Vellino provided insightful questions and advice on the final draft, and smiled encouragingly through my presentation and answers at the defense. Thank you all so much.

I would also like to thank my friends and family who stood by me along the way. My wife, Andy, has always been my champion and my sounding board. Andy has a way about her that is sharp, honest, witty, and caring all at the same time, and she has supported me unconditionally, whether my plan was to get my Ph.D. or to work towards Freedom 32. My parents, Kathy and Leonard, encouraged me in my decision to move to Ottawa to pursue my doctorate, and welcomed me home for much-needed holidays and turkey dinners. Casey and Marie Rocznik embraced me as part of their family and provided respite from my dissertation in Winnipeg, New York, Boisdale, and Madeira Beach. My brothers and sisters, Camilla, Gibby, Emma, and Colin, my aunt Patty, Paul and Ronda White, my cousins, my nephew Noah, Pam, Adam (who kindly helped me edit my thesis), Robbie, Melissa, Nick, Gavin, Andrew, Jenn, Crystal, and many others gave me places to stay, lots of laughs, and loving support.

The $12^{\text {th }}$ floor of Dunton Tower has very much been like a second home to me for the past five years. I would like to thank Mary Casaubon, Cathy Schmeuck, Hadbaa Zebala, and Lori Dearman for helping me navigate the bureaucratic demands of grad school and for always cheering me on. Thanks to Paul Litt, Richard Nimijean, Pauline Rankin, André Loiselle, François Rocher, Brian Johnson, Jennifer Henderson, and Roxanne Ross for their wisdom and guidance. Thanks also to my colleagues, especially Julie Tomiak, Lisa Prosper, Ted McCoy, Jeff Ruhl, Robyn Green, Tim Di Leo Browne, Samah Sabra, Oren Howlett, Sophie Tamas, Miha Vieru, Francesca L'Orfano, Lyndal Neelin, and Mandy McCarthy, who helped me refine my ideas at various points and commiserated with me over lunch, coffee, and beer about research and life choices.

Finally, I want to thank my grandfather, Peter White, who saw me through every stage of my academic career, from taking me out for breakfast on grading day in elementary school, to giving me my X-Ring, to pestering me about completing my Ph.D. Strangely enough, he passed away the same week as I submitted my final draft, and just days before I could finally give him a definite date for when I'd be finished. Expressing how much he meant to me in an acknowledgements page is impossible, but I'd still like to make the very modest gesture of dedicating this dissertation to him.

As Lynn Coady might say, may God bless and keep SSHRC, the Ontario Graduate Scholarship Programme, and Carleton's Faculty of Graduate Studies for their generous financial support of this research. 


\section{TABLE OF CONTENTS}

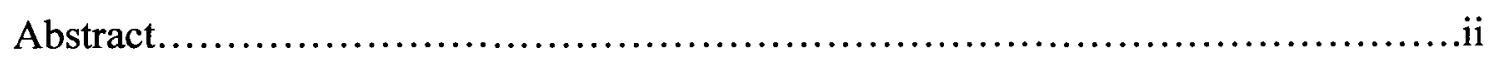

Acknowledgements............................................................

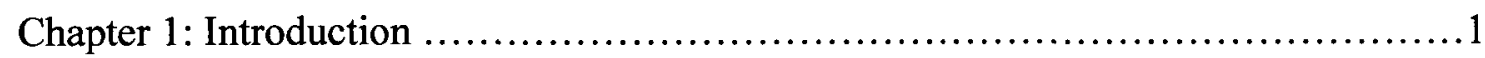

Chapter 2: Creating Space for Contemporary Maritime Fiction $\ldots \ldots \ldots \ldots \ldots \ldots \ldots \ldots \ldots .21$

Chapter 3: Post-structuralism and Canadian Ecocritical Theory ......................53

Chapter 4: Constructions of the Body and Nature in Coady's Fiction...................75

Chapter 5: Coady's Subversion of the Maritimes' Idyllic Landscape..................136

Chapter 6: Coady's Post-Industrial Cape Breton..................................196

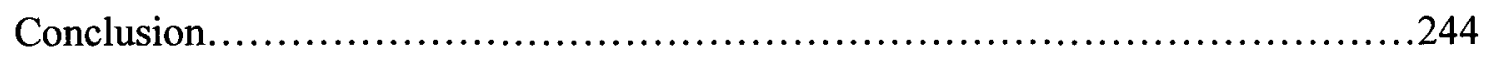

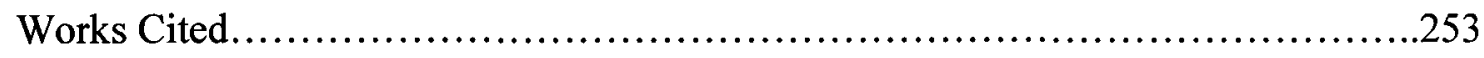

Appendix A: Bibliography of Writings by Lynn Coady ..........................280

Appendix B: Journal Articles and Book Reviews on Coady's Work................289 


\section{CHAPTER 1: INTRODUCTION}

\section{Overview}

Industrial Cape Breton - the region in which Canadian author Lynn Coady (b. 1970) was raised - is home to obvious and not-so-obvious scars of two closely-linked developments that took place over the last half-century: the advent of North America's post-industrial era and the rise of an unprecedented environmental crisis. The collapse of key resources such as coal, timber, and fish has devastated the Maritimes' economy, and the remnants of Cape Breton's industrial projects blight its landscape. Lynn Coady saw first-hand the effects of the breakdown of the region's economy on her community, Port Hawkesbury, a pulp and paper town near the Canso Causeway that separates Nova Scotia from Cape Breton. During the early 1980s, a small business her father owned went bankrupt (Steeves 231). The Cape Breton in which Coady grew up has also experienced the fall-out from North America's environmental disaster, as the all-but-abandoned industrial sector upon which the island was built has left a legacy of toxic waste in the form of the Sydney tar ponds and the shuttered mines and manufacturing sites that dot the island.

Out of late twentieth-century society's increased awareness of its reckless treatment of the natural world has emerged ecocriticism, a literary and cultural theory that examines the role of the environment in art and literature. Ecocriticism has both political and theoretical aims: at the political level, it proposes that critics should be attentive to the potential for texts to embody a sense of environmental responsibility, and at the theoretical level, ecocriticism contends that humanity's problematic relationship with the natural world is the product of an epistemological disjuncture between culture and nature, 
a gap which it actively seeks to bridge by promoting "environmentalist" literature (Kerridge 5, Rosendale xvi, Love 201-2). As the field has grown in scope, however, ecocritics have begun to argue that in focusing solely on "nature writing," its proponents ignore spaces altered by humans and endorse a linguistic model that views society and the natural environment as discrete entities.

The sharp distinction between nature and culture employed by many ecocritics is also present in Canadian literary criticism and early ecocritical analyses in Canada. As recent studies in Canadian ecocriticism have pointed out, this field has traditionally been concerned with nature poetry and environmentalist literature that romanticizes wilderness spaces. ${ }^{1}$ Post-structuralist ecocriticism maintains that in order to fully understand what a relationship between human society and the environment might or should look like, critics must acknowledge that definitions of "nature" are contested. Post-structuralist ecocritics argue that "nature" is a difficult concept to pin down. For example, in "The Trouble With Wilderness; or, Getting Back to the Wrong Nature" (1996), William Cronon suggests that nature's meanings are contingent and ambiguous and its various manifestations "are cultural constructions that reflect human judgements, human values, human choices" (34). Just as contemporary cultural theory has pinpointed the dangers inherent in essentializing groups of people, so it has demonstrated that it is equally unsatisfactory to essentialize nature; conventional ecocriticism often attempts to do just that, however, by appealing to the idea of a universal and fundamental nature whose meaning is "transparent and uncomplicated" (Cronon 34).

\footnotetext{
${ }^{1}$ See Lousley, "Knowledge, Power and Place: Environmental Politics in the Fiction of Matt Cohen and David Adams Richards" (2007), Calder, "The Wilderness Plot, the Deep Map and Sharon Butala's Changing Prairie" (2002), and O'Brien, "Articulating a World of Difference: Ecocriticism, Postcolonialism and Globalization." (2001).
} 
In what follows, I argue that in Lynn Coady's fiction, ${ }^{2}$ nature emerges as a constructed, rather than essential, entity. Coady achieves this by undermining three conventional definitions of nature: as gendered, as idyllic, and as untouched wilderness. While Canadian writers whose texts critics deem "proto-ecocritical" dramatize a search for redemption or enlightenment through the natural environment (Relke, "Feminist Ecocritique" 73, Bondar, "Metapoetics" 19, Forster 107), Coady instead presents an historicized account of Maritime Canada's construction of the natural world. As I discuss in further detail in the following chapter, Coady makes use of satirical approaches in order to undermine restrictive elements of Maritime Canadian society, including gender relations, class status, regional stereotypes, religious mores, and especially, as this thesis explores, definitions of nature. Coady deconstructs the societal structures that present romanticized portraits of the region and its landscape as permanent, essential, and arising spontaneously.

For Coady, conventional definitions of nature are based on three inter-related socially constructed truths: that women are ideally close to nature, while men ideally possess the ability to control it; that the region is idyllic and welcoming to outsiders looking for dramatic yet accessible scenery; and that the natural world exists primarily as pristine wilderness. While traditional understandings of nature are bound up with the idea of "purity," William Cronon, Lawrence Buell and Donna Haraway observe that

\footnotetext{
2 This thesis examines Coady's four published works of fiction: Strange Heaven (1998), Play the Monster Blind (2000), Saints of Big Harbour (2002), and Mean Boy (2006).

From this point, the texts will be abbreviated as follows in parenthetical references: $\underline{\mathrm{SH}}$, $\underline{\mathrm{PMB}}, \underline{\mathrm{SOBH}}$, and $\underline{\mathrm{MB}}$. Coady is a very prolific writer who has published plays, dozens of articles and reviews, and short stories in a variety of forums (See Appendix A). While I do not focus on Coady's non-fiction work, I discuss it occasionally, when it assists in understanding her fiction.
} 
postmodern writing is often marked by what they call "toxic discourse," or a preoccupation with images of pollution and waste. These critics suggest that authors who employ "toxic discourse" depict contemporary North America in physical and social decay: airborne pollutants and chemical spills spread dangerous toxins to even the most remote wilderness spaces, and post-industrial economic conditions inspire fights over dwindling resources. Coady similarly undermines images of the Maritimes and its landscape as "pure," "authentic," and "pristine;" in her fiction, the region is contaminated by a toxic masculine culture, an exploitative tourism industry, and smog emitted from the mills and pulp trucks that dominate her settings.

While traditional ecocriticism in Canada often objectified the natural world, Coady's fiction shows that constructions of nature are not innocent: they are imbued with ideology and deployed for specific purposes. Coady employs images of the abject to challenge the idea that women are connected to nature through mothering and dramatizes the harmful personal and environmental effects of the process by which adult males indoctrinate adolescents into a violent masculine culture that advocates control over nature. By juxtaposing outsiders' expectations of the Maritimes with the impoverished communities they encounter once there, Coady contests the tourism industry's depiction of the region as idyllic. Finally, Coady's fiction undermines the definition of nature as untouched wilderness through her emphasis on the permanence of the pollution and waste products that dominate rural Cape Breton's post-industrial landscape. As I will demonstrate, the feminine and masculine body, pastoralism, and toxic landscapes are three of post-structuralist ecocriticism's most important concepts and are also critical aspects of Coady's fiction. Coady's texts refuse to romanticize natural settings; she 
instead explores the tension between conventional environmental thought and the reality that many of her characters find it necessary to exploit the land within an economic system that is largely resource-based.

\section{Coady and the Critics}

Since Lynn Coady is a young and still emerging writer, her fiction has not yet received a great deal of attention in academic circles in Canada or elsewhere. At present, there are four dedicated critical articles or chapters on her work, all of which focus on her first novel, Strange Heaven, and many book reviews in newspapers and journals on her four published works of fiction. ${ }^{3}$ Coady is actively involved in Canada's literary scene: she has written columns in newspapers and magazines for years, she has participated in discussions and panels on Canadian literature and culture in a variety of settings, she has edited volumes of short stories and collections, ${ }^{4}$ and she has granted numerous interviews. ${ }^{5}$ The book reviews and scholarly research on Coady's writing unanimously agree that her work represents a move away from traditional depictions of the Maritimes and that it specifically attacks stereotypes of the region. Book reviews of Coady's work also identify three other major themes in Coady's fiction: her treatment of gender relations, ${ }^{6}$ violence, ${ }^{7}$ and class. ${ }^{8}$ Several reviewers make cursory mention of the role the

\footnotetext{
${ }^{3}$ See Appendix B. In this introductory chapter, I offer a short summary of the key issues which arise from the journalistic reviews of Coady's work and provide a review of the approaches taken by the academic articles written on her thus far in order to differentiate my reading from them. I also examine the specific claims made by some of the critics and reviewers in the later chapters.

${ }^{4}$ See Appendix A.

${ }^{5}$ See Appendix B.

${ }^{6}$ See Venetis 154, Kemp 416, Hoefle 3, Drainie 33, Matthews 133, Venetis 154, Fuller, "Living in Hopes" 199. Some reviews suggest that Coady's work can be divided into
} 
environment plays in Coady's fiction; however, they do so mainly in the context of pointing out that Coady's "wrecked landscape" contributes to her depressing portrait of the post-industrial Maritime region. ${ }^{9}$ This thesis provides the first sustained reading of Coady's response to environmental and ecological issues. ${ }^{10}$

Most reviewers of Coady's work are concerned with her conflicted relationship with the physical, imaginative, and literary space of the Maritimes. While some highlight her use of the linguistic rhythms of the East Coast, which, they argue, places her firmly in the tradition of the region's storytellers, ${ }^{11}$ most point out that Coady's work represents a departure from the social realism of Alistair MacLeod and David Adams Richards. Others, however, see in Coady's writing a complete rejection of the authors who precede her. In his 2006 review of Mean Boy, for example, R.M. Vaughan observes that Coady dismisses and undermines the tradition of social realist and romantic writing characteristic of earlier generations of Maritime writers: "Coady has created a body of work that positions her as the anti-Alistair MacLeod. You won't find any of the familiar stereotypes of Atlantic Canadians in Coady's books -- no stoic, hard-bitten natural poets ennobled by grinding poverty, no long-suffering seamen's wives wandering the harbours

female texts (Strange Heaven and Play the Monster Blind) and male texts (Saints of Big Harbour and Mean Boy). Coady has said that she agrees with this observation (Steeves 235).

${ }^{7}$ See Kavanaugh C13, Hollander B3, Tong M18, Grainger D13, Ryan 33, Kemp 416, Hepburn 122.

${ }^{8}$ See Donnelly J3, Vaughan WP 15, McGillis, "Here's why Lynn Coady is one of Canada's best" I1, Van Herk, "Teen struggles to find truth in a riptide of lies and terror" D11, Kemp 416, Bigge D17.

${ }^{9}$ See Vaughan WP15, Tong, "The Trials of Creative Writing School" D13, Walker E5, Daurio D3, Kavanaugh C13, among others.

${ }^{10}$ I should also point out that this is the first study to look at Coady's work in its entirety.

${ }^{11}$ See, for example, Bethune 84, Taylor 29-36, Hepburn 122-24, Donnelly J3 and Walker E5 among others. 
wrapped in shawls and seaweed, no toothless fiddlers full of gingery wisdom. Coady smartly leaves that nonsense to the lighthouse-haunting romantic" (WP 15). Although Vaughan suggests that the Canadian literary community might have cause to be disappointed because Coady's writing fails to live up to their belief that Maritime writing should be filled with down-home friendly characters, a majority of reviews of her novels respond positively to the profane and irreverent way in which she reimagines the region. $^{12}$

The major recurring theme in these reviews is the sometimes delighted and sometimes horrified shock that critics express at her no-holds-barred depiction of life in Maritime Canada and her ironic use of stereotypes from within and outside the region. ${ }^{13}$ These reviewers argue that Coady upsets conventional notions of Maritime literature in two ways: she at once uses the representational power of uncomfortable stereotypes of the region's inhabitants and upsets the sensibilities of people from outside the region by insisting that the living conditions of which she writes do exist in Canada. In what follows, I argue that Coady uses alcohol and drug abuse, scatological references, violence, and the sense of despair that seems to pervade her work in order to deconstruct romanticized literary and cultural portraits of the Maritimes. The book reviews tend to treat this aspect of Coady's work as a novelty; I argue, however, that it signals Coady's ambivalent relationship with the authors who precede her in the region.

In this thesis, I also examine the ironic relationship with Maritime stereotypes that Coady reveals in her fiction. Instead of suggesting, however, like Vaughan and others,

\footnotetext{
${ }^{12}$ See Tong, "The Trials of Creative Writing School" D13, Donnelly, Van Herk, "Campus Poets Go Wild" D3, McGillis J4, Daurio D3, Levine 1, Bethune 84, Halim 24.

${ }^{13}$ See Haggas 300, Hoefle 3, Drainie 33, Matthews 113, Venetis 154, Attridge 101, Hamilton 163, Fuller, "Living in Hopes" 199, Hodd 89, Pyper 1, Sugars 6, Taylor 29.
} 
that Coady completely dismisses the romantic working class ethos of writers like Richards and MacLeod or the stereotypes about the region maintained by outsiders, I agree with reviewers like Murray Tong and Aritha Van Herk that Coady uses the representative power of the dissonance created by writing about such uncomfortable issues. In an interview about Play the Monster Blind, Coady talks about this aspect of her work: "'I don't like to reject stereotypes, I like to flip them over, explore them ... [i]n writing about Cape Breton I like to get beyond the coal mines and alcoholism and incest. There is all of that in my work but I like to think I'm doing it in a way that makes it accessible and interesting to the rest of the world"" (Carlson C5). In this thesis, I take this statement to mean that Coady is comfortable making room for these stereotypes in her work, as she considers it valuable to acknowledge and investigate them, even if she ultimately moves beyond them. I argue that this is how Coady treats the authors and regional themes that precede her in the Maritimes: she sees some elements of Maritime social realism as useful and she is critical of others.

The academic criticism on Coady's work can be separated into two approaches. The first - taken up by David Creelman, Tony Kelly and Herb Wyile - places Coady in the context of previous and contemporary Maritime literature. Wyile and Creelman in particular argue that Coady's commandeering of regional stereotypes and her uncomfortable use of violence marks a shift away from nostalgic portraits of the region characteristic of earlier writers. Lorna Hutchinson, on the other hand, groups Coady with contemporary women authors from Canada who employ "strategies of the grotesque," rather than with other writers from the Maritime provinces. 
While my approach overlaps with that of Creelman, Kelly and Wyile, in that I also examine Coady's deconstruction of Maritime literature's familiar images, I focus on her treatment of the physical space of the region, instead of the family, as they do. Although I draw on Hutchinson's treatment of the grotesque in Strange Heaven, there are substantial differences between her reading and the one I provide in this thesis. While Hutchinson focuses almost exclusively on Bridget's apathy, I examine the way in which Coady employs images of the abject to undermine the demands of Strange Heaven's patriarchal culture.

In the chapter "Breaking Silence: Smyth, Bauer, Wilson, Corey, Coady, Bruneau, and MacDonald" from his 2003 study, Setting in the East: Maritime Realist Fiction, Creelman suggests that Coady's project in $\underline{\text { Strange Heaven is to disrupt and reimagine }}$ conventional portraits of the family in Cape Breton literature. Creelman's treatment of Strange Heaven examines the kinds of controls placed on Bridget by her family especially her father, Robert - and health care professionals throughout the novel. Creelman explores the question of agency as it relates to Coady's narrative strategy in the novel and the world of contemporary Cape Breton as she represents it.

In keeping with his reading of realism in Maritime Canadian literature - a narrative form that he contends has been used by the region's authors in every historical period to work out their relationship to place and to political, economic and social questions, including gender - Creelman argues that Bridget spends the entire novel deferring and undercutting her subjectivity and the authenticity of her own voice. Creelman suggests that the novel moves "towards a nihilistic position only to pull back at the last moment" (189). Like Herb Wyile, Creelman maintains that Bridget ultimately 
does discover a way to assert herself at the close of the novel. He also observes that, in spite of Coady's implicit condemnation of the patriarchal family, Bridget ultimately finds comfort in that structure. In this thesis, I build on Creelman's analysis by further examining the controls placed on women in Coady's texts by Maritime Canadian society. I specifically focus on the way in which she undermines gendered constructions of nature. My study breaks away from Creelman's strict realist analysis by examining Coady's use of irony and fragmentation, and the self-consciously confusing way in which she constructs the imaginative and physical space of the Maritimes.

In "A Place Called Strange Heaven" (2004), Kelly argues that Coady shocks the sensibilities of those who have preconceived notions about what life might look like on Canada's East Coast. He states that Coady has replaced the search for the rural idyll characteristic of earlier Maritime writing with violence and confrontation. $\mathrm{He}$ acknowledges that Coady's irreverent language, occasionally bizarre characters and constant focus on social ills contest readily-held assumptions not only about the kind of literature that emerges from the region but also real-world stereotypes of the Maritimes. Kelly's article also considers the possible strategies that Coady presents in Strange Heaven for young women to negotiate a sense of identity in disruptive social and familial settings. He argues that the novel is a valuable tool for educators and counsellors. Like Creelman, Kelly focuses on Coady's construction of gender roles in the novel. My reading of Coady's fiction overlaps with that of Kelly to a certain degree, in that I also suggest that it undermines the tourism industry's depictions of the region as innocent and idyllic; however, while Kelly examines this in relation to Coady's presentation of the 
Murphy family and Bridget's relationship with her friends, this thesis focuses on the role of the natural environment in such idealized portraits of the region.

In his 2006 article, "As For Me and Me Arse: Strategic Regionalism and the Home Place in Lynn Coady's Strange Heaven," Wyile links Coady's Strange Heaven to other English Canadian novels that accentuate the often claustrophobic and suffocating elements of small towns. He also places Coady's fiction in what he identifies as a general movement within Atlantic Canadian writing which undermines many of the traditional markers of that literary space - the comfort of the home place, the conservative lament for earlier times, the nuclear family headed by a noble and hard-working father - and subverts earlier generations of authors from the region. Wylie aligns Coady with contemporary East Coast writers such as Ann-Marie MacDonald, Michael Winter and Lisa Moore. His analysis of Strange Heaven centres on the image of the home place one which Gwendolyn Davies argues in Studies in Maritime Literary History 1760-1930 is a source of comfort for earlier authors of the region who dealt with problems such as outmigration, deindustrialization, and urbanization - and the way in which Coady reimagines it. Wyile draws a distinction between Davies' treatment of this trope and Danielle Fuller's 2004 study, Writing the Everyday: Women's Textual Communities in Atlantic Canada, which sees the home place as a space of conflict. He notes that Coady negotiates a balance between the two approaches. Coady does this, he suggests, by spending much of the novel parodying the traditional Maritime family, calling attention to the aggressive controls Bridget's father places on her, and presenting her Cape Breton home as a locus of violence and hopelessness. 
Like Creelman, Wyile observes that Bridget eventually finds a degree of comfort and security in the Murphy household. For Wyile, Coady strikes this balance by employing "strategic regionalism," an approach that "challenges essentialist constructions of the East and dramatizes the patriarchal strictures that complicate the image of the home place as a nurturing environment for women" ("As for $\mathrm{Me}$ and $\mathrm{Me}$ Arse" 88). Wyile also focuses on the gaze of the outsider, which Coady explores in Strange Heaven through the character of Alan Voorland. Whereas Wyile focuses mainly on the way in which this gaze creates problematic representations of the people of the region, in this thesis I argue that Coady also uses it to complicate essentialist readings of the Maritimes' natural environment. The academic criticism of Coady's work in large part sides with reviewers who point out that Coady has a conflicted relationship with Maritime stereotypes and writers from the region who precede her. Creelman, Kelly and Wyile focus specifically on Coady's construction of the family as evidence of this aspect of her writing. While my reading overlaps with their observation that Coady's fiction reveals a tension-filled and ambivalent treatment of the home place, in this thesis, I stress that she also undermines conventional representations of the natural environment.

In her $2004 \mathrm{Ph} . \mathrm{D}$. thesis, Strategies of the Grotesque in Canadian Fiction, Hutchinson suggests that Strange Heaven is one of several contemporary Canadian women's texts that make use of a "middle voice" narrative strategy in order to disrupt the concept of feminine subjectivity. For Hutchinson, in the "the middle voice model ...the narrator, whose role as agent is to consciously instigate the act of telling a story, does not fulfil that role in any clear manner, and no single consciousness seems to govern the narration. Rather a kind of doubled discourse unfolds. Narrators tell a story, or so it 
seems, yet they are simultaneously active and passive in their role as narrators, both present and absent in the telling of the story ..." (94-5). She links Coady with other contemporary Canadian authors such as Margaret Atwood, Barbara Gowdy and Miriam Toews, who employ the grotesque to blur boundaries, like those between life and death, passive and aggressive, and attraction and revulsion in order to complicate the subjectivity of their main female characters. Hutchinson specifically examines the role of maternity and childbirth in Strange Heaven, which, she argues, Coady uses as a way of accessing the grotesque. She maintains that the maternal state is a very useful example of the grotesque, as it disrupts the seemingly clear dichotomy between inside and outside the body, resulting in a fractured understanding of the concept "woman."

Hutchinson argues that Coady can be grouped with other Canadian writers who use the grotesque to confound notions of identity and represent the paradoxical nature of subjectivity. While she does briefly examine Coady's emphasis on images of the abject in Strange Heaven - the element of the novel on which I focus - she is more interested in Bridget's apathy, indifference, and ambivalence. She suggests that Bridget uses her apathetic persona and her detachment from the world around her to take control of her life. Hutchinson maintains that she gains this power by ignoring the wishes of others and coming to terms with the events of her life on her own (161). While Hutchinson briefly explores the demands Bridget's family places on her, this thesis examines in greater detail the way in which the prison-like institution of the psychiatric ward and the doctors under whose care she is in while there duplicate and, in fact, intensify the Murphys' regulations. While my reading of Coady aligns with Hutchinson's observation that in Strange Heaven, "the abject pits idealizations of women against pollutants that are not 
containable" (171), I demonstrate that Coady makes use of the abject in order to contest representations of the female body as close to nature. As mentioned above, Hutchinson is the only critic who does not examine Coady's work in the context of Maritime literature. In this thesis, I argue that Coady's construction of the female body plays an important role in her relationship with previous and contemporary writers from the region.

\section{Chapter Outline}

The body of this thesis is divided into five chapters. In Chapters 2 and 3, I stake out my own theoretical position within the two bodies of criticism with which the thesis engages: Maritime literary criticism and ecocriticism. The final three chapters use this theoretical material in readings of Coady's four texts. Rather than organizing the thesis so that each text would be represented in a stand-alone chapter, I divide my reading thematically so that the chapters correspond to the three constructions of nature used by Coady in her fiction: the relationship between the gendered body and nature (Chapter 4), portraits of the Maritimes as idyllic (Chapter 5), and the toxic landscapes of postindustrial Cape Breton (Chapter 6). Each of these chapters uses the same methodology: building on the theoretical material provided in the two opening chapters, I begin with a short critical discussion of the construct on which that particular chapter will focus and then proceed to discuss Coady's four texts in relation to it in chronological order. ${ }^{14}$

Chapter 2, "Creating Space for Maritime Fiction," considers the implications of classifying Coady as a "Maritime writer." This chapter focuses on the concepts of region and regionalism in Maritime literary criticism. This chapter examines the role that

\footnotetext{
${ }^{14}$ Thus, each chapter begins with Strange Heaven, and moves on to Play the Monster Blind, Saints of Big Harbour, and finally Mean Boy.
} 
postmodern human geographers such as Tim Cresswell, Doreen Massey and Henri Lefebvre can play in regional studies. The use of geographic or cultural determinism to secure definitions of regional space - which is characteristic of many studies on Maritime literature - obscures the region's internal differences, minimizes the importance of class and gender conflicts in creating spatial representations, and downplays the role of political forces in exploiting the environment to the point where the region is now in decline (Calder, "Reassessing Prairie Realism" 60). In this chapter, I argue that the assumed stability of the category "region" that this criticism employs can be reworked using spatial identity theory and recent work on regionalism in Canadian literary criticism. This discussion is crucial for accessing Coady's understanding of the physical and literary dimensions of the space of the Maritimes. This chapter also establishes that Coady contests the conventional way in which critics define the Maritimes through her understanding of how that space is gendered, claimed as idyllic, and labelled "natural."

As I demonstrate in Chapter 2, studies of Maritime literature traditionally look for the ways in which the region's writing reflects its political and economic conditions. Rather than adopting this model, which would establish in its early stages a detailed history of deindustrialization in Cape Breton and then examine the way in which Coady's fiction dramatizes these "real-world" environmental problems, this thesis relies on Coady's historicized account of the Maritimes' social and economic circumstances. I also briefly discuss Coady's strategic use of narrative satire and postmodern irony.

Chapter 3, "Post-Structuralism and Canadian Ecocritical Theory," provides the theoretical background for this thesis by developing a definition of "nature" that acknowledges it as a discursive construct. In this chapter, I review recent debates in 
Canadian ecocriticism and argue that post-structuralism provides a framework for pushing past its traditional emphasis on pastoral literature and nature writing. I also examine Canadian ecofeminism and argue that a focus on the relationship between the masculine and feminine body provides a way to move beyond essentialist approaches in this field. Finally, I consider ecocriticism's treatment of toxic spaces. Post-structuralist ecocritics suggest that contemporary writers use toxic landscapes to call attention to ecological despoliation and the excesses of late capitalism, and to undermine the boundary between natural and artificial.

Chapter 4, "Constructions of the Body and Nature in Coady's Fiction," focuses on the relationship between the gendered body and the environment in Coady's fiction. This chapter establishes Coady's strategy for constructing nature by examining this aspect of her fiction in relation to her most frequently used image: the male and female body. Coady's texts, as many reviewers contend, reveal an obsession with corporeal imagery, and she works out many of her fiction's themes, including religion, class, and, as this thesis explores, definitions of nature, in relation to the body. As Herb Wyile and Lorna Hutchinson demonstrate, a reading of the female body in Strange Heaven can be used to make sense of Coady's use of the home place (Wyile) and her use of the grotesque (Hutchinson). While I also briefly explore these aspects of her work, Chapter 4 instead focuses on the way in which abjection and constructions of the female body link Coady's treatment of gender to her treatment of place. It does so by considering her use of excrement, blood and childbirth (Strange Heaven) and her deconstruction of the idea of nature as a male-dominated space ("Play the Monster Blind," Saints of Big Harbour and Mean Boy). By examining the way in which ideal definitions of the male and female 
body impact her portrayal of nature, this chapter demonstrates that in Coady's fiction, the personal and the spatial are closely linked and that definitions of nature have direct personal consequences.

Chapter 4 begins with a short discussion of recent studies in ecofeminism, which acknowledge both the body and the environment as deconstructive spaces. Building on this theoretical material, this chapter argues that Strange Heaven examines the controls and expectations that patriarchal institutions, such as the church, the small towns of which she writes and the family, exact on Bridget's body. Coady links her construction of the female body to her depiction of nature in two ways: she at once demonstrates that this patriarchal culture casts the female body as part of nature and places controls on it that work to uphold a very specific type of femininity, and she also aligns the expectations placed on the female body (to be maternal, natural, beautiful, and quiet) with those placed on nature. In Strange Heaven, Coady disrupts the regulations Bridget's family and community place on her by focusing on images of the abject.

As is suggested by her use of male main characters in her later texts, "Play the Monster Blind," Saints of Big Harbour and Mean Boy are concerned with the way in which the "ideal" male body is created. Chapter 4 demonstrates that while they have seemingly opposing - but, in actuality, surprisingly similar - views on what it means for men to be close to nature, Isadore (Saints of Big Harbour) and Jim Arsenault (Mean Boy) attempt to indoctrinate their young charges, Guy and Larry, into a masculine culture that thoughtlessly exploits the environment, either as a crude object of exchange or as an imaginative resource. In "Play the Monster Blind" and Mean Boy, John Sr. and Jim Arsenault valorize masculine activities like working on the land; however, the major 
consequence of their actions is that they appear ridiculous and out of touch. The macho working class ethos Isadore promotes in Saints of Big Harbour is a toxic force, as it demands that young men like Guy and Dan C. expose their bodies to physical harm in dangerous work environments like the pulp mill and steel plant.

Chapter 5, "Coady's Subversion of the Maritimes' Idyllic Landscape," focuses on Coady's deconstruction of romanticized portraits of the natural environment. Because her fiction is set in Maritime Canada, Coady encounters definitions of nature which are informed by historical and literary representations of nature in that region: specifically, that the Maritimes is often framed as a nostalgic, serene, and idyllic space. In this chapter, I argue that Coady's preoccupation with idealized constructions of the Maritimes and her overt references to the tourism industry demonstrates that conventional renderings of the region as idyllic and pastoral overlook what she sees as the region's social and economic realities. Earlier generations of Maritime authors used pastoralism as a means of working out the relationship between human society and the natural world; however, Coady's fiction satirizes the region's pastoral impulse. Coady makes use of settings that, on the surface, appear to be idyllic: she uses rural Cape Breton as the setting for Strange Heaven, much of Play the Monster Blind, and Saints of Big Harbour, and the picturesque New Brunswick liberal arts college of Westcock, which she contrasts with the crass, commercial property owned by Larry's parents, for Mean Boy.

Each of these texts treats Cape Breton (and in Mean Boy, PEI and New Brunswick) as a space that is marked by death, disease, alcohol and drug addiction, and violence. By focusing on Coady's treatment of the region's tourism industry, Chapter 5 demonstrates that the version of nature it propagates is inaccurate. In Coady's texts, 
aesthetically pleasing experiences of the environment are accessible only to tourists who visit the region. Outsiders often tell inhabitants of rural Cape Breton that they live in one of the most beautiful places in Canada, overlooking the fact that their communities are often marked by poverty and violence. In addition to fleshing out some of the problems with the neo-pastoral tradition of Canadian nature poetry, this chapter is further evidence that the place-based claims to Maritime identity made by earlier literary critics are unsatisfactory.

Chapter 6, "Coady's Post-Industrial Cape Breton," argues that Strange Heaven, Play the Monster Blind, and Saints of Big Harbour ${ }^{15}$ exhibit what Cynthia Deitering calls a "toxic consciousness." I begin with a short critical discussion of the term "toxic consciousness" and then proceed to demonstrate that it is present in other contemporary Maritime texts such as David Adams Richards' Road to the Stilt House (1985), Leo McKay's Like This (1995), and Christy Ann Conlin's Heave (2002). These works are representative of a major shift in contemporary Maritime literature in which the identifying marks of region have moved from the distinctive topographical and cultural makeup of the Maritime provinces to a landscape gutted and ruined by industrialism. In this chapter, I suggest that characters in Coady's texts attempt to have conventional experiences of nature - children look to play in the woods and adults try to escape into the calm of nature - but they often find that the "natural spaces" that they seek are polluted.

\footnotetext{
${ }^{15}$ Perhaps because of its temporal setting (the early 1970s) or because the bulk of its action takes place on Westcock's university campus, rather than, say, a pulp and paper or mining town in Cape Breton's industrial belt, Mean Boy does not make use of a landscape ruined by pollution and toxic waste. Therefore, this chapter is confined to

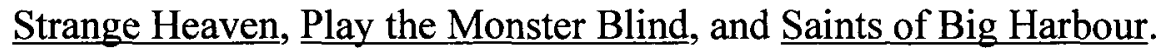


In Chapter 6, I argue that these texts present an ironic relationship between the inhabitants of post-industrial Cape Breton and the landscape. The pollution and toxic waste of which Coady writes is permanent and ubiquitous to the point where her characters are forced to organize their daily lives around it. Coady presents a landscape that is completely eviscerated by its experience of industrialization: the coal, steel and pulp industries have extracted everything possible from Cape Breton's physical environment and have left behind only their waste products. This chapter demonstrates that Coady's fiction undermines conventional definitions of nature that associate it only with pristine wilderness spaces. She does so by presenting a Cape Breton where people live in and on top of post-industrial society's toxic residue.

While Coady's texts have, at all times, an ironic and comedic edge that seems to dilute her political stance on issues like poverty, gender relations, ethnicity, and environmental degradation, I argue in this thesis that her deconstructive and satirical narrative strategy exposes the harmful effects of conventional definitions of nature. Coady's fiction demonstrates that idealized and essentialized constructions of the natural environment have tangible consequences. One of Coady's constant themes is the various strategies used to condition people who live in the Maritimes to accept an impoverished and disempowered way of life. She points out that artistic, corporate and governmental efforts to invent the Maritimes' romanticized natural environment promote a stifling and toxic patriarchal culture, encourage the region's inhabitants to accept and accommodate the tourism industry and external stereotypes, and overlook the economic and industrial forces that create Cape Breton's toxic landscape. 


\section{CHAPTER 2:}

\section{CREATING SPACE FOR CONTEMPORARY MARITIME FICTION}

I rip out Atlantica's subscription card and stick it in my notebook. So this is the Canadian literature of my time! No more trees and rocks and oceans and lakes and prairies and farms, but barricades. And battle lines-both intellectual and aesthetic. Upper Canadian snottitude versus hard-nosed regionalism. City versus Town, fake versus real. It's raw and pugilistic. Like a hockey game. Or war. It's so new. I never imagined poetry could be like this.

-- Lynn Coady, from Mean Boy.

Atlantic Canadians, and Atlantic Canadian writers, have grown up right alongside of the rest of the Western World. It might have taken some of us a bit longer to shed our mullets (I'm not quite sure for what I'm using the mullet as a metaphor in this instance - perhaps it's not a metaphor at all), but the point is, we exist in the here and now, no matter how unfashionable our hairdos. Bemoan it if you will, the way of the world, how the cultural fault lines have merged, solidified, in the past century. I choose to look at the bright side: we have matured. In time, we all of us have cut off our rat-tails. The new literary work coming from the Atlantic provinces very much demands your respect, as you will see. You will enjoy it no matter where in the world you are - not for reasons of nostalgia or quaintness but because it's just so good.

-- Lynn Coady, from "Books that say arse."

\section{Introduction}

The above quotations point to a shift that has taken place over the last twenty-five years in Maritime literary criticism and Maritime literature as a whole. Larry Campbell, Coady's naïve poet protagonist in Mean Boy, adopts the romanticized, battle-hardened version of regionalism advanced by renegades in the Westcock English department and declares "war" against Upper Canadian writers on behalf of "authentic" Maritimers like his mentor, Jim Arsenault. The novel demonstrates that this essentialist approach to regionalism is ultimately unsatisfactory not only by exposing the emptiness of Arsenault's personal crusade but also by creating contradictory and ironic spaces out of its most important settings: the small New Brunswick town of Timperly, the campus of Westcock University and Jim's rural home. As Coady reveals in "Books that say arse," 
her introduction to Victory Meat: New Fiction from Atlantic Canada (2003), the spatial and identity referents employed by earlier Maritime writers and literary critics are contested by contemporary texts that have emerged from the region.

As several critics have pointed out, the Maritime literary scene is in a stage of transition. ${ }^{1}$ Authors like Coady, Carol Bruneau, Ann-Marie MacDonald, Christy Ann Conlin, George Elliott Clarke and Rabindranath Maharaj challenge conventional notions of regional identity on the East Coast and self-consciously rework both the romantic tourist version of the Maritimes as idyllic and old-fashioned and the social realist vision laid out by earlier writers such as Alden Nowlan, Alistair MacLeod and David Adams Richards. They do so by exploring contradictory and deconstructive notions of gender, space, and ethnicity. In this chapter, I suggest that traditional approaches to regionalism in the Maritimes have trouble accounting for this shift. Postmodern theories of space provide a critique of Maritime regionalism that will assist in understanding Coady's selfconscious construction and deconstruction of definitions of the environment in her fiction. This approach is especially useful for pinpointing her narrative strategy, one that employs postmodern irony and satire.

Much of the pioneering work on regionalism in Canadian Studies has come out of the Maritimes. ${ }^{2}$ This scholarship disputes the assumption that the East Coast's twentiethcentury economic downturn was linked to the region's culture and insists instead that it was the result of several factors, including a Canadian economic and political system that favours some areas of the country over others. The two major comprehensive studies on

\footnotetext{
${ }^{1}$ See Wyile, "As for Me and Me Arse" (2006) and Honnighausen, "Defining Regionalism in North American Studies" (2005), among others.

${ }^{2}$ See Ernest Forbes, David Alexander, Ian McKay and others.
} 
the region's literature, Janice Kulyk Keefer's Under Eastern Eyes: A Critical Reading of Maritime Fiction (1987) and David Creelman's Setting in the East: Maritime Realist Fiction (2003) make use of the regionalist framework that Forbes, McKay, Alexander and others employ in Maritime historiography. They use this method to construct a narrative of deindustrialization and downturn in the region that they overlay on the East Coast's literary and cultural movements. In this chapter, I argue that the assumed stability of the category "region" can be reworked using postmodern concepts of geography, an approach that Canadian literary criticism has only incorporated recently into studies of regionalism. This limited definition of "region" has created an atmosphere where only a certain type of text - rural fiction written in the social realist genre that explores the negative effects of economic disruption and modernization - is seen as authentic Maritime writing.

\section{Maritime Literary Criticism: A Short Historical Sketch}

Because many critics tend to use the terms "region" and "regionalism" interchangeably, Frank Davey proposes more precise definitions in his article "Towards the End of Regionalism" (1997). For him, the term "region" simply refers to a geographic space that is set apart from adjacent areas on the basis of one or more criteria: political, ideological, cultural or topographical uniformity, shared historical ties and so on. "Regionalism," on the other hand, is a political or social movement that understands identity claims based on geographic location to be as important or more important than other forms of identity, including gender, ethnicity, class, and sexual orientation. Davey points out that the ideology of regionalism mimics that of nationalism by absorbing 
divergent points of view under its banner and by concealing ideology under the supposedly neutral marker of geographic space (15).

The related concepts of region and regionalism have evolved in Canadian literary criticism and historiography over the last thirty years. William Westfall, in "On the Concept of Region in Canadian History and Literature" (1980) and Gerald Friesen, in "The Evolving Meanings of Region in Canada" (2001), identify three approaches to regionalism in Canada. The first is "formal regionalism," which maintains that regional cultures emerge because of the country's vastly different geographical areas, such as the Arctic, the East Coast and the Prairies. Friesen points out that in the second half of the twentieth century, scholars began to critique formal regionalism because of its reliance on the outmoded concept of environmental determinism and replaced it with "functional regionalism."

Functional regionalists find the basis for regional identities in the cultures of Canada's regions, rather than the country's diverse geography. This approach is closely linked to the concept of "limited identities" advanced by Canadian historians J.M.S. Careless and Ramsay Cook. Careless and Cook argued that Canadian historiography should not downplay the country's internal differences in the interests of defining a national culture; rather, historians should attend to the differences between the various groups of people who live in Canada. They maintain that regionalism exists alongside other "limited identities," including gender, class, and ethnicity. Although functional regionalism considers regions to be home to uniform cultures, this approach acknowledges that culture is constructed, rather than essential. As this section demonstrates, this shift in regionalist theory also took place in Maritime literary criticism, 
as formalist approaches characteristic of scholars like Desmond Pacey and A.G. Bailey gave way to Gwendolyn Davies' more focused regionalism, which examines the impact of the region's economic and political circumstances on the development of its literary culture.

Maritime literary criticism has, for decades, betrayed the discomfort with which scholars (and writers) from the region view their place in mainstream Canadian literary circles. While approaches to regionalism have changed over time in the Maritimes, one important assumption has remained constant. Critics from outside of the Maritimes, as well as within the region, argue that the trajectory of a successful regional writer's career should look something like the following: his or her early work should establish local bona fides by displaying an intimate and meticulously realized knowledge of his or her home place. After being celebrated at the provincial and regional level for these early texts, the writer is eventually recognized for the way in which his or her later work which is also set in the region - explores broader themes of national or perhaps international importance.

In accordance with this formula, Maritime writers such as Hugh MacLennan and Alden Nowlan never cease to be regional writers; they simply become nationally recognized regional writers. In his 1976 article, "Notes on Regionalism in Modern Canadian Fiction," Robert Chambers, for example, expresses the widely-held opinion that Hugh MacLennan expanded the scope of his fictive world by progressively "mastering" the various levels of society that he saw around him: the regional, the national, the international and then finally the individual, which, Chambers argues, constitutes the universal: 
[MacLennan] has a rare capacity to see the places of Canada vividly in terms of their geographical and historical contexts, and to chart the movements of men and ideas against this natural background, so that the Halifax, Cape Breton, Quebec, and Montreal of English Canadian literature are cities and regions of his creation. Through a process of gradual maturing, not without its disappointments and failures, he has moulded characters at once recognizably indigenous and approaching - in his later work - universal significance. ("The Novels of Hugh MacLennan"10)

In "Mapping the Terrain" (1978), David Staines detects a similar pattern in MacLennan's novels:

[t]he journey of MacLennan's fiction is the route of many Canadian writers, and of many writers of all nationalities, who must confront their own society and not utilize foreign or conventional literary worlds developed and promoted elsewhere. Before he could examine individual human beings in his own country, however, MacLennan had to define Canadian society, and in the act of definition that occupied his novels of the forties, he performed a service of inestimable value to the development of Canadian fiction. (138)

Many of the most influential Maritime literary scholars, from Douglas Lochhead and Andrew Seaman to Janice Kulyk Keefer and David Creelman, justify what they see as an obsession with the region in its literature by arguing that these writers should not be ignored because they write about a "marginal" area of the country. Instead, they argue that they deal with universal truths in a localized setting. Although theories of 
regionalism have changed over the years, as Davey points out, this idea is a constant in Maritime literary criticism since the 1950s.

Before they adopted what Davey calls a regionalist model of literary criticism, Maritime literary critics considered writing from the region to participate in, rather than contest, Canada's nationalist cultural movement. Scholars in the 1940s and 1950s such as Desmond Pacey and A.G. Bailey pointed out that the birth of Canadian literature took place in the Maritimes and that authors like Thomas Chandler Haliburton and particularly the poet Charles G.D. Roberts played instrumental roles in establishing a unique strain of English literature in Canada by modifying British romanticism to fit the context of North America (Bailey 231). In his 1949 article, "The Literature of Nova Scotia," Bailey argues that the territorial and cultural markers that form the basis for later critics' regionalist framework are inconsequential. For him, the Maritimes should be grouped with the whole of Canada as a new world space characterized by social disruption, because of both the "British-ness" on which it was founded and the aboriginal populations that it displaced, with whom it shared "no significant or lasting continuity" (233).

While later critics such as David Creelman and Andrew Seaman frame the conflict between tradition and progress found in the novels of Charles Bruce, Hugh MacLennan, Ernest Buckler and Thomas Raddall as quintessential issues of the Maritime provinces, earlier scholars saw texts such as Barometer Rising (1941), The Mountain and the Valley (1952), and The Nymph and the Lamp (1950) as important contributions to the project of Canadian nationalism undertaken in the middle of the twentieth century. For Chambers, Hugh MacLennan was concerned with "mapping out" Canada as writers before him had done in countries like England and Italy. He suggests that in 
MacLennan's texts, "character is shaped not primarily by inner-directed impulses, but by the play and interplay of those historic forces which sweep across Canadian life" ("The Novels of Hugh MacLennan" 4). Chambers and others cite the antimodernism of these writers - which David Creelman and Ian McKay see as instrumental in creating a unique sense of place in the Maritimes - as evidence of their campaign against the dehumanizing force of American-style capitalism, rather than a political response to the economic policies of central Canada. This sentiment is present in D.O. Spettigue's 1967 assessment of the pastoral elements of Buckler's novels, an article that maintains that Maritime writing fits seamlessly into the blossoming canon of Canadian literature. Spettigue highlights Buckler's expression of "the way it was," a common constituent of Canada's antimodern movement (55).

Other critics of this time period speak to the way in which certain Maritime writers are steeped in the tradition and feeling of the region; however, the kind of regionalism they express in these accounts is both diffuse and politically neutral. For example, in "The Maritime Writer and the Folks down Home" (1976), popular journalist Donald Cameron writes that Thomas Raddall's work should be celebrated for its dedication and fidelity to the unique Nova Scotian spirit, which, for him, is literary and cultural, rather than activist, in nature: "Raddall ... is loved in Nova Scotia ... because he expresses the feeling of Nova Scotians for their land, its history, its people; if he is romantic, so - in their way - are they. Nova Scotia, key to Canada in the French wars and the American Revolution, has history in the bones of its people, and it is to that quality to which Raddall speaks" (547). In "Thomas Raddall: The Man and His Work" (1976), W.J. Hawkins similarly argues that Raddall is indeed incapable of writing about regions other 
than the Maritimes: “[h]e writes about the Maritimes because it is only when writing of the Maritimes that he possesses sufficient concrete and abstract detail to place the subject completely in his grasp, and he will be satisfied with nothing less" (138). While Hawkins notes that Raddall is, in fact, "a regional writer," his definition corresponds with Davey's first politically non-committal version of regionalism.

\section{Maritime Literary Regionalism}

In his 1984 article, "Fighting Back: The Regional Renaissance in Recent Canadian Fiction," Stanley Atherton notes that regionalism did not play a significant role in the development of Canada's national literature before the middle of the twentieth century (128). This changed, however, in the 1960 s and 1970s. During this time, regional presses sprung up, critics became ambivalent to the nationalist fervour that overtook the country during the centennial celebrations, early postcolonial critics highlighted problems with the nation-state (Atherton 128), and writers from marginal regions of Canada grew to resent the centralizing agenda of Canadian literary circles (Lynes and Wyile 122). In the mid-1970s, a regionalist movement began to overtake literary studies in the Maritimes, and justification for speaking about a body of literature unique to the region came from the historiographical framework developed by scholars such as Ernest Forbes, John Reid, Ian McKay and others. Regionalist literary critics during this time period looked beyond a romanticized sense of history and community to define the culture of the Maritimes and of the broader Atlantic region as unique. They incorporated scholarship from historiography and political economy in order to link this notion of community to a growing sense of economic and cultural alienation in the region. 
In his introduction to the 1976 Atlantic Canada Literature Colloquium, "The Literary Heritage: The Place, The Past, The Prospect," Douglas Lochhead attributes the sentiment of "political responsibility" found in the texts of Alden Nowlan, Alistair MacLeod and David Adams Richards to the strong sense of history that is characteristic of the East Coast. He attributes his contention that "there is a literature of Atlantic Canada" to the "profound awareness of the importance of the past" (3). While later critics have pointed out that Newfoundland has a much different political history than the three Maritime provinces, Lochead's definition of regionalism is based on the idea that "[t]he four Atlantic provinces are a natural reality, a fact of geography, of history, and politics" ("Atlantic Regionalism and Literature" 262). Andrew Seaman echoes Lochhead's definition of regionalism and in 1976 wrote that Maritime literature is unique for the way in which the authors of the region are wholly steeped in the culture, the history, and the political causes of the Maritime provinces:

It is a phrase casually dropped - "felt life" - and yet a useful one, which helps to get at a quality in much of the fiction of Atlantic Canada which holds the secret of its value and importance. No group of authors in Canada has been more singly concerned with the sense of place and the value of heritage than our Maritime fiction writers, and those values can often be perceived through the intensified quality of "felt life" in their writings. ("Fiction in Atlantic Canada" 26)

The political aims of this strand of regionalism - which consisted mainly of raising the profile of Maritime literature on the national stage - relied on a stable definition of place. In a 1985 paper, Fred Cogswell defines regional fiction as 
fiction which attempts to utilize the peculiar resources of a non-metropolitan region - history, topography, flora, fauna, speech patterns, and the mores of its inhabitants - as a basis to attract readers and/or to develop their insight into human life by reference to a milieu whose characteristics are simpler, more stable, and more easy to relate to human behaviour than those of urban life. ("Regional Fiction in the Maritimes"192)

Cogswell points out the importance of the realist genre in the development of regionalist fiction. He argues that writers like Raddall, Buckler and above all, Richards - who he predicts will one day be recognized as the greatest to emerge from the region - are important to the Maritimes because of the way they resonate with the people who actually live there and provide those who do not with an accurate picture of what they are missing.

In many ways, Gwendolyn Davies' Myth and Milieu: Atlantic Literature and Culture 1918-1939 (1983) and Studies in Maritime Literary History, 1760-1930 (1991), while not as comprehensive as later studies by Janice Kulyk Keefer and David Creelman, provide the starting point for discussing contemporary critical approaches to Maritime literature. Her reading is similar to that of Cogswell and Seaman; however, she achieves a more focused treatment of regionalism by explicitly linking the political and economic circumstances of the Maritime provinces to the region's literary history. She argues that the various periods of economic depression and political disillusionment that plague the Maritimes did not and do not have a negative impact on either the quantity or the calibre of the texts the region has produced. Instead, this uneven history and uncertain future are 
important contributing factors in the development of the Maritime's literary tradition (Myth and Milieu iii).

In Studies in Maritime Literary History, Davies focuses on the "home place." She argues that tracing this image through the region's literary history provides a framework for understanding its various creative shifts. The idea of the home place evolves from the pastoral images of L.M. Montgomery and Bliss Carman, to the anti-modern rural settings of Hugh MacLennan and Charles Bruce, and finally to the culturally defiant version of a peripheral region in decline painted by David Adams Richards and Alistair MacLeod. Although it has changed over time, Davies argues that Maritime literature is different from that of other regions in Canada because "from the 1920s onward, the 'home place' emerges as a symbol of cultural continuity and psychological identification in the face of social fragmentation, outmigration, and a continuing hardscrabble economy" (Studies in Maritime Literary History 194).

Janice Kulyk Keefer's Under Eastern Eyes: A Critical Reading of Maritime Fiction (1987), the region's first comprehensive study, provides a loose historical overview of Maritime literature framed by the major regional themes she identifies: the relationship between literature and nature, the prevalence of outmigration, and the privileging of the historical and realist genres. Keefer adopts a liberal pluralist approach in her introduction that informs the study's goal of asserting the importance of the Maritimes as a literary region and inserting Maritime texts into the national canon. In the preface, she argues that the debate between nationalism and regionalism is the most important question Canadian literary criticism faces. She also contends that longstanding neglect of the region's literature by the central Canadian critics corresponds to the 
economic decline and political alienation that the East Coast has suffered since the time of Confederation.

Like earlier critics such as Terry Whalen, Fraser Sutherland, Donald Cameron and others, Keefer maintains that there is an identifiably unique Maritime sensibility that dominates the region's literature. She borrows Ronald Sutherland's "sphere of consciousness" theory, which describes a writer's "total cultural conditioning" (Under Eastern Eyes 5) and shapes his or her experience of the world. For Keefer, the distinct Maritime voice reveals a conservative longing for a lost golden age (Under Eastern Eyes 5). This voice lays claim to a sense of regional place with a "confidence foreign to modernist and post-modernist alike, a belief in the reality and significance of the accessible world of human experience common to reader and writer" (Under Eastern Eyes 6). In addition to this, Keefer sweepingly defines the tradition of Maritime literature as one that champions rural life, decries the city as a "meaningless mill of profit and pleasure" (Under Eastern Eyes 17), and is expressed almost exclusively in the realist genre. Keefer argues that the Maritime literary canon is stocked with realist texts because of the intense effort by its authors to accurately and authentically convey the area's unique history.

Wolfgang Hochbruck's introduction to Down East: Critical Essays on Contemporary Maritime Canadian Writing (1996) discusses the possibility of employing postmodern approaches in Maritime literary criticism. He argues that the work done by Keefer should be updated to include postcolonial and postmodern theory and maintains that doing so would shed light on the Maritimes' experience of what he calls "new regionalism" (17). For him, critics should discard the debate between the national and the 
regional - which is central to so much of the criticism that came out of the Maritimes in the 1970s and 1980s - in favor of critical methods that attend to globalization and the Maritimes' "re-emerging cultural identity that runs parallel (and sometimes athwart) the mainstream of Anglo-Americanadian mass culture" (17).

David Creelman's Setting in the East: Maritime Realist Fiction (2003) picks up on many of the themes articulated by Keefer and specifically examines the developmental arc of the realist genre in the region. Even as he chides Keefer for her positivist and essentialist approach to the Maritimes, Creelman agrees that the region's "writers share a common regional identity that shapes the subtexts of their fictions" (1). For Creelman, the history of the Maritime region is complex, diverse, and filled with transformation. The literature produced against the backdrop of this history, however, approaches these events in a singular fashion. For Creelman, the overarching theme of Maritime literature is the rapid industrialization of the region, which almost overnight brought both unparalleled prosperity and cultural uncertainty and the equally rapid impact of deindustrialization over the latter part of the twentieth century. This process has left the East Coast in economic and social disarray and has never been overcome. According to Creelman, the region's authors invoke the realist genre so that they can more forcefully pinpoint the causes and effects of the extreme social transformation that they see around them.

Although many of these critical accounts make reference to the diversity of the literature that has emerged from the Maritime region, they uphold the traditionally unquestioned assumption that there is a distinctive Maritime voice and look to regionalist historical and sociological research to bolster this claim. Because of this assumption, and 
the unproblematic way in which they link geographic space to the literary canon, critics like Keefer and Creelman find it difficult to account for non-traditional texts or genres and, as a result, they often attempt to pass them off as anomalous exceptions to the prevailing pattern. ${ }^{3}$

\section{Textual Communities and Strategic Regionalism in the Maritimes}

Lisa Chalykoff's 2000 study, Space and Identity Formation in Twentieth-century Canadian Realist Novels: Recasting Regionalism in Canadian Literary Studies, highlights the increasingly elastic nature of the analytical category "region." She argues that "regional fiction" in Canada is a label that conventionally refers to literature that embodies unique and identifiable characteristics of Canada's marginal areas. Critics evaluate texts grouped into this category on their fidelity to the spirit of the region from which they emerge (Chalykoff, Space and Identity Formation 16). Thus, the idea of region in Canadian literary criticism relies on establishing and maintaining stable regional characteristics that explain divisions in the Canadian nation-state. Chalykoff goes on to note that the formal regionalism characteristic of Canadian literary criticism proposes a

land-based social unity [that] effectively depoliticises regional space by mitigating the inevitability of social contestation within regional borders. Such an approach also places questions of social difference outside of the interpretive

\footnotetext{
${ }^{3}$ This sentiment is present not only in reviews of, for example, Ann-Marie MacDonald's work, which express surprise that such a novel could come out of the conservative Maritimes (see Scofield C9, among others) but also in Creelman's description of the problematic way in which contemporary non-realist feminist texts refuse to fit in with the Maritime literary canon he identifies (Setting in the East 175).
} 
paradigm because it works from the assumption of intra-regional social cohesion. And to assume - without demonstrating - the existence of a shared regional consciousness is to refuse to recognise even the potential existence of subjectivities that could belie such a claim. (34)

She notes that writers - especially contemporary writers - do not play a role in the process of constructing a regional literature and identity; their writing is judged against and lumped with texts that predate them and are thought to express or reflect the unique character of the region.

Citing the work of Alison Calder and other critics of conventional approaches to region in Canadian literary criticism, Chalykoff argues that formalism stifles the use of concepts such as class, race and gender within regional scholarship. Chalykoff offers a new definition of regional Canadian literary criticism that she calls "strategic regionalism," which examines the role of critics, writers and other members of "textual communities" in creating regions. She argues that the role of the critic in literary regionalism needs to be rethought. By replacing the stable category of region with the idea of space as a constantly changing product of social positioning and representation, critics are directly implicated in the construction of regions.

In Writing the Everyday: Women's Textual Communities in Atlantic Canada (2004), Danielle Fuller calls attention to the problematic way in which regionalism is deployed in Atlantic Canadian literary criticism. She argues that in attaching a political agenda to the region's literature that pits it against Central Canada, regionalist scholarship adopts an exclusionary definition of what constitutes "authentic" East Coast writing. She maintains that although conventional regionalism promotes a strict 
distinction between centre and margin, the political project of regionalism still remains valid and should continue. Fuller observes that

[c]ontemporary Atlantic women's writing ... poses a critical challenge to literary regionalism. It demands that it include multiple perspectives that frequently refer to (and sometimes prefer) non-regional communities. Yet women's creative texts and women's work as members of textual communities suggest that regionalism may be a useful concept if it is configured as a common ground of resistance to ruling relations that marginalize various groups. (31)

Like Davies, Fuller contends that contemporary women writers in Atlantic Canada, especially in their deconstruction of the "home place," complicate regionalism by introducing new categories of definition: "women's narratives prefer social rather than physical geographies as a means of mapping communities or understanding identity. Their terms of reference do not delineate a coherent geographic space, and they should not be forced to do so" (37). Fuller maintains that Atlantic Canadian literary critics should put Chalykoff's strategic regionalism to use. Writing the Everyday rejects the exclusionary principles of conventional regionalism, but maintains that there is a set of shared experiences upon which textual communities are based, which should form the basis for a revised version of regionalism.

While strategic regionalism points out many of the problems of conventional regionalism and is attentive to the ways in which space is created by social relations, it has several limitations as a critical paradigm. Fuller and Chalykoff argue, for example, that the analytical category "region" should be replaced with "textual communities," which consist of both writers and critics. While they deconstruct conventional approaches 
to space, they over-emphasize the role text plays in creating regions and fail adequately to examine external factors. Strategic regionalism tends to leave the impact of geography unaccounted for in its critique of the assumed neutrality of place and its retreat from physical space in favour of social relations. In the section below, I argue that a workable theory of regionalism should take into account the way in which regions are created through discursive practices and through the limitations and possibilities of the space that comprises them.

In his 2003 article, "Intersections in Cultural Policy: Geographic, Socioeconomic and Other Markers of Identity," Rob Shields claims region as a performative entity:

Cultural practices, events and institutions often have a symbolic, 'performative' quality ... it is not necessary to enact all elements of a cultural identity to effectively signify and reproduce it. The same is true of spatialisations that are not only concretized in the development of heritage landscapes, built environments and the creation or husbanding of affordances. They must also be reproduced and continued through enactment. (7)

He maintains that although physical space does not determine culture, it is a concrete entity that makes some actions possible and others impossible in certain locations. For Shields, regions offer "affordances" that orient behaviours within them: "Region provides the concrete environment that supports or hinders everyday cultural practices and events this includes ... businesses and the churches, church halls and community centres" (2). It is for this reason that regions, although they are constructed and contingent entities, should be seen as more than textual creations. 


\section{Postmodern Human Geography and Regionalism}

In a 2001 article, “'Limited Identities' and Canadian Historical Scholarship: An Atlantic Provinces Perspective," Phillip Buckner challenges historians to attend to the tensions, rather than the perceived uniformity, of the Atlantic region. He warns against the tendency in regional scholarship to make use of stereotypes that portray the region as unchanging and conservative and notes that "in rejecting the ideal of a single "national unity,' regional historians [often] fall into the trap of creating an equally artificial regional identity and culture" (192). He goes on to argue that regional academics have internalized many of the artificial constructs and theoretical assumptions of nationalist scholarship and, as a result, run the risk of offering nostalgic and simplistic accounts of Atlantic society.

Herb Wyile and Jeanette Lynes agree with Davey's assertion that regionalism, like nationalism, is a modernist concept that should be challenged by post-structuralist approaches to space. In "Regionalism and Ambivalence in Canadian Literary History" (1995), they argue that "the regional ultimately tells us less about a specific region or even a regionalist aesthetic than about the ideological assumptions a body of criticism sometimes unwittingly rests upon" (124-5). Elsewhere, Wyile has written that "it will be necessary to develop a more nuanced appreciation for regionalism as a discursive framework" (“Postnational Times" 159).

Recent studies on regionalism in Canadian literary criticism rethink the assumed importance and cogency of conventional definitions of place. Informed by scholarship on the concept of "space" that has come out of postmodern human geography in the last decade, critics like Linda Warley, Robert Viau, John Ball, W.H. New and Chalykoff seek 
to rework the role of regionalism in Canadian literary criticism. These critics move away from searching for landscapes and physical characteristics that explain the unique character of the country and its various regions, and instead insist on the need to understand why only certain representations of the land are defined as quintessentially Canadian (Warley et al. 2). Making use of the work of post-structuralist theorists Henri Lefebvre, Edward Soja, Doreen Massey and Tim Cresswell, these critics argue that the supposed neutrality of space in conventional literary studies is conceptually unsatisfactory. For them, space is not simply a backdrop for the actions of human society; it is a concept that is produced by things like social exclusion, class struggles, gender, and representations of identity that constantly change over time.

Massey and Cresswell define spaces as complex networks of social relations used to construct normative behavioural codes within landscapes. They argue that certain actions are normal and acceptable only within the confines of specific spaces. For Massey, the social relations that define space are never fixed, but rather constantly in process. W.H. New's Land Sliding: Imagining Space, Presence, and Power in Canadian Writing (1997) makes the case for the use of this theoretical work in Canadian literary criticism. He argues that the term "space" refers to a way of thinking about approaches and attitudes towards social production and social power. New emphasizes the culturally constructed nature of space, rather than its "inevitability." This reformulation of the concept of space makes possible discussions of multiplicity suppressed by the exclusivist assumptions that conventional definitions of region and nation employ.

In "Defining Regionalism in North American Studies" (1995), Lothar Honnighausen gestures to some of the tensions between postmodern deconstructions of 
spatiality and traditional regionalism. For example, he points out that although the concept of regionalism should be exposed as exclusionary and based on arbitrary boundaries, it is important to remember that it is a valid response to the logic of nationalism and globalisation. He maintains, however, that in Atlantic Canada, new forms of regional identity have sprung up that are based on, rather than wary of, the fragmentary and contradictory elements of postmodern and urban life. He further argues that new theories of regionalism should attend to the effects of regionalism's "boundary maintenance" and the ways in which authors combat it: "[Ann-Marie] MacDonald's and [David Adams] Richards' work leaves little doubt that the focus in rendering place is no longer on idyllic sites in the sense of the locus amoenus but on bleak northern sceneries ... Both the locale of the new regionalism and its personnel are very different from the regionalism of previous epochs ... it clearly demonstrates how the treatment of place ... is intimately connected with that of ethnicity and gender" (151). Honnighausen goes on to state that conventional and strategic regionalism are problematic because they fail to recognize that "[r]egion as a cultural construct, because of its combination of spatial and socio-political aspects, works particularly well in capturing economic and cultural change" (156).

In their introduction to the 2006 special issue on Atlantic Canadian writing in Canadian Literature, Marta Dvorak and Coral Ann Howells point out that there is a disconnect between the physical and demographic scope of the Maritime provinces and the amount of imaginative energy that has been spent defining it. Because of the proud sense of the past that Lochhead and others cite, as well as the history of cultural conflict that has taken place on its shores, the Maritimes is a larger-than-life entity that can be 
burdensome to write about. They further posit that writers such as Ann-Marie MacDonald and Lynn Coady react to the Maritimes' literary myths by rewriting the history of the region. They claim it as an ethnically diverse space and ironically distance themselves from conventional definitions of the East Coast.

Studies of contemporary Prairie literature have incorporated recent developments in human geography and spatial identity more fully than those of any other region in Canada. In "Reassessing Prairie Realism" (1998), Alison Calder argues that in the context of Canadian literary criticism, regional literature is ultimately doomed to failure, as texts that acquire that label will inevitably continue to be held in less esteem than "Canadian" literature that universalizes the country's experience (53). She observes that critics in Canada treat regionalism like a developmental stage not unlike childhood, which must be grown out of in order for canons to fully mature. This paradoxical treatment of regional literature dictates that if texts from marginal areas of the country attempt universality they will no longer be considered regional, which means that the genre has a "built-in obsolescence." For this reason, analyses of regional fiction in Canada have focused on its nostalgic tone, backwards content and homogenous product. Regional literature is judged according to its ability to speak authentically and passionately about a group of marginalized and unknown people, so it necessarily strives to remain eminently familiar and free of controversy.

For Calder, traditional treatments of regionalism in Canadian literary criticism that rely on geographic or cultural determinism to establish secure definitions of the Prairies discount the possibility that this region has been and is imagined in multiple and competing ways. Most studies of Prairie literature focus on the unsettling presence of 
human society in its vast and unforgiving landscape. For Calder, this theoretical approach overlooks the region's internal complexities, minimizes the importance of class and gender conflicts in creating spatial representations and downplays the role of political forces in exploiting the environment to the point where the region is now in decline ("Reassessing Prairie Realism" 60).

These debates highlight the suspicion with which recent studies in Canadian literary criticism view the category "region." This scholarship has revised conventional regionalism in various ways: by redrawing regional boundaries, pointing to the interconnections between regions (Calder, "Reassessing Prairie Realism" 59), and emphasizing the impact of globalization and communication technologies in subverting cultural and geographic determinism. The key for each of these critiques is that the accepted correlation between regional literature and stagnant culture needs to be rethought.

By treating the relationship between the economic downturn and other material conditions of the Maritimes and the texts that the region has produced as clear-cut, the critical accounts of Keefer and Creelman are limited in several ways. As Calder argues, this method limits the discussion of concepts such as gender and race and internal issues such as mistreatment at the hands of local governments and corporations. By treating the region as economically unviable, critics obscure the way in which capitalism affects the landscape through mining and over-fishing and help create conditions necessary for excessive resource exploitation. This model also quells discussions of the way in which authors from the region respond to and engage with the benefits and problems of postmodernism. By insisting on an unproblematic relationship between author and text, 
and text and the real world, such critics of Maritime literature have essentially said that postmodernism has not yet arrived in the region. In this way, they perpetuate the stereotype that the Maritimes is backwards and pointedly oblivious to cutting edge artistic movements.

\section{Coady and Regionalism}

In Coady's texts, there is a close relationship between constructions of region and constructions of the natural environment. As Calder argues, conventional regionalism is unsatisfactory because its often-nostalgic sentiment undercuts the political stances taken by authors who deal with issues related to physical space, gender, and class conflicts. Conventional regionalism does this by trumpeting similarity and obscuring difference within regions. An extension of this, according to Calder, is that regionalism often internalizes economic problems to the point where they become an essential part of the area's culture, a trend that has tangible environmental implications. By repeating the mantra that a region like the Maritimes is home to a seemingly irreversible depression and chronic unemployment, political forces in the region can appeal to this commonsense understanding to heedlessly exploit the environment for the sake of creating jobs and stimulating the local economy. ${ }^{4}$ By creating a framework for understanding the ways in which social processes contribute to the construction of regions such as the Maritimes, and how authors like Coady reimagine them, spatial identity theory assists in

\footnotetext{
${ }^{4}$ The capacity for government and corporate interests to use economic downturn to justify the development of industry that is harmful to workers and the environment is a major theme in recent Maritime fiction, including David Adams Richards' Mercy Among the Children (2000) and The Friends of Meager Fortune (2006), and Leo McKay's Like This (1996) and Twenty Six (2003).
} 
understanding the environmental politics of regional literature. This approach aligns with contemporary ecocritical theory, which emphasizes that nature is a discursive construct. Just as spatial identity theory allows critics to recognize postmodern, urban texts with troubled versions of space, gender, and ethnicity as part of the regional literature of the Maritimes, so contemporary ecocriticism also includes urban and suburban texts, where it once recognized only nature writing.

Both popular and scholarly analyses of Maritime literature consistently share the assumption that the region is inherently knowable and easily accessible. This sentiment is pervasive for two reasons: the first is that the Maritimes lacks the imposing northern frontier that is characteristic of every other Canadian region and has been settled by Europeans for a significantly longer period than the rest of the country. The second reason the region is framed as easily understood is that it is deemed by the rest of the Canada to be at best conservative, and at worst primitively backwards. In this estimation, the Maritime provinces are at once physically comprehensible and culturally coherent. That both of these assumptions rests on a limited and essentialist definition of the Maritime region is not necessary to point out. However, as this chapter has discussed, such definitions pop up in and are supported by even the region's revisionist literary scholarship. The problem with Creelman and Keefer's reliance on a stable definition of "region" is that their approach assumes that regional literatures have a tendency to explore the same themes, using the same literary forms, over and over again. This paradigm relies on the notion that regions are knowable, essential, and that the experience of hardship within them is universal. 
By adhering to this straightforward treatment of regional space, critics treat nontraditional constructions of place, like those found in the recent works cited above, as anomalous within the Maritimes. Other writers from the region, most notably David Adams Richards, respond to postmodernism by stripping the language in their texts down in a quest for authentic accounts of regional experience. Although this would seem to fit in with Creelman's claim that realism continues to dominate Maritime literature, it would be wrong to assume that writers from the region do not engage with contemporary experimental genres - many simply find them unsatisfactory. ${ }^{5}$ Recent scholarship on regionalism in Canadian literary criticism takes into account developments in spatial identity theory and reworks this method. This approach allows critics to explore the ways in which authors such as Lynn Coady participate in the construction of a regional space that is contested and shaped by complex social interaction and struggle.

\section{Satire, Irony and Coady's Narrative Strategy}

In his 1990 article, "Between Space and Time: Reflections on the Geographical Imagination," David Harvey explains that in regions like the Maritimes, conventional spatial definitions are long-standing and firmly entrenched and therefore inspire marginalized individuals and groups to rally against them. He argues that although space has been proven to be a social construction, conventional spatial definitions still exist and play an important role in negotiating identity (418). He goes on to state that this notion of

\footnotetext{
${ }^{5}$ In her 2007 article, "Knowledge, Power and Place: Environmental Politics in the Fiction of Matt Cohen and David Adams Richards," Cheryl Lousley also argues that Richards engages with postmodern strategies. She maintains that his fragmentary narratives in Lives of Short Duration (1981) and Mercy Among the Children (2000) contribute to his construction of the Miramichi River region in New Brunswick as an ecological "sacrifice zone" (28).
} 
space as a social construction depends on the capacity of those affected by essential definitions to struggle against them: "social space, when it is contested within the orbit of a given social formation, can begin to then take on new definitions and meanings" (422).

In this thesis, I argue that Coady's fiction engages in this kind of project. It is filled with references to families, like the Murphys, the MacNeils, and the Campbells, who live according to conventional gender roles, the tourist gaze as well as festivals and tourist infrastructure that celebrate the region's supposedly idyllic and serene landscape, and characters who attempt to run, play or reflect in the wilderness, only to find that it is poisoned. These definitions of space offer Coady, in Rob Shields" terms, "affordances" that she at once acknowledges and undercuts. In this thesis, I specifically argue that Coady makes use of postmodern irony and narrative satire to construct and deconstruct conventional definitions of nature.

Much has been written on the relationship between satire and irony. At first glance, there are significant differences between the two: most importantly, satire gains its evaluative and aesthetic power from clear and unequivocal meaning, and irony is necessarily ambiguous. There is, however, a connection between them, as satire makes use of irony's disparity between the intended and literal statement in undercutting its targets. In Anatomy of Criticism (1957), Northrop Frye wrote that "satire is irony which is structurally close to the comic: the comic struggle of two societies, one normal and the other absurd, is reflected in its double focus of morality and fantasy ... Two things, then, are essential to satire: one is wit or humour founded on fantasy or a sense of the grotesque or absurd, the other is an object of attack" (224). Irony - which Kenneth Burke and Hayden White call a "master trope" that "expresses the disparity between appearance 
and reality, what is acknowledged and what is repressed" (Rutland 6) - provides the content for satire. Although they are not necessarily connected, it is generally understood that satire employs irony in order to make its ethical judgements about the world outside the text (Pavlovskis-Petit 510).

Although traditional verse satire purports to have a solid grounding in the real world, in that it identifies wrongs that should be righted and ridiculous characters who should be chastised (Palmeri 6, Knight 33, Quintero 3), when narrative works, such as those of Lynn Coady, make use of satire, critics find that they do so in a way that muddles authorial intention and the text's ideological position. ${ }^{6}$ Whereas a trademark of traditional satire is a strongly defined and consistent moral stance, contemporary narrative satire is dialogic and home to multiple voices and competing political positions. Authors use narrative satire to expose official and conventional definitions as empty abstractions. In what follows, I demonstrate that, in her fiction, Coady reveals that conventional representations of nature are similarly discursive constructs that she undermines.

Frank Palmeri and Valeri Cunningham note that narrative satirists, in their quest to challenge conventional notions of truth and moral certainty, look to confuse distinctions between concepts like mannered and civilized, educated and ignorant, and nature and culture by focusing on the human body. Narrative satire is filled with references to the body and to human waste, images that authors use to align cultural and moral decay with physical and corporeal contamination (417). As Chapter 4 demonstrates, Coady's fiction reveals an almost uncomfortable obsession with the human

\footnotetext{
${ }^{6}$ See, for example, Bakhtin, "Discourse in Life and Discourse in Art (Concerning Sociological Poetics)" 113, Palmeri 1, Palmeri and Cunningham 417.
} 
body, and with images of the abject. Her characters constantly discharge bodily fluids of all kinds and make persistent use of scatological language. Coady's focus on the abject provides a framework for linking her treatment of the human body to her treatment of the physical environment, as she uses it to examine the effects of industrial pollution and conventional gender definitions on the bodies of her characters.

In her writing on this subject, Linda Hutcheon has argued that contemporary works of satire and parody employ what she calls "postmodern irony" (A Theory of Parody 43-53). While she points out satire and parody differ in that the former is often aimed at the world outside the text and the latter is intertextual, Hutcheon maintains that satire and parody "are often used together" and that "[s]atire frequently uses parodic art forms for either expository or aggressive purposes" ( $\underline{A}$ Theory of Parody 43 ). While Coady's fiction often explores external stereotypes and the economic and social conditions of life on the East Coast, her deconstructive approach to the natural environment is also closely related to the way in which she contests representations of the region by previous generations of Maritime writers.

In Splitting Images: Contemporary Canadian Ironies (1991), Hutcheon notes that postmodern irony discards the "strong moral accent" (5) and "balanced ambiguity" characteristic of previous strains of irony, and opts instead for a "suspensive" ethical position that refuses evaluative judgements. She draws on the work of Alan Wilde in Horizons of Assent (1981), which points out the limitations of “"premodernist' Augustan irony and compares it with Romantic irony, serving the interests of the poet-ironist and modernist irony as theorized by the New Critics, that aims for balanced ambiguity of statement" (Rutland 6). Hutcheon's work also corresponds with Umberto Eco's essay 
"The Frames of Comic 'Freedom"" (1984), in which he argues that comedy, carnival and satire are inherently conservative, since each proposes and stays within "intertextual frames" (4) and can therefore "exist only as an authorized transgression" (6). In their moral judgements about the world outside the text, comedy, carnival and satire differ from irony, which destabilizes and subverts these "frames." Hutcheon argues that postmodern writers replace the evaluative tone of earlier ironists with a search for paradox and contingency.

Rather than using humour to make judgements and expose irrational or ridiculous behaviour, authors employ postmodern irony in order to destabilize certainty, expose strategies of communication as ambiguous, and undermine all sides of a given issue, including their own. Just as conventional satire makes use of irony, so postmodern irony is the content of narrative satire. While she is not a traditional satirist, in the sense that she declines to identify obvious vices or individuals that she would like to correct, Coady satirizes her own characters - especially the father figures in her earlier texts and Larry from Mean Boy - and, as this thesis argues, uses satire to expose definitions of the environment as arbitrary and socially constructed, rather than essential.

A particularly telling example of Coady's narrative approach appears in "Big Dog Rage," a story from her 2000 collection, Play the Monster Blind. In this story, the narrator's sometime friend, Gerald, whose father forces him to become an altar server, shocks the rest of the community when he, as Coady would later describe it, "falls in love with blasphemy" (Bookmunch par. 13), a love which he expresses by picking his nose during the priest's homily, disrupting Mass, and performing the "Dirty Boogie" (PMB 139) on the altar. 
Gerald's actions provide a useful insight into Coady's narrative strategy. His project is to test the boundaries of his small religious community and to expose its rules, regulations and definitions as arbitrary and, above all else, socially constructed. The narrator describes his aim in these terms: "The whole thing made me uncomfortable because it looked to me as if Gerald was getting ready to do to the world one of his favourite things to do to everything else: take it all apart. Unscrew all the teensy imperceptible screws, and start tinkering around inside" (PMB 139). The narrator talks about Gerald's blasphemy and irreverence functioning as an educational tool for her; prior to him openly mocking the various elements of the Mass, she had believed that God appeared in the church every week to ring the bells before communion. For her, Gerald's pranks exposed the ritual of serving the altar as a cultural performance akin to "any other foolish thing your parents would force you to do, like violin lessons" (PMB 140).

As I briefly discuss in the following chapter, Christian tropes often inform pastoral representations of nature. Coady's deconstruction of definitions of the natural environment often intersects with and depends on the way in which she satirizes Cape Breton's religious mores and institutions. Aside from this, however, the above passage is relevant here because Gerald effectively summarizes Coady's general narrative strategy. Coady's fiction is obsessed with these "teensy imperceptible screws": the elements of Maritime Canadian society that present and uphold things such as gender relations, class status, regional stereotypes, religious mores, and, above all, as this thesis explores, definitions of nature as permanent, essential, and arising spontaneously. In what follows, I argue that Coady's treatment of "the natural environment" in her texts is comparable to 
Gerald's approach to religion: her texts underscore that the natural world is a product of human construction and undermine seemingly straightforward definitions of nature. 


\section{CHAPTER 3:}

\section{POST-STRUCTURALISM AND CANADIAN ECOCRITICAL THEORY}

\section{Introduction}

Linda Hutcheon's 1993 essay, "Eruptions of Postmodernity, the Postcolonial and the Ecological," brings into uncomfortable contact two potentially antagonistic critical methods, postmodernism and ecocriticism. Although she maintains that postmodernism offers strategies for responding to the harmful consequences of modern events such as the industrial revolution, European imperial conquest, and the campaign to impose Cartesian rationality on nature (146), ecocritics in Canada have, for the most part, shied away from postmodernism. Hutcheon argues that in order to level a meaningful challenge to Canadian society's exploitative and abusive treatment of the natural environment, the country's literary criticism needs to move past its dominant paradigm for reconciling nature and culture: Northrop Frye's romantic description of taming the land and making it productive ("Eruptions" 153). Although conventional ecocriticism in Canada clearly rejects the environmental politics of Frye's work, its challenge is limited because it does not question many of his framework's key definitions. Until recently, Canadian ecocritics relied on the same sharp distinction between civilization and wilderness that characterizes Frye's garrison thesis, and argued that the political strength of Canadian nature writing comes from its visceral descriptions of the way in which human society looms as a threat to pristine wilderness. ${ }^{1}$

It is for this reason that many ecocritics in Canada view the postmodern - which challenges the stability of definitions such as pristine and wilderness as well as the

\footnotetext{
${ }^{1}$ See Relke, Forster, and Bondar, among others.
} 
authenticity of experience that nature writing depends on - with a degree of suspicion: "Where the early post-structuralists failed women writers, and Canadian criticism more generally, was in the binarism of their own thought, by setting Canadian postmodernism in opposition to virtually everything that went before it. Instead of understanding it as one of the many evolutionary extensions of modernism, they were as guilty as their structuralist adversaries of misleading and misdirecting the act of reading" (Relke, "Feminist Ecocritique" 73). In this chapter, I argue that Hutcheon's definition of a postmodern ecological ethic can have useful applications in Canadian literary criticism, especially when read side-by-side with post-structuralist theorists such as William Cronon, Donna Haraway and Karla Armbruster, who question the rigid way in which conventional environmental thought defines "nature."

In this chapter, I develop a definition of the term "nature" that acknowledges it as a linguistic construct imbued with, as W.J.T. Mitchell explains, ideological force. My post-structuralist ecocritical approach identifies three potentially deconstructive sites: the male and female body, idyllic portrayals of nature, and polluted spaces. In this chapter, I begin with a short discussion of Canadian ecocritical theory; while early Canadian ecocritics focused mainly on nature poetry, more recent studies in this field examine literature which, like Coady's fiction, is concerned with human-occupied spaces. I then review debates in ecofeminist theory in Canada and abroad. Contemporary ecofeminists argue that deconstructing the relationship between the natural environment and ideal definitions of the male and female body provides a strategy for pushing past some of the essentialist approaches in this field. Finally, I examine post-structuralist ecocriticism's treatment of toxic landscapes. Recent scholarship in this field observes that writers use 
polluted spaces as a metaphor for rampant consumerism and ecological despoliation and to call attention to the effects of ecological damage on marginalized communities. The theoretical material I provide in this chapter sets up my reading of Coady's deconstruction of conventional definitions of nature.

While the ideas and theories that inform ecocriticism emerged loosely in the 1970s, many point to a 1978 convention of the Western Literature Association in Eugene, Oregon as the field's foundational moment (Love, Practical Ecocriticism 4). Since this time, several different strains of ecocriticism have emerged, including social ecology, ${ }^{2}$ deep ecology,${ }^{3}$ and as I discuss in detail in this chapter, post-structuralist ecocriticism and ecofeminism.

Although ecocriticism is clearly influenced by a materialist understanding of reality, one that relies on a concrete relationship between the writer and the world he or she is motivated to protect, David Mazel, Karla Armbruster, Kathleen Wallace, Robert Kern and William Cronon argue that contemporary ecocritics should view nature as a discursive construct. In Beyond Nature Writing (2001), Armbruster and Wallace observe that the sharp distinction between human society and the natural world employed by conventional ecocritics has led them to focus only on texts with overt environmental themes. Mazel, in his 2001 book, American Literary Environmentalism, maintains that this approach works to "obscur[e] and enabl[e] the economic, political, and historical relationships at the root of both environmental destruction and human oppression" (xiii). In the following section, I examine the effects of this debate on ecocriticism in Canada.

${ }^{2}$ See, for example, Bookchin, The Philosophy of Social Ecology (1995).

${ }^{3}$ See, for example, Sessions (ed), Deep Ecology for the Twenty First Century (1995) and Katz et al. (eds), Beneath the Surface: Critical Essays in the Philosophy of Deep Ecology (2000). 


\section{Ecocriticism in Canada}

Until recently, two approaches dominated studies of landscape in Canadian literary criticism. The first is most closely associated with Northrop Frye's garrison thesis. Frye, in his "Conclusion" to A Literary History of Canada (1965) and his collection, The Bush Garden (1971), argued that Canadian writers respond to the immensity of the country's landmass either by expressing terror at the violence of nature or, to a much lesser extent, delight at nature's bountiful resources (The Bush Garden 138). Although Frye saw this as a problem in Canadian culture that should and could be overcome by a process of artistic maturation, the thematic critics adopted a version of this thesis that maintained that this fear of the country's landscape meant that certain images and word patterns came to stand in for the land throughout the first two and a half centuries of the European conquest of Canada (Moss, "Landscape" 35). Margaret Atwood's Survival: A Thematic Guide to Canadian Literature (1972) summarizes the major "patterns" found in Canadian literature and advances the idea that the country's authors have treated the landscape as a menace in need of subjugation. For Atwood, the unifying theme of this canon has been the attempt at grim survival by human society in the face of the malicious land that surrounds it.

Many studies that investigate landscape in Canadian literature have not abandoned this vision of human society in a constant battle with the cruel wilderness. The thematic approach has been used by more recent critics in their assessments of the role of landscape in Canadian literature. In her 1985 study, The Wacousta Syndrome, Gaile McGregor argues that Canada's harsh and unforgiving landscape has inspired a sense of 
terror and confusion in its art and literature (6). Diana Brydon, in speaking of affinities between the literary tradition of Canada and that of Australia in 1981, argues that the difficulties writers in each country have experienced in comprehending the landscape has propelled their literary traditions (279). In "Empty as Nightmare: Man and Landscape in Recent Canadian Prairie Fiction" (1976), an essay that has been challenged by his later work and by others like Alison Calder, Laurie Ricou notes that the dominant image that haunts Western literature in Canada is that of a vast and empty landscape where human society exists only as an intrusion (144-5). In his 1998 article, "The Ecological Ethic: Sustainability, Ecophilosophy, and Literary Criticism," David Wylynko claims Frye and Atwood as early ecocritics in Canada and writes that "each shows how Canadian works of art, both literary and visual, depict the importance of nature - as an economic resource and a spiritual force - to the Canadian identity" (134).

The second approach to landscape in Canadian literary criticism is the study of pastoral literature and nature writing. Several Canadian ecocritics suggest that the Confederation poets' romantic portrayal of the landscape make them early examples of "proto-ecocritical" writers in the country. In "The Politics of Nature: Archibald Lampman's Socialism" (1999), James Doyle, for example, argues that Archibald Lampman's "socialist ideas and his love of nature can be seen as parts of a unified poetic vision" (12-13) that both idealized nature and took nineteenth-century industrialization to task. In his 2001 introduction to Canadian Poetry's special issue on nature writing, D.M.R. Bentley similarly observes that the romantic vision of the Confederation poets should form the basis for ecocritical readings of Canadian poetry (11) and cites Lampman and Isabella Valancy Crawford as examples of early ecopoets. In "The Ecological Vision 
of Isabella Valancy Crawford: A Reading of 'Malcolm's Katie"” (1991), Diana Relke argues that Crawford's "Malcolm's Katie" (1884) castigates Malcolm and the nineteenthcentury industrial class he represents for the irresponsible way in which they subjugated the landscape (52).

Pastoral literature and, by extension, criticism that considers pastoralism a useful way of framing the relationship between human society and the environment, tends to objectify nature. In exploring the tension between tradition and progress - a conflict most commonly represented by a contrast between wholesome rurality and decadent urbanity the escape to the countryside characteristic of pastoral literature is a search for stability in the face of change. Criticism on pastoral literature in Canada has focused on its escapist elements. Walter Pache, for example, argues that the pastoral tradition in Canadian literature is as strong as its political edge is dull. For him, pastoralism constitutes an "escape into a world of illusions" (18) and a celebration of the ideal over the realistic. ${ }^{4}$ In Ecocriticism (2004), Greg Garrard points out that the pastoral also evokes the Christian ethic that nature is a bountiful resource that exists so that human society can exploit it. He writes that while the environmental movement often makes use of such "ancient tropes" (176) that romanticize the natural environment, contemporary ecocritics deconstruct this sharp distinction between nature and culture as well as the often problematic way in which religious discourse informs perceptions of the natural world. ${ }^{5}$

\footnotetext{
${ }^{4}$ Recent studies in Canada have argued for a more complex understanding of the pastoral mode. Robert Stacey, for example, argues that in contemporary literature the pastoral is often "an inescapably political negotiation of social responsibilities" (92). See also Giltrow and Stouck, “'Mute Dialogues': Michael Ondaatje's Running in the Family and the Language of Postmodern Pastoral" (1992).

${ }^{5}$ See also Lynn White, “The Historical Roots of Our Ecologic Crisis" (1996).
} 
In Under Eastern Eyes, Janice Kulyk Keefer cites Maritime literature's strong pastoral tradition in positing that the region's writers do not fit in with Frye's "garrison thesis." She maintains that Maritime writers have neglected the sweeping emotional and psychological "generalizations" characteristic of other regions. ${ }^{6}$ Keefer argues that Maritime writers historically have been preoccupied with the practical benefits and drawbacks of the region's landscape. As I discuss at length in Chapter 5, Coady's fiction subverts the pastoral impulse that Keefer identifies in Maritime literature. In that chapter, I examine the tension between conventional definitions of the Maritimes as idyllic and the bleak post-industrial landscape Coady often evokes in her fiction.

By claiming pastoral and romantic literature as "eco-texts," literary criticism in Canada paves the way for the country's most influential strain of ecocriticism: the attempt to demonstrate that Canada has been an important space for the production of “proto-ecocritical" literature written by such authors as Margaret Atwood, ${ }^{7}$ John Steffler, ${ }^{8}$ and by far the most important figure for contemporary Canadian ecocriticism, the nature poet Don McKay. As the leader of an emerging cadre of ecopoets in Canada that includes Tim Lilburn, Jan Zwicky, Dennis Lee and others, McKay's poetry calls attention to the spiritual and aesthetic qualities of the natural world that modern society threatens. Critics of McKay's work focus on his rich and incisive use of metaphor and the way in which his

\footnotetext{
${ }^{6}$ See also Davey, Reading Canadian Reading, 5. Keefer refers to Maritime authors Ernest Buckler, Charles G.D. Roberts, Thomas Raddall, Alistair MacLeod, David Adams Richards and others.

${ }^{7}$ See, for example, Johnston, "Reconstructing the Wilderness: Margaret Atwood's Reading of Susanna Moodie" and Haag, "Ecological Aurality and Silence in Margaret Atwood." While critics have deemed Surfacing (1972) and The Journals of Susannah Moodie (1970) "proto-ecocritical," Atwood's later work, such as Oryx and Crake (2003), would not fit this label.

${ }^{8}$ See Jaeger, “'The Land Created a Body of Lore': The Green Story in John Steffler's The Afterlife of George Cartwright."
} 
elusive language mirrors the ambiguity of the natural world. ${ }^{9}$ In his 2007 thesis, Notes to a Poetics of Earth, Mark Dickinson argues that Canadian nature writers Dennis Lee, Robert Bringhurst and Don McKay turn to ancient Greek philosophy as a strategy for asserting "at-homeness" in a world in which modernity and technology separate the human from the natural. Dickinson argues that the "homelessness of the twentiethcentury results from a form of human consciousness at odds with nature [and that these] poet thinkers offer ... the promise of a uniquely Canadian poetics that re-imagines and refashions human dwelling on earth" (6).

By limiting their readings only to nature writing, early ecocritics in Canada often ignored the spaces where people actually live. A common assumption in Canadian ecocritical theory is that " $[\mathrm{t}]$ he strength of the nature poetry aesthetic is that it incorporates aspects of both post-structuralist and Romantic thought" (Bushell 52). In this estimation, the contingency of post-structuralism provides space for, and strengthens encounters with, the pure wilderness, and the project of ecocriticism and "eco-texts" should be finding language that can harness this potential. Alison Calder argues that conventional studies on nature writing propagate exoticized portraits of nature, allowing for peripheral areas such as the Prairies and the Maritimes to be cast as stagnant patches of wilderness. For Calder, the environmental politics of such criticism is "deceptive because at the same time as it proposes meaningful environmental change, the way in which it represents the environment makes change impossible" ("The Wilderness Plot" 166).

\footnotetext{
${ }^{9}$ See Bondar, "'that every feather is a pen, but living, // flying' Desire: The Metapoetics of Don McKay's Birding, or desire.," Bushell, “Don McKay and Metaphor: Stretching Language Toward Wilderness.," and Forster, "Don McKay's Comic Anthropocentrism: Ecocriticism Meets 'Mr. Nature Poet."'
} 
Canadian literary criticism that has examined the intersection of post-colonial and ecocritical approaches also stresses the need to move beyond nature writing. In her 2001 essay, "Articulating a World of Difference: Ecocriticism, Postcolonialism and Globalization," which examines Anita Rau Badami's The Hero's Walk (2001), Susie O'Brien states that conventional ecocriticism's preoccupation with realist and rural texts places it at odds with post-colonialist and post-structuralist literary theories. She argues, however, that contemporary ecocritical theorists' emphasis on hybridity and globalization partially addresses "the question of how to combine postcolonialist and ecocritical approaches to understanding contemporary culture" (141). This focus on hybridity as the way to bridge these theories appears also in Simone Hartmann's "Feminist and Postcolonial Perspectives on Ecocriticism in a Canadian Context: Toward a 'Situated' Literary Theory of Ecofeminism and Environmental Justice" (2006). In this article, Hartmann observes that in Thomas King's Truth and Bright Water (1999), "Images of the natural environment are bound up with ideas of ethnic/indigenous and national identity and difference ... [T] $]$ he experience of physical displacement and spiritual alienation from the natural environment along with processes of cultural dispossession and appropriation play a decisive role" (102). Hartmann also notes that King satirizes and undermines the myth of the "ecological Indian" in deconstructing and resisting western narratives.

In her 2007 article, "Knowledge, Power and Place: Environmental Politics in the Fiction of Matt Cohen and David Adams Richards," Cheryl Lousley also critiques Canadian ecocriticism's tendency to idealize the natural environment. In focusing on the "politics of knowledge," Lousley suggests that the fiction of David Adams Richards and Matt Cohen exposes the power relations behind environmental degradation. She argues 
that ecocriticism in Canada should move beyond environmental determinism and its tendency to subsume "social inequalities and differences in the name of environmental crisis" (12). Her framework links environmental despoliation to structural features of a late industrial and capitalist society that exploits marginalized populations and resourcerich regions. She notes that a "key task for ecocriticism is to consider how knowledge of environmental ills and risks - or the very lack or limitations of environmental knowledge - is staged in contemporary literature" (28). Lousley observes that in contemporary Canadian literature, characters who live in economically depressed regions of the country feel the effects of environmental degradation more readily than inhabitants of wealthy areas. Her analysis of the Miramichi as an "ecological sacrifice zone" informs my discussion of the post-industrial landscape of Cape Breton, as Coady also depicts communities that have been gutted by the industrial complex. Like Calder and Lousley, I argue in this thesis that in order for ecocriticism to be useful in the Canadian context, it is necessary to move beyond conventional approaches to nature writing that focus on and reinscribe pastoral values.

\section{Ecofeminism and the Body}

Ecofeminist theory in North America has also undergone a series of transformations over the past thirty years. In her 2000 essay, "A Post-Structuralist Approach to Ecofeminist Criticism," Karla Armbruster observes that ecofeminism has traditionally been plagued by two problems. The first is that in critiquing patriarchal society's treatment of nature, ecofeminists often forged an essential connection between women and nature, and paid little attention to the differences between women (198). 
There is, however, a large body of ecofeminist writing that has contested and directly challenged this approach. ${ }^{10}$

The second problem is that in identifying masculine culture's domination over nature (and women), some early ecofeminist writing relied on another dualism: the rigid separation of nature from culture. For example, while Carolyn Merchant's 1980 book, The Death of Nature: Women Ecology and the Scientific Revolution - which has been very influential in the field of ecofeminism - challenges the essentialist conflation of women and the natural world, it also promotes a utopian vision of nature prior to the industrial era. Merchant argues that western society has rationalized nature since the Enlightenment. For Merchant, the project of compartmentalizing the natural environment and dissecting it to the point where it ceased to be a dynamic force resulted in "the death of nature." Her study is useful for exposing the way in which "[t]he new image of nature as a female to be controlled and dissected through experiment legitimated the exploitation of natural resources" (189). More contemporary ecofeminist theory, however, critiques Merchant's romanticized portrayal of the natural world.

While Merchant laments the influence of scientific discourse on the natural environment, in her 1991 essay, "A Cyborg Manifesto: Science, Technology, and Socialist Feminism in the Late Twentieth Century," developments in science and technology undermine the distinction between nature and culture. Haraway traces the historical development of categories such as sex and gender and uses their inconsistent and contradictory meanings to call attention to the fragmented

\footnotetext{
${ }^{10}$ See, for example, Griffin, "Ecofeminism and Meaning" (1997) and Sandilands, The Good Natured Feminist (1999), among others.

${ }^{11}$ This essay expands on the 1985 version and is found in Simians, Cyborgs and Women: The Reinvention of Nature.
} 
way in which the concepts "woman" and "nature" emerge in the highly technologized, post-industrial late twentieth century. Haraway's work provides a framework for reassessing conventional ecocriticism, particularly feminist ecocriticism, in Canada. As I discuss below, her work also contributes to post-structuralist ecocriticism's treatment of toxic landscapes.

The continuum between Merchant's and Haraway's approaches is reflected in Canadian ecofeminism. Early ecofeminists in Canada carried out Merchant's project of exposing linguistic and cultural stereotypes that cast nature as feminine. However, recent studies in this field argue that conventional ecofeminism excludes from its purview minority groups who struggle for access to the natural environment and relies on essentialized definitions of nature.

Ecofeminist critics in Canada traditionally focused on the way in which nature poetry contests the dominant myths of the land in Canadian literature, which not only excluded women's experiences but also, as Diana Relke writes in "Feminist Ecocritique as Forensic Archaeology: Digging in Critical Graveyards and Phyllis Webb's Gardens" (1998), "[gendered] nonhuman nature as female" (72). In "Women in the Wilderness" (1998), Heather Murray argues that wilderness writing by women in Canada forces literary criticism in this country to rethink definitions such as "land," "nature" and "wilderness." Like Relke, Murray argues that the garrison and frontier myths claim the land as a space available only to men and reinforces a dichotomy that distinguishes between nature and culture, with women being represented by nature. In her 1998 article “Narratives of Coming Home: Gilean Douglas and Nature Writing," Andrea Lebowitz employs a method very similar to that of Relke and Murray. She argues that Douglas's 
writing was marked by a sense of the way in which nature stood as a threat to culture in Canada; however, she maintains that this changes over the course of her career to a feeling of affinity with and indebtedness to the wilderness.

In "Timothy Findley's Not Wanted on the Voyage: an Exemplary Ecofeminist Text" (1998), Dorothy Nielson links many of the problems identified by Murray, Relke and Lebowitz to a general tendency in ecofeminist theory to deploy essentialist notions of women and nature. She argues that a nuanced ecofeminist reading would reveal the ways in which texts like Not Wanted on the Voyage "vividly and succinctly present the ecofeminist argument that by excluding diversity and privileging the supposedly 'masculine' value of power over the Other, patriarchal cultures have sanctioned destruction of our ecosystem" (105). She points out that Findlay's novel "advocates a sense of self that is interdependent with human and non-human nature" (118). As Nielson contends, the framework ecofeminist writers in Canada use is successful in exposing the push to establish connections between women and nature and in destabilizing the unitary notion of female that this equation relies on. Nielson claims, however, that this scholarship continues to essentialize non-human nature by defining it so narrowly.

In Inhabiting Ecocriticism: Canadian Women Writers Write Environmentalism (2003), Erin Whitmore calls attention to the problematic way in which Canadian literary critics have used ecofeminism. She argues that traditional ecofeminism is exclusionary, as it has largely been concerned with only white, middle class women and their experiences of nature (9). Whitmore goes on to identify two major problems with conventional ecofeminism in Canada: the field does not link issues such as class and race 
to gender in describing women's experience of nature, and it remains wholly fixated on nature writing. The latter is problematic for several reasons: "this predilection towards nature writing has a negative effect on the role of women's writing and feminist literary criticism within ecocriticism ... Nature writing which leaves unproblematised notions of privilege and access to these spaces situates itself in perceptions of non-human nature that often embody classist, racist and sexist assumptions" (Whitmore 15). Whitmore points out that early ecofeminist studies in Canada share conventional ecocriticism's sharp spatial distinction between pristine and modified nature. She argues that for this reason, Canadian ecofeminists tend to favour nature writing and often fail to consider texts outside of this purview.

In this thesis, I argue that one way of moving past the essentialist reading of nature characteristic of much early ecofeminist criticism is by focusing on connections between definitions of the ideal masculine and feminine body and the natural environment. Building on the work of feminist scholars Simone de Beauvoir and Judith Butler, who stress that gender is performed and the body is a site of contestation, contemporary ecofeminists view the body as a deconstructive site. ${ }^{12}$ In her 2000 essay, "Is the Body Essential to Ecofeminism," Terri Field argues that ecofeminists are often reluctant to engage with the body, as it is a "hotbed of essentialist discourse." Field maintains, however, that ecofeminists should view the body as a deconstructive space because it "provides a point from which to rethink all those binary pairs associated with the $\operatorname{mind} /$ body dualism, including inside/outside, private/public, and self/other" (40) and that

\footnotetext{
${ }^{12}$ See The Second Sex (1953) and Gender Trouble: Feminism and the Subversion of Identity (1990).
} 
"it has the ability to empirically manifest (at times) the consequences of our domination of nature" (55).

Contemporary ecofeminism is particularly suspicious of the essential connection often made between the maternal body and nature. In "Feminism, Ecofeminism and the Maternal Archetype: Motherhood as a Feminine Universal" (1994), Lynn Stearney argues that this conflation, one that has existed in western literature for centuries and has been co-opted by the environmental movement, casts motherhood as natural, rather than socially constructed: "[t]he mother archetype, however powerful, cannot function in this way without reinforcing the contemporary patriarchal ideal of motherhood as natural, limitless, and exploitable" (146). In the following chapter, I suggest that this kind of ecofeminist reading provides a productive framework for understanding the relationship

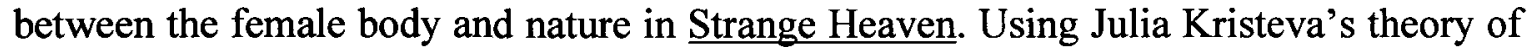
the abject, I argue that Coady's focus on blood, vomit, excrement, and childbirth calls attention to the ways in which maternity and motherhood are socially constructed rather than "natural." Coady is careful not to forge an essential connection between women's bodies and the environment. Rather, her fiction aligns the institutional, societal and familial controls placed on the female body with normative, nostalgic and ultimately masculine definitions of landscape.

In addition to its deconstruction of definitions of nature as feminine, recent studies in ecofeminism have also examined the relationship between masculinity and the natural environment. Contemporary ecofeminists point out that essentialist definitions of the body and nature also cast men as dominant over it and naturalize a kind of "toxic masculinity." In Proving Manhood (1997), Timothy Beneke defines "toxic masculinity" 
as a hegemonic masculine culture in British and North American societies that privileges strength, virility, large body-types, toughness, heteronormativity, and domination over women and the natural world (1).

While cultural and literary theorists most often use the concept "toxic masculinity" in studies focused on domestic abuse and sports, in her 2003 dissertation Second Natures: Media, Masculinity and the Natural World in Twentieth-Century American Literature and Film, Jeanne Hamming examines the way in which anxieties surrounding masculinity in contemporary North American society impact the natural environment. She observes that "notions of masculine identity are bound up in a certain ideological relation to nature, the supposed disappearance of the natural world and its replacement by a post-industrial technoscape is accompanied by crises regarding the authenticity of masculine identity" (16). For Hamming, what she calls "masculine crises in relation to nature" (61) have resulted in intensified efforts to extract resources from the land.

Like Thomas Dunk in his 2003 study, It's a Working Man's Town: Male Working-Class Culture, Hamming observes that the connection forged between "traditional" notions of masculinity and resource-extraction places both the environment and workers at risk. This is true, she argues, because "increases in production and resulting decreases in material resources can be forestalled by technological developments that temporarily boost production, but as technologies use up more remote and more expensive resources, the cycle of production and environmental stress once again veers toward diminishing returns" (24). As I discuss in further detail in the 
following chapter, Dunk maintains that judging masculine strength according to the ability to extract resources results in workers accepting dangerous conditions in mines and mills and sacrificing their bodies for industrial projects. Coady focuses on this "toxic masculinity" most explicitly in Saints of Big Harbour, where members of Guy's family and community push him to participate in violent sports and perform dangerous manual labour.

\section{Ecocriticism and Toxic Landscapes}

While much early ecocritical discourse focused on nature writing, more recent scholarship in this field has turned to literature that represents the effects of pollution. In their seminal texts Silent Spring (1962) and The End of Nature (1989), Rachel Carson and Bill McKibben examine the health-related and philosophical impact of industrialized society's ubiquitous chemical toxins. Building on the work of Carson and McKibben, post-structuralist environmental theorists argue that because contaminants and twentiethcentury technologies have so drastically modified the environment, North America is now home to a "postnatural landscape."

For William Cronon and Donna Haraway, this "postnatural landscape" blurs distinctions between natural and artificial, beneficial and dangerous, and civilization and wilderness. Cronon, in his essay "The Trouble with Wilderness; or, Getting Back to the Wrong Nature" (1996), notes that human society has transformed the environment so drastically that it is impossible to insist that "nature" exists only in untouched spaces. For Cronon, contemporary environmental thought reminds us that human activity has always impacted natural ecosystems, as much of human history has involved controlling and 
influencing nature (36-37).

Cronon maintains that the moral imperative to protect the integrity of the nonhuman environment relies on what he calls a "naïve realism" that assumes that "nature" can be easily identified and separated from that which threatens it: the implements of culture. Cronon's work builds on W.J.T. Mitchell's Landscape and Power (1996), which traces the ways in which landscape art firmly establishes human society's dominance over the land and inculcates the environment with ideological values. This is possible, according to Mitchell, because human society treats nature as a blank slate upon which it can project cultural values.

Similarly, in "A Cyborg Manifesto: Science, Technology, and Socialist Feminism in the Late Twentieth Century" (1991), Haraway contends that twentieth-century technology has broken down the distinction between organic creatures and machines: "[l]ate twentieth century machines have made thoroughly ambiguous the difference between natural and artificial, mind and body, self-developing and externally designed, and many other distinctions that used to apply to organisms and machines ... the certainty of what counts as nature - a source of insight and promise of innocence - is undermined, probably fatally" (152-3). Although radical feminism and other cultural movements are uncomfortable with losing their firm analytical categories and experiential constructs, Haraway argues that there should be "pleasure in the confusion of boundaries and responsibility in their construction" because "[t]he stakes in the border war have been the territories of production, reproduction, and imagination" (151). For Haraway, since Western ideological traditions such as racism, sexism, the myth of progress and the unabated exploitation of nature depend on a strict boundary between organism and 
machine, this breakdown is an important analytical tool.

In "Toxic Discourse" (1998), Lawrence Buell brings this theoretical material to the study of contemporary American literature. He argues that events such as Chernobyl, the Exxon Valdez, and Love Canal have alerted authors to the effects of chemical spills and the presence of toxins in the environment. Buell maintains that chemical pollutants are problematic for environmental thought: toxins are tiny and often difficult to detect; however, they are also durable and extremely mobile. Buell notes that for these reasons, it is impossible to identify "natural" spaces that have not been intruded upon by human society. He writes that

physical nature's cultural importance, indeed nature's nature itself, ceases to be located in its promise as past, present or future sanctuary but rather in its role as humanity's codependent and coconspirator in coping with what Bill McKibben has called "the end of nature," that is, the fact/awareness that the nature one engages must not inescabably be - if indeed it has not always already in some sense been - not pristine but "second" (that is, inevitably somewhat modified) nature ... involving some sort of mutual constitution of the natural and the social. $(656-7)$

Following from Buell, Ursula Heise, in her 2002 essay, "Toxins, Drugs and Global Systems: Risk and Narrative in the Contemporary Novel," argues, using a "risk analysis" approach, that much contemporary American literature depicts individuals and communities that are at risk of exposure to harmful chemicals. Like Cronon and Haraway, Heise maintains that toxic landscapes provide a productive site for deconstructing traditional ecocriticism's emphasis on pristine environments. She writes 
that "contemporary novelists use chemical substances as a trope for the blurring of boundaries between body and environment, public and domestic space, and harmful and beneficial technologies" (748).

Buell and Heise argue that contemporary American writers employ toxic events and landscapes in two principal ways. The first is as a metaphor for western society's outof-control consumerism, lack of ecological responsibility, and penchant for disposing of the things it creates. They observe that the vast garbage dumps, contaminated air, and toxic rivers characteristic of the work of Thomas Pynchon and Don DeLillo function as a general warning about late capitalism and its excesses (Deitering 200-201, Reeve and Kerridge 311). Secondly, Buell and Heise argue that toxic landscapes call attention to the way in which the contemporary ecological catastrophe places certain populations at disproportionate risk. Literature that features what Buell calls "toxic discourse" emphasizes the way in which marginalized communities that lack political and economic clout often bear the brunt of ecological damage. In Chapter 6, I argue that the toxic landscape performs both functions for Coady: while environmental despoliation is an integral part of her construction of Cape Breton as a "fallen world," racialized and impoverished groups are also unduly exposed to pollution and the dangers of the postindustrial economy in her fiction.

\section{Conclusion}

Post-structuralist ecocriticism provides a framework for overcoming the nature/culture divide that is present in much Canadian literary criticism. Canadian ecocriticism has, until recently, been reluctant to consider this approach primarily 
because post-structuralism reconsiders the highly visceral reading of nature and environmental degradation that ecocritical studies in Canada often rely on. By seeking a unified subject in nature, setting wilderness off from civilization, and searching for authenticity in experiences of the natural world, early ecocriticism in Canada failed to make use of the theoretical gains of post-structuralism that Linda Hutcheon calls essential for combating the movement to rationalise nature ("Eruptions" 147). Early ecofeminism in Canada also objectified the natural environment and focused mainly on nature poetry. Recent scholarship in this field points out that essentialized definitions of the environment serve to naturalize representations of the female body as close to nature and the male body as dominant over it. Post-structuralist environmental thought also suggests that contemporary North American writing that focuses on toxic landscapes complicates the idea that nature exists primarily as pristine wilderness and breaks down distinctions between the natural and the artificial.

In what follows, I demonstrate that Coady engages with the male and female body, idyllic portrayals of the Maritimes, and toxic landscapes in order to undermine conventional definitions of nature. In her texts, the relationship between gender and nature is shown to be based on two socially constructed truths: that the female body is close to nature and the male body is dominant over nature. She challenges conventional representations of the male and female body by using images of the abject that contest the idea of the maternal body as natural, and by calling attention to the hypocritical, ridiculous and ultimately dangerous consequences of the masculine body being judged in its ability to extract resources from the environment. Coady also examines the way in which the tourism industry exploits idyllic depictions of the Maritimes to promote the 
region as a therapeutic and romantic space that modernity has left behind. Her fiction contests this notion by calling attention to the poverty and violence that often marks the Maritime region. Coady's texts subvert definitions of the environment as pristine wilderness by highlighting the ubiquity and permanence of pollution and toxicity in postindustrial Cape Breton. 


\section{CHAPTER 4:}

\section{CONSTRUCTIONS OF THE BODY AND NATURE IN COADY'S FICTION}

As mentioned in the previous chapter, contemporary ecofeminist scholars have identified the male and female body as productive sites for deconstructing conventional representations of nature. For Coady, notions surrounding femininity and masculinity in the small Maritime communities of which she writes are bound up with definitions of nature. She subverts the related ideas that women are ideally close to nature because of experiences like giving birth and raising children and that men ideally possess the ability to control it. She does so by exposing maternity and motherhood as social constructs and

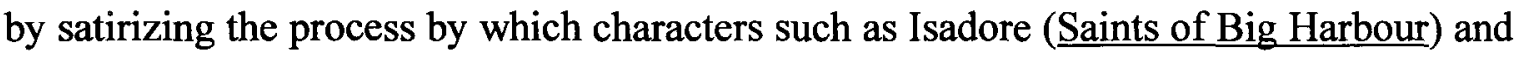
Jim Arsenault (Mean Boy) indoctrinate adolescent males into a masculine culture that advocates domination over nature.

Early ecofeminists often affirmed the essentialist link between the maternal body and the natural world and used it as a basis for arguing that women's intimate knowledge of, and affinity with, nature provide them with the skills necessary for protecting it. However, as Catriona Sandilands writes in a 1997 article entitled "Mother Earth, the Cyborg and the Queer: Ecofeminism and (more) Questions of Identity," ecofeminist scholars have largely distanced themselves from this position: "affinity and identity are not the same; where the latter involves the equation of women with nature, the former requires that the differences and contradictions also must be recognized and politicized. In order to accomplish this, ecofeminism needs to take into consideration the limits of identity, and indeed needs to make the job of politicizing these limits part of the very core of its project" (19). Sandilands argues that recent ecofeminist writing critiques the 
"ontological 'woman-nature' identity connection" so prominent in western thought through deconstruction and an emphasis on postmodern theories of subjectivity.

In this chapter, I argue that Coady employs images of the abject in Strange Heaven to deconstruct this connection between the maternal body and nature. Contemporary feminist and psychoanalytic theory attentive to the role of the female body in art and literature insists that the body is not an essential and natural entity but is coded and given meaning through representation, discourse and regulation. In Powers of Horror: An Essay on Abjection (1982), Julia Kristeva suggests that the social, spatial and institutional regulations placed on the body work to exclude elements of it which are deemed inappropriate and impolite. She says that the sanitation of things like excrement, vomit, food, and other reminders of disorder, which she calls the abject, produces the body. Kristeva writes that the abject subverts dichotomies like inside and outside, pleasure and pain, and dead and alive: "[i]t is thus not lack of cleanliness or health that causes abjection but what disturbs identity, system, order. What does not respect borders, positions, rules. The in-between, the ambiguous, the composite" (4). The abject calls stability into question by challenging the most fundamental definition: that of the self as unified subject.

Kristeva observes that the maternal body is particularly ambiguous, as it "straddles the 'nature-culture' split" (Spillers 288). Avant-garde artists make use of the abject's subversive power by actively engaging it in order to challenge the controls placed on the body by institutional and familial structures. Images of the abject do this by reminding us that these expectations are ultimately socially constructed. In "The Body of Signification" (1990), Elizabeth Gross explains that the abject "is the body's 
acknowledgement that the boundaries and limits imposed on it are really social projections ... It testifies to the precarious grasp of the subject on its own identity, an assertion that the subject may slide back into the impure chaos out of which it was

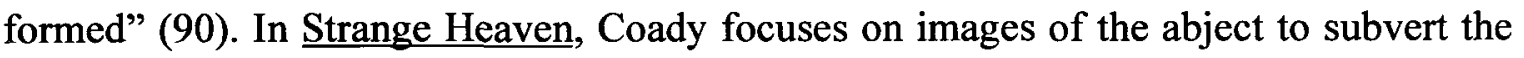
controls placed on Bridget by the church, the health care system, and her family, and to dispute the idea that the maternal body is "natural." The novel's deconstructive approach to gender roles also subverts conventional ideas surrounding femininity and nature. Coady occasionally employs the maternal body in her later texts, particularly in Mean Boy, where Janet stages a fake pregnancy in a sociological experiment on her family.

While the female body appears in much literature and popular culture as maternal, quiet, beautiful, exploitable, and as a metaphor for nature, the ideal male body, on the other hand, is equipped to conquer and tame the natural environment. Marti Kheel, in "Ecofeminism and Deep Ecology: Reflections on Identity and Difference" (1990), argues that popular images of men as hunters and as harvesters of natural resources uphold the notion that masculine culture is dominant over the natural world. Kari Marie Norgaard notes that "because of the way in which nature is drawn upon to normalize both femininity and masculinity, both genders have been 'naturalized.' Interestingly, due to the shifting definition of nature, when we talk about what is naturally male, nature itself becomes something different than when we refer to that which is naturally female ... Some of these associations between men and nature - particularly that of hunting - have been discussed in terms of men's desire to separate from and conquer nature" (199-203).

Roger Horrocks similarly maintains that representations of masculinity in much North American literature and popular culture uphold and celebrate the idea that male 
culture dominates nature (and women, who are often cast as part of nature). He observes that this is particularly true with respect to the western movie, which "symbolically restores to men something they have lost - not simply being able to live in nature and its beauty, but their own nature, their own beauty. The snow-covered hills. The 'pretty country' that men gaze at in wonderment - surely these are symbols of something internal to men, that has been cut out of them ... there is a utopian vision here" (73).

In Coady's industrial Cape Breton, this "utopian vision" is based on male characters' relationship with resource-extraction. In his 2003 study, It's a Working Man's Town: Male Working-Class Culture, Thomas Dunk argues that the prominence of resource-based industries in places like Northern Ontario (and, by extension, Cape Breton) has a profound effect on definitions of the ideal masculine body. Since extracting crude materials from the natural environment is such an important part of the local economy, the ideal masculine body is one that can participate in this activity and survive in this world. For Dunk, this "reflects the macho culture of the region. Northwestern Ontario is a place of long, empty distances, of big machinery, large trucks, and lake ships. These objects provide models and metaphors for the human body. Size and power are important aspects of the ideal body type. ... the ideal man in this world is someone who is physically strong and well coordinated ... who is 'not afraid of work' and doesn't 'take any shit;' who does not complain about physical inconvenience ... there is an echo of the ethos of workmen in the staples economy" (75-76). Dunk goes on to argue that even though machinery and other forms of technology have taken over from the brute strength of the worker in physically harvesting and transporting ore, trees and even fish, male 
working-class culture still demands conformity to this body-type, as it connects contemporary industrial workers with the "pioneer" culture that precedes them. ${ }^{1}$

In large part, it is this conflict that Coady is most interested in addressing: John Sr., Jim Arsenault and Isadore brand themselves as authentic examples of a lost masculine culture even though John runs a restaurant, Arsenault writes poetry for a living, and Isadore has not worked in years, as the result of an industrial accident. Coady's fiction undermines their appeals to authenticity by calling attention to their elaborate and hypocritical methods for fabricating their masculine personas. Coady satirizes John Sr. and Jim Arsenault for their bluster about the masculine body by exposing their hypocrisy - under the surface, they are ridiculous, petty, and ultimately violent characters. Coady's treatment of the relationship between the male body and the natural environment is more piercing in Saints of Big Harbour; masculinity appears in this novel as a toxic force, as Isadore's macho working class code demands that young men like Guy and Dan C. join the region's proud tradition of resource extraction, exposing them to physical harm in Cape Breton's mills and steel plants.

While such a reading of nature as gendered is not unique to Maritime writing, it does appear in much of the region's literature, including that of Thomas McCulloch, Lucy Maud Montgomery, Charles Bruce, and David Adams Richards. The most obvious

\footnotetext{
${ }^{1}$ Studies in the field of social reproduction point to a link between the two sides of this essentialized relationship between the body and nature. As feminist political economists such as Mary O'Brien, Kate Bezanson and Meg Luxton contend, patriarchal society makes use of the "motherhood as natural" argument in the interests of maintaining control over reproduction: "the way in which the population as a whole, and a labouring population in particular, is produced is as critical to the organization of any mode of production as the organization of objects (raw materials) and forces of production (tools)" (Luxton 28).
} 
contemporary example is Ami McKay's The Birth House (2006), a novel that details the conflict between traditional mid-wife practices and the construction of a new maternity hospital near Canning, Nova Scotia, on the Bay of Fundy. The Birth House provides a useful example of the conventional attitude that Coady looks to subvert in her fiction. Set in the early twentieth century, McKay's novel includes descriptions of the Annapolis Valley's almost magical landscape, which is home to mysterious and bountiful woods, pastoral scenery and the kind of environment where human society lives in peaceful harmony with the natural world.

The Birth House extols traditional practices like hard work on the land, the use of midwives, and "natural" births that take place in the home, rather than "in a clean, sterile environment, with the finest obstetrical care" (McKay 30). The novel makes a clear connection between the ideal maternal subject - established early in the novel when the protagonist, Dora Rare, and her mentor, Miss Babineau, are appalled by Mrs. Ketch's rejection of her still-born child - and the fertile valley which is the backdrop for the action of the novel. In the prologue, for example, McKay's first-person narrator, Dora, makes heavy use of natural metaphors in talking about the maternal body: "In the secret of the night, mothers whispered to their daughters that only the moon could force the waters to submit. It was the moon's voice that called the men home, her voice that pulled their babies into the light of birth. My house became the birth house. That's what the women came to call it, knocking on the door, ripe with child, water breaking on the porch" (McKay ix).

In the same section, Dora notes that the typical and ideal relationship between the male body and nature is one in which masculine culture surveys, tends, and holds 
dominion over the environment: "The seasons were reflected in their faces, and in the movement of their bodies. When it was time for the shad, herring and cod to come in, they were fishermen, dark with tiresome wet from the sea. When the deer began to huddle on the back of the mountain, they became hunters and woodsmen. When spring came, they worked the green-scented earth, planting crops that would keep, potatoes, cabbage, carrots, turnips. Summer saw their weathered hands building ships and haying fields, and sunsets that ribboned over the water, daring the skies to turn night" (McKay viii). McKay's novel, which was named a number one bestseller by The Globe and Mail, succinctly describes two ideal body types, one female and one male, suited to the economically severe and culturally rich Maritime region. Just as the narrator understands the relationship between women and the environment through the actions of child-birth and child-rearing, so the men participate in a proud tradition of tilling and taming the land in The Birth House - an image McKay borrows from earlier regional writers like Charles G.D. Roberts, Charles Bruce and, to a certain extent, Alistair MacLeod and David Adams Richards. Through her focus on images of the abject and on constructions of masculinity, Coady satirizes such representations of the relationship between the gendered body and nature.

\section{Images of the Abject in Strange Heaven}

Strange Heaven is the story of Bridget Murphy, a teenager from industrial Cape Breton whose parents have recently shuttled her from her unnamed community to a hospital in Halifax in order to give birth. After what Bridget calls "The Birth," she gives the baby up for adoption and doctors diagnose her with something resembling post- 
partum depression - or, a more general feeling of "apathy," as the narrator calls it - and admit her to the psychiatric ward of the children's hospital. More than anything else, Bridget's story is one of alienation: she is separated from her baby and her family, the timing of her pregnancy and her treatment mean that she misses her last months of high school, and she is estranged from her own body, which the narrator describes as "indifferent" to her. Her relationship with Alan Voorland, a seemingly cosmopolitan and sophisticated son of rich parents from Guelph suggests that she finds it difficult to fit in with her working class family and community; however, she also talks about how Mona, her best friend on the ward, is completely foreign to her because Mona's family is wealthy ( $\underline{\mathrm{SH}}$ 8). When she teaches Alan to curse in Gaelic and he asks her if the language she speaks is Irish or Scots Gaelic, she admits that she does not know, which suggests that she is also at odds with, or disconnected from, her cultural heritage ( $\underline{\mathrm{SH}} 32)$.

In this way, Bridget is perhaps the prototypical subject for what has been called the "Maritime gothic": her sense of identity is completely fragmented, she yearns to leave the region, she is surrounded by violence, despair, and a tourism industry that relentlessly denies the presence of both, and she embodies Coady's version of Cape Breton's contemporary youth culture, which is wracked by hopelessness and a crushing sense of ennui.

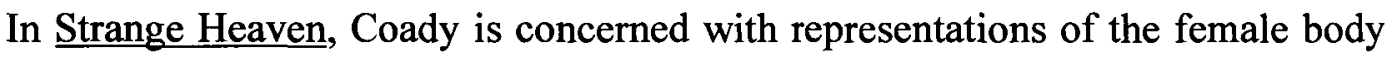
within the unnamed community, the Murphy family, the "old-fashioned" space of Cape Breton, and the institution of the hospital - all governed by a restrictive patriarchal ethos.

\footnotetext{
${ }^{2}$ See, for example, Howells, Where are the Voices Coming From? Canadian Culture and the Legacies of History 53. This term is most often applied to the work of Ann-Marie MacDonald.
} 
Coady's constant and often uncomfortable emphasis on excrement, urine, blood, food, vomit, and other forms of what Julia Kristeva calls "the abject" exposes the regulations that these institutions place on the bodies of women such as Bridget and her grandmother, Margaret P. Coady aligns the institution of the family with the Catholic Church and Canada's health-care apparatus, each of which seek to place restrictions on the female body by imposing moral standards, denying women's sexuality, assuming control over reproduction, and regulating access to medical care.

The influence of these forces, especially the psychiatric ward's constant surveillance and policing, exacerbates the intense alienation Bridget experiences. Coady's sustained and often unpleasant focus on images of the abject subverts the demands of this masculine culture by highlighting the "constructed-ness" of limits placed on the body. It also calls attention to the controls placed on the female body and asserts that the institution of motherhood is socially constructed, rather than "natural." In this way, Coady contributes to an ecofeminism that declines to establish an essential connection between femininity and the environment and instead locates both the body and nature as deconstructive spaces.

\section{Surveillance of Bridget}

David Creelman links Bridget's constant struggle to assert her individual identity to her intense disconnection from everything around her. He argues that this sense of dislocation frustrates her attempts at coming to terms with the experience of giving birth: "For a long time, even the possibility of a privately constructed sense of significance seems to be beyond Bridget's powers. Most of the time, she is curiously detached from 
her surroundings. In the hospital she is disengaged and removed from all around her" (Setting in the East 191). Creelman's assessment centres on Bridget's mostly unsuccessful struggle to assert a sense of self amidst the chaos of the psych ward and her family. I would like to argue, however, that Bridget also internalizes the hospital's sterile and institutional atmosphere - an aspect of her personality that Coady establishes immediately, when Bridget expresses no emotion upon hearing about the murder of her friend Jennifer MacDonnell ( $\underline{\mathrm{SH}}$ 2). Separated from her family and her daily life, Bridget adopts the persona of a detached observer during her stay at the children's hospital. She watches and is careful not to participate in most of the conversations, arguments and fights that take place on the ward and speaks about events such as this murder that affect her and her family as if they are things she has read about in a newspaper.

Bridget often refers to giving birth as the "ordeal" ( $\underline{\mathrm{SH}} 25)$ and establishes an ironic distance from the people around her, similar to her friend, Alan Voorland, who "was from Guelph and wandered around town examining and exclaiming at everything like an anthropologist" ( $\underline{\mathrm{SH}}$ 31). While Alan's privileged position as an outsider from Ontario informs his perspective, the distance Bridget maintains between her and the people around her is one of her strategies of rebellion against familial and social restraints (Hutchinson 150). The diffuse emotional controls Bridget's family places on her become solidified in the hospital as physical confinement and constant surveillance. In Discipline and Punish, Michel Foucault argues that the pervasive systems of surveillance and control - which he calls "disciplines" - employed by modern society work to "produce subjected and practiced bodies, 'docile' bodies. Discipline increases the forces of the body (in economic terms of utility) and diminishes these same forces (in political terms 
of obedience). In short, it dissociates power from the body" (182). The demands of the institutions of motherhood, the hospital and the family each take away from Bridget her feeling of control over her own body. As a result, she feels increasingly alienated from society, family and friends.

In Coady's later texts, surveillance is an intangible force that works through gossip and other mechanisms of the small town; in Strange Heaven, however, Bridget is intimately aware of being watched. For example, when she tells Dr. Solomon that she experienced giving birth as if it happened to someone else, with her watching on a television screen, the doctor deems this a breakthrough. In order to show Bridget how much progress she has made since being admitted, Solomon shows her the videotape of her initial assessment at the hospital:

It was Bridget, of course, during the preliminary interview with Solomon and the social worker. The Friday before the Tit fiasco. Oblivious to the fact that she was being taped. The oversized mirror obscuring almost an entire wall - she had scarcely noticed it at the time.

She looked terrible but this was mostly due to the stark fluorescent lighting in the room, turning everything the usual hospital electric grey. She did not understand how they could expect anyone to talk in that room, to open up, as Solomon might say. You feel so exposed under all that light that the last thing you want to so is open up. What you want to do is scuttle into the air duct like a beetle. This is what she remembered, looking at herself. (프 57)

Staff members at the psychiatric ward stifle Bridget, make her self-conscious, and place her under constant scrutiny in an environment that at once resembles a child's playroom 
and a police interrogation cell. While the narrator notes earlier that Bridget processed Jennifer MacDonnell's death "like a thing on a screen" ( $\underline{\mathrm{SH}}$ 2), at this point the events of her own life literally appear on a television set in front of her. Coady's narrative technique enhances this sense of disassociation: a third-person narrator who is focalized on Bridget relates the story, which unfolds as a series of flashbacks, so that Bridget is physically and temporally removed from its action. In this scene, Solomon forces Bridget to observe herself; she maintains this distance from the people around her and her own emotions throughout the novel.

In addition to this relentless supervision, the physical and bureaucratic organization of the hospital also work to exacerbate Bridget's sense of alienation. After she gives birth, the doctors move Bridget from the maternity ward of the hospital to the psychiatric ward of the children's hospital. The narrator points out that it is ironic that, in the eyes of the hospital, "she had bureaucratically gone from adult status, in giving birth, to that of a child, in being depressed" and that it was "as arbitrary as the days were long" ( $\underline{\mathrm{H}}$ 101). The psychiatric ward is designed for children, and not for Bridget, Byron, and Mona: "The playhouse was another thing on the ward which didn't belong there, like the Lego blocks and the Snakes and Ladders. It had Smurfs all over it and was a thing children, rather than teenagers, were supposed to enjoy ... And Mona had used it to hide from Gabby. Being the only hiding place on the ward, however, it wasn't a very good one" (ㅍH 129)" Since Bridget has recently given birth and is actually a mother, being placed in a psychiatric ward so obviously suited to children is especially inappropriate.

Bridget's contradictory position in the hospital's bureaucratic system calls attention to the ways in which the health care apparatus infantilizes women. This 
connects Bridget with characters from Coady's later texts such as Murdeena ("Jesus Christ, Murdeena") and Pam Cormorant (Saints of Big Harbour) who also struggle against familial and societal forces that infantilize them. Being categorized in this way not only further complicates her subject position but also puts her in the awkward position of being around the other small children in the hospital, an ignominy that even Byron notices, saying, “"That's why you can't stand to see the sick kids. Because you're

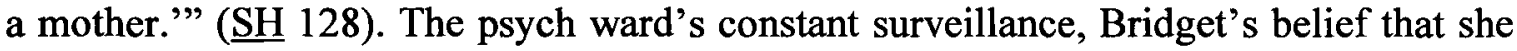
was forced into having the baby and giving it up for adoption, and her contradictory position as a mother in a children's hospital each call attention to the "constructed-ness" of motherhood. Coady's preoccupation with images of the abject also emphasizes this point.

\section{The Body}

Strange Heaven is unrelenting in its focus on vomit, feces, urine, blood, and other elements of the bodies of Bridget and the other female characters. Coady's emphasis on the abject, which confuses the boundaries between exterior and interior, exposes attempts by patriarchal forces like the church and the family to pacify female sexuality and manage motherhood and mental health. She does this by dwelling on the abject's ability to disrupt. Kristeva argues that the abject has a great deal of representational power; the ambiguities it embodies elicit horrified responses, and its position between the repugnant and the desired throws aesthetic judgement into chaos. She notes that "abjection is above all ambiguity. Because while releasing a hold, it does not radically cut off the subject from what threatens it - on the contrary, abjection acknowledges it to be in perpetual 
danger" (9). Images of the abject disrupt the seemingly clear moral imperatives set in the world of Strange Heaven by the Roman Catholic church, the patriarchal family and the Murphys' community.

Bridget's refusal or inability to abide by these rules and her failure to act elated by the birth of her baby and then devastated by the prospect of being separated from it result in her being admitted to the psychiatric ward. While Strange Heaven is filled with women whose bodies are marked by trauma, the novel is ultimately about Bridget's alienation from her own body, something which the recurrent presence of excrement, bodily fluids and other markers of the abject combat. In this way, the abject becomes a strategy for Bridget to assert her presence in the different spaces that comprise the novel, since she often finds it either impossible or unsatisfactory to do so through speech and expression.

The intense alienation that Bridget feels from those around her, from her cultural traditions, and from the physical space of Cape Breton emerges most clearly on the rare occasions where she speaks about her own body. At various points, most notably when she gives birth and when she experiences pain, Bridget describes feeling as if she is having an out of body experience or as if she is a character in a movie, being directed by someone else. Coady links Bridget's lack of control over her own body to the strict Roman Catholic mores of her family and community. This is evident in the Murphy family's strategy for dealing with Bridget's pregnancy. The course of action that they take - sending her to Halifax to have the baby and quickly giving the child to a family "from away," which the narrator describes as "a cliché ... but at that point who cared?" (SH 13) - is reminiscent of films like Butterbox Babies and is designed to minimise their embarrassment in the eyes of the religious community. 
Although the controls, boundaries and designations that religious, community and familial structures place on the female body in Strange Heaven are nagging and ubiquitous, the novel uses elements of the body itself to combat them. The confusion over labelling Bridget a child or an adult and her intense feelings of alienation and separation from her own body call attention to the "constructed-ness" of the maternal body and the ambiguous nature of subjectivity. Strange Heaven's sustained focus on the traumatic experience of child-birth, on illnesses like depression and anorexia, and on death align Coady with contemporary critical theorists who notice a "general shift in conceptions of the real: from the real understood as a result of representation to the real understood as an event of trauma" (Foster 107). Bridget's mother, who adopts her daughter and the narrator describes as an infertile yuppie ( $\underline{\mathrm{SH}}$ 97) whose "slight figure practically shouted its infertility to the world" ( $\underline{\mathrm{SH}}$ 98), and Bridget's anorexic friend from the ward, Maria, "about whom there was nothing otherworldly in the least because she was obviously so close to the physical reality of death [with] rotten teeth and hair like that of an old, abandoned doll" ( $\underline{\mathrm{SH}} 70$ ) stand as physical manifestations of the consequences of this patriarchal culture's demands on women. It is significant that the narrator points out that Maria's nearly dead body is somehow hyper-real; Strange Heaven employs images of the abject such as this to resist the surveillance and controls placed on women's bodies and uses pain, excrement and other elemental processes as a means of asserting corporeality.

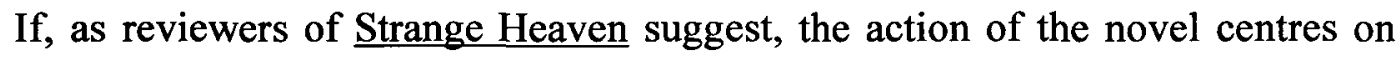
Bridget's quest to find a physical and emotional space that allows her authentic expression, the patriarchal elements of the hospital and her family often frustrate this project. Her conversation with Dr. Solomon about the possibility that she is suffering 
from post-partum depression - the moment in which, for Solomon, Bridget achieves clarity of thought and a degree of introspection for the first time since being admitted reveals that Bridget's experience of being thrust into motherhood is an event that also distances her from control over her body. As Gill Rye suggests, the maternal body is caught up in religious, political and cultural discourses and is often stereotyped, and "the pregnant, breastfeeding, nurturing body of the mother has been mythologized (in the Barthesian sense), positioned, contained, as an emblem of women's plenitude" (93). Kristeva's description of childbirth as an experience that negates sexuality and confronts the mother with a series of subverted boundaries - it is at once horrifying and beautiful, the simultaneous bloodshed and creation of life destabilizes the most basic dichotomy, that between life and death, and giving birth breaks down claims to autonomous identity for the mother - contests this idealized portrait (Carruth 61).

While it is difficult to say that Bridget experiences what psychoanalytic theory would call horror and revulsion during childbirth, because of her indifference and alienation from the experience itself, it is a traumatic event for her:

"Do you think much? About it? The Birth?"

"Oh, I dunno. Now and then."

"And what do you think?"

"Well," Bridget straightened up. "It struck me that, for an event that everyone claims is so natural, the most natural thing in the world, it didn't seem natural at all."

"No?"

"Nope." 
"And what did it seem like?"

"It seemed like a joke someone was playing. And when it didn't seem like that it kind of reminded me of a movie."

"Which movie?"

Bridget made a quick decision not to cite Rosemary's Baby. "Aliens," she said.

"Ah," said Solomon. Then she admitted she had never seen that particular film. "The body is invaded, I gather, by some foreign entity?"

"An alien," said Bridget, "and it comes smashing out of your chest and ... kills everybody."

"Including its host?" the doctor asked with excitement.

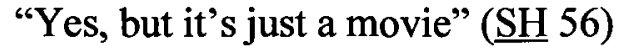

In this passage, Bridget thinks of two films in which unwanted, malignant, and supernatural beings invade the bodies of women: Rosemary's Baby, in which the protagonist becomes pregnant after Satan rapes her, and $\underline{\text { Aliens, }}$ in which otherworldly creatures implant an embryo in Ripley. For her, the act of giving birth is not only unnatural, it takes place with her on the sidelines and, she implies, without her consent.

Bridget also points out that she has experienced the recent events of her life as if they were taking place in a movie, rather than actually living them. Dr. Solomon is oddly excited by this revelation and does not believe Bridget's traumatic experience of "The Birth" to be problematic, although she is unaware of the gruesome scene from Aliens to which Bridget refers - a famous sequence in which characters' bodies are ripped apart by parasitic monsters which burst through their chests. Bridget clearly expresses horror at 
the loss of autonomy over her body that pregnancy and giving birth caused for her, but Solomon simply ignores these feelings. By calling her baby a "foreign entity" and comparing it to a monster from a science fiction film, Bridget discloses the degree to which this episode alienated her from her own body and the child she delivered.

Bridget's response to "The Birth" is ambivalent; while she at times seems to feel a connection with the baby, referring to him by the non-committal but warm nickname "the wah wah" ( $\underline{\mathrm{SH}}$ 149), she also tells Alan that she had no idea what it felt like to be pregnant ( $\underline{\mathrm{SH}}$ 189), and views pictures of the baby only because she feels the social worker wants her to want to look at them ( $\underline{\mathrm{SH}}$ 16). Bridget finds it difficult to feel connected to her body because it has been invaded by the baby and then claimed by, at once, the state, her family and her boyfriend Mark. As I discuss in the following chapter, Mark is often abusive towards Bridget, and admonishes her for choosing to give the baby up for adoption without first consulting him.

Coady's heavy emphasis on bodily functions combats the sense of alienation that dominates Strange Heaven; it does so by having Bridget, Margaret P., and peripheral characters like Mona occupy ambiguous positions. The novel at once denies women access to their bodies and uses the most elemental aspects of those bodies to assert their presence. Coady expresses this ambiguity in the preoccupation with bodily functions she displays in Strange Heaven, a theme that many reviewers of the novel point out, in a strange mix of shock and delight. The novel is overflowing with scatological references, which seem to function as the Murphy family's chief conversation topic, descriptions of the bowel movements of the patients who live on the ward, and the vomit-filled exploits of Bridget's friends, who spend their free time drinking and fighting. 
Scatological banter functions both as an insult and a refuge for Coady's characters. For example, Bridget fondly remembers reciting a rhyme that her uncle Albert had taught her in front of her class at the age of six: "There was a little bird/ No bigger than a turd / Sittin on a hydro pole / He stretched his little neck / And he shit out a peck / And he puckered up his little / Arse-hole" ( $\underline{\mathrm{SH}}$ 13). The family also frequently embarrasses and punishes Bridget's uncle Rollie for urinating outside. The novel makes a connection between this sense of shame surrounding bodily fluids and the Roman Catholic ethos of the unnamed community; Robert, for example, calls Father Boyle "the fat-assed jeezless souse [who comes around] to tell me I'm going to hell for forgetting to bless myself every time I sit down to take a shit" (Hㅐ 117). When Bridget's constipation finally subsides and she tells her family to leave her alone, as she plans to spend the next few days on the toilet, her mother gets so excited that she gives Bridget tea and toast, and recites another poem:

"Here you go," she said. "Might as well start filling up the tank!"

"I don't ever plan on digesting anything ever again."

"You have to, dear. It's nature. I don't know what those doctors were thinking of. Don't you want your curtains open?" She stood to open them, humming something and smiling.

"What are you saying, Mumma?"

"The worms crawl in, the worms crawl out, they eat your guts and shit 'em out! We used to sing that when we were kids. I always thought it was so funny. Oh, I got in so much trouble with my dad!"

"That's not funny at all, Mumma, it's morbid." 
"Yes, but the word 'shit," her mother explained with typical patience. ( $\underline{\mathrm{SH}} 151)$

Elsewhere, Mona explains to Bridget that she detests her father because of his constant need to control her: "It's control. And it's, like, the great almighty privilege of being an asshole. And treating people like shit! Like the shit that comes out of an asshole." (ㅍH 28). The novel is peppered with references to these bodily functions, from Bridget's struggle with constipation, to Margaret $\mathrm{P}$. having turned into "a series of leaks that needed stopping up" and the behaviour of Bridget's friends, who seem to be vomiting constantly.

When Bridget leaves the hospital for a long weekend with Albert and Bernadette, she discovers that she has conceded control over her body to the "doctor who wore brown socks and sandals and said that he didn't like being called Doctor" ( $\underline{\mathrm{SH}} 36)$ when she runs out of medication to ease the pain and discomfort of lactating. Bridget refers to this incident as the "Tit Fiasco," because of her frantic experience of begging for a prescription at the pharmacy while her breasts secreted to the point of soaking through her sweatshirt. In describing this moment, the narrator suggests that the medical establishment exercises its authority cruelly and arbitrarily:

What happened was that she went to a pharmacy to beg for a refill because she was in terrible pain and they were dripping. She jumped from foot to foot feeling like some kind of prescription junkie while the pharmacist phoned the doctor who didn't like to be called Doctor. In the hospital, the doctor had assured Bridget that he would let her have one more round, but now that the pharmacist was calling, 
he suddenly changed his mind and said that it would be better not to give her any more. ( $\underline{\mathrm{SH}} 36)$

The narrator speaks to the way in which Bridget's lack of control stems from her class position as well as her gender. The narrator notes that had Bridget been one of Alan's rich friends from Guelph, she might have made a scene in the pharmacy and demanded that she be given medication to ease the obvious pain and embarrassment she was experiencing. Because she did not have this sense of entitlement, however, "she took a taxi to Albert and Bernadette's, and Bernadette, who had been a nurse, wrapped bandages tightly around Bridget's upper body until she looked like a burn victim" (SH 37). Bridget moves from a chaotic yet religiously conservative home place to the children's hospital, where doctors place her under even more strenuous control; however, her body, by constantly spewing fluids, rebels against forms of confinement.

By confronting her audience with images of the abject and, as one reviewer notes, creating a novel where the reader can "smell the vomit and sense the despair" (Moore G3), Coady participates in a tradition of feminist avant-garde artistic expression - which includes artists like Cindy Sherman, Janine Antoni and Jana Sterbak, among others - that emphasizes the ambiguous nature of subjectivity and subverts the idea, to which Bridget's parents and doctors adhere, that the maternal body is "natural."

\section{Deconstructing Gender Roles}

In addition to contesting images of the maternal body as "natural," Coady's texts also highlight the fluidity of gender roles. While patriarchal institutions in Strange Heaven like the church and the Murphy family see masculinity and femininity as fixed 
and essential, Coady, like Judith Butler and Donna Haraway, presents gender as socially constructed and performed. Many of Coady's female characters cross traditional gender barriers: the unnamed narrator of "Big Dog Rage" and "Run Everyday" displays a repressed desire for violence and participates in the supposedly male world of sport; Coady depicts Jim Arsenault's wife, Moira, as gruff, blunt, aggressive, and possessing "masculine" qualities, which runs counter to Jim's portrait of her as a "protean mass of female sensuality" (MB 25); and in Mean Boy, Larry implies that Ruth Dekker is transgendered, describing her "man's jawline, and ... man-hands," and reporting that she describes herself as "this town's best kept secret" (В 150). Coady's fiction is preoccupied with constructions of femininity and the pressures placed on women like Moira and Bridget to conform to patriarchal society's ideas of how women should look and act. Along with her emphasis on images of the abject, her presentation of contradictory and deconstructive notions of gender challenges the conventional idea that women are close to nature and that men should dominate over it through activities like hunting and resource extraction.

As mentioned in Chapter 1, reviewers of the novel focus mainly on Bridget's attempts to find a space where she can assert herself. Herb Wyile and David Creelman argue that although Coady spends much of the novel undermining the restrictive patriarchal family, Bridget guardedly returns to her family at the close of the text, signaling Coady's ambivalent treatment of the home place. ${ }^{3}$ Creelman and Lorna Hutchinson maintain that Bridget's extreme apathy is a strategy for claiming subjectivity. They observe that she confounds her family and the doctors by ignoring their demands

\footnotetext{
${ }^{3} \mathrm{I}$ discuss the end of the novel in further detail in the following chapter.
} 
and evading interaction with them. In "Look, and Pass On," the sequel to Strange Heaven, Alan Voorland explains this aspect of Bridget's personality: “[h]er answers became as meaningless as she could possibly make them, and he felt himself getting angry. Deliberately. She was like this on purpose. It was not emotional laziness, as he had once supposed. Her mind was constantly in action, behind the heavy eyelids, forming strategies of avoidance" (PMB 100). In addition to these "strategies of avoidance," Coady's deconstructive approach to gender also allows Bridget moments in which she asserts subjectivity. As is the case with her later texts, Strange Heaven's masculine culture is largely based on the ability of men to survive in the wilderness and to participate in activities like violent sports and hunting. Most of the men in Bridget's life are strong, silent, overweight, and boast about their exploits in the woods. This is particularly true of Bridget's uncle, Albert, whose harsh language, imposing size, persistent alcoholism, and his choice to wear woodsman's attire in spite of living in Halifax make him reminiscent of many of David Adams Richards' male characters. Towards the end of the novel, the narrator notes that Albert and her father did not allow Bridget to go hunting with them as a child simply because she was a girl:

Now Albert was gone. She thought if she had been a boy it would have been more fun. She would have got to go hunting with Albert and her father and Albert's five sons. Gerard had never liked to go because Albert's boys would pick on him because he didn't like the blood, didn't like having to castrate the bucks the moment after they killed them. But Bridget would have gone, if she had been a boy. She would have killed and castrated the deer and gutted them on the spot. 
She would have sat around the campfire with the boys, passing around a thermos of hot buttered rum. ( $\underline{\mathrm{SH}}$ 193-4)

The narrator's description of Bridget's desire to kill and castrate bucks and the fact that her brother Gerald is reluctant to enter this arena undermines her family's idea of nature as a masculine space. The men in Bridget's life, Alan Voorland, Albert, Mark, and her father, spend the entire text either explaining to her what kind of girl she is - to Albert and her father, she is a "good girl" (태 114), to Alan, she is a "fascinating young lady" ( $\underline{\mathrm{SH}} 31$ ) - or berating her for failing to live up to their expectations. While Bridget uses apathy as a way of combating the pressures her family and community place on her, the narrator also calls attention to Bridget's longing to engage in such supposedly masculine rituals, further undermining the strict gender roles promoted by Cape Breton's patriarchal culture.

\section{The Maternal Body in Play the Monster Blind and Mean Boy}

While I focused in this section on Coady's most sustained treatment of the maternal body, her depiction of Bridget in Strange Heaven, her other texts also use minor characters to call attention to the constructed nature of motherhood. This includes the mothers from "Ice Cream Man" and "Nice Place to Visit," who seem ready at times to abandon their families in the face of the pressures their communities place on them to adhere to an idealized version of motherhood, and Marianne Boucher, who, in Saints of

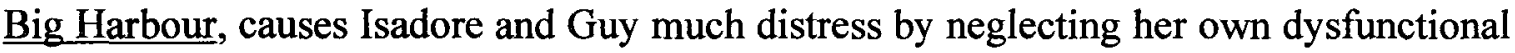
home in order to tend house for the MacAskill family. While Coady clearly satirizes the familial and social structures that suffocate these women in her early work, in Mean Boy, 
she softens these attacks. In Mean Boy, Coady directly examines the idea of constructing the maternal body when Larry's cousin Janet fakes a pregnancy as part of a sociological experiment designed to expose her family as old fashioned and out-of-touch.

Although, as this chapter has emphasized, Coady engages in a project similar to that of Janet in her fiction, in that she also looks to deconstruct the sexist and nostalgic elements of the society about which she writes, she steps back in this instance and seems to be sympathetic to the members of Larry's family whom Janet dupes: "I reared back even farther in my chair, so that its feet shrieked against the floor. 'What do you mean, we all were? So you had the devastated mother, the evil father, and then - what - the asshole cousin?' ... 'I don't think you're an asshole. My father is not evil. My father ... My father is a very sweet man. But he's not the most progressive guy in the world, Larry. You'll agree with me on that one, right?"' (MB 259-260). Her descriptions of her professor"s "fascination" with this case study and her blatant belief that she is not only more progressive but also more intelligent than the rest of her family cast Janet as an immature and condescending intellectual bully, like Vera from David Adams Richards' Miramichi Trilogy. ${ }^{4}$ Coady's portrayal of Janet sheds light on her tentative and ambivalent treatment of the home place: in spite of the instances in which Coady attacks the "traditional" Maritime family, she is loathe to side with characters who cast themselves as uninvolved outsiders who have a passing interest in the culture of the region - characters like Janet, Bethany, the unnamed narrator from "Run Every Day," Alan Voorland, Jim Arsenault, and, to a certain extent, Larry.

\footnotetext{
${ }^{4}$ Nights Below Station Street (1988), Evening Snow Will Bring Such Peace (1990), For Those Who Hunt the Wounded Down (1993).
} 


\section{Constructions of the Male Body in "Play the Monster Blind"}

In her later texts, Coady largely moves away from her exploration of the female body and emphasizes constructions of the male body, and the pressures placed on young men to adhere to the region's traditional masculine code. She satirizes the notion that the ideal male body is large, equipped for manual labour, and dominant over the natural environment. While this aspect of her writing appears in Strange Heaven with respect to Robert and especially Albert, her treatment of this masculine culture is more detailed and more biting in her subsequent texts, beginning with the title story in Play the Monster Blind.

The narrator of "Play the Monster Blind" focuses on the observations of Bethany, who has travelled to Cape Breton with her fiancé, John, to meet his family and to see his hometown. Coady's separation of the story into vignettes with titles like "Drinking," "Eating," "Swimming," and "Boxing" lends to this narrative a kind of documentary-like objectivity, as does the narrator referring to members of John's family as "the father," "the mother," and "the sister." These labels project on the characters a sense of universality, suggesting that the narrator (and, by extension, Bethany) sees them as caricatures of "typical" Cape Bretoners. In particular, calling John Sr. "the father" evokes not only his absurd demands to be respected and recognized as the head of the family but also establishes him as an ironic representation of the recurring father figure in East Coast literature. By maintaining this distance from her hosts and treating them like interesting characters she observes from the outside, Bethany exaggerates the cultural and social differences that separate her from John's family and establishes herself as an outsider relative to both them and the region. 
Bethany immediately notices that members of John's family tend to follow traditional gender roles. For example, after her first dinner there, the men retire to the back porch to relax and admire the yard, while the women clean the dishes. She is more surprised, however, by John Sr.'s constant descriptions of his own hyper-masculinity: he points out that his burly frame was shaped by his years spent as a semi-professional boxer, he wears only clothes appropriate for working in the woods, and he brags about his unmatched ability to drink heavily. Bethany also notices that John Jr. closely resembles his father, in that both of them have large bodies suited to violent sports and manual labour. The narrator says that "[t]he father was built all of hard, stubborn fat, but John was just as big. They sat quietly torturing their lawn chairs together" (PMB 4). The narrator also notes that John is actually quite self-conscious about his body:

He told her he used to be fat. He was very sensitive about it. He told her that he had never told that to anyone. In high school he stopped eating and started taking handfuls of vitamins, which made him thin and absent-minded, but his mother stopped buying them and he had no choice but to go back to eating. In university he just gave in to everything and ate and drank until he ballooned. Now he was

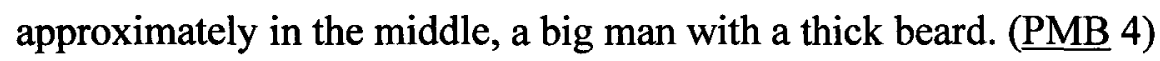

Just as Coady explores the pressures society puts on women to look and act a certain way in Strange Heaven, a novel which is highly conscious of the consequences of these constraints, so she is also interested in the way in which this patriarchal culture demands conformity from young men. In this story, she examines these issues side-by-side, juxtaposing John's struggle to achieve an ideal body image with his sister's battle with anorexia. While eating disorders and anxieties over the female body dominate Strange 
Heaven, Coady glosses over Ann's anorexia in "Play the Monster Blind" in favour of an extended exploration of constructions of the male body.

Much of the male characters' dialogue centres on how men should look and act. John tells Bethany that he drinks rum because spritzers are "for pussies" (PMB 6), his brother Hugh refuses to speak unless the topic of conversation drifts to masculine subjects like sports, and John Sr. describes himself as "an old boxer ... I hit people" (PMB 18). In addition to his stories about "partying his hole out" ( periodic martial arts demonstrations, Hugh also uses slogans on his clothes to advertise his manliness: “And after a few days Bethany began to realize that Hugh didn't own any shirts except T-shirts with sayings on them. He sat around in T-shirts that said things like: I'D RATHER PUSH A FORD THAN DRIVE A CHEVY and IT'S NOT HOW DEEP YOU FISH, IT'S HOW YOU WIGGLE YOUR WORM!" (PMB 10). Men like John and his father, on the other hand, do not feel the need to trumpet their masculinity on T-shirts; unlike Hugh, they conform to the region's ideal body-type.

In the context of rural Cape Breton, the natural environment plays an important role in imagining the ideal male body. For John Sr., men should have bodies suited to logging, farming, fishing, mining, or harvesting a living from the land in some way. John Sr. compares the boxers he admired from his youth to animals, making an implicit connection between hyper-masculinity and nature: "He said he had met more than a few of these fellows in the ring, and could tell her something about the style of each if she was interested. The Dago, for example, was a smart fighter, a thinking fighter. Always went in with some kind of strategy. Archie the Rigger, however, had nothing going for him but a hard head and had the record to prove it. Fisher was the prettiest of fighters, 
floated on air. Sailor Dave was like a goddamned bull, just an ox. The father went on and on in this vein" ( $\underline{\mathrm{PMB}}$ 9). John Sr. tells Bethany and anyone else who will listen many times that the thick body-type possessed by the two Johns, their uncle Lachie, and many of the fighters he remembers is "natural." For the narrator, the lengths to which John Sr. goes to construct and call attention to this masculine persona undermines his use of the adjective "natural" to describe it.

There is also a discrepancy between the rural masculine code in which John grew up and the lifestyle he encounters at university. The narrator notes that when Bethany met John for the first time, she was taken aback by his choice of clothes: "She had thought, when she first met John, that he looked like a lumberjack. He wore plaid shirts and work boots whenever she saw him in class, not because it was fashionable, and not fashionably, but because it was what he wore. She learned where he was from and imagined they all must dress like that, that it must be a very welcoming place, rustic and simple and safe, just like John himself" (PMB 4). As I discuss in the following chapter, the people she meets and the things she sees while driving around the Cabot Trail shatter Bethany's assumptions about the rustic people and landscape of rural Cape Breton.

Coady is careful with her use of satire in this instance: she portrays John as a polite, respectful "dip-lo-mat" (PMB 18) who cares deeply for his family and wants nothing more than for his fiancé to fit in with them; however, he is also a representative of the outdated masculine culture Coady parodies. The above passage brings out a particular tension associated with the decline of the Maritimes' resource-based economy. Characters like John and his father dress and act as if they are members of a working class culture that performs manual labour even though John Sr. runs a family restaurant 
and his son is enrolled in university. It is in her characters' troubled relationship with this industrial past that Coady's ambivalent relationship with Cape Breton's working class culture emerges most clearly: John and his father are, respectively, the objects of gentle and severe satire for their refusal to abandon this masculine ethos, yet Coady seems to lament the lost sense of pride in place and lifestyle associated with Cape Breton's fading male working class culture.

As the story progresses, the tone of Coady's attack on this version of masculinity sharpens, particularly as it relates to John Sr., whom the narrator portrays as a drunken, often violent, buffoon. John Sr. yells at waitresses and at his children, complains about injustices that he has endured, proclaims that Cape Breton is infected by "[a] little fucking thing called incompetence in the workforce" (PMB 14), picks drunken fights with the people around him, and generally acts like an alcoholic fool. For Bethany and the narrator, John Sr.'s absurdity stems at least partly from his complete lack of selfawareness. He views himself as a traditional father figure who continually offers wise advice to children who ignore it. The narrator, however, points out that this performance rings hollow, ironically calling him "a benevolent father regaling the family with priceless and innumerable anecdotes from a rich and varied life" (PMB 15).

Bethany is clearly sympathetic to John's complicated relationship with his father. She is glad that her fiancé has managed to retain some aspects of his family's workingclass background while becoming cosmopolitan and aware that such belligerent behaviour is unacceptable. Bethany is, however, relentless in her scorn for the outdated and empty masculine code that John Sr. extols. Her utter disdain for John's father seems to build as the story's action progresses, until the final afternoon of the trip around the 
Cabot Trail, when she explicitly ridicules his self-serving stories, his bloated face that, to her, resembles a piece of barbequed bologna, and his compulsive drinking. In the final description of the father, the narrator notes that the family sees him as a monster in a science fiction film:

On the path back to the cabin, they saw the father coming towards them. The sun had set moments before and their eyes were used to the dark, but the father's weren't. They saw him first, walking with great clomps, his arms stretched out in front of him like Boris Karloff in Frankenstein. Bethany remembered hearing that, in Frankenstein, Boris Karloff had stretched his arms out before him like that because the filmmaker had at first wanted to have the monster be blind. They never followed up that aspect of the story, but they kept the footage of Karloff playing the monster blind anyway, and that was why the enduring image of Frankenstein ended up being this clomping creature with his arms stuck out in front of him. The problem was that this was what John's father looked like, coming towards them - a frightened, blind monstrosity. (PMB 25)

As mentioned above, by referring to him as "the father," a label that has obvious religious connotations, the narrator satirically positions John Sr. as an archetypal father figure - a subtle reminder of his failings as a role model and a parent. As Bethany and John prepare to leave the family behind, the narrator submits this no-holds-barred condemnation not only of the father but also the brand of masculinity that he represents.

For Bethany and the narrator, John Sr. is violent, ridiculous, and resembles a monstrous character from a horror film. The narrator's reference to the careful measures taken by Boris Karloff in capturing the movements of the Frankenstein monster implies 
that John Sr. is consciously performing a role when he asserts himself the family's father figure. ${ }^{5}$ Bethany makes it clear that his masculine persona exists only on the surface: he constantly talks about what it means to be tough, to be a good man, to be a good father, and to be a decent person; however, in reality, he is a violent loudmouth whose bold statements serve only to mask his insecurity and lack of self-awareness.

At the close of the story, Coady pulls back from this attack on the familial structure of rural Cape Breton, and, in particular, her satirical treatment of John Sr. After Ann elbows Bethany during a typical fight with Hugh, splitting her lip and loosening a tooth, John spends their entire final night apologizing profusely for his family's behaviour. Although she has already forgiven Ann and harbours no ill feelings because of the incident, Bethany lies silently in bed while John berates his siblings and pretends to be angry with him for the rest of the night, seemingly in order to further distance him from his family and "[k]eep him up all night with worry, her very need for him in question" (PMB 27). Although the entire story deconstructs the kind of masculinity to which John Sr. adheres and exposes problems with the image of the family in Cape Breton literature, at the close of the text, Coady portrays Bethany as vindictive and calculating. Just as Bridget's return to the Murphy house at the close of Strange Heaven is evidence of Coady's ambivalent treatment of the home place, "Play the Monster Blind" affirms John's relationship with his dysfunctional yet loyal family by exposing Bethany as manipulative.

\footnotetext{
${ }^{5}$ The image of "the father" as monster in this scene also parodies the familiar trope of the female body as monstrous in women's science fiction. See Sandra Gilbert and Susan Gubar's 1984 study, The Madwoman in the Attic: The Woman Writer and the Nineteenth-Century Literary Imagination for their discussion of the "monster woman" and "angel woman" (240) and Jane Donawerth's Frankenstein's Daughters: Women Writing Science Fiction (1997).
} 
Toxic Masculinity in Saints of Big Harbour

Coady revisits her deconstruction of the relationship between hyper-masculinity and the natural environment in Saints of Big Harbour. Whereas in Play the Monster Blind and, as I discuss below, Mean Boy, Coady satirizes John Sr. and Jim Arsenault for their ridiculous and obviously constructed personas, masculine culture is a tangibly dangerous force in Saints of Big Harbour, as it demands physical exposure to the toxic elements of Cape Breton's resource economy. Although John Jr. and Larry display anxieties over their ability to live up to their father's definitions of masculinity, the consequences of them entering that world are minimal. Isadore Aucoin's version of Cape Breton's working class culture, however, is toxic and physically hazardous, in that it requires young men to sacrifice their bodies and often their lives in extracting resources from the natural environment.

As is suggested by Coady's choice of names for her main character, Guy, the novel is intimately concerned with male insecurities, most notably the pressures Guy's uncle, Isadore, and the rest of the community place on him to conform to a specific masculine code. ${ }^{6}$ Guy lives in a rural Acadian community on the southeastern coast of Cape Breton. Characters make passing references to the real Acadian communities Isle Madame and Louisdale - at one point, Gordie MacLellan says that the Aucoin house is "out Louisdale way" ( $\underline{\mathrm{SOBH}} 355$ ) - but Coady does not assign a name to Guy's

\footnotetext{
${ }^{6}$ Guy's last name, Boucher, also has several connotations: as a noun, the French word boucher translates to "butcher," but as a verb, it means "to block," and can also be used as a slang term for mentally "blocked" or "thick." Havre Boucher is also a coastal village on the mainland side of the Strait of Canso, which separates Nova Scotia from Cape Breton. Guy's middle name is Sebastien, which might refer to St. Sebastien, the patron saint of soldiers and athletes.
} 
hometown. The community seems to be little more than a road through the woods. It is more precise to say that Guy lives in the rural area that surrounds the fictitious English town of Big Harbour, which seems, like Bridget's unnamed community, to be loosely based on Coady's hometown, Port Hawkesbury. ${ }^{7}$ The novel's action hinges on Guy's conflicted relationship with his family, especially Isadore, who lives with him and his mother for most of the novel, largely against their wishes. In the absence of Guy's father (who left when his son was a child), Isadore establishes himself as the man of the Boucher household: he orders his sister and his nephew around, lectures Marianne on her parenting techniques, and calls Guy by the diminutive "mon petit," often in a "fatherly tone" ( $\underline{\mathrm{SOBH}} 243)$. In this way, Isadore appoints himself as Guy's father figure, a position the community legitimizes, as evidenced by the judge who orders him into Marianne's care calling him a positive influence on Guy and by Constable MacLellan acknowledging him as the "family's voice of authority" ( $\underline{\mathrm{SOBH}} 302)$.

Just as Isadore may be, according to Guy, like "Santa Claus in reverse when he comes to take [the] television" (SOBH 243), he is also like Guy's father in reverse in his interactions with his nephew. Instead of supporting and protecting Guy and imparting valuable lessons to him, Isadore torments him, implores him to attack other boys his age, and throws childhood incidents back in his face in order to embarrass him and maintain his emotional power over him. Isadore uses his abusive treatment of Guy to entrench himself as his nephew's primary male role model. This is a responsibility that Isadore

\footnotetext{
${ }^{7}$ Pinpointing Guy's exact location is difficult because of the way in which Coady mixes fictional and real place names in the novel, as she acknowledges in her author's note (SOBH 417). The real Big Harbour is a small village on the north side of the Bras D'or Lake in Victoria County, but it does not resemble the Big Harbour of Coady's novel and is nowhere near Isle Madame or Louisdale. Interestingly, the MacAskill museum overlooks the Canso Causeway in the novel, but the real site is very close to Big Harbour.
} 
takes seriously; he sees himself as the only person who can bring Guy into the traditional masculine culture he looks to uphold. Isadore teaches his nephew that masculinity is judged in large part on the ability to stand up to and dole out violence, warns him of the importance of heteronormativity, and valorizes a male culture that dominates the natural environment. Isadore often attempts to shame Guy into falling in line with this traditional version of masculinity.

\section{Masculinity and Heterosexuality as "Natural"}

As reviewers of the novel often suggest, Isadore selectively aligns himself with traditional values in order to establish his own moral superiority over the rest of the community and cajole Guy into behaving properly. He calls himself a "solid man whose life was no easier than anyone else's, yet who always seemed to have a good word and to be concerned with the things that really counted in life, family, community, and loyalty above all" ( $\underline{\mathrm{SOBH}} 382)$. On this basis, he badgers his sister for her failings as a mother and he tells Guy that his effeminacy is a stain on the Aucoin family name. He positions himself as the family's patriarch in order to regulate their behaviour. For example, he berates his sister for letting Louise and Guy watch television while they eat dinner, and views that appliance as a signal of the loss of tradition and an impediment to oldfashioned family interaction. Isadore talks incessantly about how Guy, Louise, and Marianne should respect him in the same way that he respected his own father, and about the importance of the family unit, often invoking religion to make this point: "Marrying Kenzie, Guy's father - a confirmed bastard, reportedly - had been bad, but getting divorced was worse, seeing as how she was "supposed to be a Catholic" (읍 66). 
Isadore makes frequent, vaguely derogatory remarks about Kenzie, most of which question his heterosexuality. In one typical instance, he says that when he and Kenzie once travelled to Monastery to "dry out," Guy's father decided to stay there for extra time because he "liked it better up there with the boys!" (SOBH 105).

Coady juxtaposes Isadore's descriptions of the happy, conventional Cape Breton Catholic family with his frequent drunken and violent outbursts, one of the worst of which takes place during Louise's eighteenth birthday party, when Isadore destroys every dish in Marianne's house, including his own mother's fine china, as retribution for Guy quitting the hockey team. This incident is a striking example of the force of Isadore's destructive personality: in spite of his rhetoric, he shows an equal measure of disdain for objects that symbolize the continuity of the family as he does for the modern technology that he fears threatens it.

Spurred on by his anxieties over Guy's manliness, Isadore pushes his nephew into a world of masculine violence, encouraging his penchant for rough play in hockey, teaching him tactics for exacting revenge on his enemies, and showing immense pride in Guy's central role in a brawl that sets off a spate of violent attacks between Big Harbour and a neighbouring community ( $\underline{\mathrm{SOBH}} 77$ ). When a group of boys from Port Hull assaults Guy and he comes home badly beaten, his mother orders him to quit the hockey team; however, Isadore objects on the grounds that shying away from this kind of violence is a sign of effeminacy: “'Don't be so dumb,' he said. Marianne stared at him. 'He's not a little girl,' he added" (SOBH 82). Isadore's understanding of masculinity is compelling to Guy because he presents it to him as "common sense." In asserting himself as Guy's male role model, Isadore works against two influences in his nephew's life: that 
Guy largely grew up without a male role model, and that his father fails to live up to Isadore's version of ideal masculinity. Both of these aspects of Guy's childhood run counter to Isadore's notion of a "natural" order; Isadore insists that it is normal for men to assert their physicality over other men, and that sports like hockey and boxing can provide a young man with the tools to accomplish this.

\section{Masculinity Under Threat}

In addition to his anxieties over Guy's masculinity, Isadore also worries often that the decline in Cape Breton's industrial economy threatens the region's "traditional" and "virile" working class male culture. Isadore expresses concern that the politically correct modern society in which he lives seeks to quell "authentic" masculinity. Isadore claims that violent sports such as hockey and boxing provide an environment in which the primal aspects of male culture emerges. The novel implies that the ritualized violence in which Howard and Hugh engage is another strategy for unlocking this "primitive" (SOBH 116) and natural virility that modern society has diluted.

In Saints of Big Harbour, Coady examines the way in which the social construction of masculinity is connected to the social construction of certain aspects of ethnicity. As I discuss in further detail in the following chapters, Coady's Big Harbour has a subtle ethnic ranking: characters with Scottish backgrounds like the MacAskills, the Gillis's, and the MacPhedrons occupy positions of relative authority and wealth as politicians or managers at the mill, while Acadian characters like Guy, Isadore, and Rene Cormier live in poverty. Guy is also in almost constant fear because his Acadian heritage makes him a target. While Howard and Hugh ostensibly seek out Guy because of the 
rumour that he has "bothered" Corrine Fortune, they also randomly attack members of the Acadian community: "He's looking in one direction, and violence comes out of the other, asks him if he's French, asks, Are you the little French fuck? and doesn't wait for an answer" (ㅇBH 183).

The disparity between the English world of Big Harbour and southeastern Cape Breton's peripheral Acadian communities functions for Coady as a microcosm for the Maritimes' place within Canada. While the Maritime provinces are marginalized by the rest of the country, within the region, Acadians and other disenfranchised groups are subjected to racism and exploited by the white Anglophone community. Coady's texts illustrate that the Maritimes' experience of economic downturn pits its residents against one another and inspires a kind of bare-knuckles capitalism in which characters like Guy and John Jr. learn from their father figures that it is those who are the most "masculine" and most able to dole out violence who survive. Coady's Acadian characters face the most severe effects of this: Isadore hardens Guy by stealing food from him, tells him that part of being "manly" and heterosexual is extracting resources from the land, and teaches him that he needs to hone his body and be as vicious as possible on the ice and in the boxing ring.

To the extent that they appear in the novel, Mi'kmaq characters and African Nova Scotians are even further marginalized. Guy briefly mentions that he attends high school with "pissed off" Mi'kmaq teenagers because the on-reserve school has recently closed: "Apparently two schools in the county have been shut down this year, one from River Bourgeois, one from the reserve. The River Bourgeois kids seem happy to be here. The reserve kids don't" (SOBH 191). Alison Mason recalls Isadore telling his friends at the 
monastery about his boxing exploits with a black man in Toronto. In this story, this connection between the social construction of gender and ethnicity emerges:

[Isadore] was telling them a story about a Canadian boxer everybody knew. A black man they all admired in the odd, detached way white men admired black athletes, seeing them as pure physicality in some ways, sheer man.

If their prejudices against black men could ever be articulated, wrote Alison, the noise would sound like this: They are deep us. They are more us than we are. They are unthinkable, therefore. But sometimes one is great. That is certainly most us. That is deep us on display. Only then can it be celebrated. (SOBH 69)

The often silent but palpable ethnic hierarchy that exists in Big Harbour and its surrounding areas has several implications. In addition to the Acadian community's lack of job prospects and the violence directed towards characters such as Guy and Rene Cormier, it also impacts the way in which Isadore and his friends understand masculinity. Just as the rest of Canadian society sees the Maritimes as a bastion of antimodern culture, so English Maritimers romanticize the Acadian community and its traditions, and Isadore believes that black men retain a kind of primal and natural masculinity that modern society and technological change conspire to suppress.

Isadore and his friends make a strict distinction between men who perform manual labour and those who do not. Men who fall into the first category tend to drink heavily (although Coady's middle class male characters also abuse alcohol), hunt and fish, spend much of their time talking about, playing, or watching sports, and are often overweight. The working class men of the novel - almost all of whom work at the pulp 
mill in Big Harbour or, like Isadore, once worked at the now-closed steel plant - often make jokes about the sexual orientation of the local teachers, insurance sales-men and lawyers and regard them with suspicion. In this world, the education system works to carefully separate these two types of men from each other:

Doobie courses were understood to be for kids too thick to take chemistry and physics. These were classes like oceanography and industrial arts. Such classes were filled almost entirely with boys, shit disturbers. The men who taught these classes were uniformly overweight and angry much of the time. Girls were never considered doobies - the closest equivalent was slut ...

Since they had graduated, the two stuck out in town like thumbs on a foot. Howard, especially, because he had never been as integrated into the community as Hugh. Hugh had startled everyone by not leaving town to go to school. He kept his many doobie friends - all of whom started jobs at the mill and elsewhere around town after graduation - and took the exotic, new computer courses being offered at the vocational school, while his honours friends were packing trunks for university. (

Of course, this distinction is also closely related to class and ethnicity. Characters with Scottish names like Howard Fortune and Hugh Gillis come from wealthy families and are expected to go to university, while their Acadian counterparts work at the local mill. In the above passage, the narrator suggests that Howard's inability to fit into the community stems from his class position, his scholastic talents and his thin, athletic body-type. After his "honours friends" leave Big Harbour for university, Howard attempts to conform to 
the behaviour of the men at Leland's tavern by drinking heavily and constantly starting fights.

Hugh, on the other hand, more closely resembles the other men from Big Harbour and subscribes to the idea that physical dominance is a requirement for survival in rural Cape Breton. This description of the two classes of people in Big Harbour and its surrounding rural area makes a key connection between the male body and the space of industrial Cape Breton. People like Isadore impress upon the young men of the community that in order to survive the tough environment of industrial Cape Breton, they must develop a body-type that resembles his. Howard and Hugh's integration into this community involves the same kind of physical activity Isadore expects from Guy: they construct home gyms in order to bulk up, and practice their fighting skills in preparation for their planned confrontation with Guy. The above passage also suggests that gaining this body-type is important because male working class culture is often defined in relation to resource-extraction. In addition to her satirical treatment of Isadore's campaign to indoctrinate Guy into this masculine culture, Coady also implicates a high school education system that identifies ideal employees for the area's pulp mills and steel plants.

Isadore often expresses discomfort with the way in which modernity threatens traditional practices and ideas surrounding masculinity. For example, Isadore and Alison Mason draw a contrast between their upbringings. Alison believes that Isadore had a "traditional, authentic childhood" growing up in a gritty but loving home while he endured a soulless, urban existence with parents who neglected him. Isadore often tells Mason stories about going into the woods with his father, Emile, to cut trees and shoot 
rabbits. The narrator says that "Isadore liked the idea of his own life and world as a fairy tale in contrast with the cold, urban, inauthentic America that Alison bemoaned" ( $\underline{\mathrm{SOBH}}$ 213). Isadore's understanding of this "authentic" masculinity is bound up in traditions like hunting and trapping. The macho culture that Isadore represents valorizes the ability to extract resources from the natural world, either through hunting and fishing or through industrial labour. For Isadore, the middle class culture Alison Mason represents poses a threat to this brand of authentic masculinity, and he sees in the decline of Cape Breton's resource economy a rise in the urban and effeminate values that characterize modernity.

In addition to the threat to working class masculinity posed by modernity and technology, Isadore also argues that the elitist environmental movement seeks to dilute industrial Cape Breton's traditional culture by blocking the extraction of resources from the natural world. For example, Guy reports that for Isadore, there were three kinds of people: "normal people - those of whom Isadore didn't particularly disapprove ... The second kind of people were crazy people. Isadore could not really say he disapproved of them, because they simply didn't count. These were people like the environmentalist who lived in Point Tupper and was always campaigning to have the mill shut down" ( $\underline{\mathrm{SOBH}}$ 65). ${ }^{8}$ Isadore teaches Guy that the environmental movement's attempts to encroach on the right of communities in industrial Cape Breton to harvest resources from the land make them elitist, weak, and out of touch. Earlier, Guy links the environmental movement to what he sees as an effeminate middle-class culture that has infiltrated rural Cape Breton: "The English teacher has a girl's name - Alison Mason - but he likes to be called Al, for obvious reasons. He is from New York, and everybody says he is a draft dodger and a

\footnotetext{
${ }^{8}$ The third group, "bastards," mainly refers to people who have betrayed Isadore.
} 
back-to-the-lander because anyone who would come here from the States always is" (SOBH 5). The continued domination of the natural environment plays a large role in the masculine culture that Isadore both valorizes and represents.

\section{Masculinity as a Threat}

While "Play the Monster Blind" deconstructs John Sr.'s brand of masculinity by highlighting his ridiculous and violent behaviour, Saints of Big Harbour offers a more specific critique of the relationship between resource extraction and the masculine culture of industrial Cape Breton. In this novel, Coady focuses squarely on the way in which this macho culture perpetuates the exploitative and toxic practices of the resource industry. It does so by encouraging men to perform dangerous work for little pay on the basis that to refuse is a sign of weakness. Thomas Dunk points out that "the boredom and alienation of this kind of wage labour is overcome by interpreting it as a test of masculinity. Workers prove their worth as men by their ability to withstand dirt, noise, danger, and boredom. Working conditions are 'read' as a challenge to masculinity, rather than as an expression of the exploitation of capitalist relations of production" (SOBH 97). In Saints of Big Harbour, masculinity is a toxic force on several levels: just as it is threatening to women and often encourages harmful environmental practices, so it also places the men who adhere to it in personal danger. As mentioned in Chapter 4, while much early ecofeminist criticism made an essential connection between women and the earth and called attention to the ways in which masculine culture dominates both, the literature on toxic masculinity emphasizes the social construction of both gender and nature. Coady's fiction examines social processes like education and compulsory participation in sports which indoctrinate 
young men like Guy into a dangerous and violent masculine culture.

The culture of masculine violence in the community encourages and even demands constant fights, resulting in bloodshed and injury. Coady connects this aggression to the island's industrial economy. Her working class men internalize the violence that is commonplace in their mines and mills - an element of the culture of industrial Cape Breton that spans generations: "Currently, Dan C. rented a room a few miles away, in the home of the man he worked for in Isle Madame. He was from Glace Bay, but moved farther down the island because he wanted to get away from the mines and the steel plant. Dan C. had, Louise said, an uncle who'd been blown up alongside a coke oven, and his grandfather had been crushed underground in the mines" (SOBH 103104). Isadore questions Dan C.'s manliness several times, and makes the implicit suggestion that his choice to shy away from a way of life that has so gruesomely killed members of his family makes him a coward.

Isadore talks often about his own exploits in the arena of dangerous industrial labour. These stories, along with his larger-than-life personality and bulky stature, lend him a mythical status in the eyes of the community. Although people like Leland and Lauchie Puddicomb have various run-ins with Isadore that reveal their mild distaste for him, the men of Big Harbour respect his strength and his abilities as a storyteller, and often say that he is an example of ideal masculinity. His friends call him "Saint Isadore," a nickname that ironically recognizes the discrepancy between his self-serving sermons on morality and his own destructive behaviour. ${ }^{9}$

\footnotetext{
${ }^{9}$ The relics of St. Isidore, one of the Catholic Church's founding fathers, are housed in an inner sanctum in St. Mark's Cathedral in Venice. Isidore is also a common surname in Nova Scotia's Mi'kmaq community.
} 
His sacrosanct place in community lore is apparent when Sampson Roach recounts to Alison Mason the most famous Isadore legend, his sixty-foot fall from a halfconstructed building that took place while he was employed as an ironworker in Sydney. Isadore's glove was caught on the hook of a crane and he dangled above the worksite until he finally fell to the ground, "whappin' himself on girders all the way down" (SOBH 221). Isadore, Roach exclaimed, appeared to be made out of metal. His portrait of Isadore as indestructible fits in with Alison's perception:

It boggled the mind, and yet was so surreally in keeping with Alison's image of Isadore as some kind of primal force - a mythical, working-class superhero ...

"On the goddamn disability ever since," Isadore said, as if he resented the income.

Alison thought it was strange he hadn't heard about this before. But it made perfect sense - why else would such a prime physical specimen like Isadore Aucoin, a self-described jack-of-all-trades not be caught dead, in all the time Alison knew him, doing physical labour? ( $\underline{\mathrm{SOBH}} 222-223)$

Elsewhere, Alison calls his friend "the ultimate specimen of manhood" (SOBH 240), a description that inspires in Isadore "a moment of childlike glee at hearing what he had always believed about himself articulated so unequivocally" ( $\underline{\mathrm{SOBH}} 241)$. Like Jim Arsenault from Mean Boy, Isadore often appeals to this working-class mythos in order to assert himself as a vestige of lost masculinity. His understanding of masculinity is based on the mythical link between the male body and nature; even Alison says that this masculine ethos is a primal natural force, and that middle class urban culture suppresses masculinity by rewarding effeminacy and education. 
While Marianne talks often about her father's abuse towards her and intimates that his masculine ethos placed her childhood health at risk, Isadore fondly traces his pride in work and resource extraction to his father's influence. In addition to the extreme violence of the hockey arena, the various assaults enacted on Guy by students from Big Harbour, and the randomly belligerent streak of Howard and Hugh, Big Harbour's hypermasculine culture also had profoundly destructive effects on Emile Aucoin's health:

"Oh, your heart's fine," scoffed Isadore, sobered, it seemed and revitalized. Like Guy's grandfather, Isadore had refused to acknowledge Marianne's heart problem since the day it was diagnosed before Guy was born. When Emile died, they learned she had inherited it from him. A doctor later told them it was amazing the old man had lived the life he did, and for so long. As he cut hay into the evening season upon season and drove horses and dug rocks from the field and smoked one cigarette after another and never even sat down to drink his tea half the time the whole while his deficient heart had been rattling along like a desperate, halfassed engine. ( $\underline{\text { SOBH } 108)}$

Coady implicates the Maritime region's resource economy in encouraging a masculine culture of sacrifice that has destructive effects not only on the natural environment but also on the bodies of the men themselves. The novel can be read, on one level, as a cautionary tale about mindlessly imposing this male culture on young men.

The material I have been discussing is indicative of a shift in Maritime literature that has taken place over the past three or four decades. Although some earlier nineteenth and twentieth century Maritime writers and popular musicians lauded this masculine 
culture of sacrifice, ${ }^{10}$ contemporary writers such as Leo McKay, Carol Bruneau, Joel Campbell as well as Coady expose the way in which resource capitalism exploits this macho culture. While much of the region's early music and literature, particularly that which concerned coal mining, tended to celebrate a masculine culture that sees injury and death on the job as a kind of heroic sacrifice, Coady and her contemporaries refuse to romanticize the violence and carnage, both human and environmental, that accompanies the industrial economy.

\section{Masculine Anxieties in Mean Boy}

Loosely and partly based on John Thompson, the hard-drinking, fiery, eccentric and ultimately tragically self-destructive poet and professor of Creative Writing at Mount Allison University during the early 1970s, Mean Boy's Jim Arsenault evokes a conflicted response in Larry as well as the reader, both of whom find his romantic belief in creativity and his narcissistic rejection of banality simultaneously attractive and offputting. In her 1978 essay on Stilt Jack, Margaret Atwood observes that Thompson's poetry and actions revealed a passionate rebellion against the "compromises" of society and a desire "to escape from the human body and in particular from the human head" and that for him, "[p]urity [was] a fish on a hook, a knife" (311). Elsewhere, Peter Sanger comments that Thompson was "passionately committed to living out the romantic mythologies of landscape and the natural life" (18). While Coady does express, as Cynthia Sugars argues, a degree of admiration for Arsenault, who is equally happy to

\footnotetext{
${ }^{10}$ See, among many other examples, the music of Rita MacNeil and The Men of the Deeps, John O'Donnell's The Men of the Deeps (1975 anthology of coal-mining literature from Nova Scotia). There are also, of course, earlier writers such as Dawn Fraser and Alden Nowlan who condemn this industrial culture.
} 
eschew the demands of the "human world" in favour of the "archetypal possibilities" of poetry and the wilderness (7), I would like to suggest that her ironic construction of Arsenault undermines his appeal. Although Larry Campbell, buys into and aspires to match Arsenault's fierce nihilism at the beginning of the text, Coady satirizes him for this. The second half of the novel highlights the lengths to which Arsenault goes to create and protect this hyper-masculine and romantic persona. At the end of the novel, Larry realizes that Jim's bluster is ridiculous and ultimately harmful, and retreats to the pragmatic common sense of his working class father.

One of Mean Boy's key tensions is Larry's anxiety over the pressures his two primary role models, his father and Arsenault, place on him to live up to their own standards of masculinity. Larry's male insecurities frequently occupy his thoughts, and he traces this angst back to childhood incidents in which his father pushed him to be tough and athletic, two qualities that Larry totally lacks. In one typical example, he remembers his father forcing him to play softball, an experiment that failed miserably when Larry, reciting Leonard Cohen songs in his head instead of paying attention to the ball, gets hit in the face and breaks his nose. Larry's painful conflicts with his father over his lack of masculine attributes continue during his first year at Westcock, when Mr. Campbell berates him for moving out of a residence filled with - in Larry's estimation - "assholes or psychopaths or both" (Bㅡ 43), believing he had missed out on a year of "living with all those other guys, the masculine fellowship toughening [him] up" (MB 44).

When Larry shies away from the rural working class masculinity his father teaches him and people like Charles Slaughter exemplify, he replaces it with a different macho code, the one advanced by Arsenault. Arsenault insists to Larry that only real men 
write good poetry, and makes a sharp distinction between the "virile" and "authentic" literature that emerges from the Maritimes and what he sees as the effeminate literature of central Canada. Although he is, in the eyes of Larry, the complete opposite of his father, much like Wayne Campbell, Arsenault bases his understanding of masculinity in large part on the relationship between the male body and nature. While characters like John Sr. and Isadore incorporated the ability to survive in the wilderness and extract resources from it into their idealized version of masculinity, Arsenault exploits the land as an imaginative resource and voluntarily performs manual labour like chopping wood to show off and stay in shape. Coady's project in Mean Boy is to disrupt Arsenault's strategies for indoctrinating Larry and his other students into this specific version of masculine culture.

\section{Poetry as a Manly Pursuit}

Jim Arsenault has dedicated himself to the idea that only masculine and virile cultures produce good poetry. This notion informs Arsenault's hyper-macho persona: he often describes weak writing as "effeminate" and pays Larry what they both think is the most flattering of compliments when he tells him that his "new style is 'muscular"' (MB 25), an adjective Larry uses when talking about the ghazal ${ }^{11}$ later in the novel (MB 288). When he enrolled at Westcock, Larry believed that his love of poetry would preclude him from fitting into a masculine culture; however, when he tells some of Arsenault's other students that "poetry is faggy in general, I've accepted that a long time ago" (MB 75), Todd corrects him: 'It's not about rich people, it's not about privilege and decadence, it's

${ }^{11}$ John Thompson also used the ghazal in Stilt Jack (1978). 
not a bunch of counts and lords walking around in a field of daffodils, wandering lonely as a cloud wearing monocles and cravats. It's about real people living real lives! Working and fucking and hunting and scraping out a living ... and community and family"' (MB 76). Arsenault echoes Todd, and insists that "poetry's not about visionary shit anymore, or being written by fops and courtiers about their pansified concerns ... Suddenly the experience of people like us (us!) is no longer being dismissed ... It counts for something" (MB 79). In his rants about "real" poetry, Arsenault often conflates masculinity and regional allegiance.

The connection Arsenault makes here between masculinity and working class culture is problematic for two reasons. The first is that his definition of masculinity is limited and exclusionary, and he claims heterosexuality as a prerequisite for belonging to this culture. The second is that in spite of Arsenault's claims to sharing the experience of living and growing up in the working class with Larry, the novel suggests that there is a large socio-economic discrepancy between them.

For Arsenault, the "masculine" poetry Maritimers produce is "authentic" because it is concerned with harvesting resources and the relationship between men and the land. He makes a clear distinction between this literature and what he calls the cosmopolitan and effeminate poetry of Toronto and Montreal. Arsenault's rants are reminiscent of those of Isadore and John Sr., in that he recites them at random and they identify modernity and urbanity as vague threats. In Mean Boy, however, Coady transports her blowhard middle-aged male character to the highbrow world of academia. In his scathing review of Dermot Schofield's Malignant Cove, Arsenault outlines his distaste for central Canadian poets, who fail to measure up either as writers or as binge drinkers: 
Perhaps this is what passes for talent in the perfumed salons of the Toronto literary elite, where running low on cognac is the closest anyone gets to hardship and the professor-poets dally in the faculty-club cloak room with colleagues' wives in the attempt to graft some semblance of passion and genuine human feeling onto their airless, obtuse existence. This is no "garden" of "stay" as Schofield professes, although it is indisputably stagnant and fecund - much like a swamp, or a diseased animal - the perfect breeding ground for pestilence and infestation. God grant Canadian poetry be inoculated against the wasting illness that is Dermot Schofield. ( $\underline{\mathrm{MB}} 45)$

The metaphors from the natural world that Arsenault uses to describe Toronto's literary scene make it clear that he sees the intellectual culture of the Maritimes as fertile and rugged in comparison. Like Isadore, he also describes the urban culture emerging from central Canada as a threat to the Maritimes' masculine traditions. Here and elsewhere, he relies on the concept of "authenticity" to characterize himself and the masculine culture he represents.

The tension between these two camps informs much of the novel's action. Larry adopts Jim's disdain for decadent urban poets and declares himself a combatant in the fight between "Upper Canadian snottitude [and] hard-nosed regionalism" (ㅉ 45). He joins this battle not only by concurring with Arsenault in his assessment of Toronto's poetry but also by identifying his central Canadian Westcock classmates as enemies. Like Arsenault, he uses evidence of a relationship with nature as a way to judge masculine strength: 
Another sunny autumn day. I walk across the quad disrupting waist-high dunes of crisp, fallen leaves. Getting colder now, students wandering about in thicker coats, in chunky wool sweaters. But I can differentiate them - the leather coats versus the nylon parkas with polyester fill. The expensive store-bought woolen sweaters versus acryllic, or else the threadbare homemade ones. Like the one I have on - my father's old curling sweater with the moose and the hunter on the back, so stretched out it almost reaches my knees.

The point is what I'm seeing: I see the difference. I see campus like a line drawn down a blackboard now. (MB 46)

As Larry becomes further entrenched in the world and views of Arsenault, he begins, like his mentor, to selectively adopt affectations that are useful to him. Although Larry rejects his father's portrait of what a real man should look like at the beginning of the text, and passes him off as old-fashioned and out-of-touch, when he discovers that Jim also believes in these principles - although he articulates them in a way that makes hypermasculinity seem intellectual and sophisticated - he changes his mind. Since Arsenault imparts to him the importance of being able to survive difficult encounters with nature, Larry decides that the hunting-scene imprint on his father's worn-out curling sweater is a fitting advertisement of his affinity for the natural world and the masculine qualities that befit this lifestyle. Throughout the text, Coady parodies this version of masculine culture by portraying Arsenault as deceitful and Larry as naïve.

Arsenault intimates that the Toronto literary scene is infested with emasculated, impotent men who spend their time sipping expensive wine, while in the Maritimes, poets forge their creative sensibilities through working class struggle and a close 
relationship with the harsh wilderness. For Arsenault, Canada's elite writers, because they lack the gritty, "real-world" experience that has shaped him, fail to live up to his standard of masculinity. Arsenault constructs for himself a persona that incorporates such qualities: he lives in a shack in the woods with no electric heat, he cuts his own wood, and he brags constantly about his ability to fight. These are the attributes that make Jim attractive to Larry at the beginning of the text. Although Larry decides early in life that he could never aspire to fulfil his father's blueprint for masculinity because of his clumsiness and his distaste for manual labour, Arsenault teaches him that poetry is a manly pursuit - or, at least, it is outside of Canada's literary centres, where "real" men create "real" poetry.

The traditional masculine code that Arsenault attaches to the Maritimes is based in large part on manual labour and living close to nature. Jim dresses in flannel shirts and talks constantly about toiling in the woods in order to connect himself with New Brunswick's working class and the region's resource economy. When Larry asks him why he cuts his own wood, Arsenault admits he does it in part because of vanity: "That's what keeps me fit ... you try chopping a cord of wood every day, see who messes with ya" (MB 220). For Larry, this is one more example of Jim's ability to incorporate rugged masculinity into his creative lifestyle: "I imagined Jim in his yard, heaving an axe sweat flying from his black hair - bringing it down on a slab of wood with a satisfying, splintery chunk that echoes through the surrounding woods as if to warn it what's to come. There was something so primal about the image, so Canadian, so Jim" (MB 221). This passage hints at the implicit homoerotic attraction that Larry feels for Jim in the early half of the text, one that inspires him to defend his professor against the attacks of 
his students and colleagues at the English department and eventually even to do his chores.

The image of Arsenault in his yard cutting his own wood reinforces Larry's belief that Jim combines creativity with masculinity. Larry eventually realizes that Arsenault takes great pleasure in telling his students and his colleagues about this aspect of his life, and uses it to bolster his masculine image. The sound of chopped wood functions as a warning for the nearby trees, linking Arsenault's hyper-masculinity with the idea of domination over the natural world and control over its resources. Coady links this masculine ethos, familiar from MacLeod and Richards' working class characters, ${ }^{12}$ and its relationship with nature to the exploitative practices of the resource industry.

\section{Masculinity, Nature and Regional Academic Discourse}

In keeping with the novel's focus on the creative process, academic writing, and literature, Arsenault's concerns over masculinity are also connected to his place in two seemingly adversarial cultural movements taking place in the early 1970s: a Maritime regionalist project that combined social realism and political economy critiques from the social sciences, and a nationalist movement led by writers such as Margaret Atwood, Dennis Lee and others that rejected American cultural imperialism and looked to move Canada beyond what these writers saw as its colonial position. The novel satirizes Arsenault for his hypocrisy in periodically changing his ideological position in order to serve his own interests.

${ }^{12}$ See, for example, Richards' Nights Below Station Street (1988), As Evening Snow Will Bring Such Peace (1990), For Those Who Hunt the Wounded Down (1993) and River of the Broken-Hearted (2003) and MacLeod's "The Boat"(1976), "The Closing Down of Summer" (1976) and No Great Mischief (1999), among many others. 
Arsenault's conflictual relationship with Westcock's English department stems not only from its refusal to grant him tenure but also from his distaste for what he sees as its colonial mindset, an attitude perhaps best exemplified by Sparrow's instructions to Larry that he should forget about Canadian literature and focus only on "the classics" if he would one day like to study at Oxford (MB 289). In addition to resenting Sparrow for characterizing Canada as a cultural backwater, Arsenault also argues that the British culture to which Sparrow belongs is effeminate and therefore inferior. For Arsenault, this stands in direct opposition to the Maritimes' organic masculinity. In an exchange with Larry, he argues that the success of the feminist movement on campus is owed to the absence of real men and the presence of British professors at Westcock:

"I have nothing against women in the classroom," Jim tells me.

I try to jump in. "Well, of course not, but -"

"But that sack of shit Sparrow thinks we should coddle them. That's what's sexist, if I may partake of the new vernacular."

"I mean, for Christ's sake, Sparrow would have us return to the days of segregated education. By 'segregated' I mean, of course, some for the pampered sons of pampered sons, none for anyone else. But God save us from the English boy's school ethos, those bastions of so-called masculinity." Jim smirks, sips. I smirk, sip. (MB 13-14)

Arsenault blames this "weak" British culture for the success of the feminist movements taking place at Westcock. Later, he uses natural imagery to explain to Larry the need to reject people like Sparrow: "Jim smiles at me, relaxing a little. 'You're the next generation, Larry. It's up to you. You've got to clear away all this deadwood"' (MB 14). 
In using the word "deadwood Jim implies that Sparrow and the rest of Westcock's old guard are impotent, and unable to stand up to even the women who have infiltrated the university.

While Jim is firmly entrenched in the intellectual and cosmopolitan culture of the university, his understanding of masculinity in large part borrows from notions of Maritime subsistence and "folk" culture. Arsenault occupies an ambivalent ideological space: he at once represents a nationalist movement that looks to rid the country of British imperial culture and a regionalist movement that renounces the influence of urban Canada. He seems to separate "authentic" nationalist writing from what he sees as an effete and decadent strain of urban literature emerging from Toronto and Montreal at this time. Arsenault claims that cultural nationalism is a rural movement. It is for this reason that he aligns himself with Maritime regionalism: he sees the rural Maritimes as a place where an authentic new world culture persists - one that is based on traditional masculine values.

Coady satirizes both nationalism and regionalism by suggesting that each movement is based on essentialism and exclusion. ${ }^{13}$ When Arsenault arranges for his staunch nationalist friend, the appropriately named Abelard Creighton, to deliver a reading at Westcock, Larry engages in a discussion about the merits of nationalism with Bryant Dekker and his wife, Ruth, who tells Larry that nationalism is the "ultimate colonial give away": “'Should a country wish to announce itself as a backwater,' she

\footnotetext{
${ }^{13}$ Of course, Coady is not alone in making this assessment. See Davey, "Towards the Ends of Regionalism," Chalykoff, Space and Identity Formation in Twentieth-century Canadian Realist Novels: Recasting Regionalism in Canadian Literary Studies, and others, who argue that regionalist movements often use the same exclusionary and essentialist strategies as nationalist movements.
} 
said, gazing at me the way you might a blank wall, a void surface, 'should a country wish

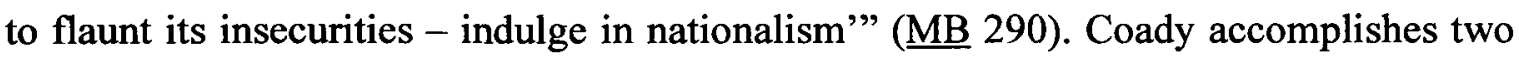
things with Ruth's dismissal of cultural nationalism: she aligns herself with post-colonial critics who argue that it shut out minority groups and aboriginal peoples and is simply a reconstituted version of colonialism. Through her satirical treatment of Jim Arsenault, she also stakes out the position that regionalism simply reimagines nationalism.

Later, the novel offers a more specific critique of nationalism, one that suggests that it shares the patriarchal and environmentally irresponsible language of Arsenault's version of Maritime regionalism: "By some, it has been called a 'frontier' - and these people mean the word to have less than flattering connotations. But it is indeed a frontier, affirms Creighton. A new frontier, an intellectual frontier, still being shaped by the precious raw materials that we are fortunate enough to claim as our birthright" (MB 326$)$. In doing so, the novel reveals that regionalism and nationalism use troublingly similar rhetoric concerning ownership of the land and the need to protect authentic and masculine cultures.

\section{Rejection of Jim}

Arsenault's political position is complex, contradictory, and seems to change arbitrarily. Larry realizes this in the second half of the novel, recognizing that Arsenault's ideological stance changes to suit his own needs and is largely based on petty personal feuds. This is particularly evident in his rude treatment of Dermot Schofield on the basis of his neutral review of Arsenault's Blinding Light, and his unabashed welcome of the "hack" Abelard Creighton, who spends his entire visit to Westcock praising Arsenault. 
Larry not only comes to resent Arsenault's manipulative behaviour but also decodes the strategies he uses to construct his persona and establish a sense of authority over his students. When Arsenault gives him a B in Creative Writing as a reprimand for leaving him alone during the holidays, Larry immediately realizes that this is a ploy to get him to come to the office and check in on him. Arsenault's lies become so obvious that Larry predicts them to himself as they discuss his grade: "At that point, Jim was supposed to look appalled, yank open a drawer, and withdraw the folder he kept his marks in. Flip it open. Run his finger down the page. And finally sigh with relief - shooting me a mockscolding look: Naughty-naughty. Playing games are we? It's an A, Larry. Broad grin. Right here in black and white, kid" (MB 284). Just as Arsenault goads Larry into comforting, validating, and praising him through actions such as this, so he manipulates Sherrie, Claude and the rest of his adoring students into petitioning the university to reconsider his application for tenure.

The novel's climax brings these issues together. After Creighton's reading, Arsenault hosts a party at his house that ends when Charles Slaughter, high on magic mushrooms, arrives and attacks him. Slaughter does this because he believes that Arsenault sexually assaulted his girlfriend, Sherrie, who is also the woman Larry obsesses over. Everyone, including Jim's good friend Creighton, leaves the house, except for Larry, who stays overnight to tend to his professor. In spite of this, Arsenault quickly turns on Larry: '“A-an excuse, an excuse-fer,' repeated Jim like a retarded parrot. I looked up at him, speechless, in high school, bashed against lockers, tackled from behind ... 'The red face on him,' Jim remarked after a moment, as if to a cadre of like-minded thugs" (MB 379). 
Although Larry leaves behind the rural common sense of his father and revels in the romantic intellect of Arsenault for most of the novel, he reverses his position during this final scene. Recalling an earlier incident in which Arsenault left the house while a roast was in the oven, an act that violated Wayne Campbell's warnings about never leaving a fire unattended, Larry takes comfort in his father's advice - which he spent the whole novel mocking: "I stood there so long that the red of the kitchen had started to mellow and shift - give way to something more gingery - and finally sat back down in the chair, thinking I'd better wait for the logs to burn down at least enough so I could close the stove properly. It was bad enough to be leaving a fire unattended while people slept. I tried not to think of what my father would say" (MB 382). By leaving Jim's house and thinking of his father's advice while doing so, Larry abandons his professor in favour of his first masculine influence. Wayne Campbell's lecture to Larry about "running around doing chores for some prick" (MB 226-227), and Larry's defence of his uncle and father following Janet's pregnancy experiment (MB 259-260), foreshadow this choice. Just as the final action of Strange Heaven signals a tentative return by Bridget to the comforts of the family unit, at the close of Mean Boy, Larry takes solace in the incessant advice of his father that he initially rejects in favour of Arsenault's exotic brand of creative masculinity.

While Arsenault is the most obvious object of the novel's satire, Coady also portrays Larry as an immature and often unreliable narrator. This emerges most clearly at the beginning of the narrative, when Larry is unable to recognize Arsenault's manipulative behaviour. While Larry's eventual dismissal of Jim is a positive move towards maturation, his final thoughts suggest that he has not grown up, as his position at 
the close of the novel is essentially the same as when it began. Although Larry does leave Jim behind at the end, it seems difficult to argue that this is a significant step forward. Larry departs before Arsenault wakes up, but it is Slaughter who actually defeats him, both physically and psychologically. By aligning himself with Slaughter and his father at the end of the novel, Larry subtly accepts the importance of masculine values like strength, virility and the ability to outmuscle enemies - symbols of a lifestyle that he has come to university to avoid. Larry acknowledges this even before the party begins: "it seems to me that Chuck is a kind of poet himself. That is to say, there is a poetry about his weirdness, and his bigness, and his violence. His good cheer and his loyalty" (MB 316). In this sense, Larry is still somewhat immature, naïve and unsure of himself and his choices at the close of the novel. As a result, he retreats to the comforts of the more traditional and seemingly more authentic masculine lifestyle of his father.

\section{Conclusion}

Coady's fiction identifies and challenges two conventional constructions of the relationship between the body and the natural environment. As contemporary ecofeminists argue, much western literature and academic discourse depicts the female body as part of nature and uses the idea of motherhood as natural to secure this

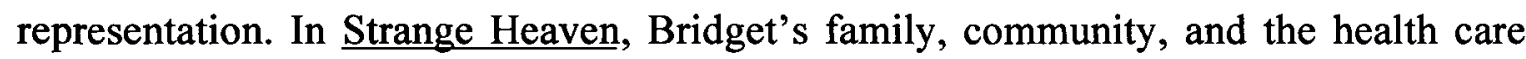
apparatus look to control her; however, Coady's focus on images of the abject highlights the process of giving birth as ambivalent and socially constructed. Although in Mean Boy she parodies Janet for her arrogant and cruel pregnancy experiment, Coady's fiction subverts depictions of the female body as, like nature, quiet and exploitable. In her later 
texts, Coady deconstructs the notion that the ideal male body is dominant over nature. She does this in "Play the Monster Blind" and Mean Boy by satirizing John McNeil Sr. and Jim Arsenault for constructing ridiculous and hypocritical macho personas based on the importance of working on the land. Saints of Big Harbour links the macho working class ethos advanced by Isadore to tragic industrial accidents and the continued destruction of the natural environment.

As I discuss in detail in the following chapter, in Coady's texts, there is a constant tension between Maritime Canada's historical treatment of the environment as a resource base and the fact that her characters belong to a post-industrial generation to whom this experience of the natural world is almost completely foreign. Coady's characters live in a region where government and corporate leaders instill in the region's inhabitants the idea that consumption of the environment has entered a new phase: while the natural world previously offered material resources for the taking, in Coady's texts, the tourism industry often uses the supposedly pristine beauty of the region's physical geography as a marketing tool. 


\section{CHAPTER 5:}

\section{COADY'S SUBVERSION OF THE MARITIMES' IDYLLIC LANDSCAPE}

As suggested by the previous chapter, because Coady's fiction is set in Maritime Canada, she encounters definitions of nature that are informed by the historical and contemporary conditions of life in that region. Coady exposes the dangerous way in which the region's masculine working class culture often claims scars and injuries as badges of honour and evidence of the ability to survive in the rugged world of resourceextraction. In this chapter, I demonstrate that she engages with another particular aspect of the region's relationship with the "natural" environment: the idea that the Maritimes is home to an idyllic landscape. As I discussed in Chapter 3, idealized landscapes play an important role in conventional Canadian ecocriticism. Many critics identify "protoecocritical" texts as those which reveal a pastoral relationship with nature similar to that found in earlier Maritime writing, such as the work of Bliss Carman and Thomas McCulloch. Coady's fiction undermines this construction of the Maritimes' natural environment. Her characters find that the region, often characterized by the tourism industry and earlier writing as "down-home" friendly, old-fashioned, serene and dramatically scenic, instead can be home to violence and strikingly impoverished communities.

\section{The Maritimes' Idealized Landscapes}

The decline in the Maritime region's industrial economy that took place in progressive stages throughout the twentieth century and the resulting rise of an entrenched tourism industry in the region has created what Ian McKay calls in Quest of 
the Folk: Antimodernism and Cultural Selection in Twentieth Century Nova Scotia (1994) a "common-sense" image of the region as idyllic and therapeutic (31). McKay argues that in the middle of the twentieth century, political elites in Nova Scotia were quick to capitalize on what he calls an "urban fascination with rural ways." During this time, the tourism industry, the provincial governments, and cultural producers each worked to ascribe to Nova Scotia a distinctive folk culture (9) and, as is particularly germane to this chapter, an idyllic and recuperative landscape that offers reprieve from modernity's frenetic pace.

McKay argues that the state consciously constructed a definition of the province's culture and geographical space that saw it as primitive, impoverished, fixed in time, set off from the rest of the modern world, and welcoming to tourists interested in experiencing a "traditional" way of life: "Nova Scotia came to be defined more and more unequivocally as a 'therapeutic space' removed from the stresses and difficulties of modern life - and an internally generated set of ideas about Nova Scotia which local cultural producers considered to be self-evidently true [arose] ... Innocence was a way of seeing and thinking through which the pre-modern 'Otherness' of Nova Scotia was 'naturalized' (that is, made to appear an obvious and common-sense interpretation)" (31). As Del Muise suggests in his 1990 article, "Who Owns History? Reinventing Atlantic Canada for Pleasure and Profit," because the region relies so heavily on the economic boost of tourism, this "common-sense interpretation" of the region's culture and landscape as idyllic and pre-modern is one that business and governmental representatives protect vigorously (125). 
As McKay, Muise, Danielle Fuller, Lothar Honnighausen and other critics argue, Maritime folklorists such as Helen Creighton and writers such as Hugh MacLennan, Ernest Buckler and Thomas Raddall assisted in establishing and nurturing this idealized portrait of the region's landscape. These critics trace a pastoral impulse through Maritime literature that begins with the work of L.M. Montgomery and Bliss Carman, intensifies with Buckler's The Mountain and the Valley (1961) and even extends to contemporary writers such as David Adams Richards. ${ }^{1}$ In Under Eastern Eyes: A Critical Reading of Maritime Fiction (1987), Janice Kulyk Keefer pinpoints "three identifying marks on the body of Maritime literature": "an indelible historical sense, cultural homogeneity, and a social stability whose corollary is stasis, or worse, stagnation" (35) and suggests that "[t]he strength and continuity of community experience in the Maritimes have given the region's writers a great advantage in creating their fictive worlds [and] access to what Raymond Williams calls 'knowable communities"' (37).

Keefer's chapter "The Book of Nature" (1987) and her 1996 article "Nova Scotia's Literary Landscape" argue that much Maritime writing reveals a pastoral relationship with the natural world. She states that many of the region's texts characteristically portray nature as a mode of transportation, a provider of nourishment and a source of beauty:

In Maritime fiction ... [n]ature does not possess the implacable hostility that seems to rain or hail from the skies of Sinclair Ross's fictions, for example; neither is it stonily indifferent to those whose lives are, in Buckler's words, "hewn

\footnotetext{
${ }^{1}$ See Dvorak, Ernest Buckler: Rediscovery and Reassessment (16), Young, "The Pastoral Vision of Ernest Buckler in The Mountain and the Valley" (219), Gittings, "Melodrama for the Nation: Emily of New Moon" (196), MacDonald, "War of the Worlds: David Adams Richards and Modern Times" (19), among others.
} 
to the shifting seasons" ... Maritime writers, inhabiting a region in which heavy industry has made comparatively minor inroads and in which a considerable number of people still make their living off land or sea, have acquired what Charles G.D. Roberts called a "habit of openness to nature," a habit created by the special qualities of the Maritime "landscape, earth, and sea and sky." (Under Eastern Eyes 70)

Keefer notes that in addition to Maritime society valuing the natural world as an object of beauty and an economic resource, nature also functions for the region's writers as a space for spiritual renewal in the face of an encroaching urban world.

Erik Kristiansen contends that this pastoral impulse is taken up in the 1940s and 1950 s by Maritime writers whose work condemns the arrival of large-scale industrialization in the region. He maintains that the sharp distinction that writers such as Charles Bruce and Ernest Buckler make between the urban and rural world, and between modernity and progress, contributes to the antimodern movement that took place in Nova Scotia during this time period (225).

Other critics find this pastoral impulse in more contemporary Maritime writing. For example, in his introduction to the 2005 volume, The Sea's Voice: An Anthology of Atlantic Canadian Nature Writing, poet Harry Thurston states that the region's nature writers are driven primarily by their response to the region's beautiful natural landscape: "[t]here is a century-old tradition of nature-writing in Atlantic Canada, dating back to the early animal stories of Charles G.D. Roberts. It is a tradition that is alive and well thanks to a growing list of new practitioners of the nature story. Among them are poets, biologists, novelists, and naturalists, all bearing witness to the extraordinary richness of 
the natural world in this seagirt region" (1). Similarly, in his introduction to Landmarks: An Anthology of New Atlantic Canadian Poetry of the Land (2001), Brent MacLaine argues that in the contemporary poetry of the Atlantic region "[t]here is a profound respect for natural forms, which, in these days of heightened environmental consciousness, is nothing short of cautionary - as it was, of course, for many of the Romantic poets, especially Wordsworth ... Indeed, it becomes clear after reading such a collection as this that the literary pastoral tradition remains a fertile one for the poetic imagination and continues to find a contemporary voice" (13).

David Creelman, Lothar Honnighausen and Gwendolyn Davies, on the other hand, see in contemporary Maritime literature - especially fiction - a move away from the nostalgic and pastoral treatment of nature found in the region's earlier texts. ${ }^{2}$ Creelman argues that while authors such as Frank Parker Day, Charles Bruce and Buckler upheld the idealized vision of nature characteristic of Charles G.D. Roberts, L.M. Montgomery and Thomas McCulloch, recent authors display an "immersion in the alienating post-industrial conditions of the region [that] undercuts any flight towards nature" (Setting in the East 147). Honnighausen sees bleakness and battles over

${ }^{2}$ Earlier writers from the region, most notably Hugh MacLennan, Alden Nowlan and David Adams Richards (although some critics call his work neo-pastoral) called attention to the region's violent social and economic conditions. More recent texts which challenge the idyllic reading of nature in the Maritimes include Christy Ann Conlin's Heave (2002), which specifically contests Buckler's pastoral construction of the Annapolis Valley, and Joel Campbell's Tarcadia (2004), a story about four young boys who build a raft to sail on the Sydney tarponds. Campbell's novel, which consciously mocks this idyllic portrait of the Maritimes, is full of descriptions of the boys "coming down the side of Slag Mountain like a California surfer" (35), having water fights with the black water of Muggah's Creek, and their exclamations that "[f]unny things ... happened on the tar pond all the time" (125) and that "This is the best place in the world to be" (143). 
resources, rather than idyllic settings, in the fiction of Richards and Ann-Marie MacDonald, which he also attributes to the region's post-industrial malaise (138).

Gwendolyn Davies' discussion in Studies in Maritime Literary History, 17601930 of the importance of the home place to Maritime literature - a concept that plays an key role in the later criticism of David Creelman, Danielle Fuller and Herb Wyile - also makes the case that a pastoral or nostalgic relationship with place is not a necessary trademark of Maritime literature. She notes that The Song Fishermen, for example, a group of poets based in Halifax in the 1920s and 1930s who self-consciously romanticized the rural Maritimes in their earlier work, displayed in their later writing an awareness of the economic forces that threatened the region's lifestyle. She also argues that "McKay's [charge] that much Maritime literature is merely a literature of nostalgia created by middle class writers who idealize a pastoral, golden age as part of a 'culture of consolation' ... ignore[s] the elements of realism, irony and economic cynicism permeating much of it" (194-195).

In this chapter, I suggest that Coady's fiction represents more than what Creelman and Honnighausen call a shift away from the pastoral and nostalgic impulse in Maritime literature. Coady instead specifically looks to mock and undermine conventional experiences of the Maritime region's landscape. Her fiction is not only bleak and marked by "alienating post-industrial conditions;" it acknowledges that idealized constructions of nature exist and consciously challenges them. While Creelman and Honnighausen assume a concrete relationship between the region's writers and its social conditions, as detailed in Chapter 2, I instead examine the way in which Coady's ironic treatment of nature exposes definitions of the landscape as socially constructed. 
Coady contests this interpretation of the region's landscape as idyllic by satirizing the tourism industry's version of the natural environment. She undermines conventional definitions of space in Cape Breton - which appear in her fiction as nostalgic portraits of an island painted as backwards by the tourism industry and the pastoral reading of nature that appears throughout Maritime literature. In Strange Heaven, Coady specifically challenges the serene and welcoming portrait of Cape Breton by accentuating the presence of violence in Bridget's hometown, by satirizing Alan Voorland's outsider's view of the region, and through Robert Murphy's selective and exploitative performance of the folk subject. In Play the Monster Blind, Coady confronts this idyllic representation of the Maritimes by highlighting the impoverished communities along the supposedly scenic Cabot Trail and characters' resentment of outsiders telling them the region is a paradise in spite of having no understanding of its economic and social problems. $\underline{\text { Saints }}$ of Big Harbour draws a clear parallel between the community's "carnival of violence" and the performance of the tourism industry. In Mean Boy, Coady satirizes Jim Arsenault and other characters' attempts to tap into this pre-modern folk culture. Arsenault does so in order to brand himself a rugged woodsman, while the proprietors of the Crowfeather Inn appeal to the idea of the region's serene landscape in order to market their hotel. Coady exposes each effort as fabricated and designed to impress students and colleagues or to move product.

\section{Cape Breton as a Fallen Space in Strange Heaven}

Strange Heaven undermines the image of Cape Breton as an idyllic space by focusing on violent incidents in Bridget's hometown such as the shooting of Jennifer 
MacDonnell, by subverting Alan Voorland's tourist gaze, and by highlighting Robert's cynical performance of the "folk" in order to sell his tourist crafts. The story displays anxieties over outsiders' experiences of the Maritimes; for example, Alan has come to the region to look for interesting and rustic people, and Robert worries that the Maritimes projects itself as freakish and violent. Strange Heaven foreshadows Coady's treatment of space in Play the Monster Blind, in that its ambivalent construction of Cape Breton runs parallel to its satirically pastoral construction of a middle class urban Canadian space, Alan's descriptions of Guelph and Georgian Bay.

In his 2006 article, "As for Me and Me Arse: Strategic Regionalism and the Home Place in Lynn Coady's Strange Heaven," Herb Wyile writes that Coady uses the claustrophobic nature of small towns, a common preoccupation in English Canadian writing, to subvert Eastern Canadian stereotypes. She does this by demonstrating that the communal ethos that Janice Kulyk Keefer and others pinpoint in the region's literature is often difficult to find in the increasingly disjointed and fractured world of Atlantic Canada. Wyile argues that in this way, Strange Heaven can be read as a deconstruction of the rest of Canada's view of the East Coast (85). For Wyile, Strange Heaven turns the notion of the Maritimes as an innocent folk community on its head by calling attention to the emotional and economic dysfunction that dominates its atmosphere and the alcoholism and violence that courses below the surface. My reading of $\underline{\text { Strange Heaven in }}$ this section aligns with Wyile's assessment of the novel; however, while he focuses primarily on the home place, I would like to argue that the novel's treatment of the physical space of Cape Breton is also evidence of Coady's deconstruction of literary portraits of the region. Coady undermines interpretations of the Maritimes as idyllic and 
innocent through her use of violence, and especially by juxtaposing the expectations of outsiders like Alan Voorland - who comes to the Maritimes looking to meet "rustic people" - and the region's economic and social problems.

In the first sequences of the novel, Coady establishes both the narrative style - the story's third-person narrator provides a series of flashbacks layered over the novel's time present - and the extreme violence that defines her setting. Bridget's hometown is a place where Marianne Boucher's "no good brudder" steals her television for alcohol (파 117) and where her daughter spends weekends in the women's shelter, where Bridget's friends Stephen Cameron and Dan Sutherland "were never able to set foot at a dance without getting pummelled" (배 140) and where shootings and suicides are commonplace. The novel is permeated with references to various diseases, ailments and "infestations" that attach themselves to the bodies of main characters and peripheral figures. The spectre of disease looms over the action of Strange Heaven, a novel that is populated with the gaunt, anorexic bodies of Kelly and Maria, the deathly Margaret P. and the disfigured Tina. The narrative is punctuated by constant reminders of the imminence of death and the prevalence of cancer and other diseases in Bridget's family and community. Coady draws a clear parallel between the community's post-industrial economic and social decay and the physical decay of characters' bodies.

The death of Jennifer MacDonnell also lingers in the background as an example of the kind of domestic violence that is almost routine in Bridget's hometown. Throughout the novel, friends and family warn Bridget that the father of her child, Mark, is angry about her decision to give away the baby and, presumably, break up with him. They tell her that it is improper for a girl to break up with the father of her child while she 
is carrying the baby and reprimand her for opting for adoption without his consent. Bridget's flashbacks make constant reference to Mark's quick temper, "drunken nastiness" ( $\underline{\mathrm{SH}} 45)$ and controlling personality, and when they finally meet near the close of the novel, Bridget braces herself for his inevitable barrage of accusations and thinly veiled threats: "What he wanted to know was, Didn't she know how hard this all had been on him? Did she know he was a mess? She must have heard. Did she know he had gone into rehab?" ( $\underline{\mathrm{SH}}$ 237).

The novel implies that the combination of Bridget's decision to break up with Mark, his aggressive temper, and the community's violent atmosphere could easily result in a similar fate for Bridget. Although this never comes to pass, the death of Jennifer MacDonnell serves as a reminder for Bridget of the possible consequences of this culture of violence. Margaret P.'s mistaken belief that "Bridget Murphy, her own granddaughter, had been shot to death by a boy" (프 21) reinforces this link. Later, Margaret P. tells the family that she can smell Bridget's rotting corpse in the house: "Not only was Bridget dead, but she stank, according to Margaret P. This was all anybody heard about on Christmas Day. Margaret $P$. was adamant about it every time Bridget came into her foggy line of vision" ( $\underline{\mathrm{SH}} 165)$. Elsewhere, Margaret P. erroneously tells the family that Bridget is in purgatory and lobbies for her release by leading them in rosaries and prayers for her soul.

Strange Heaven contributes to the growing sentiment within contemporary Maritime literature, identified by Creelman and others, that the region is often marked by conflict, the imposition of patriarchal authority, and violence. The fact that the community is also so wracked with violence makes the idea that the region is somehow 
more innocent and pre-modern than the urban spaces of Canada difficult to sustain. The consequences of the Maritime region's deindustrialized economy, which appear in this novel in the form of the creeping presence of corporate Canada and an increase in joblessness, hopelessness and, ultimately, violence, comprise the backdrop of $\underline{\text { Strange }}$ Heaven. All of these factors contribute to the confused sense of regional space that Coady constructs in her work, and to the way in which she consciously undermines so many of the traditional markers of the region.

\section{Outsider Experience}

The novel sets up a contrast between Bridget's and the rest of the community's experience of the region's socio-economic conditions and that of Alan Voorland, a twenty-five-year-old man who has moved from Guelph to the unnamed town to work at the mill for the summer. Constantly unhappy with his own choices, Alan romanticizes the Maritimes prior to arriving there, and pines for an idealized version of Guelph once he tires of his life on the East Coast. The narrator notes that Alan moved to industrial Cape Breton because he resents the peaceful and sterile lifestyle offered to him by his affluent parents, and talks about his interest in the "sociological" aspects of the working class people he has met in Cape Breton. He maintains this ironic distance throughout the novel by poking fun at Bridget's family and her accent and by reading her "character sketches he had written about a couple of the guys at the mill whose personalities, he said, he 'delighted in"' ( $\underline{\mathrm{SH}}$ 107). Spending the summer working the night shift at the hot, smelly, dangerous mill, however, gives him a different perspective on Cape Breton and the people who live there: 
Alan told her he wanted to get back to Guelph. The place that had once been so fascinating had rapidly lost its rustic charm and begun to do bad things to him, he said. He was getting fatter and fatter with no gym to work out at, and the shifts at the mill were completely fucking up his internal clock. And the guys he worked with on the platform were either drunk or hung over all the time and were going to kill somebody soon. (프 38$)$

When Alan moved to the region, he brought with him a series of preconceived ideas about Cape Breton and the people who live in that space. Before arriving there, and even during his first few months on the job, he believed the people who worked at the mill were fascinating examples of "the folk": they worked hard, they made their living from extracting resources from the land, they were simple, and they were backwards. After working at the mill for a few months, he realizes that the industrial economy takes a heavy toll on the body. He notes that his shifts upset his sleep routine, and, after work, he is too exhausted to take proper care of himself physically.

However, these are mild effects. He also tells Bridget that the rampant alcoholism of his fellow workers and management's complete lack of safety oversight at the mill mean that he is in constant fear of being injured or dying on the job. This passage suggests that, for Coady, the idea that the Maritimes is home to a pre-modern "folk" culture works only at first glance. Alan's initial encounters with the people who work at the mill confirm his prior assumptions about Cape Breton's working class culture, but spending several months there sours his idealized portrait of the region. Coady satirizes Alan's aloofness throughout the novel. Here, his complaints about the inhumane 
conditions of the mill fall flat because, as he notes, he is can leave at any time, unlike the men who work beside him.

Although Alan travels to Cape Breton to gain firsthand experience of the interesting working class culture he assumed existed there, by the end of his time in the region, he becomes nostalgic for his hometown of Guelph, which he believes is not afflicted by Cape Breton's social problems. While Alan once moved to Cape Breton to escape the sterile environment of Ontario in favour of the gritty and idyllic Maritimes, he changes his mind by the end of his stay. He discovers that Cape Breton is, in fact, home to violence and economic depression, and decides that Guelph is the real utopia:

"They don't shoot people in Guelph?"

It's not so close. Not right under my nose like that. If I hadn't been at work, I could have stood at my window and watched the whole thing. "Oh, I want to go home," he said loudly and suddenly, not like he was reading the news. ( $\underline{\mathrm{SH}}$ 38)

In Guelph, Alan lives with his parents in a wealthy neighbourhood where his class position separates him from such violence. Alan is perfectly happy to observe Cape Breton's working class culture from the safety and comfort of his parents' Lexus; however, when he actually comes into close contact with the conditions of life in the region, they make him uncomfortable. Alan quickly discovers that these kinds of safe, affluent neighbourhoods are missing in industrial Cape Breton, a place where economic depression encapsulates entire communities.

Alan's distaste for Cape Breton leads him to rethink his rejection of his parents' affluent lifestyle, and he tells Bridget that it is actually his hometown that is idyllic, rather 
than her community. When Bridget complains about her disastrous Christmas meal, one that included her father bullying them through Grace, her uncle Albert falling off the wagon, her grandmother telling the family that Bridget has been shot and is now in purgatory, and her uncle Rollie knocking the dinner table over with a violent sneeze,

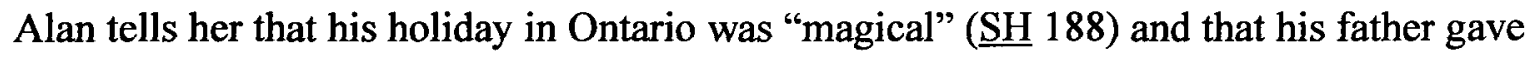
him a new car as a pre-Christmas present. Bridget, in turn, romanticizes Alan's life in Ontario, and often seems to buy into his assessment that Cape Breton is populated with

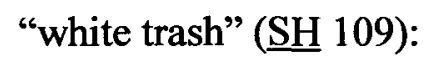

To think of her and Alan and Deanna and all of Alan's cool buddies who worked in television and were photographers and played in rock and roll bands, real rock and roll bands, not George and Mark mangling Aerosmith in Chantal's living room ...

Bridget felt badly for him. He used to narrate happy stories of himself and all his friends on Georgian Bay - tanned sons and daughters of lawyers and accountants ... He was still friends with all his old lovers. And he and all his friends would go and see concerts and baseball and hockey games in Toronto. He made it sound like so much fun, and it probably was. (프 39-40)

In making this connection between Alan coming to the realization that the rustic and simple definition of the Maritimes is a purposeful and misleading construction and his stories about the perfect utopia of Guelph, Coady undermines the idealized portraits of both spaces. The novel is clear in demonstrating that Alan's idyllic lifestyle in Ontario reflects his socio-economic position, and his disenchantment with rural Cape Breton is the result of having to work in the mill. Coady's deconstruction of idealized definitions of 
space extends from Cape Breton to other parts of Canada in this instance. She satirizes Alan's detached search for the Maritimes' simple "folk" culture as well as his position as the son of wealthy Upper Canadians who lives a life of leisure with the rest of his privileged friends.

Although, as the above passage suggests, Bridget seems to accept Alan's romanticized version of Ontario and his dismissal of Cape Breton's "backwards" culture, Coady further undermines his position through Bridget's tentative embrace of her family, which she renounces several times, at the close of the text. While Alan's privileged class position and detached personality allow him to flee uncomfortable situations at any time he pleases, Bridget finds it difficult to leave her family behind. The narrator says that Bridget previously engaged in adolescent behaviour which included meeting up with Mark at three in the morning, laughing while Chantal bullied other girls at school, "drinking and doing hot knives and puking, always puking" ( $\underline{\mathrm{SH}}$ 176) to rebel against the lunacy of her overbearing father, her cheerfully oblivious mother, and her ghoulish grandmother whose bedpans she was responsible for emptying.

Towards the end of the novel, however, Bridget realizes that "[t]hat was selfish. You can't be that way when there is an old woman and her retarded son to look after" ( $\underline{\mathrm{SH}}$ 176). Bridget finally asserts herself at the end of the novel when she yells at Mark to "'Eat your own shit,'... [which she says] because Margaret P. had been saying it to every body of late, shocking her family terribly" (태 240). In the final line of the novel, the narrator says that in spite of the family's fears that the grandmother will soon pass away, "she would not die, Bridget knew. Because there wasn't any of that" ( $\underline{\mathrm{SH}} 244)$. At the 
end of the novel, Bridget cautiously embraces her family, in spite of her ambivalent feelings towards them.

Although Bridget seems happy to return home following her stay in the psych ward and embraces the duty of caring for her grandmother, Strange Heaven's final pages point to potential problems with this decision. When Dr. Bransk, a Polish war survivor who moved to Cape Breton to practise medicine, asks Bridget why she did not come to him for an abortion, she admits that she was scared that her family would find out, which suggests that her home is still an oppressive space. This emerges most clearly when Robert berates Bridget for abandoning Margaret P. during the snowstorm, even though she leaves only for a few minutes to finally end her relationship with Mark: "when the average human being failed to comport his or herself in accordance with these modes, it seemed to him that such a human being had to be a few goddamn aces short of a full house or however the saying went ... That was only his opinion, but it seemed to him it was the right one, otherwise the whole world would be running around in the middle of snow storms and letting their grandmothers die all alone" (프 241-242). The chaos of Strange Heaven's final pages, Robert's demands that Bridget place the interests of her family above her own, and her gradual and hesitant retreat to the home place seem to signal that Bridget, like Larry, is still somewhat naïve at the close of the novel. While she clearly finds a degree of comfort in the familiarity and permanence of her family, the narrator makes it clear that the Murphy household is still marked by overwhelming conflict and hostility. While Bridget is successful in disposing of Mark from her life when she meets him at the post office, she ultimately finds it more difficult to rebel against the stifling influence of her mother and grandmother and the abusive treatment of 
her father. As I discuss in the following section, Coady revisits this aspect of Bridget's relationship with Cape Breton and her family in the story "Look, and Pass On."

\section{Performance of the Folk Subject}

Aside from Alan, the other object of Coady's satire, with respect to her deconstruction of the definition of the Maritimes as idyllic and home to an "authentic" folk culture, is Bridget's father, Robert, a woodworker who sells souvenirs to tourists. Robert has a conflicted relationship with the region's tourism industry: he aggressively rejects being called a Maritime folk artist, but on the grounds that he is a craftsman, rather than an "ar-teest" (태 84), not because he has a problem with being lumped in with the ubiquitous, corporate tourism industry that dominates Nova Scotia's artisan market. He also calls the community's annual bag piping contest "Cat Killing Days;" however, in his capacity as town councillor, he devises schemes aimed at drawing visitors to the area, because he relies on them for his livelihood.

In this way, Coady aligns Robert with Isadore and Jim Arsenault, characters who, as the next sections demonstrate, selectively assert themselves as representatives of "the folk" when it benefits them personally. Although Robert rejects the town's pride in the bagpiping contest, "one of the many things that made the community unique" ( $\underline{\mathrm{SH}} 84)$, on the basis that it misrepresents the region's culture, he often positions himself as a quirky Cape Bretoner in order to justify the outrageous prices he charges for his merchandise:

The shop did a fairly good business because he made cabinets as well and because he over-priced his art for the tourists. He had also acquired a reputation for being a character, and local people were always stopping by to see what he'd do. They 
found his insults endearing, but if ever they loitered too long, he'd bark, "If you're not buying, you're leaving," in a deliberately less charming kind of way, in such a way as to make them fear they had offended him somehow. ( $\underline{\mathrm{SH}} 85-86$ )

Robert's controlling and overbearing personality, the threats he makes to Bridget when her stay in the psych ward does not immediately make her "feel better," and his performance of this caricatured artisan's persona for tourists combine to make him a frequent target of the narrator's scorn. Not only does Robert tap into tourists' appetite for "authentic" down-home culture, he also forces his mentally-challenged brother to carve religious statues for the shop (which he advertises with a sign that says "Religious Wooden Statues. Done by Retarded Man. Twenty-five dollars a piece" (보 89)). In doing so, he similarly exploits his Catholic heritage, which he renounces throughout the novel.

Robert's actions call attention to the way in which the tourism industry in the Maritimes often encourages people to conform to external stereotypes about the idyllic and backwards nature of the region. In addition to the novel's satirical treatment of Robert, who, along with Isadore, John MacNeil Sr., and Jim Arsenault, adheres to an outdated and often hostile belief in traditional values, the above passages serve to critique the way in which Maritime culture often internalizes the infantilized and vulgar "schlock" that, for Coady, satisfies tourists' expectations of this space. The novel aligns its attack on Alan Voorland's idealized and condescending assumptions about the Maritime provinces with its disapproval of Robert's attempts to capitalize on them.

The narrator also gestures to the exploitive and hypocritical aspects of Cape Breton's folk and tourism industry when describing "The Ballad of Jenny Mac," a song written by a local fiddler commemorating the life and death of Jennifer MacDonnell. In 
spite of the community's enthusiasm for the ballad and her mother "[turning] it up whenever it came on and always [taking] up a handful of Kleenex" (HH 197), Bridget detests the song because it is so clearly derivative of "The Wild Colonial Boy," a traditional Irish ballad about a Robin Hood figure who leaves Kerry County for Australia in the nineteenth century. She also resents the song's misrepresentation of its subject in order to secure commercial appeal: "And Jennifer MacDonnell, who had never been called Jenny in her life, had sunk entirely beneath the horizon. Something else being erected in her place. She was queen of the prom, on her parents' mantelpiece forever, now" (SH 198). On one level, Coady is demonstrating that this kind of violence is commonplace to the point where it is present even in Cape Breton's traditional music. She also makes a broader point in linking the region's culture, one in which young people routinely "[kill] each other and [kill] themselves" ( $\underline{\mathrm{SH}}$ 115) with the tourism and folk industry, which, for Coady, works to objectify and trivialize the inhabitants of the region. Coady makes an implicit connection between the violent death of Jennifer MacDonnell and the destructive treatment of the environment in Cape Breton. Just as the local fiddler capitalizes on this shooting by writing and marketing a packaged and derivative song about it, so Cape Breton's tourism industry touts the pastoral and idyllic version of the island in order to obscure the economic, social and environmental problems the region faces.

The Tourist Experience in Play the Monster Blind

In Play the Monster Blind, Coady returns to her deconstruction of idyllic depictions of the Maritimes. The collection does this in three principal ways: in "Play the 
Monster Blind," Coady undermines the tourist experience of the Maritimes' landscape by focusing on the impoverished communities on the Cabot Trail; in "A Great Man's Passing," she satirizes outsiders' perceptions of "the folk;" and in "A Nice Place to Visit" and "Look, and Pass On," she includes parts of Ontario and the west coast in a broader deconstruction of idealized landscapes.

"Play the Monster Blind" is driven by tensions between Bethany's perspective as an outsider to the region and the things her fiancé, John, shows her during their visit to his childhood home in Cape Breton. As detailed in Chapter 4, Bethany is often shocked by the violent and ridiculous behaviour of John's family. The story parodies the recurrent theme of characters returning home to Cape Breton, which in earlier literature appears as a cathartic and joyous moment, ${ }^{3}$ but in "Play the Monster Blind" is embarrassing and painful for John. Coady also satirizes standard tourist experiences in challenging the notion that the region is idyllic and serene. In order to introduce her to Cape Breton, John's family takes Bethany around the famous Cabot Trail, a highway that traverses the northwest side of the island, running through key tourist destinations like Cheticamp, Ingonish, and Cape Breton Highlands National Park. The Cabot Trail is one in a series of secondary highways that the Nova Scotia government has turned into "Scenic Routes." Along with other roads, such as the Evangeline Trail, which takes visitors through the Annapolis Valley and the Acadian region of Clare, it is a central part of the province's tourism infrastructure (Muise 125).

\footnotetext{
${ }^{3}$ See, for example, MacLeod's "The Return" (1976), Home For Christmas: Stories from the Maritimes and Newfoundland (1999), among others. There are other texts that present alternatives to the "quintessential" experience of coming home to the Maritimes; the most obvious recent example is R.M. Vaughan's dystopic 'Saint Brendan's" (2003).
} 
In The Culture of Nature: North American Landscape from Disney to the Exxon Valdez (1991), Alexander Wilson argues that the pervasiveness of the tourism industry in Canada and the United States has redefined encounters with the landscape. He observes that the pastoral response to nature is very similar to the constructed and controlled experience of the consumer. In the chapter "The View from the Road: Recreation and Tourism," Wilson posits that nature parkways and scenic highways are constructed in a way that manages our view of the surrounding environment. He writes that these roads, "in the design of their curves and rest areas instruct drivers about how best to appreciate the scenery out the window ... the car further divides the landscape, and our experience of it, into discrete zones. It promotes some landscapes and discourages others" (28). In "Play the Monster Blind," Coady portrays the Cabot Trail as this kind of highway; however, Bethany finds that unsavoury elements of Cape Breton society creep into her view of the landscape.

Excited at the prospect of circling the island and experiencing the dramatic terrain and the welcoming culture she assumes exists in rural Cape Breton, Bethany finds that the landscape and hospitality both fail to live up to her expectations. Instead of the gentle, lush and accessible coastline she anticipated, Bethany encounters scenery that confuses her, and she is surprised to find out that many of the communities along the Cabot Trail are economically depressed rather than quaint. For example, when she discovers that, from the highway, mountains often obstruct the view of the ocean, she becomes irritated: "They stopped at a lookout point, and Bethany climbed out of the car before the rest. In every direction she turned, she could see nothing but dark fuzzy mountains. The everpresent ocean was nowhere in sight, and it disoriented her. She didn't know if this was 
beautiful or not." (PMB 16-17). Bethany also asks John to explain to her why she cannot see the coastline from his backyard. In spite of her preconceived ideas about Cape Breton, John's family does not live on waterfront property. This alludes to the way in which the rise of Nova Scotia as a tourist destination has displaced the region's inhabitants from plots of land with access to the beach or with the best views. Here, Coady sets up a direct confrontation between the received portrait of Cape Breton as serene and idyllic and Bethany's actual experience of it. Bethany's uncertainty as to whether what she sees is beautiful or not stems from the discrepancy between what she had heard about Cape Breton and what she actually sees once there.

"Play the Monster Blind" sets up a situation in which the main character's family essentially becomes a group of tourists in their own home when they take Bethany on this quintessential Cape Breton journey. The story insists that the experience of Cape Breton's natural environment through the lens of the Cabot Trail is an artificial one. Bethany's confused disassociation from the landscape that surrounds her takes place at one of the Cabot Trail's many lookout points, which are essentially large gravel patches located strategically along the shoulder of the highway so that people can take pictures of the most striking scenes. Even though the tourism industry makes the experience of being overwhelmed by the spectacular views offered by the Cape Breton Highlands so easily accessible, Bethany comes away unconvinced. It is also significant that she experiences this confusion during one of the few moments in which she is alone and without her native regional guides. When faced with more than one thing to look at, she freezes and is unsure of where to focus her attention. 
In addition to her anticipation of the landscape, Bethany also expects the inhabitants of Cape Breton to be charmingly backwards and welcoming. The tourism industry's campaign to capitalize on Maritime Canada's folk culture includes depictions of the region's inhabitants as eminently polite and hospitable; however, "Play the Monster Blind" captures a feeling of bitterness that accompanies the region's harsh economic realities and the experience of being required to perform this role for outsiders. In this story, what is supposed to be a tour of the island's most impressive scenery becomes, for Bethany, a display of the region's scars of economic depression:

And then the road would sink lower and lower imperceptibly, until they were trundling through some infinitesimal community and she'd see grey, halfdemolished barns with black letters spelling CLAMS painted across the roofs ... She went into one of [the stores] to get lemonade and ice-cream bars for everybody and the woman behind the counter was not nearly as friendly as Bethany had been expecting. (PMB 20)

Although the Cabot Trail is classified as a "Scenic Route" in Cape Breton, one that does not even have an official highway number - the province instead identifies it on signs with a picture of a mountain - it is still a road that inhabitants of the region use regularly, and, as the story makes clear, live alongside. Bethany is shocked by this, and is even more taken aback upon seeing that the people who have houses on the non-coastal side of the highway often live in poverty. Coady's use of space and perspective in this instance emphasizes this point: it is the highway itself, rather than towns or attractions on it, that tourists come to Cape Breton to experience. Additionally, road signs encourage passengers to look towards the coast in order to see its breath-taking scenery. Bethany's 
confused and uncomfortable gaze, however, occasionally drifts to the opposite window, the one that overlooks the impoverished communities that skirt the highway.

Here, Coady draws a biting contrast between the supposedly rich and beautiful scenery that characterizes the Cabot Trail and the economic hardship of the people who actually live on it. Bethany's shock comes from seeing that because they live so close to the "Scenic Route," the lives of these people are actually on display for the tourists who come through the region. In making this connection, Coady brings out a sense of humiliation that accompanies life in the tourism-dominated space of Cape Breton. The people in these houses not only live in poverty, outsiders also constantly drive past their "half-demolished" homes and businesses, taking pictures and expecting to be welcomed. It is not surprising, then, that the woman who serves Bethany at the counter is not as friendly as she had hoped. This description of the abandoned "CLAMS" restaurant hints that tourism is an unsustainable economic model for the rural Maritimes: people who shift their focus from farming to the hospitality industry do not make enough money even to keep their restaurants in decent repair, and opt to shut them down.

\section{Constructions of the Folk in "A Great Man's Passing”}

Other stories in the collection examine the discrepancy between outsiders' expectations of what the region should look like and what they find once there. "A Great Man's Passing" also contests the notion that the Maritimes is home to a serene folk culture that not only lives harmoniously with nature but is also open to sharing this lifestyle with outsiders. The story's main character, Bess, has two very different sets of relatives: one side of the family is the perpetually impoverished Sloanes, and the other is 
her well-off relatives from Ontario who travel to Cape Breton for her grandfather's funeral. The story draws a sharp contrast between the two perspectives as it relates to the supposedly idyllic space of Cape Breton:

People who didn't know, and that was mostly tourists, thought that the Sloane house, about a hundred feet backed up from the main road, had to be deserted. They didn't even think this in a conscious way. They processed it the way drivers process the things they see on a long, empty country road. House. Cow. Mailbox. Deserted house. It never occurred to anyone that such a place could be inhabited. (PMB 105)

In Coady's fiction, outsiders who visit the region are taken aback by things like people living in houses that appear to be deserted for two reasons: aside from people inhabiting what, for them, is an unliveable house, sights such as this fail to match up with their preconceived notions of the region's idyllic lifestyle. This story, like "Play the Monster Blind," draws a sharp contrast between the tourist experience of rural Cape Breton and that of the people who actually live in the region.

In “A Great Man's Passing," Coady uses two characters, Bess's grandfather, Iain, and Red Rufus Banks, to disrupt outsiders' assumptions about Cape Breton's pre-modern folk culture. There is a striking discrepancy between Bess's memories of her grandfather, the ironically named "great man" of the title, which consist of things like his chair, which stunk of "ancient smoke and piss emanating from its fibres" (PMB 119) and those of her cousins from Ontario, who heap what she believes is unwarranted praise on him: “" $\mathrm{Ah}$, Bessie, you don't remember him like I do. What a man. What a great man. The stories he used to tell. But a simple man, you know?' But I've lived with him all my life, Bess 
wished to say" (PMB 127). In addition to Bess's discomfort with calling her unremarkable grandfather a "great man," the scene that greets mourners at his wake also undermines the cousins' condescending portrait of him as folk hero. The people who arrive at the house find the dripping carcass of a buck illegally killed out of season hanging on the front porch. Coady places Bess and her Ontario cousins in drastically different positions with respect to their relationship with the grandfather and the region itself. Bess's cousins valorize their grandfather because, for them, he embodies the Maritimes' folk culture, much like the local fiddler hired by Bess's father to play at the wake, who "had a deep, resonating voice and was known to be a storyteller" (PMB 124).

Coady draws a parallel between the cousins' exoticized portrait of the grandfather and their love of watered-down examples of East Coast culture. Bess remembers that her cousins "would do things like buy a case of Alexander Keith's and go to square dances and Judique on the Floor Days and all the other festivals. They would come back to the house and sit in the kitchen with their Keith's and start all their sentences with 'Jesus, Mary and Joseph,' and 'Lord t'underin' Jesus.' They would play their Rankin Family and Rita MacNeil tapes" (PMB 126). Bess's bitterness towards her Ontario relatives for their condescending impressions of Cape Bretoners disrupts the narrative of serenity that accompanies descriptions of "the folk." Her memories of her grandfather living in his own filth and her family's irresponsible and violent treatment of the natural environment also undermine her relatives' assumption that their Maritime counterparts live in a pre-modern, backwoods utopia.

Like Bess's cousins, Red Rufus Banks is an outsider who positions himself as old-fashioned and backwards in order to fit into Cape Breton society. Banks is an 
American who once vacationed in the region but eventually bought a hotel in Bess's community because he loved Cape Breton so much. He calls himself "Red" because he had "noticed that everyone around here had nicknames ... one of the things he loved about the place" (PMB 110). Coady portrays Rufus as a ridiculous character: the town tolerates him because "he was rich and American" (PMB 114), but he is also the butt of jokes because of his lack of knowledge of the area. ${ }^{4}$

While Play the Monster Blind shows a genuine concern for the harm inhabitants of the region suffer at the hands of the tourism industry, its characters often exhibit an ironic and scornful attitude towards outsiders. Coady's characters often consciously reject the stereotype of the innocent, backwards and cordial folk, and, like the store-clerk from "Play the Monster Blind," openly resent visitors to the region. In "A Great Man's Passing," Bess's father displays this detached relationship with outsiders:

[Ruf] had come to Daddy in the summer wanting to know where he could catch trout, and so Dad asked the man over for dinner and took him behind the house and down the side of the hill and they fished about a mile upriver from where Dad's gaspreaux trap was set up. Everyone but the American knew there wouldn't be any trout, but they also knew that he would be just as satisfied if he caught even one bony gaspreaux, which he did, and he was. (PMB 108-109)

In this scene, the narrator's father, as well as the rest of the inhabitants of the community, use Ruf's ignorance of Cape Breton's natural environment to appease but also embarrass him. This instance calls attention to what Coady sees as the arbitrary whims of the

\footnotetext{
${ }^{4}$ In "Tracking the Cheshire Cat: Ethnic Americans and American Ethnicity on Cape Breton Island" (1991), Michael Taft examines Americans who have moved to the island as a distinct ethnic group. He argues that "come-from-aways" often feel like "strangers" in Cape Breton.
} 
tourism industry: as long as someone tells Ruf that what he catches is a trout, it does not matter to him that it is actually a gaspereaux. Here, Coady again exposes the tourist encounter with the region as a constructed experience in which expectations and reality consistently fail to match up.

As the story progresses, the disconnect between his outsider's perspective of Cape Breton and that of the people who actually live there widens. Distressed because Bess's family lives full-time in the region and fails to share his enthusiastic love for its landscape and culture, he tells them over his beer-battered gaspereaux, "You people have a paradise here, do you know that?" (PMB 109). What Ruf fails to understand is that for native Cape Bretoners who constantly struggle to make a living, witness their supposedly beautiful landscape being wrecked by post-industrial economic schemes, and battle alcohol and drug addiction, the region is decidedly less than perfect.

In these stories, the outward appearance of the region often fails to match up with the lived experience of it, as Ruf's impression of the place, gained from summers spent there dreaming of his eventual retirement, is much different from the realities of life in contemporary Cape Breton. In Bess's hometown, insidiously toxic industry is touted as the cure for economic downturn, people are told they must leave in order to find work, and those who stay are at once humiliated for their reliance on government programs and encouraged to accept dangerous jobs in order to avoid it: "She saw men on television who said that all they wanted to do was work. They would do anything, clean out toilets, mop floors, but they could not stand the ignominy of welfare. They said they felt degraded" (PMB 110). Coady accentuates the discrepancy between Ruf's assessment of the region as idyllic and Bess's experience of Cape Breton's often intense poverty. 


\section{Broader Critique of Idyllic Landscapes}

Although, as many critics note, earlier Maritime literature displays a struggle over the prevalence of outmigration in the region and the way in which economic circumstances force young people to make the difficult decision to leave, in Play the Monster Blind, fleeing Cape Breton is a compelling option for characters who view growing up in the rural Maritimes as an often suffocating experience. While Maritime literature traditionally portrays outmigration as a painful necessity, for Coady's characters, it offers the possibility of escape from a restrictive space. At various points in the collection, characters make explicit reference to the idea of moving away from the region, and mock the notion that people who leave the Maritimes would lament this decision. When Bethany arrives at the MacNeil house, for example, Ann comments on her expensive luggage, saying that " it would never even occur to me to have bags like that"' ( $\underline{\mathrm{PMB}} 9)$, at once calling attention to the difference in their class positions and betraying jealousy at Bethany's ability to come and go wherever she pleases.

Two of the collection's later stories, however, complicate the idea that utopian spaces exist for characters beyond the region. "Look, and Pass On," a story detailing Bridget's journey away from Cape Breton in a Lexus that belongs to Alan Voorland's mother, undermines Alan's judgement that leaving home offers Bridget an escape. Although Bridget, like Ann, expresses a more or less clear longing to get away from her family, she finds that it is difficult to follow up on this choice. At first, Bridget sees moving from rural Cape Breton to Ontario as a painful yet necessary step towards maturation. In the first half of the story, she seems to accept Alan's assessment that she 
needs to distance herself from her family and friends in Cape Breton. Alan tells her that she will need to change the way she speaks, the way she dresses, and her general attitude in order to fit into the sophisticated community that she is about to enter. In this way, the road that runs between Cape Breton and Georgian Bay is a space of transformation. Alan implores Bridget to "grow up" and mocks her accent, her underwear and her desire to see and experience things and places she had only heard about before this trip. ${ }^{5}$

In this story, Coady highlights Alan's privileged position. He makes fun of Bridget for wearing her dead grandmother's underwear and begs her to get a thong, a conversation that recurs throughout the story and calls attention to Bridget's need to cling to symbols of the comfort of home as well as her ambivalent attitude towards Alan and his affected sophistication. In keeping with his objectification of Maritimers as well as women in general, Alan calls Bridget "Thing" throughout the story. Their road trip brings them through New Brunswick and Quebec, where Bridget, unaccustomed to being a tourist, insists that they stop to see "all things big," and through Montreal, where Alan's friends marvel at how she is "[s]exy in that wholesome kind of way" (PMB 101).

As mentioned in Chapter 4, Alan is a detached observer of Cape Breton culture in Strange Heaven, enjoying his time there only because the inhabitants of the region were interesting to him from a sociological perspective. He reprises this role in "Look, and Pass On," becoming the disaffected tourist of the story's title. Being the son of wealthy Ontarians who can afford to give him a luxury car for his summer trip to the Maritimes, it is exceedingly easy for Alan to decide over a beer that he is going to leave Cape Breton

\footnotetext{
${ }^{5}$ The trope of moving to central or western Canada for personal or economic benefit and the problems inherent in this decision arises many times in Maritime literature, film and music. See, among many other examples, Goin' Down the Road (1972) and No Great Mischief (1999).
} 
forever; however, he has no idea that it might actually be difficult for Bridget to do the same. In "Play the Monster Blind," Ann longs for Bethany's ease of mobility; in "Look, and Pass On," Alan provides Bridget with an escape, but she finds that she is more attached to home and less enamoured with him than either of them originally thought. The story undercuts Bridget's initial dismissal of her family and the region's culture in its ironic and critical portrait of Alan's detached sensibility, and in its description of the sadness she experiences when Alan refuses her one last swim in the Saint John River Valley (PMB 90).

Ultimately, Coady's ironic treatment of the spatial markers of Cape Breton matches her deconstruction of the supposedly idyllic middle-class lifestyle Alan enjoys in cities like Montreal and Toronto, and especially at his parents' cottage: "they would go for good swims in the Georgian Bay once they arrived. He would have a long weekend to show her the sights before she had to be at the university to start her first year of school. Alan was excited about this. He would take her to his parents' cottage on the bay, show her the beauty" (PMB 90). Later, the narrator reports that Bridget, upon entering every hotel room in which they stayed on the trip, would jump up and down on the bed, to "christen the room" (PMB 91), just as she and her brother had done on family vacations. In connecting Bridget's journey to central Canada with her family's childhood trips in the Maritimes, Coady implicitly aligns the constructed tourist experience of the East Coast with that of other spaces that cater to tourists, like Georgian Bay. Bridget believes that the lifestyle Alan offers her in Ontario is one that centres on consumption and vanity, rather than the values of family and community which she leaves behind in industrial Cape Breton. 
Coady revisits this question in the collection's final story, "Nice Place to Visit." The story returns to Bess, who has travelled from rural Cape Breton to British Columbia to visit her cousin, Meg. Much of the story's dialogue focuses on Meg's attempts to convince Bess to move to British Columbia with her son, Dylan, leaving behind the "hellhole" (PMB 231) that is industrial Cape Breton for the beauty and opportunity of the west coast. At various points in the story, Bess expresses a deep desire to leave her home in Nova Scotia for the cosmopolitan life Meg has found. One such instance takes place when she remembers the filthy houses in which both of them grew up: "One time Bess dropped by to find a pair of freshly caught fish on the coffee table in the living room, and young Alistair with his boots propped up alongside of it, watching 'The Price is Right' and flicking cigarette ash into a bowl of tomato soup" (PMB 230). She is surprised to find out that it is a pleasure to walk around in Meg's new community, unlike her hometown, whose "streets were ugly and adversarial ... there were days when she could not bring herself to contemplate moving around on them" (PMB 229). This desire to leave is also evident in the stressful dreams Bess has during her stay; while others might have anxiety dreams about writing exams or car accidents, Bess's are about moving back to her parents' house. Finally, the closing lines of the story note that in spite of her discomfort with staying in a stranger's house and with the tense relationship between Lyle and Meg, Bess is relieved to have a respite from her difficult life in the Maritimes and "planned for herself a lengthy vacation, knowing there might never come another chance for such ease, and escape" (PMB 246).

Like Bridget, however, Bess has ambivalent feelings about leaving the Maritimes. Although Meg's life in British Columbia is appealing, Bess is attached to her family and 
friends in Cape Breton. As the story progresses, she realizes that Meg's seemingly perfect life with her sophisticated friends and charming boyfriend exists only on the surface: her domestic life is filled with the same kinds of petty anger and violence she seemingly left behind in rural Cape Breton. Bess immediately recognizes that the beautiful landscape and idyllic lifestyle she finds in British Columbia is contrived and artificial: "Mount Baker rose like an iceberg up from the centre of the August haze, and Bess was feeling guilt again, because it was all so beautiful. Below her, green islands dotted the blue sea and Meghan was pointing out whales and screaming to be heard over the engine ... The plane lowered itself towards the island and skipped across the harbour like a pebble and Bess was reminded of the opening credits of 'The Beachcombers"' (PMB 227).

Bess feels guilty at this moment precisely because she is so unexpectedly happy to have left her family, and because they are stuck in a difficult place while she is off enjoying the scenery and prosperity of the west coast. She also believes that she and Meg have no ties to this location and she has, as a result, become one of the tourists she expresses such clear bitterness towards in the earlier story. In comparing the landscape she sees to a television show like "The Beachcombers," Bess calls attention to the constructed experience of tourism, something she was cognizant of as it pertains to her cousins and is now even more aware of as an outsider to British Columbia. The title of the story reaffirms this idea: Bess discovers that British Columbia is a nice place to come as a tourist, but it is not her home. In making an implicit comparison between the two superficially idyllic spaces of Cape Breton and the West Coast, Coady makes a broader statement about the tourism industry here. Bess's experience of seeing tourists come to her hometown and tell her how beautiful it is while she lives in squalor informs her 
assessment of the West Coast. While other people might be seduced by this region's appearance of serenity and affluence, Bess is aware that this is a façade, and that turmoil exists under the surface, as it does in rural Cape Breton.

\section{Performing Violence in Saints of Big Harbour}

Just as "Play the Monster Blind" and "A Great Man's Passing" depict the sometimes-harsh treatment of outsiders by inhabitants of the Maritimes, so many of the characters in Saints of Big Harbour have a similarly conflicted relationship with the tourism industry. As mentioned in Chapter 4, Guy derisively describes Alison Mason as having come from the United States in the 1960s looking for a rugged wilderness in rural Cape Breton. Mason acknowledges that he is friends with Isadore because he is such an interesting and uniquely authentic specimen of Cape Breton's folk culture and says that he has only a "sociological" interest in the people who live in the region. Isadore fails to live up to the mythical status Alison attributes to him, just as the region as a whole fails to live up to the idyllic standard established by the tourism industry. In Saints of Big Harbour, Coady deconstructs conventional definitions of Cape Breton as nostalgic and tourist-friendly by accentuating the presence of violence in Big Harbour, satirizing the influence of the tourism industry in rural Cape Breton, and accentuating Guy's ambivalent relationship with his rural Acadian community.

Isadore expresses discomfort with the way in which the tourism industry constructs Cape Breton throughout the novel. Upset that Marianne leaves him in the apartment all day to work for the MacAskills, a family who lives in Big Harbour, Isadore 
mocks their family name, asking, "What do they think they are, a bunch of giants?" and linking them to Cape Breton's most famous sideshow:

He was referring to the legendary Giant MacAskill, the seven-foot-nine Scotsman who had lived in the 1800 s and whose massive wax likeness had graced the museum out by the causeway for years. Isadore had always thought this foolish, and often pestered Leland when he was the MLA to have the statue removed. The local freak show, Isadore called it. Isn't this a lovely image for the tourists to be carrying away with them, he had complained. Leland had assumed out loud that Isadore was just jealous of the one man on the island bigger than himself. (SOBH 347)

The comparison of Isadore and Giant MacAskill is significant, as it aligns Isadore with the monstrous portrait of John MacNeil from "Play the Monster Blind," making him another grotesque and oblivious father figure. That MacAskill is a wax statue found in a small museum suggests that the two giants stand as examples of an outdated and obsolete culture. The irony of all of this is that, in spite of his obvious and almost shameless performance of the traditional Cape Bretoner, Isadore resents the tourism industry's commodification of the region, evidenced by its promotion of a "freak" like Giant MacAskill in order to profit from the region's history and culture.

The image of tourists travelling to see the wax rendering of MacAskill's body also recalls Sheldon Currie's story, "The Glace Bay Miner's Museum" (1995), in which the wife of a coal-miner killed in a collapse displays pieces of his body for visitors. Both texts highlight a cannibalistic tourism industry that turns not only the material history but also the actual people of the region into attractions. In satirizing the tourism industry's 
impulse to put anything remotely saleable on display, the novel also makes an implicit connection between Big Harbour's marketing of its culture of violence - which, as I discuss below, takes place during the hockey playoffs - and the recent trend in the Maritimes of building museums that document the proud history of destruction exacted on them by industrial enterprises like the coal industry. ${ }^{6}$

\section{Violence and the Landscape}

In addition to specific statements characters make about the exploitative and demeaning aspects of the tourism industry in Cape Breton, the novel also makes a link between the violence that pervades this space and the image the region crafts for itself. Violence is a key aspect of Saints of Big Harbour; while it often appears randomly, the novel also examines the way in which it is connected with socio-economic class and ethnicity.

The novel's diffuse and always-palpable violence emerges most clearly with respect to Coady's treatment of hockey. Isadore is determined to "make a man" out of Guy by pushing him into bloody sports like hockey and boxing and encouraging his attacks on other players, the referees, and even spectators. Coady makes a broader social comment by linking the extreme violent streak that envelops the entire town during the hockey playoffs to a sense of pent-up frustration and depression that surrounds the town's economic prospects. The novel is populated by unemployed and under-employed male characters who drink excessively, berate their wives and daughters, and start fights with friends and enemies alike. As Ian McKay, Erik Kristiansen, James Overton, and others

\footnotetext{
${ }^{6}$ See, for example, Summerby-Murray, "Interpreting De-industrialized Landscapes" 49.
} 
argue, the tourism industry works to entrench serenity, safety and innocence as important facets of the region's external image. Officially sanctioned events like festivals (the Highland Games in Antigonish, the Pictou Lobster Carnival, and others) serve to legitimize and uphold this these notions.

Just as Coady satirizes male role models through Isadore's absurd performance as Guy's father, so she undermines the idyllic and peaceful portrait of the region by

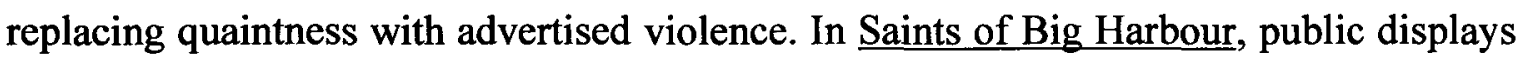
of the region's culture take the form of violent spectacles. For example, the hockey playoffs set off a series of confrontations between the towns of Big Harbour and Port Hull, including one between Guy and the local referee, Freeman Day, another between Guy and the mother of a Port Hull player, which leads to Isadore threatening to kill the woman, and eventually a series of ritualistic clashes that take place on the streets:

The town became a carnival of violence and the hockey rink was the main attraction, like a big tent pitched in its center. Leland offered absurd drink specials throughout the playoffs. Pitchers of rum - he never specified what brand - for $\$ 10$ on Thursdays, $\$ 1.50$ bar shots on Saturdays. People came and nearly killed each other every night. At four in the morning Mounties peeled them from the dance floor and the parking lot ...

Since the last game where Guy attacked the fat kid, the weekend dances in the area had become battlegrounds. With the playoffs, it only accelerated. Carloads of boys from Port Hull trawled one community hall after another, looking for players from Big Harbour, or else anyone wearing a Giants jacket. Big Harbour boys, in turn, drove through Port Hull at midnight, blasting Lynryd 
Skynrd and hurling bottles at storefronts and mailboxes. It all began with Guy's fight. ( $\underline{\mathrm{SOBH}} 77-78)$

The Bakhtinian term "carnival of violence" implicates the community as a whole in encouraging this kind of aggression. While writers often deploy the carnivalesque to subvert authority and established rules, Bakhtin and subsequent scholars on his work reveal that the carnivalesque is paradoxical, as its inherent humour and parody work to contain transgression. ${ }^{7}$ In Saints of Big Harbour, the hockey playoffs legitimize and celebrate a violent streak that the community promotes. In addition to public spaces like Leland's tavern being home to this drunken violence, figures of authority like Constable Gordie MacLellan excuse Guy's penchant for getting into fights by saying that it is completely normal for boys to need to prove their toughness (SOBH 302).

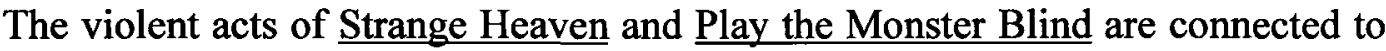
personal feuds, but in Saints of Big Harbour, aggression creeps into civic events. Coady deconstructs the idea that the region's small towns are idyllic by using public spaces like the local pub and weekend dances as the settings for these fights. Leland makes this violence even more public by replacing advertisements of drink specials on the tavern's marquee with disparaging comments about Big Harbour's rivals, such as "PORT HULL MARTYRS (the team was actually called the Saints)" (SOBH 78). The clash between the two towns takes on particular symbolic importance; their names (the Port Hull Saints and Big Harbour Giants) correspond with Isadore's two most prominent nicknames and implicitly link the violent performance of this rivalry with the Catholic Church and the

\footnotetext{
${ }^{7}$ See Rabelais and His World (1941), Lacombe, "Carnival" 517, and Hutcheon, $\underline{A}$ Theory of Parody 74-75.
} 
Giant MacAskill museum - which stand as symbols of two of Coady's most frequent satirical targets: the church's moral code and the tourism industry.

In ironically using the description "Saint" for the violent teenaged boys of Port Hull, Isadore, and the community of Big Harbour (by switching the town's team name in the novel's title), Coady aligns this patently false descriptor with definitions of the Maritime region as innocent and idyllic. Instead of conveying the pastoral and serene image of the Maritimes preferred by the tourism industry, Big Harbour puts this "carnival of violence," which the towns universally enjoy and officially sanction, on public display. Accordingly, destructive behaviour functions as a form of celebration and aggression as a symbol of both rage and happiness for Coady's characters, who instead of grudgingly tolerating violence, crave it, enjoy it, and treat it as a form of creative expression. The narrator describes, for example, Howard and Hugh's ritualistic search for fights: "They perfected the choreography of climbing out of the car at precisely the same time, unfurling their bodies, slamming their doors in unison for maximum intimidation effect. Drinking and driving around the back roads every weekend in their alternating outrage and exhilaration, Howard and Hugh wove together a sort of mythology involving Guy Boucher" ( $\underline{\mathrm{SOBH}}$ 311). Coady's characters often display an ambivalent relationship with violence: Howard and Hugh's mixed feelings of "outrage and exhilaration" match the simultaneous experience of fear and excitement Guy has while pummelling opposing hockey players at Isadore's request.

In Saints of Big Harbour, Coady discredits the tourist-friendly version of Cape Breton and replaces the performance of being down-home friendly and old-fashioned with the choreographed violence of Howard and Hugh and the rest of the community. 
The campaign against Guy is based on spurious gossip, the aggression that Howard and Hugh express is practiced, rather than spontaneous, and they mythologize their enemy, imagining that he will identify himself to them by displaying a "malignant halo" ( $\underline{\mathrm{SOBH}}$ 312 ), in order to intensify their rage against him. Although this event is central to the plot of the novel, it is clear that it is not the cause of the "nebulous rage that seemed to float over everyone's head" (ㅇBH 284 ): it instead simply provides a focus for the town's violent streak.

If nothing else, conventional definitions of Cape Breton as recuperative and fixed in time portray it as "safe." According to this description, Maritimers supposedly protect and value tradition, the family unit is there to provide comfort and support, and the type of violent crime common to urban centres does not exist. Coady undermines the portrait of Cape Breton as serene in this novel by calling attention to a protracted sense of hopelessness that engenders such violent behaviour and also to the racial tensions that exist in this space. Each of the text's primary settings, Guy's home (both the Aucoin house and the apartment Marianne rents in Big Harbour) and the school, are decidedly unsafe for Guy: Isadore terrorises him physically and psychologically at home, and he is subject to unpredictable, ruthless and racially-motivated assaults carried out by people like Howard and Hugh at school. Coady undermines the idyllic rendering of the Maritimes by calling attention to the presence of this kind of violence.

\section{Guy's Relationship with the Rural Maritimes}

In his addition to his struggle to free himself from Isadore's influence, Guy also displays a very ambivalent relationship with the space he occupies. In the first half of the 
novel, Guy is obsessed with the idea of leaving the rural Acadian community in which he grew up, and longs for the measure of anonymity the comparatively urban space of Big Harbour offers. He resents being born in rural Cape Breton, is happy when, after seeing television programs set in the United States, his mother tells him that "we sort of live in America, too" (SOBH 181), talks in glowing terms about the space of Big Harbour - he often calls it "Disneyland" (SOBH 8) - and longs for the day that he and his mother will leave their community: “And I keep wanting to say to Rene: I am moving. I am leaving here at the end of the summer. Sorry Rene, but I won't be from around here and you will. You'll be from here, and I will be from Big Harbour and that will be that" (OBH 166). Elsewhere, Guy basks in the feeling of being a stranger to the people in Big Harbour: "She kept yelling in my ear, 'You're not from around here, are you?' because I think saying it made her feel sophisticated but it also made me feel pretty cool, because I realized I could have been from anywhere, instead of just out in the sticks, out in Frogtown. That's what she was thinking, too. I could've been from New York for all she knew. Since the music was blasting, she probably never noticed my accent" ( $\underline{\mathrm{SOBH}} 7-8$ ).

In addition to her satirical treatment of conventional notions of space in Maritime Canada - which she aims at the machinations of the tourism industry and its treatment of the region as a serene, idyllic and old-fashioned locale - Coady also examines the way in which this construction of the region glosses over ethnic tensions. As Del Muise notes, Acadie plays an especially important role in the development of the Maritimes' cultural tourism industry, as popular literary works such as Longfellow's Evangeline: A Tale of Acadie (1847) established a sense of romance that surrounded the expulsion of the 
Acadians, attributed to contemporary Acadians a mysterious, old-fashioned and timeless culture, and instilled a belief in Acadie as a lost utopia (125-126).

In her review of Clive Doucet's Notes From Exile: On Being Acadian (1999), Coady criticizes his portrayal of the Maritimes' "quaint" Acadian communities: "chronic disenfranchisement doesn't seem to accord with his idyllic vision of Acadie. It's a tempting vision, without question: peaceful, pastoral folk united in their love of the land ... [however], Acadians always [seem] to be getting the dirty end of the stick when it [comes] to the economy, and in Atlantic Canada, it hasn't been a very clean stick to begin with" ("Acadian drifter" D18). ${ }^{8}$ While her fiction is imbued with the ironic edge of a writer sensitive to postmodern critiques of subjective experience, her literary journalism directly attacks sentimental portraits of this kind and points out that they run the risk of trivializing social cleavages like the racism directed towards Acadians in Atlantic Canada.

As I suggested in the previous chapter, ethnic tensions appear in sharp focus in Saints of Big Harbour. Guy is alienated from and bitter towards his cultural heritage. In the opening pages of the novel, Guy talks about the derisive treatment that he and other Acadian students receive from their history teacher, who "is English, from Truro or somewhere, and thinks it's hilarious to call everyone Monsieur this or Mademoiselle that when most of us don't even speak French" ( $\underline{\mathrm{SOBH}}$ 5). People from Big Harbour call the small community in which Guy grew up "frog-town," and Pam calls him a "fucking frog." The various forms of racism Guy faces has a profound effect on his experience of

\footnotetext{
${ }^{8}$ Doucet's The Priest's Boy (1992) offers a less than romantic portrait of Cape Breton in the 1930s. This collection accentuates the stifling presence of St. Joseph de la Mer's Catholic church and the desire of young men to escape the crippling poverty of this rural community.
} 
space; he wishes to get away from his Acadian roots, and expresses comfort in people being unaware of his ethnic background upon moving to Big Harbour.

As mentioned in Chapter 4, the novel makes an implicit link between socioeconomic class and ethnicity. Nowhere does this relationship between ethnicity and class emerge more convincingly than in Coady's portrayal of Marianne, who is a housekeeper for an affluent Scottish family in Big Harbour. In addition to the resentment that Isadore and Guy express towards her taking care of men other than them, Marianne worries that the MacAskills might disapprove of her working class Acadian family - she almost loses her job when Gordie MacLellan arrives at their house in a police car to pick her up for questioning - and treats them with a mixture of awe and respect. For example, when Guy notices that his mother carries around a portrait of the MacAskills, he is immediately struck by her admiration of Scottish culture: "But they just look like any family from anywhere, the kind of picture you see in the window of a camera store or somewhere, but my mother likes looking at the children. The baby is wearing a knitted cap with cat ears, and the boy is in a tartan vest. 'He's a little highlander,' says my mother. I don't know what that's supposed to mean ..." ( $\underline{\mathrm{SOBH}} 19)$.

In spite of the novel's clear condemnation of the racism directed at Acadians in Cape Breton, Coady retains her elusive political stance with respect to this issue. The text's satirical treatment of ethnicity emerges most clearly with respect to Isadore; in what Alison calls "Isadore Aucoin doublespeak" (SOBH 230), Isadore tells his friend that he "coulda been a lot of things if [he] was born with Mac at the front of [his] name and a doctor for a father and a tartan diaper to soak up [his] piss and a set of golf clubs shoved up [his] ass" ( 
expresses pride in his heritage and highlights the racist treatment of Acadians only when it benefits him directly, and downplays it at other times, as exemplified by his response to Gordie MacLellan's threats to arrest him for his role in a brawl at the tavern: "Ach,' said Isadore, falling into MacLellan's Gaelic accent. 'Boys will be boys"' (ㅇBH 301). Guy is ultimately ambivalent towards his own ethnicity. As mentioned above, he wants to disappear in the Big Harbour high school student body, he has no interest in learning French beyond the few phrases he uses with his family, and he laments his Acadian name and accent, because they make him susceptible to taunts and threats at the hands of other teenagers.

In the opening stages of the novel, Guy rejects the Acadian community in which he grew up and believes that he will be able to blend in with the rest of the inhabitants of Big Harbour. Guy's high hopes for moving into town are quickly dashed. Isadore follows them to Big Harbour, Marianne essentially disowns Louise because of her relationship with Dan C., and Guy unknowingly becomes the target of a police investigation and a vicious revenge plot perpetrated by Howard and Hugh. Although leaving the rural setting of the novel eases some of the racial tensions he feels, and does afford him an increased sense of anonymity, he discovers that Big Harbour does not offer him respite from his class-related anxieties or threats against his personal safety: "I used to think town would be the answer to all our problems, but it's not like that exactly. One day and all of a sudden I had everything I wanted. My mother, her job, the apartment, the school, the mall. The absence of Isadore. And her. A fifteen-minute walk away. And then I got the crap beaten out of me, worse than ever in my life" (SOBH 193). 
Coady presents the rural community in which Guy grew up and the urban space of Big Harbour as interchangeable and equally unsatisfactory for him. The last lines of the novel underscore the seductiveness of the mysterious space that exists beyond his rural community:

It was just that one great night I couldn't let go of, when we danced so many times and she didn't know who I was and she said that I wasn't from around here like it was the best thing a person could be. I couldn't get it out of my head. I never wanted it out of my head" (

The temporal focus of the final line is revealing. Guy seems to say that prior to this moment, he did not want to lose his feeling of belonging in Big Harbour, but at this point, after having seen all the trouble that Corrine and her fantasies have caused him, he is comfortable leaving that aspect of his life behind. He also mentions, "I didn't think I was ever in love with her or anything" (SOBH 413), suggesting that his infatuation with Corrine stemmed from his intense desire to feel that he had moved past the rural space in which he grew up. The final lines of the novel accentuate the degree to which, for Coady, conventional definitions of space are arbitrarily imposed: the novel undermines the nostalgic and pastoral representations of Acadie and other parts of rural Cape Breton; however, it also deconstructs the notion that the space beyond these places is cosmopolitan and sophisticated. The notion that Big Harbour is less violent, less racist, less marked by class difference, and less susceptible to the regressive influence of the family unit exists only in Guy's mind. 
Performing "The Folk" in Mean Boy

As mentioned in the previous chapter, Coady satirizes Jim Arsenault for fabricating a masculine working class persona. In this section, I argue that Coady's treatment of Arsenault also deconstructs conventional definitions of space in the Maritimes, in that he creates for himself a rural "folk" ethos that she parodies. Two other aspects of the novel contribute to this project: Larry's ambivalent relationship with the tourism industry, and the novel's portrayal of the violence of the natural environment, which undermines the idyllic image of Westcock University.

Mean Boy is a meditation on academic discourse and intellectual posturing. Arsenault is conflicted because of his intense need to be "authentic" and his professional success: he says that his experience as a working-class New Brunswicker shapes his poetic voice, even as he dismisses the "sing-songy industrial poetry" (브 33) emerging from the Maritimes during this time period, he lives in a run-down shack with no heat even though he is a professor, and he preaches to his students that regionalism is a militant political project while aligning himself with phony nationalists like Abelard Creighton. Larry says that although Jim could have, supposedly, settled anywhere in the country on the back of his national and international reputation as a poet, he chose Timperly "because he is a native New Brunswicker himself, and his poetry testifies to his reverence toward the land and its people" (MB 36). In positioning himself as the spokesperson for rural New Brunswick and its inhabitants, Arsenault creates a role for himself that matches Ian McKay's description of "the folk": he lives a pre-modern life in a run-down farmhouse with no hot water, he brags about his ability to live off the land, 
and he dismisses the cosmopolitan aspects of Westcock University in favour of the backwoods. In satirizing Arsenault's attempts to achieve this image and accentuating the lengths to which he goes to construct it, the novel undermines the idea that the Maritimes is home to an antimodern culture with close ties to the land.

As mentioned in the previous chapter, Larry and Jim occupy unequal class positions. The novel is sympathetic to Larry's parents, who struggle to make a living from their small motel business, and is unfavourable towards Arsenault, who constantly rants about being "authentic" while living a fabricated life in the woods, in spite of his comfortable middle-class social status. When Larry visits Jim's house for the first time, he is shocked to find out that his professor lives without an electric stove or microwave and chooses not to use his furnace, relying instead on a wood stove for heat.

While Larry expresses a confused sense of respect for Arsenault's woodsman's lifestyle during his first visits to his house, by the end of the novel, he realizes it is a charade: "So this is how Jim lives, I thought. I imagined having a bath - immersing myself in a tub of hot water - but remembered there was no bathtub. Jim was a professor at Westcock University, the most respected under-graduate college east of Ontario. He had a full-time job, an expectation of tenure. Why did he live like a goddamn pioneer?" (MB 375). The word "pioneer" is telling here: it refers to the notion that the Maritimes retains a pre-modern culture that is an extension of the region's early settler society, one that harvested resources from the land. Coady satirizes Arsenault for his deliberate and self-important attempts to tap into the Maritimes' folk culture. Like the tourism industry and regional elites, he pretends that modernity does not exist in the region, or at least that 
it does not fit there, and he looks to capitalize on this sense of cultural distinctiveness that he creates.

While Jim positions himself as a member of the working class in order to bolster his "authentic" image, he also aggressively denies his own possible Acadian heritage and teaches his students that taking pride in their cultural background is an academic pretension. In arguments with his Acadian classmate, Claude, Larry sarcastically calls Acadie "the Promised Land" and ridicules his friend's father for being "all politicised" about his ethnicity (MB 16-17). Elsewhere, Larry calls Claude an "Acadian cocksucker" and hopes that Jim has overheard him, as it would no doubt "make him proud" (MB 18). The novel provides only vague and fleeting references to Arsenault's personal history: he was born and raised in New Brunswick, he moved to Paris for an unspecified period of time when he was 17, he completed his B.A. and M.A. by the time he was twenty nine, and he lived in Toronto until two years before Larry decides to attend Westcock. While he lives, writes, and teaches in English - at, significantly, an English university in New Brunswick - his surname is distinctively Acadian. Whereas Saints of Big Harbour brings out the complexities of Guy's Acadian identity, highlighting his bitterness at being targeted for it and his struggle to come to terms with his family history, in Mean Boy, Coady's treatment of ethnicity is limited to the few insults Larry directs at his classmates and her use of the name Arsenault. Nowhere are the problems inherent in making this choice without fleshing out Jim's relationship with his ethnic heritage more apparent than when Larry mistakes Jim's screams of "arsehole" at Sparrow after being denied tenure for "Arsenault" (MB 10). The novel seems to gloss over Arsenault's background and does not address the contradictions involved in his decision not only to recast himself as 
English and mock students who take pride in their own ethnicity but also adopt an exaggerated "folk" persona.

\section{Deconstruction of the Tourism Industry}

Coady also subverts the idyllic image of the Maritimes through Larry's conflicted relationship with the region's tourism industry. When Larry accompanies Dermot Schofield from the train station to the Crowfeather Inn, he comes into contact with people who, like Jim, attempt to conform to this image for personal gain. The Crowfeather is a Victorian home once owned by Timperly's most prestigious family, the Graysons, which has been bought by a group of Americans, to whom Larry refers as "hippies," and remodelled into a quaint, tourist-friendly bed and breakfast:

It was revealed at that point that the two American hippies were rich - had more money than they knew what to do with. The commune had been like a hobby to them, and now starting up the Crowfeather was their hobby. This annoyed locals who were further annoyed to see how well the inn did. People made fun of it initially, just as they had made fun of the commune. But the hippies took out ads in Harper's magazine and The New Yorker. They made Timperly, New Brunswick, a summer holiday destination - something no home-grown entrepreneur had ever accomplished. Still, locals disdain the place, say that it is big-feeling. They feel obliquely ripped off by the Crowfeather Inn somehow. It's the Westcock crowd that keeps the place going - sucking up the antiques, the opulence. (MB 123) 
Larry's description of the conflicted relationship between the "locals" and the Crowfeather Inn not only sheds light on the controversial role the tourism industry plays in rural New Brunswick but also asserts the university as an ambivalent space. It does so by calling attention to the class discrepancy between the people who work at and attend the university as well the people who own and frequent the hotel, and the people who actually live in Timperly.

Just as Strange Heaven and Play the Monster Blind interrogate the benefits of the Maritimes' ubiquitous tourism industry, in Mean Boy, Coady again explores the problematic relationship between residents of the region and visitors to it. Although her portrait of the Crowfeather Inn is much more ironic and sympathetic than, for example, her construction of the Cabot Trail in "Play the Monster Blind," in that she seems to satirize the locals for being jealous of the inn's success at the same time as she is critical of people who move to the town and capitalize on its folksy charm, the novel clearly condemns New Brunswick's tourism industry for misrepresenting both itself and the region. The inhabitants of Timperly resent the Crowfeather Inn because the people who own it sell to their customers not only a room at a hotel but also an image of the lifestyle that exists on Canada's East Coast. In the ads that they take out in The New Yorker and Harper's, the owners of the Crowfeather portray the region as old-fashioned and backwards, regardless of whether or not this is an accurate depiction of the Maritimes.

Like Arsenault, the people who own the hotel work hard to uphold this image. When Larry and Schofield arrive, they find out that Arsenault has not made a reservation or paid for the room as promised, leaving his friend to foot the bill unexpectedly. In addition to being humiliated because of Arsenault's intentional "oversight," Larry, whose 
family also works in the hotel business, is horrified when the clerk requires that Schofield provide a deposit for the room. Although Larry sets off a conflict with the clerk by challenging this practice and telling him that "it seems a little mercenary" (MB 125), the man at the desk still greets Schofield with practiced down-home charm:

“On your way somewhere for Christmas?"

"To Nova Scotia, yes."

I peer at the desk guy to see if he's an American hippie. But he's leaning on his counter, getting comfortable, prepared in that Maritime way to talk all night long about geography and weather systems.

"Where in Nova Scotia, now?" His accent grows folksy now that he knows he's not dealing with an Upper Canadian or someone from the States. "I've got a sister up in Yarmouth," he proffers.

"Down Antigonish way," Schofield obliges.

"The Highland Heart of Nova Scotia," recites the desk guy, quoting some tourist brochure from days gone by. (MB 123-124)

The most significant part of this exchange is that after Larry wonders to himself whether or not the desk-clerk is an American hippie or a local, the answer to that question suddenly becomes irrelevant. When the clerk launches into his rehearsed routine about Antigonish being the "Highland Heart of Nova Scotia," a trite description found only on road signs and in dated tourist brochures, he reveals himself to be, like Arsenault, adopting the persona of the welcoming and folksy New Brunswicker for the purpose of selling product. 
In keeping with the novel's exploration of the representation of concepts like regionalism, the folk, and landscape in the literature and academic writing that emerges

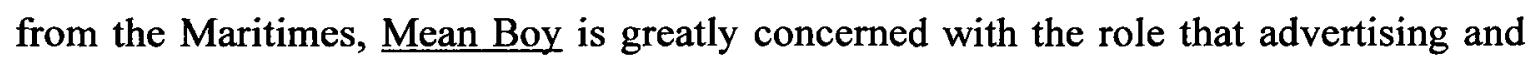
other forms of discourse play in constructing the experiences of New Brunswick's people, the natural environment, and the region itself. Coady aligns the way in which the Maritimes is constructed as a region with Arsenault's creation of his own persona through his writing and lectures. Just as characters from outside the region often buy into the notion that the Maritimes is old-fashioned and backwards, so Larry at first accepts Arsenault's affected persona but eventually sees its cracks. Larry's eventual discovery of the dark side of Arsenault's personality is tantamount to Bethany's discovery that everyone from Cape Breton is not armed with a fresh cup of tea and an interesting story for the benefit of tourists.

In challenging the desk clerk's legitimacy as a Maritimer, Larry brings into focus the question of ownership of the land as it pertains to the relationship between inhabitants of the Maritimes and the natural environment. Coady positions the Crowfeather Inn as an in-between space. Its Victorian décor, and the fact that it was built by a member of the Grayson family, all point to its conflicted relationship with the colonial project of settling the region. The name "Crowfeather" calls attention to the erasure of aboriginal peoples from the region. In choosing this name, the proprietors co-opt a symbol of the aboriginal community in order to entrench their claim to the land, but in doing so obscure the area's actual history.

Here, Larry expresses an anxiety common to residents of the Maritimes when he questions the right of "American hippies" not only to purchase property "rightfully" 
owned by inhabitants of the region but also attempt to capitalize on the image of the East Coast as idyllic. In this sense, Larry connects his own objections to idealized renderings of the Maritimes to a larger capitalist economic order, one that uses relentless advertising, product positioning, and the appearance of quality to produce profit. In creating this portrait, Coady demonstrates that the tourism market works in a similar way in places like Timperly, New Brunswick: by reciting practised lines culled from a brochure, the desk-clerk inadvertently reveals that this version of the Maritimes is a manufactured façade.

Coady also uses Larry's relationship with his parents and his condemnation of their chosen profession to comment on the tourism industry that is so prominent in the Maritimes. Like Bridget's father in Strange Heaven, Larry's parents rely on tourists who pass through Prince Edward Island for their livelihood. Larry is embarrassed because of this for two reasons: not only does the motel business make his parents dependent on and, as an extension, subservient to, wealthy visitors to the region, but it is also a tacky, lowrent industry - one that infantilizes the culture of the Maritimes. Larry frequently rails against the Maritimes' omnipresent tourism industry, which, he writes in one of his earliest poems, has turned PEI into a "“Phony Island of the Mind"” (MB 135). Although Coady condemns the exploitative and counterfeit aspects of the region's tourism industry, she also satirizes Larry for his rejection of his parents and their business venture. As I suggested in the previous chapter, Larry's affirmation of his father's advice in the final lines of the novel, as well as Coady's juxtaposition of Arsenault's affectations with the Campbells' common sense, undermines Larry's arrogant denunciation of his parents' working class lifestyle. 
The novel's treatment of the spatial markers of New Brunswick and PEI, which results in an implicit challenge to the region's narrative of serenity, turns into a broader exploration of the tourism industry in the second half of the novel, when Larry submits a series of poems about the Hollywood House of Horrors to Schofield. The Hollywood House of Horrors is a tourist attraction in Summerside that Larry and his friends visited as children. In the novel, it is a wax museum that houses monsters and villains from American films, and "[s]pikes through heads ... Brains, dripping. Women pinned spreadeagled on tables, naked. Working Guillotines. Expelled eyeballs, dangling from heads" (MB 304). Larry says that "[t]he main exhibits of the Hollywood Horrors used to give me nightmares as a kid, just like everyone else I grew up with" (MB 303). After reading the poems, Schofield tells Larry that "[t]hey really evoke the notion of childhood as a kind of Gothic landscape. This wax museum, it's a great metaphor. The intermingling of glamour with the grotesque." (MB 367). It is in this passage that Coady's deconstruction of the tourism industry in the Maritimes emerges most clearly. Larry's experience of PEI's tourism industry is unsettling on several levels: he despises the role his parents play in it, he sees it as antithetical to authentic creativity, and he fears that it is a signal of the threat of American mass culture. He expresses his profound animosity towards this institution in his poems, which portray the tourist experience as confusing, sensationalistic, and ultimately disturbing.

In spite of this, however, he is shocked to hear that Schofield did not visit the Hollywood Horrors on his trip to Summerside, which indicates it is still seductive for him. The Hollywood Horrors is loosely based on two institutions in Cavendish: the Ripley's Believe it or Not! Museum, which offers a full skeleton of a stegosaurus and a 
twenty-foot replica of the Berlin wall, and the Royal Atlantic Wax Museum, a more conventional tourist attraction that houses wax figures of Elvis, Madonna, US presidents, and Anne of Green Gables. While Larry's poems mix glamour with the grotesque, Coady's novel mixes familiar markers of region with mass culture, implicitly aligning regional symbols such as Anne of Green Gables with massive, global ventures like Ripley's Believe it or Not. While Larry's description of the terrifying aspects of the exhibit calls attention to the violence of the tourism industry, the fact that people travel to Summerside in order to look at depictions of Hollywood films, instead of the beautiful scenery or distinctive culture of the region is a more persuasive denunciation. Just as the clerk at the Crowfeather Inn's affected Maritime personality dislocates notions of authenticity at a personal or cultural level, PEI's homegrown culture being trumped by the homogeneous detritus of US mass culture in Summerside undermines many of this industry's basic tenets. The "local freakshow" of Saints of Big Harbour becomes, in Mean Boy, an international freakshow, one that serves to further deconstruct claims to an old-fashioned and pastoral way of life in the Maritime provinces.

\section{Treatment of Westcock}

In addition to confounding the seemingly clear spatial boundary that exists between PEI's "schlock" and Westcock's idyllic scenery, Coady also undermines pastoral images of New Brunswick throughout the novel. Although Larry and his classmates live in picturesque beauty on the Westcock campus, a setting that incorporates the rugged splendour of the Tantramar Marshes with nineteenth-century Maritime architecture, Larry insists throughout the novel that there is a disconnect between 
peoples' expectations of what an experience of nature might look like in this place and reality:

It's sunny, bright. A postcard autumn New Brunswick day. You'd think that would be good.

A fat mama squirrel appears at the window and stares at me. I know this squirrel. I used to be quite fond of her, in fact, her and all her brood, but now I think the squirrel can fuck off ... When I went home for the long weekend, I decided to keep my window open a crack and lined up a few peanuts on the sill, just so they wouldn't miss me too much.

Well, I got home and the little bastards had ransacked the apartment. They tore up my Humpty Dumpty stash and boxes of cereal, and shat on my kitchen counter.

So that was it for me and nature. I never opened my window to the squirrels again. Every once in a while Fat Mama still shows up and gives me an indignant glare, just as she's doing now, as if to say, "We're squirrels, you know? Vermin." (MB 20-21)

This portrait of Larry becoming friends with a particularly nice squirrel who looks as if she should be in a fairy-tale rather than on his windowsill, letting the animal into his life, and then being betrayed by its rude and filthy behaviour is, in many ways, a perfect example of Coady's treatment of nature in her texts. In this instance, Larry specifically mentions that this is the kind of day that lives up to New Brunswick's aesthetic standards as dictated by the tourism industry in the form of post-cards; however, he quickly discovers that nature is violent and unpredictable, rather than easily controllable. 
Coady also juxtaposes Westcock's idyllic landscape with portraits of the underbelly of Timperly. On the same day on which Larry takes offence at the use of the word "rustic" to describe "tomatoey" stew by the proprietors of the Crowfeather Inn, he complains that it is equally inappropriate to label Timperly idyllic. He compares the recently fallen snow to "dandruff" (MB 173), and describes the town's most popular bar as a wasteland: "Inside the bar are bodies and smoke, a blue apocalyptic fog looming over everyone's heads. I push my way through assorted human limbs: arms and shoulders, backs and asses. It's an apocalyptic scene in general, reminding me of those paintings by Hieronymus Bosch, the suffering sinners on Judgement Day - what my grandmother's daydreams probably look like" (MB 171). Larry's comparison of supposedly quaint Timperly to the work of Hieronymus Bosch, art that features horrific landscapes, terrifying amalgams of human and machine, and frenetically violent confusion, accentuates the discrepancy that exists between officially-sanctioned evaluations of this space and reality.

The violent relationship between the text's space and the people who live on it manifests itself not only in the ambivalence characters feel towards the university, the region, and tourist attractions in the Maritimes but also in their relationship with nature. In spite of pastoral descriptions of the relationship between the region's inhabitants and

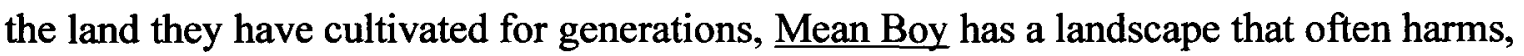
rather than nurtures, people, and a cast of characters who treat the land with hostility. For example, during one of his visits to Arsenault's house, Larry finds his professor locked in a battle with the crows that populate his back yard: 
Jim had a complicated relationship with the crows, it turned out. He had just finished shooting one out of the sky, on behalf of his dog. They "teased" Panda, he told me. Because crows, he said, are smart. They are cruel and cunning and they know dogs are stupid, so they tease them. Crows, he said, have a particularly malicious sense of humour ...

Jim hung the mess of crow from a tree, giving it a jaunty poke in order to make it swing. Blood sprinkled itself around. He told me the other crows would take this for a warning and keep their distance. It seemed to me he was talking out of fairy tales. Panda was going insane at our feet. The dog seemed to have been convinced that Jim would at some point hand over the crow for Panda to devour. Seeing it suspended out of reach - swinging and sprinkling away - added insult to injury. (MB 213)

Many of the novel's characters share Arsenault's "complicated relationship" with the natural world, often complaining about cruel treatment at the hands of the region's weather patterns. Coady specifically parodies the idea that a pastoral relationship exists between the region's inhabitants and the land. Although Arsenault talks about his romantic reverence for the natural landscape, he sadistically kills crows out of a bizarre sense of retribution, displaying one of their maimed carcasses in order to send a message to their counterparts. Larry's description of Jim's plan as a "fairy tale" accentuates Coady's satirical treatment of the region's romanticized space. 


\section{Conclusion}

As mentioned at the beginning of this chapter, Ian McKay has argued that in the middle of the twentieth century, the tourism industry and artists from the region "naturalized" an image of the Maritimes as idyllic and therapeutic. Such landscapes play an important role in conventional ecocritical studies, as ecocritics often valorize pastoral imagery and nature writing in their search for environmentally sensitive texts. Coady's fiction consciously disrupts the idealized landscapes propagated by the Maritimes' tourism industry and earlier writers from the region. As I suggested in the previous chapter, Coady deconstructs traditional social and familial relationships that for her are problematic in part because they secure the persistence of restrictive gender roles.

Each of the three definitions of nature that Coady identifies and undermines rely at least partly on notions surrounding the loss of tradition in the Maritimes that has taken place over the last hundred years. Bridget and Janet use subversive strategies like extreme apathy and duping family members to contest the pressures their families and communities place on them to adhere to conventional gender roles, calling attention to the need to discard such traditions. John MacNeil, Isadore and Jim Arsenault push their brand of masculinity on John Jr., Guy and Larry so forcefully in part because they see themselves as vestiges of a working class culture that is under threat. The Maritimes' tourism industry counteracts this in two ways. It satisfies North American society's anxieties over urbanization and modernization and the resulting loss of rural culture by providing a place where members of the middle class can experience a pre-modern culture. It also purports to offer a solution to the economic problems that accompanied 
deindustrialization in the region. In Chapter 6, I argue that Coady identifies the toxic landscape of Cape Breton as one of the major consequences of the collapse of the region's economic base that took place as a result of deindustrialization. In her fiction, the often harmful and exploitative corporations that have replaced resource industries capitalize on the decline of traditional occupations by using these economic circumstances to skirt safety and environmental regulations. 


\section{CHAPTER 6: COADY'S POST-INDUSTRIAL CAPE BRETON}

In the previous chapter, I argued that Lynn Coady consciously subverts the idyllic portrait of the Maritimes' landscape often advanced by the tourism industry and present in earlier writing from the region. James Overton observes that the process of deindustrialization created an identity crisis in Atlantic Canada in the twentieth century, as distinctive regional lifestyles associated with the fishing, farming and mining industry disappeared (63). As natural resources such as coal, fish, and timber that once fuelled industrial growth in the region declined, government and corporate leaders looked to replace them with tourism and service-based ventures which they market as the answer to the region's present economic problems. In addition to the rise of ideas surrounding the region's pre-modern culture, the post-industrial era also saw significant destruction of the Maritimes' natural environment, particularly in Cape Breton, which is home to highly toxic abandoned industrial sites such as the Sydney tar ponds. In her first three works of fiction, Coady constructs a post-industrial Cape Breton that is scarred by excessive resource-exploitation and the waste products of manufacturing. ${ }^{1}$

Drawing on the ecocritical method outlined in Chapter 3, this chapter demonstrates that Coady's focus on toxic spaces undermines definitions of nature as pristine wilderness. Coady's fiction, like other contemporary writing from the Maritime region, embodies a "toxic consciousness" in which her characters find that the landscape that surrounds them is dominated by pollution and industrial waste. Coady's ambivalent

\footnotetext{
${ }^{1}$ As mentioned in Chapter 1, this chapter will focus only on Strange Heaven, Play the Monster Blind and Saints of Big Harbour. Mean Boy is Coady's only novel which is not set in industrial Cape Breton and instead takes place in the university town of Timperly; therefore, the novel does not include descriptions of the pollution produced by pulp and steel mills.
} 
construction of post-industrial Cape Breton complicates traditional ecocriticism's project of valorizing wilderness and ignoring human-occupied spaces, as her characters often see the region's effluents as a permanent feature of the landscape.

Coady, in a 1999 column in This Magazine, identifies what she calls a culture of "half-formed expectations" in the post-industrial Maritimes. She contrasts Cape Breton's sense of dependency with the feeling of entitlement exhibited by inhabitants of cities like Toronto and Vancouver. She argues that Cape Breton's masculine culture, which dismisses people who dare to complain about yellow arsenic "goo" seeping into their basements as "wimps," also conditions people to accept things such as untreated sewage in their backyards, skyrocketing cancer rates and endemic unemployment. This anecdote about arsenic appearing in basements on Sydney's Frederick St. in the late 1990s, an incident that dominated the city's editorial pages at the time and remains a defining moment in the fight to clean up Muggah's Creek, is indicative of the degree to which toxicity dominates the lives of residents of post-industrial Cape Breton.

In this article, Coady argues that the region's environment and inhabitants are equally at risk at the hands of a governmental and corporate culture that is desperate for any kind of development. Coady notes that in attempting to exploit what remains of the region's natural resources, industrial developers and the government appeal to the economic woes caused by deindustrialization as an excuse for circumventing safety and environmental standards in new projects. She goes on to state that earlier generations of popular artists from Cape Breton not only overlook such problems but also are complicit with government and industry in hiding them. She says that Rita MacNeil, for example, 
hardly sings about Sydney at all, come to think of it, and she doesn't sing about Port Hawkesbury either, my hometown, all by itself one of the biggest polluters in the province of Nova Scotia. I read only recently about the detrimental effects of sulphur to the health. That whole damn town smelled of sulphur every wet day of the year. Rotten eggs wafting through your window on a rainy morning.

But what would become of Port Hawkesbury if it weren't for the sulphurspewing pulp mill? It certainly wouldn't be the boom town it is today with three Tim Horton's and a mall and a brand new Canadian Tire and, as of a couple of years ago, even a McDonald's.

The truth is, Port Hawkesbury is hanging on by its fingernails, and has been for as long as I can remember. So is the rest of Cape Breton. We are one step away from Newfoundland's economically induced diaspora. Industry — big, smelly, nasty industry in particular — is the only thing keeping us going. Everybody knows it. Environmentalists are not a welcome breed in Cape Breton. Any implicit threat to our industries has the same emotional impact as a loaded gun being pointed in our faces. Industry knows it. Government knows it, too. ("There's No Place Like Home" 32)

Coady's fiction embodies this conflicted relationship with corporate and industrial activity in the region. Characters in Strange Heaven, $\underline{\text { Play the Monster Blind and Saints of }}$ Big Harbour accept and even at times seem to celebrate the presence of companies that exploit them and industries that pollute the environment and harm workers. In her journalistic work, Coady connects the pollution present in the Maritimes with the rise of an insidious service sector that pushes toxic food on residents of the region and quells 
union organizing. ${ }^{2}$ In Coady's fiction, corporations such as Tim Hortons and McDonald's not only oppose unions and exploit workers through low wages but also create products to which her characters refer as "trash."

In "As For Me and Me Arse: Strategic Regionalism and the Home Place in Lynn Coady's Strange Heaven," Herb Wyile argues that the novel is evidence of contemporary Atlantic Canadian literature's retreat from the comforts of community and the pride of the industrial and resource-based economy, which has been replaced by the service sector:

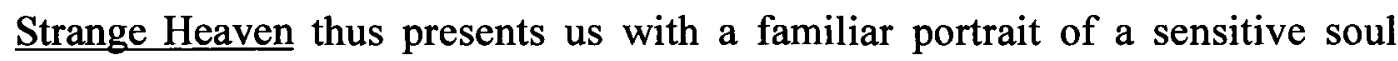
straining against the prevailing mores of a small town, not in the pastoral, romantic, premodern Maritime landscape but in a "fallen" postmodern world of welfare apartments, tabloid violence, and donut shops - call it Anne of Tim Hortons. (190)

A crucial aspect of the new, subversive writing that has emerged from the region is the way in which it internalizes the faceless and even sinister elements of the Maritimes' corporate culture. The fact that Green Gables is the name of a chain of convenience stores common in the rural Maritimes which Sobeys Inc. took over in the 1990s makes this even more ironic.

The term "Anne of Tim Hortons" refers not only to the process by which corporate development has made the region's distinctive topography homogenous but also Cape Breton's most famous "fast-food murder," the horrific shooting that took place at a

\footnotetext{
${ }^{2}$ See Sacouman and Veltmeyer, From the Net to the Net: Atlantic Canada and the Global Economy (2005) and Workman, Social Torment: Globalization in Atlantic Canada (2003).
} 
McDonald's in Sydney River in 1992 - an event which almost certainly inspired the murder of Jennifer MacDonnell that Bridget's mother describes on the first page of Strange Heaven. By having this incident take place at a donut shop, Coady also calls to mind a 1998 episode where locals claimed to see the face of Christ on the wall of a Tim Hortons outside of Sydney, which she alludes to in an essay written in This Magazine:

But back home, it almost seems more expedient to park your arse in the parking lot of the A\&K Lick-a-Chick across the street from the Tim Horton's and await the reappearance of Christ on the outside wall, see if He can't do anything about it. (His image disappeared, to the consternation of all, when they changed the outdoor light bulb, but hope springs eternal in the hearts of those who would invest their life's savings in Atlantic Lotto Inc.) ("There's no place like home" 32)

Coady's description of this religious experience suggests that life in contemporary Cape Breton offers the people who live there what she sees as three equally unappealing and futile options: the church, the lottery, and the service sector which has replaced the mines. The above quotation is also significant because, like the term Anne of Tim Hortons, it calls attention to small businesses threatened by multinational corporations. In this case, Coady juxtaposes the A\&K Lick-a-Chick, a local chain of fried chicken stands found in such places as Bras D'or and Sydney Mines, with the fast-food giant Tim Hortons.

By invoking Cape Breton's long, often violent, and proud history in the labour movement, Coady implicitly makes reference to the service sector's penchant for low wages and resistance to union organizing. For Coady, this represents a new and less apparent form of exploitation. Strange Heaven examines the fallout from Cape Breton's 
experience of deindustrialization: the often vicious clashes between unions and the management of the coal companies ended when the mines closed, and the novel's physical and emotional landscape is shaped by this experience. Strange Heaven's Cape Breton is marked by hopelessness, substance abuse, the advent of an entrenched service sector, and a different strain of hostility.

Corporate symbols appear in Coady's fiction as records of lost industry in the region. For example, in "Play the Monster Blind," Bethany notices on her trip around the Cabot Trail "little stores with Pepsi-Cola signs from the early seventies in the windows, the red in the logo faded pink and the blue now a sick green" (PMB 20). This description emphasizes the sinister effects of capitalism's push to commodify everything. When areas such as rural Cape Breton cease to be economically useful, large corporations simply leave them behind. Here, this advertisement provides a calendar record of the region's economic fortunes: since it is dated so specifically, it reveals an approximate historical timeline of Cape Breton's economic downfall. Companies like Pepsi-Cola once saw fit to maintain a presence in the region; however, as the decline of Cape Breton's economy intensified throughout the second half of the twentieth century, the island came to be forgotten by even the most ubiquitous of North America's multinational corporations. Faded corporate signs and other relics of failed capitalist development are public examples of the waste left behind by deindustrialization and stand as a constant reminder throughout Coady's texts of the economic turmoil that took place in Atlantic Canada in the twentieth century. 


\section{Toxic Consciousness and Contemporary Maritime Literature}

As Lisa Garforth observes, recent environmental philosophy destabilizes the seemingly clear boundary between natural and artificial. Like social constructionist environmental philosophers Donna Haraway, William Cronon, and W.J.T. Mitchell, she argues that our understanding of concepts like nature, the body, wilderness, and landscape is inextricably linked to the various political and cultural agendas that skew the gaze with which we look upon them. She writes:

In contemporary social and cultural theory the distinction between "external" nature and the "inner" natures of the body is seen as increasingly unstable, dissolving in the experience of social life in conditions of widespread environmental risk (to natures, to bodies) and the operations of global technoscience, so that the materiality of nature/bodies and ideas about selves and environments are imbricated in ever more promiscuous and hybrid relationships. Nonetheless, the imagination of a material and external nature, separate from and indeed conceptually constitutive of a distinctive human nature and culture, is of course deeply embedded in modern and postmodern Western societies. (5)

Because of the common-sense status the threat of ecological disaster has assumed in the popular imagination, attaching a kind of hyperrealism to nature generally stands up even to postmodern critiques of language and experience. Garforth suggests that this is problematic because conventional environmental thought often revisits many romantic constructions of nature (6). Like Cronon, Garforth argues that by fetishizing pure wilderness and pushing for it and only it to be protected by the environmental movement, 
many critical theorists overlook spaces that are being, or have been, used by human society and leave already intruded-upon and polluted spaces unproblematized.

This reading is especially pressing because, as Cynthia Deitering points out in her 1996 article, "The Postnatural Novel: Toxic Consciousness in Fiction of the 1980s," late capitalist Western society has shifted from being a "culture defined by its production to a culture defined by its waste" (196). She argues that this shift is present in American fiction of the 1980s, as writers like Thomas Pynchon and Don DeLillo expressed in their fiction fears about the future of an increasingly toxic world and warned that the logical endgame of unrepentant consumerism is a trash-covered planet. She writes that North American fiction is now home to a

"toxic consciousness" [that depicts] a society that has fouled its own nest; hence, the pollution of the natural world, as represented in these novels, inevitably transmogrifies one's experience of the earth as primal home. A number of characters in these texts express the peculiar displacement of a generation poised on the precipice of an epistemologic rupture ... Whereas the literary construct of nature during much of the nineteenth century mirrored that of a society with a profound need of nature as a spiritual healer, and the literary conception of nature for much of the twentieth century mirrored that of a society which valued nature as an economic resource, the most recent literary version of nature reflects that of a society which at some level understands itself to be living in what Bill McKibben has termed a "postnatural world." (200-201)

Deitering maintains that a hallmark of fiction that embodies this "toxic consciousness" is 
the presence of characters who work out their identity in the world through their relationship with waste, rather than with "natural" features of the environment like plants and animals. Deitering also observes that "toxic consciousness" is often ambivalent, in that characters respond to the wrecked landscape by seeking out highly sanitized or artificial spaces.

In her 2002 article, "Toxic Subjectivity: Gender and the Ecologies of Whiteness in Todd Haynes' Safe," Susan Kollin argues that contemporary authors and film-makers display a conflicted response to North America's toxic landscape. While texts marked by this "toxic consciousness" on the one hand represent pollution and industrial waste as permanent features of a gutted environment, their characters also display a longing for "hyper-sanitized" and often overtly artificial representations of the natural world. Kollin

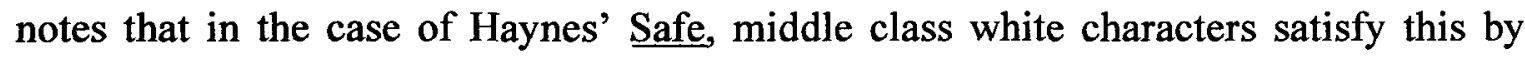
retreating to highly cultivated and pristine gated communities and suburbs and by "[fetishizing] certain idealized landscapes, particularly those places perceived to be unsullied and undiminished by human culture" (125).

This ambivalent "toxic consciousness" is present in contemporary works of Maritime fiction such as Leo McKay's Like This (1995), Christy Ann Conlin's $\underline{\text { Heave }}$ (2002), David Adams Richards' Road to the Stilt House (1984), and as this chapter demonstrates, especially in Coady's texts. These works are representative of a major shift in contemporary Maritime literature in which the identifying marks of region have moved from the distinctive topographical and cultural features of the Maritime provinces to the gutted features of a landscape ruined by industrialization. In associating their memories 
of home with violence and cultural alienation, the characters of these texts replace the nostalgia that characterized mid-twentieth-century Maritime literature with a sense of outrage at an economic system that has extracted every possible morsel from the land and left behind only the waste-products of industrial development. For example, McKay's "A New Start" details a trip in which a father brings his children with him as he searches for bottles that can be refunded for "liquor money." The story also features forgotten Pepsi and Coke billboards that symbolize the memory of failed capitalist development in the region.

This "toxic consciousness" is present also in Conlin's novel, $\underline{\text { Heave. }}$ Heave is the story of Serrie, who has recently had a nervous breakdown and is in the midst of attempts to adjust to life with her family in the Annapolis Valley after leaving the hospital. The

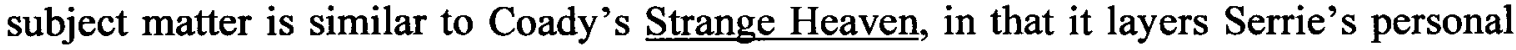
struggles over obvious emotional dysfunction within her family and the experience of her community's gradual economic and social collapse. Throughout the novel, there are references to the dying fishing industry, the continued loss of industrial development in the Valley and the distressed post-industrial landscape of urban Halifax. The most enduring image of waste in the novel, however, is the collection of outhouses that Serrie's father keeps on his front lawn:

The yard at our place on the Lupin Cove Road has outhouses everywhere now. I can never figure out how my mother feels about the outhouses, one day complaining how ridiculous they look and the next day going out and weeding the gardens around them. Percy calls them artifacts, "my father collects artifacts he's sort of an amateur anthropologist-archaeologist," I hear him say on the phone 
to some guy the second he is home from university. And he does collect them; our father hunts the outhouses down all over the province, towing them home on a trailer, then setting them on the lawn fixing them up. (Conlin 102)

The outhouse-filled garden plays an important role in the novel, as it is where Serrie goes to think, read and escape social interaction. Contemporary Maritime fiction, much like the novels that Deitering identifies, is cognizant of the durability and ubiquity of western society's detritus. In the novel, this waste seeps into living spaces - particularly in places where the industrial complex has taken flight, leaving behind only that which is unusable.

A similarly bleak and unyielding portrait of post-industrial life in Atlantic Canada emerges in David Adams Richards' 1984 novel, $\underline{\operatorname{Road}}$ to the Stilt House. The disintegration of both the local economy and the local landscape provides the backdrop for the action of the novel, which consists primarily of conflicts between the main character, Arnold, and his family. Richards' relentless use of smell - William French argues that Richards has a "preoccupation with smells of various kinds [and] a more sensitive nose than the rest of us, perhaps the result of living in an area of pulp mills" (35) - highlights both the immeasurable effect that industrial activity has had on the natural environment of northern New Brunswick as well as the way in which Arnold has internalized the material conditions of his life. When speaking to Juliet, his social worker, who represents the urban, educated middle-class, he calls attention to the way in which people experience environmental despoliation differently according to their class position: “'What do you want now?' I ask. I have a surly mouth on me - a mouth with too many germs in it, a nose that smells things she doesn't have to smell" ( House 71). 
Richards' characters have a macabre familiarity with the toxic landscapes of postindustrial New Brunswick. When Father Billy recruits Arnold to carry his golf bag, his new caddy is unnerved by the beauty of the country club: "I nod, and smile. But it does no good. The sky is so blue it is lonely. It makes me anxious. It's so clean it makes me yearn to smell a sewer in the water, a sponge of dirt" (Road to the Stilt House 32). Later in the novel, Arnold's family chastises his mother, Mabel, because she, unlike other members of the community who had received settlement cheques, forgot to participate in a government program that installed toxic urea formaldehyde insulation in their houses. Ironically, the family "became envious of other houses and other people" (Road to the Stilt House 104) because they missed out on the opportunity to be infected by this dangerous substance.

In Road to the Stilt House, characters often associate pollution and industrial waste with the comforts of home. Scenes such as one in which Arnold buries his brother Randy's remains in a landfill, where "crows lift off the rusted hoods of death cars and lash themselves to the sky, much like burnt cinders" (Road to the Stilt House 141) call attention to the permanence of waste in the Maritimes and the way in which human society has adapted to its presence. By replacing the supposedly empty wilderness characteristic of early Canadian literature with a landscape filled to the brim with such a foul record of human intrusion, Richards undermines the certainty with which distinctions between the human realm and the natural realm are made.

Coady's fiction is also characterized by this "toxic consciousness." In her texts, characters often attempt to engage with the pristine natural environment, only to find that it is ruined by the waste products of industrialization. Bridget and her friends talk often 
about the effects of pollution and "toxic" fast-food on their bodies, and throughout

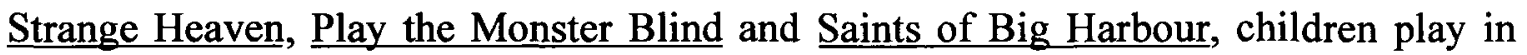
polluted water and next to highways on which pulp trucks release exhaust. Coady's treatment of Cape Breton's polluted landscape exhibits the ambivalence that Deitering and Kollin associate with "toxic consciousness." While her characters often recognize that industrial development has ruined the landscape to the point where unspoiled natural spaces have ceased to exist, they also seek out the obviously artificial and "pristine" representations of the natural environment constructed by Robert Murphy and Dan C.

\section{Toxicity and the Body in Strange Heaven}

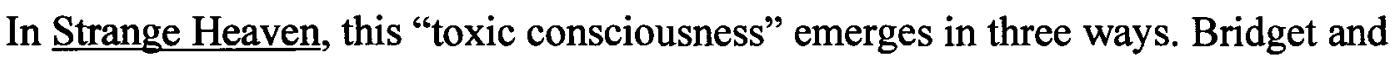
her friends speak about the effects the region's post-industrial corporate culture has on their bodies, calling the food they eat "trash" and "toxic." The unnamed community displays an ironic relationship with the local pulp mill and corporations like Irving, and commemorates their presence with toilet-paper adorned floats in the Causeway Days parade. Finally, Robert incorporates elements of the region's diseased landscape into his folk crafts, using deformed trees to create "perfect" animal sculptures.

The prevalence of images of the abject in $\underline{\text { Strange Heaven suggests a link between }}$ the waste products that appear as permanent and integral elements of the region's postindustrial landscape and characters' bodies, which are contaminated by them. This is evident in Coady's descriptions of teenaged characters constantly vomiting in the snow and on the ground (at one point, Bridget vomits into Daniel's mother's plant, causing it to die ( $\underline{\mathrm{SH}} 168)$ ), in Stephen's declaration that "we can all agree that the world is a piece of 
shit" ( $\underline{\mathrm{SH}}$ 183), and in Heidi telling Bridget that the town plans to commemorate the shooting of Jennifer MacDonnell by planting a tree in the barren field in which she was killed ( $\underline{\mathrm{SH}}$ 200). The last example makes an implicit connection between Robert's nostalgic lament that contemporary Cape Breton is overrun with violence and the sense of loss characters display at the destruction of the island's natural environment.

The narrator's description of Bridget losing control of her body during her pregnancy makes this connection between the human body and toxicity clear: "But the only rough thing about it had been her body's betrayal. She'd thought for a while and it would drive her round the bend. She would attempt to eat hamburgers and fried chicken, and as soon as the food came under her nose, she would have to put it down again. The smell was toxic" (배 16). Like Arnold's complaints about his germ-filled mouth in $\underline{\text { Road }}$ to the Stilt House, this passage links Bridget's exposure to food with little or no nutritional value and to the filthy and toxic landscape of industrial Cape Breton with her class position.

Bridget's experience of her body rejecting her normal eating habits seems to go beyond that which is typical for pregnant women, and the narrator is careful to use words like "toxic" to describe the feeling. Bridget, like Arnold, lives in a mill town where the smell of sulphur inundates her olfactory senses, and she is conscious of the effects of this toxicity on her body as well as the environment in which she lives. In addition to her disgust at being unable to eat and drink in the way she is accustomed, the narrator also notes that for Bridget the endorphins she produced while pregnant were "lies her body was perpetuating in order to keep her from walking off the top of a building" (프 17) and that the entire experience "was like a science fiction or horror movie, being controlled 
and not knowing it, not until it was too late. Like Rosemary's Baby. And she did not blame it, she did not blame him. It was nature's fault. Nature being known in some

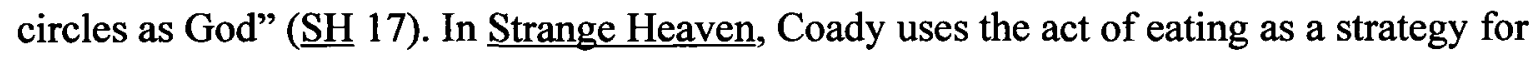
accessing this "toxic consciousness." She aligns Bridget's ambivalent response to the supposedly biologically determined institution of motherhood with her conflicted relationship with the fast food she craves. In this passage, the novel identifies massproduced food as a "toxic" force that exerts control over rural communities in Cape Breton: for Bridget, it is "natural" to want to eat this "junk food," and she rebels against her own body when it develops an aversion to these things.

In Coady's fiction, corporate entities display a complete disregard for both the natural environment and the health and safety of the region's inhabitants. Coady draws a parallel between the pulp industry that dominates Bridget's community and the objectionable food large corporate restaurant chains produce. When Stephen invites Bridget to the Dairy Queen to discuss the fallout from her break-up with Mark and the shooting, the narrator connects this toxicity with Stephen's eating habits:

She regretted it as soon as they were sitting across from one another with their one-dollar sundaes. Stephen had eaten a whole Full-meal-deal and said he would buy her one too if she wanted, but she had no appetite and was surprised to see Stephen eating so much after the night before.

"Electrolytes," Stephen had said, eating french fries. But Stephen was always eating trash. You could not walk down the street with him for more than five minutes without having to stop into a convenience store for pop and chips and a bar. He bought the same three items all time [sic], never just pop, or chips, 
or just a bar. Or never just pop and chips. It was always pop and chips (ketchup) and a bar (Big Turk). It never mattered what kind of pop, as long as it was cola. He seemed to think all three went together. He had acne all through school. (픈 183)

The link between poverty, poor diet, and health problems such as diabetes - which is an epidemic in parts of the rural Maritimes - is well documented; however, the narrator's choice of the word "trash" to describe Stephen's meal is telling. Just as Coady's deconstruction of the tourism industry implicates multinational corporations such as Pepsi in the exploitation of Cape Breton's impoverished rural areas, so the connection she makes between the battered and unhealthy bodies of Strange Heaven's teenagers and companies like Dairy Queen and Sobeys (which owns and operates most of the region's convenience stores) also calls attention to the problematic relationship between rural Cape Breton and its corporate citizens.

In Coady's post-industrial world, the retail industry has taken over the violence, mistreatment and destruction caused by resource industries like coal-mining and steelworking. Detached and distant multinational corporations and service-based operations dominate the region's economy and the bodies of the people who live there display their harmful effects. In the above passage, Coady replaces the residue of industry common to other Maritime texts with the refuse of the fast food industry. However, while cinder blocks and the tar ponds are waste products left over from industrial processes, the "trash" in this instance is the finished product. 


\section{Toxicity and the Landscape}

Just as the "fallen" Cape Breton of which Coady writes is home to violent human relationships, so it is also a place where people readily abuse the environment in the interest of almost any economic benefit. As mentioned in Chapter 4, the novel's opening imagery includes references to the murder of Jennifer MacDonnell, the various ailments that afflict Joan's friends, and Bridget's indifferent response to these horrific events. Along with this, Coady constructs a landscape which is similarly marked by death and disease. The narrator says that the empty and frosted-over field behind the donut shop in which Jennifer had been killed had "gone yellow" ( $\underline{\mathrm{SH}} 3$ ) and is close to a patch of woods filled with "discarded chunks of concrete" ( $\underline{\mathrm{SH}}$ 7) on which Bridget and her friends had once played as children. When Bridget and Alan talk about the murder later in the novel and Alan tells her that shootings in Guelph do not hit home the way this one has, his first recollection of that day is the field and being struck by how "yellow and dead" it seemed. Elsewhere, when Bridget walks to the wharf to look at the community's Christmas lights, the narrator says that the "unfrozen strait was grey and seething" (ㅍH 166). Throughout the novel, the landscape is unwelcoming to the point where it seems to be violent. While the ground turning grey and yellow is possibly symptomatic of changes in season or the onset of rain, Coady is careful to emphasize imagery surrounding death and decay in her descriptions of the land. Bridget's unnamed community is marked by grey slag, sulphurous air and water, and deformed vistas.

Strange Heaven depicts rural Cape Breton as a region threatened by corporate influence and the effects of environmental damage. This is most apparent in the way in which harmful enterprises use the region's economic conditions as an excuse to overlook 
safety and environmental standards. The residents of Bridget's unnamed community welcome the pulp mill, even though it not only pollutes the air with sulphurous smoke and makes the water of the river grey but also exposes workers to troubling industrial accidents. Cape Breton's post-industrial economic conditions lead communities to accept any kind of industry in the region, and the novel candidly demonstrates that the natural environment and the people who live on it pay a harsh price for this willingness to tolerate abuse. When the son of a manager of the local mill commits suicide, symbols of corporate Cape Breton appear at the scene of his death:

They had ended up talking about what Chantal did to Darlene MacEachern because Darlene's younger brother had killed himself that week, and they'd started out talking about that. This was what everyone was talking about - his father being so high up at the mill. Darlene MacEachern's brother had driven out to Point Tupper and parked at a place where a lot of high school students come at night. It overlooked both the water and the mill, and so at night the white and yellow and red lights of the latter would twinkle sentimentally off the former. But this had been in the afternoon, in wintertime, and he had brought all his grandmother's painkillers for her cancer, which he swallowed with Orange Big 8. ( $\underline{\mathrm{SH}} 45)$

Here, Sobeys brand orange pop and painkillers, both of which are markers of the bleak prospects of life in industrial Cape Breton, combine literally and figuratively to end the life of the mill manager's son. The pop alludes to multinational capitalism's presence on the island and the painkillers to the prevalence of cancers caused by pollution in Cape Breton as well as the region's struggle with oxycontin and other forms of opiate 
addiction. ${ }^{3}$ This scene reveals Coady's strategy for disrupting traditional definitions of nature in her work. While this appears to be a conventional description of a lookout point, where high school couples go for a romantic night in view of the water, by including the mill, Coady complicates this seemingly picturesque moment. Instead of being able to see the beauty of the water, young people who come to this spot instead find a grotesque mixture of the sulphur-spewing mill and the contaminated coastline. The pollution and waste, characteristic of Cape Breton's post-industrial experience, mix with and stand in for the natural landscape in Coady's texts.

Because of his position as a successful local businessman, former towncouncillor, and self-appointed expert on what is best for his community, Robert Murphy bridges the working-class ethos and the often distant power brokers of Strange Heaven's world, represented by the management of the mill and municipal and provincial governments. When a plow-driver, who also happens to be a former councillor, picks Bridget up on her way home from Dr. Bransk's office, he gives her a lecture on his experiences serving on the municipal government with Robert. He says that they were known as the "dynamic duo" because of their innovative ideas for reinvigorating the local economy. Although Robert and the rest of the family often rail against the problems the mill has created in the community, the plow-driver tells Bridget that when it arrived, her father bought into its promises of economic improvement. He reports that Robert saw the mill and a proposed casino as projects that would "make the town great" ( $\underline{\mathrm{SH}} 225)$.

Aside from this initial enthusiasm, Coady also uses Strange Heaven's preoccupation with excrement to call attention to the problematic relationship between

\footnotetext{
${ }^{3}$ A battle which the 2006 NFB documentary Cottonland places in the context of Cape Breton's history of deindustrialization.
} 
the unnamed town, its corporate citizens, and the mill that dominates its landscape and economy. The forestry industry plays an important role in the community's celebrations:

[Robert] wanted Causeway Days - the spring festival - to attract more tourists, to entail more than a five-float parade down the main street, two of which were always furnished by the mill, three of which were no more than locals in toiletpaper decorated pickups with signs on the front reading stuff like: “JimmyArchie's Lumber" or "Come to MacIntyre's Big Stop. Two for 99 on O

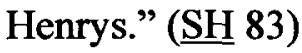

Each of the novel's harmful corporate interests are represented in this image. Big Stop is a chain of restaurants common on highways in the Maritimes and is owned and operated by the lumber, communications and energy corporation Irving. Equipped with fuel stations, a large diner, and sometimes showers, Big Stops provide truckers who transport cargo on the TransCanada Highway with a place to fill up on gas, eat dinner, and rest at the same time. Just as Big Harbour uses the local hockey playoffs to legitimize the local "carnival of violence," so Bridget's unnamed community uses the Causeway Days festival to acknowledge the presence of the mill. David Adams Richards' writing often expresses a wholesale and almost polemic condemnation of New Brunswick's forestry

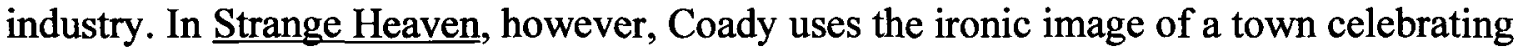
this harmful industry by parading toilet-paper-adorned vehicles through town to expose the willingness of post-industrial communities to make concessions to any company that invests in them.

The ironic relationship that Coady constructs between residents of the town and the corporations that dominate it calls attention to the structural features of Cape Breton's 
post-industrial economy that force communities to accept devastated landscapes, lax safety regulations and constant threats that they might leave at the first sign of trouble from unions and local governments. Just as Bridget and her friends talk about loving mass-produced food even though they know that it is "trash," so the community at large also expresses approval and, at times, gratitude, towards corporations that pollute its landscape and injure its workforce.

\section{Construction of Nature}

As I have suggested in this thesis, Strange Heaven is driven by a deep sense of alienation. This manifests itself in Bridget's disassociation from her own body, in the crippling feeling of ennui that grips Bridget and her friends, in the gap that exists between tourism industry portraits of Cape Breton and the reality of life in the region, and in the sense of dislocation characters express in relation to the island's post-industrial landscape. One strategy for combating this conflicted relationship with the natural environment emerges in Robert's attempts to craft perfect natural creatures from the diseased trees that surround his house. Aside from Albert, it is Bridget's father, Robert,

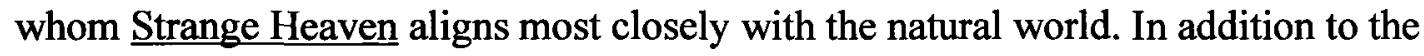
contrast that Coady draws between Robert - a traditional artisan who uses sustainable practices to gather small quantities of wood - and the mill, which clear cuts Cape Breton's forests and pollutes the air of the novel's unnamed community, he also embodies his community's conflicted relationship with the ruined environment.

As mentioned above, the inhabitants of this community have adapted to a landscape that incorporates many of the waste-products of Cape Breton's post-industrial 
economy, such as the lights and smoke of the constantly spewing mill. Robert uses deformed elements of the natural environment to create "caricatures" of animals, including ducks, owls, wolves, and ravens ( $\underline{\mathrm{SH}}(84)$. The narrator notes that he actually prefers wood ravaged by disease to non-damaged pieces:

So her father was a craftsman of wood. He drove off into the hills every Sunday to pick choice pieces. He especially liked the trees that had some disease which made the wood bulge out monstrously in places, as if gourds had become stuck in the trunks somehow. Her father liked to take the diseased trunks home and carve all sorts of faces into the bulges. $(\underline{\mathrm{SH}} 84)$

This description of Robert using diseased wood to create artificial, yet idealized, representations of nature sheds light on Coady's treatment of Cape Breton's postindustrial landscape in two ways. First, it calls attention to the absence of pristine spaces, even in Cape Breton, a region which the tourism industry often promotes as pre-modern and untouched to visitors. More significantly, however, in fabricating animals out of deformed pieces of wood, Robert reveals his own desire for unspoiled natural scenery. Since such examples of nature are almost impossible to find, Robert is forced to construct them himself from the diseased landscape.

As mentioned above, Robert occupies a contradictory ideological space in the novel. Although he rejects the tourism industry for its crass and unrealistic portrayal of Cape Breton, he participates in it by creating and selling folk art. In much the same way as he engages in the project of constructing the region's culture through his art, he also builds images of the wilderness out of diseased trees. In both cases, Robert's handicrafts satisfy the desires of tourists who travel to the region as well as his own opinions of what 
the island should look like. Just as Robert's folk art depicts Cape Breton's culture as quaint and rooted in Roman Catholicism, so he also produces a sanitized and idealized image of the local landscape. The narrator notes that the artificial version of nature he produces in his art is far more "perfect" than anything found in the actual environment:

What a lot of people really came for, though, were Bridget's father's decoys. His decoys were simply beautiful, more beautiful than any actual duck. They were completely smooth and flawless - he did not bother with feathers of [sic] any other realistic detail that might disturb the decoy's linearity. The result was a perfect, liquid platonic ideal. Perfect duckness. He stained - never painted - and then varnished them. The wood was what mattered. The acknowledgement and refinement of the wood rather than any attempt to deny it was what made the carvings very nearly sublime. People came from far and wide to purchase Bridget's father's ducks. They were all exactly the same. ( $\underline{\mathrm{SH}} 86)$

Robert's method for constructing his handicrafts is also significant. Unlike artisans who promote their pieces as "one of a kind," Robert produces his animals in mass quantities, practising his technique over and over in order to yield items that are not only faultless but also identical to one another. The narrator notes that rather than attempting to create realistic pieces, Robert's artwork is sleek and linear, which accentuates the degree to which it is artificial. Robert, however, also takes great pains not to alter the wood he uses to make these animals and in fact uses stain and varnish in order to preserve its original look - the narrator observes that it is for this reason that people like the decoys so much. These handicrafts, then, blur the boundary between the natural and the artificial, at once 
calling attention to the absence of untouched natural spaces in Cape Breton and signalling a desire for them.

\section{Toxic Games in Play the Monster Blind}

In Play the Monster Blind, the offensive sounds and smells of the pulp and paper industry and the waste products of corporations that have left the region dominate the landscape. Coady accentuates the ironic relationship between the inhabitants of Cape Breton and these toxic objects: children use the exhaust from pulp trucks in their games, characters talk about how encounters with them on the highway are seductive as well as dangerous, and Murdeena's softball team wears uniforms that read "S.O.B.s," a play on the logo for Sobeys. Although "Jesus Christ, Murdeena" highlights the destructive relationship between corporate interests and the environment as well as the residents of rural Cape Breton, the end of the story focuses on the pristine land on which the elderly members of the community grew up.

In Play the Monster Blind, children often organize their games around industrial Cape Breton's ubiquitous pollution. "Big Dog Rage," for example, is a story about two children who become friends when one of their dogs kills the other and they are forced to play together while their parents argue about compensation. The unnamed narrator and Gerald bond over this violent experience, and Cape Breton's toxic physical environment is the setting for their friendship. The narrator says that they play on a sledding hill which "gave way to the Trans-Canada Highway, where pulp trucks went barrelling past on their way to and from the mill, making their loud and angry fart noises" (PMB 142). While most of Coady's fiction employs the vocabulary of adolescents to convey the troubling 
and absurd aspects of life in contemporary Cape Breton, this story uses children's language to the same effect. The narrator and Gerald find that there is no buffer between them and the industrial complex; the highway and the hill on which they play are directly adjacent to one another, making this game both dangerous and putrid.

As is suggested by the narrator's ironic description of the pulp trucks, she and Gerald are fascinated with these objectionable vehicles and they incorporate them into their games:

In the summer we used to sit on the top of the hill and watch for a pulp truck to go by and as soon as it made its noise, Gerald would jump up, make a face, and wave his hand in the air - "Oh my God! Hold your breath!" - and I would pretend that it was too late and I was already dead. (PMB 142)

The children internalize the violence and offensive smells of the industrial complex and use it in their recreational activities. The above passage also suggests that the unnamed narrator and Gerald are aware that the trucks are dangerous and the exhaust given off by them is noxious; however, instead of avoiding the pulp trucks, they make use of them in their recreational activities.

Just as Gerald's embrace of blasphemy intensifies as the story progresses, so the games the children play also gradually become more dangerous. By the end of the story, the children shift from seeking out the exhaust of pulp trucks to bragging about their desire to die on the highway:

"Did you see that?" he said. "I came this close to the highway and I was only sliding on my stomach!"

"Where'd you get that?" 
"Someone gave it to me." He glanced down at the sled. "On this thing I'll overshoot the gully, no problem. I'll be completely killed."

"Let me go on with you," I said like nothing had ever happened. "More weight will make you go faster."

He looked skeptical.

"We'll end up right in the middle of the highway!" I enthused. "Death will be instantaneous! We'll be just one big blot on the road." (MB 144)

Just as the two children form their friendship on the basis of the shared experience of watching one dog kill another dog, so the narrator attempts to revive their strained relationship at the end of the story by sardonically proposing that they kill themselves together.

Death, violence and toxicity are pervasive in this story to the point where it dominates the lives of Gerald and the unnamed narrator. In connecting the make-believe death of these children and the sounds and smells of the forestry industry, Coady makes a broader comment on the role that the industrial complex plays in the lives of the inhabitants of rural Cape Breton. In this story, children are aware from an early age that encounters with the pulp and paper industry often result in death and injury, which is something that the people who work in it are also intimately familiar with. Gerald and the unnamed narrator display the same ironic response to the industrial complex as many of Coady's adult characters: just as industrial labour is seductive to workers because it satisfies economic needs and connects them to the region's cultural traditions, so the danger and offensive smells of the pulp and paper industry add an element of excitement to these childhood games. 


\section{Toxic Intrusions in "Run Every Day"}

Play the Monster Blind's preoccupation with violence and toxicity emerges again in "Run Every Day," which revisits the unnamed narrator from "Big Dog Rage" and her relationship with Gerald. Now an adult, the narrator frequently recounts violent episodes from her childhood, including an incident where she "threw crab apples at a boy ... until he threw up" (PMB 201) and one where she witnessed a toddler bashing another child on the head with a wooden block for no discernable reason. The narrator also recalls that as he grew up, Gerald became more and more hostile. She remembers him building a fort in the woods and terrorizing anyone who dared set foot near it, tying a girl they called "Kerrie Retard" to a tree along with her brother and forcing them to kiss, and eventually becoming a teenaged "thug" who "wore a jean jacket with the names of bands written on it in magic marker" (PMB 204).

The narrator, who has recently moved to an unspecified Canadian city where she has taken up running, contrasts her cosmopolitan and sophisticated lifestyle with the lives of her friends still residing in rural Cape Breton. Coady positions her as an outsider; the narrator not only feigns chic urbanity but also treats her one-time friends like caricatures: "It is not necessarily the case that I spotted and then ignored her. I am at the height of my run, blood churning in my head, and to see Madonna leaning against a pole inhaling smoke seems at once unreal and at the same time utterly expected. It's as if everything around me is wallpaper - the bank, the trees, the water, the crumbling street, Madonna, and the dog. To acknowledge her seems to make as much sense as saying hello to a picture on the wall" (PMB 221). The narrator draws a distinction between the supposedly 
healthy and pleasant life she has created for herself away from Cape Breton and the stagnant existence of Madonna. She also juxtaposes her own impeccable physical condition with the noxious smoke from her friend's cigarette. Running works as a metaphor for Coady on several levels in this story: the narrator signals her distaste for the community in which she grew up by literally running away from it, and in doing so casts herself as markedly different from the inhabitants of her hometown.

In a 1999 article in Saturday Night, "Coasting: Thoughts on Coming Home," Coady recalls her experience of moving to Vancouver, where she adopted a healthconscious urban lifestyle that included running in tights, spending time outdoors, eating nutritious (and often vegetarian) food, and making an effort to stay active. During a trip home to Cape Breton, her family chastised her for this change in lifestyle: "One Christmas, when I came home sporting the familiar west-coast fashion of leggings with hiking boots, certain members of my family refused to be seen in public with me ... there's only one type of individual who can get away with this sort of behaviour: A Person From Away. A tourist. But when a hometown girl waves her crack around in public in the name of fitness? Unacceptable. Laughable" ("Coasting" 27). While it seems clear that Coady makes this contrast between "gravy-faced Maritimers" ("Coasting" 27) and image-obsessed urbanites sarcastically, she suggests that members of her family and other inhabitants of rural Cape Breton view exercise as an expression of vanity alien to their rural communities.

Although "Run Everyday" highlights the absurdity of such fears surrounding "urban behaviour," Coady satirizes the narrator for believing that moving away from the rural space of Cape Breton makes her life superior to the one she left behind. She has 
fabricated this sophisticated lifestyle, and running while home for vacation is simply a strategy for proving to the rest of the community that she has matured. In an imagined conversation with Gerald, she reveals that she has crafted a story about her life to tell her childhood friends:

You see, Gerald, I had to take some time off from my fulfilling job as a cataloguer at a museum where I work while I'm finishing up my Master's thesis. Yes, that's right, another Master's. I had to come back and help my mother pack up thirty years, something I did not dread doing in the least, seeing as how she and I have such a close, caring relationship based upon mutual respect. Now that I have come to terms with all my past issues and what have you. Oh, yes, completely to terms. Yes, Gerald, I really can't tell you how gratifying it is. To bestride the earth, fully in command of yourself, utterly at ease. Heathy, of sound mind and body. Secure with your place in the world. (PMB 217)

Just as her statements about being happy with her choice of lifestyle and the kind of relationship she has with her mother are false, so her description of her healthy body being in tune with the clean and welcoming natural environment also falls apart: "A pulp truck comes up from behind and blats me awake, passing within inches. I'm enveloped in a harrowingly warm cloud, the truck's own breath. Splinters and the smell of bleeding lumber but also sheer nearness and speed. I turn around and teeter home, fireflies dancing in front of my eyes, legs of brine" (PMB 217-218). For Coady's characters, untainted landscapes exist only in fantasies. When characters look to escape the oppressive or unpleasant aspects of their lives by retreating into pristine nature, offensive sounds and 
smells of the industrial complex suddenly and often violently remind them of rural Cape Breton's polluted environment.

The narrator's description of the jarring experience of her conversation with Gerald being interrupted by a pulp truck is foul; the truck passes only inches away from her on the highway, and its exhaust covers her. This is, however, a highly ambivalent scene. In using words like "bleeding lumber" and "the truck's own breath," the narrator hints at how, in the space of rural Cape Breton, this kind of moment is grating but also "natural." The final lines of the quoted passage highlight the degree to which this experience, like her earlier forays on the dangerous sledding hill, is curiously exhilarating. Again, this instance reveals that for Coady's characters, dangerous masculine symbols like pulp trucks are strangely seductive.

\section{Corporate and Natural Symbols in "Jesus Christ, Murdeena"}

As James Taylor suggests in his 2001 review of Play the Monster Blind, "Jesus Christ, Murdeena" is a meditation on the often-silent forces deployed in small towns to secure conformity. Murdeena shocks her family by taking post-dinner walks along the beach, an action that is unheard of in her community, and eventually claims to be Christ, a notion that the rest of the town dismisses as ludicrous. Whereas in Strange Heaven the institutional features of the psych ward work to infantilize Bridget and to keep her in her place, it is the subtle machinations of her mother and the community at large that do the same to Murdeena, whom the narrator describes as "the sweetest, most uncontentious little girl ... Agreeable was the word that best described Murdeena" (PMB 76). When Murdeena begins to challenge and disobey people, her family and the community simply 
decide that she is crazy and, worse, arrogant. Although Margaret-Ann mocks her daughter for walking along the waterside to "look at it" (PMB 67), implying that the landscape is not worth seeking out, the end of the story suggests that there are natural spaces and scenic mountains in their community, but only Murdeena and the seniors can see them.

In keeping with Coady's deconstruction of the natural environment, "Jesus Christ, Murdeena" is filled with references to the receding corporate and industrial complex in Cape Breton. This story, like Strange Heaven, calls attention to the harmful actions of multinational corporations in the Maritimes. In Coady's fiction, characters are often precariously dependent on large retail businesses. Murdeena, for example, recently lost her job when the local Sobeys closed and is collecting Employment Insurance until such time as she can find work at the "big bulk store" planned for her community. While the mark of late twentieth-century business has been the development of a brand-loyalty movement that mirrors and in many ways replaces nationalism, Coady's fiction calls attention to the ephemeral nature of capital, which exists as a vague and unquantifiable force in her texts that arrives and leaves without warning. After Murdeena and her fellow workers lose their jobs, their lives go on much as they did before:

Murdeena is always on the go, everyone says so. She plays piano for the seniors every weekend and always helps out at the church tea and bake sales. She'll do the readings in church sometimes, and plays on her softball team. It used to be the Sobeys softball team before it closed down, but they all enjoyed the games so much that the employees didn't want to disband. They ripped the cheap SOBEYS 
logos off their uniforms and kept playing the other businesses in town anyway.

Nobody minded. For a joke, they changed their name to the S.O.B.'s. (PMB 72)

Coady aligns Murdeena's rebellion against her parents and the community with her softball team's mocking treatment of their uniform's corporate symbols. Just as maps of rural Cape Breton display place names inspired by influential owners of long since failed industrial projects, so Murdeena's softball team is affiliated with a corporation that has left the region. In this way, Coady presents the social fabric of these communities as predating the arrival of corporate interests and surviving after they leave. These stories depict corporate symbols as cheap and easily replaceable. This is the case because many of the companies who created billboards and advertisements left the region in the second half of the twentieth century.

Coady aligns the abuse enacted on the land by companies who wish to extract as much as they possibly can from it with the abusive treatment of residents of rural Cape Breton by multinational corporations. Murdeena and her colleagues, however, also use the logos on their softball uniforms to subtly parody and undermine the influence of the corporate interests that dominate the region. Murdeena and her friends' subversive use of the symbol "S.O.B.'s"- a decidedly working class jab at Naomi Klein's "radical chic" brand of consumer activism spelled out in No Logo - positions them as threatening to Cape Breton's post-industrial economy in much the same way as Murdeena is a threat to her family.

While much of "Jesus Christ, Murdeena" calls attention the harmful way in which the post-industrial economy impacts the region's inhabitants and natural environment, the story's final lines highlight Coady's ambivalent treatment of Cape Breton's landscape. In 
this story, members of the community gossip about Murdeena, castigate her, and go so far as to shield their children from contact with her. Murdeena finds that the only people who tolerate her are the seniors at the local rest home for whom she plays the piano. Coady's fiction suggests that contemporary Cape Breton society is selective in its use of nostalgia. The people who live in Murdeena's community are quick to call themselves old-fashioned and welcoming; however, when faced with a person or idea that makes them uncomfortable, they become mean-spirited. In contrast, while the seniors may question Murdeena's sanity, they are too courteous to do so out loud:

The seniors treat the blasphemy with more good humour than anyone else in town. Born in farmhouses, raised up on hills or in remote valleys, where to come across another human being, no matter who they were or what they had to say, was a deep and unexpected pleasure - therefore humble, charitable, and polite the old folks listen, lined up side by side in front of the piano. (PMB 85)

Here, the narrator implies that the seniors who live in the community actually do embody the attributes of the rural, premodern folk for whom Helen Creighton searched and on whose image an entire tourism industry is built. These are the people whom Bethany imagines when thinking about John's hometown: they are polite, down-to-earth, and above all else, good humoured. Furthermore, the narrator mentions that these people grew up in farmhouses surrounded by the pristine natural scenery of Cape Breton - a landscape that is absent from much of Coady's writing.

Like the endings of Strange Heaven, "Play the Monster Blind," and Mean Boy, the final passage of "Jesus Christ, Murdeena" is evidence of Coady's conflicted relationship with the home place. While her texts often challenge the historical and 
sociological evidence that stands behind images of "the folk" and questions its very existence, this story seems to maintain that a premodern Maritime ethos did exist at one time. Coady still undermines the image of Cape Breton as pristine, both physically and socially, in the story; however, the ending suggests that she is open to the idea that this portrait was once accurate. In this instance, the object of Coady's satire is a contemporary society that purports to exemplify the qualities of "the folk," but is instead narrowminded and vindictive.

\section{Saints of Big Harbour's Poisoned Landscape}

Cynthia Deitering's definition of "toxic consciousness" as emerging in the literature of a society that has "fouled its own nest" (200) is particularly useful for illuminating Saints of Big Harbour. While Bridget's community displays an ironic relationship with industrial activity by parading trucks decorated with toilet paper through its streets, the image of soiling one's living space emerges in a very literal way in Saints of Big Harbour. After Guy and Marianne flee their rural community for Big Harbour, Isadore eventually follows them into town and moves into their apartment. Unable to walk because of his fall on the ice, Isadore lies on their couch all day, watching game shows on the television he purports to detest, and drinking from a teapot that he leaves precariously close to his "pee bottle":

Isadore glances at the television. He shifts under his blanket, grunting. "Thank Christ you're here. You empty this for me, son, uh?"

Guy thinks he must be talking about the piss bottle, but then spies it on the floor beside its teapot companion. 
"Empty what?" says Guy. But he can see now. Isadore has removed a bedpan from underneath himself - pale, plastic hospital blue.

"Fuck that!"

Isadore rises comfortably to the anger. Well, what in hell am I supposed to do, lie here in my own shit?

You took a shit in our living room?

Guy screams this. Out loud or not, he isn't sure. ( $\underline{\mathrm{SOBH}} 288$ )

The logic of the resource economy dictates that peripheral regions such as Northern Ontario, the Arctic, and the Maritimes should provide urban centres like Toronto, Montreal, and Halifax with raw materials for the construction of sky scrapers, furniture, and other luxuries and necessities. The divide between the space where workers extract resources and the market separates the consumers who use these products from the injury, pollution, and waste associated with harvesting things like minerals and timber. While landscape art and pastoral literature often portray these "hinterlands" as devoid of people, creating the illusion that such activity has no human consequences (Mitchell 15), Coady's fiction reminds us of the costs of resource-extraction by constructing a Cape Breton in which people live on top of the waste products of mining, forestry and manufacturing. Isadore's breach of the boundary between bathroom and living room functions as a metaphor for his destructive treatment of his family, and, as is pertinent to this chapter, for the way in which the industrial culture he in many ways represents has poisoned rural Cape Breton's landscape. Saints of Big Harbour details the effects of living so close to the waste and effluents of the industrial complex on its two principal settings: Guy's Acadian community and the English town of Big Harbour. 


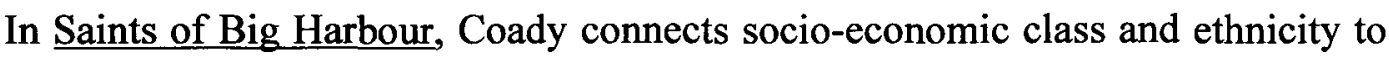
characters' experience of the pollution and dangerous working conditions created by Cape Breton's post-industrial economy. The Acadian community that surrounds Big Harbour is disproportionately exposed to injury in southeastern Cape Breton's treacherous pulp and steel mills. As I have suggested, one of the novel's key tensions is Guy's conflicted relationship with the rural community in which he grew up. Coady's treatment of "toxic consciousness" adds another layer to this struggle: Guy rejects his hometown, in part, because he believes that the clean space of Big Harbour offers him an escape from the squalor in which he grew up. The novel stresses, however, that Big Harbour is also contaminated by pollution. Pam and Corrine, in spite of their class position, encounter noxious air and water even when they play outside and walk along the harbour. Unable to avoid the filth and waste that surrounds him, Guy, to use Susan Kollin's phrase, "fetishizes" highly artificial and sanitized spaces.

In her construction of Guy's hometown, Coady draws on the tension between governmental and corporate interests that seek to resurrect harmful industries in the hopes of stimulating economic growth and the personal and environmental damage that results from such activity. Guy and members of his family are directly affected by unsafe working conditions in the island's mines and mills. In one of the only extended descriptions of Guy's father, the narrator recounts Kenzie's detached reaction to an explosion at the mill that killed two of his relatives:

At dinner one evening before Marianne and Kenzie got married, Marianne's parents had talked about the terrible explosion at the mill, which had happened only days before. Men had been blown apart, and people in the area could talk 
about little else. Kenzie had lost two of his cousins in the blast, but he made no mention of them. Instead he remarked on the jobs the repairs would create, not to mention the new vacancies. (SOBH 350$)$

Guy's obsession with his family's truck and with moving as well as Isadore's failed attempt to relocate to Toronto point to the importance of the theme of mobility in $\underline{\text { Saints }}$ of Big Harbour. As mentioned in Chapter 4, Louise's husband, Dan C., moves to the Boucher family's community in order to escape Glace Bay's violent industrial projects. The novel's ethnic hierarchy plays an important role in characters' experience of the post-industrial economy. Characters with Scottish surnames seem to sidestep such dangerous situations with less difficulty: Dan C., for example, uses his business connections to secure a job outside of his hometown. Similarly, Howard and Hugh parlay the academic credentials they gain through Honours courses into white collar positions away from the mill, and Alison Mason comes to Canada to flee the Vietnam war. Members of the Boucher and Aucoin families, however, find that avoiding exposure to pollutants and personal injury in the mill is much more difficult.

This power imbalance emerges in Coady's treatment of other parts of the postindustrial landscape. The shed behind the Aucoin house, which Isadore and Guy use as a home gymnasium, occupies an ambiguous space in the novel. While it is part of the built environment, it also symbolizes Emile Aucoin's participation in hunting and extracting resources from the land as well as Isadore and Guy's obsession with masculine strength. The shed is also the staging ground for Guy's forays into hockey and boxing. Guy and Rene Cormier, cognizant of the attacks against Acadian teenagers carried out by people like Howard and Hugh, hang a heavy bag there, intending to lift weights and train before 
beginning grade eleven; however, the shed disintegrates on top of them:

It feels like a sign. I have never believed in that kind of shit, but really - that's what it feels like. This happiness surges through me because I almost got killed by a shed, and I don't know how else to explain it. It's like the shed has spoken, and it's said that it's tired of being Isadore's. It's tired of the cardboard boxes, of serving as a storehouse for us to stuff all of our unwanted memories. It's tired of me. That is it's tired of me being a useless, medium-size kid with a sickness inside. So it tried to kill me. I can't say that I blame it either. I am actually grateful. ( $\underline{\mathrm{SOBH}} 171)$

The physical world of Saints of Big Harbour is in constant decay. In the above quotation, Guy makes a connection between the natural spaces of his rural community that have been destroyed by pollution and the human-constructed spaces that are equally contaminated. Guy's description of the shed establishes it as a metaphor for Cape Breton's abandoned and down-graded industrial sites - some of which appear in the novel as places where Kenzie's relatives and Dan C.'s cousins die in work-related accidents. Like these sites, the shed is obsolete, dirty, dangerous, falling apart, and a symbol of Cape Breton's embattled working class. And like many of his relatives, Guy is exposed to injury when he tries to enter this masculine world. Two elements of Guy's reaction to the shed falling on top of him are significant: he blames himself for the shed's attempt to kill him, and he is also strangely pleased when it happens, even though he has lost his home gym.

The former casts further light on Coady's treatment of ethnicity. For Isadore and his friends, the label "medium-size" is code for "Acadian": Guy remembers that "Isadore 
once told me Scotsmen were mostly big fuckers and Frenchmen were mostly little fuckers (except when it came to the Aucoin freaks) and I was 'lucky enough' - this was pure irony - to be the offspring of the two combined" (SOBH 167). As mentioned in the previous chapter, Guy is often resentful of his ethnic heritage and familial history. Here, he speculates that the shed targeted him because of his size and his ethnic background. In this passage, Guy implies that the combination of Isadore's influence and the Acadian community's disproportionate exposure to dangerous working conditions in the region's industrial economy place him at particular risk. While Isadore views his father's shed as an important space for passing down to Guy the masculine values of strength, a strong relationship with the natural world, and the continuity of family, for Guy, the building reminds him of the racism directed at him by Howard and Hugh and represents the consequences of the toxic masculine culture Isadore forces on him.

The latter is representative of Coady's characters' conflicted response to the region's toxic landscape: although the pollution and abandoned sites left behind by deindustrialization and the retreat of capital from the region pose risks to the health and safety of the people who live near them, the fact that they are waste-products signals the end of an often vicious and exploitative era in the island's history. Guy is happy that the shed falls apart because this blocks him from entering Isadore's masculine world. The shed's collapse also points to a generational shift: it destroys Isadore's mementos and clears the way for Dan C., who rejects this industrial culture, to move in, renovate the property and, by the end of the novel, dispose of the symbols of previous generations of Aucoins from the house. 


\section{Pollution in Big Harbour}

Just as outsiders to the region romanticize the Maritimes and its pristine scenery, so Guy constructs for himself an idealized version of Big Harbour that overlooks its polluted and often dangerous landscape. For Guy, Corrine's class position and the fact that she lives in Big Harbour shield her from contact with Cape Breton's toxic sites. Although Corrine, Howard, and the rest of her family avoid working in the dangerous mill, they still encounter the pulp and paper industry's effluents.

The action of the novel hinges on Guy and Corrine both romanticizing their nonexistent relationship: Corrine is appealing to Guy because she is sophisticated and urbane, and Corrine admits that she was intrigued by Guy because he was a stranger. When Corrine explains this sentiment, telling the reader that her boredom and intimate knowledge of every inch of Big Harbour, as well as the people who live there, makes even the slightest deviation from the norm exciting, references to pollution casually slip into her description of the landscape: "You know this town like the inside of your brain. You've ridden your bike in and out of everyone's driveway. You've played war in the woods, tag in the graveyards. You've wound your way along the railroad tracks, right out past the causeway to swim where the water isn't so polluted" (SOBH 116). This passage suggests that Corrine was aware of the toxicity of the island's environment even as a child, and learned to seek out untainted water in which to swim. Corrine's childhood memories accentuate the corrupted spaces of the town in which she grew up because she encountered waste and contaminants constantly, even when playing outside with her friends. Coady uses the recurrent image of children playing near pollution and in spaces 
marked by death and decay, such as graveyards, to highlight the degree to which waste and ruin are permanent features of the landscape of post-industrial Cape Breton.

Corrine's friend Pam also finds that the landscape of Big Harbour is dominated by toxicity, even when she walks to the waterfront to admire the sunrise. After Pam spreads Corrine's made-up story about Guy sexually assaulting her, inspiring the bloody revengepact initiated by Howard and Hugh and the local authorities' manhunt for Guy, she is so embarrassed and scared of reprimand that she essentially spends an entire summer in hiding, a period she calls "The Summer of Staying Away" (SOBH 173). During this time, Pam dedicates herself to rehearsing for school plays; she wakes up in the morning and, unable to hide in her house because of her abusive father, walks to the waterfront to practise lines. Instead of finding beautiful natural scenery, however, Pam is obliged to take comfort in Big Harbour's poisoned landscape:

Off to the waterfront to see the sun rise above the frothy squalor of the strait - to watch its rays illuminate the purple clouds of gunk that are cheerfully and steadily belched heaven-ward from the pulp mill day and night, bullying and crowding the real clouds out of existence. A Big Harbour morning. Use these quiet, stinky moments to go over the biggest speeches, the ones she can picture herself speaking trippingly on the tongue in no possible imagined future. ( $\underline{\mathrm{SOBH}} 174)$

This language accentuates the ambivalent response to pollution that Coady's characters display. Pam at once seems relieved by the seclusion and calm that the harbour offers and offended by its putrid smell. The narrator's description of the toxic clouds that the pulp mill releases makes a distinction between the effluents and the "natural" clouds on the horizon; however, it is the noxious air that takes over the sky. More importantly, in 
watching the sun rise over the harbour and glitter through the clouds, Pam appears to find an aesthetically pleasing nature scene. This seemingly pristine image falls apart, however, when the narrator reports that it is the sulphorous smoke of the pulp mill mixing with the sunlight that produces this effect. The line "A Big Harbour Morning" reads like copy written for a postcard and enhances the novel's ironic construction of the "pristine" natural environment. Pam attempts to find respite from her abusive family by retreating into the beauty and tranquility of the natural environment, but instead finds that it is dominated by pollution.

As he begins to spend more time in Big Harbour, Guy also notices the effects of the pulp industry on the town's landscape. During his first trip to visit Corrine, he gushes that the "lucky Big Harbour bastards have a mall right beside their school" ( $\underline{\mathrm{SOBH}} 16)$ but also notices that the pulp trucks familiar to him from the highway on which his family lives are also present in Big Harbour. He is so accustomed to them, however, that they are a simply mild annoyance: "A Diet Coke is nothing. I get up and get it for her anyway, though, and we go for a walk. Pulp trucks keep roaring by and we have to yell at each other to be heard, just like at the dance" ( $\underline{\mathrm{SOBH}} 17)$. Corrine and Guy are both habituated to yelling over the sound of pulp trucks on the side of the highway, and the "roar" of these machines is one element of the region's constant din. For Guy, this sound is as familiar to him as the music he hears at dances, and he notes that speaking over it is very much like trying to hold a conversation at the school gym on a Friday night. It is for this reason that Coady's characters react to the ruined and polluted landscape in such an ambivalent way: these sounds, smells, and sights are typical for them and are symbols of the environment in which they grew up. The nonchalant descriptions that Coady's 
characters use for what would conventionally be described as offensive and dangerous aspects of the Cape Breton landscape assigns a sense of permanence to the region's toxic landscapes.

\section{Guy and Sanitized Spaces}

As a result of the pollution that surrounds him, Guy often expresses a feeling of alienation from clean and aesthetically pleasing parts of the natural environment, something he attributes to his class position, his ethnic heritage, and his geographic location. In his description of a particularly beautiful fall day, Guy notes that Cape Breton's most beautiful landscapes are reserved for tourists and the residents of affluent sections of Big Harbour:

On certain days in October, on particular streets, like the one where my mother works, the trees rain prickly chestnuts that split open and lie on the street like oysters with sharp brown pearls inside ... October in Big Harbour. On certain days the water is actually purple and the trees are just lunacy. If we still had the truck, my mother and I could drive into the countryside and take in all the crazy colour - and we could go out to the house, but my mother doesn't want to meet Dan C. And the truck has been impounded. I doubt Isadore will ever have a license again. (SOBH 198)

Here, Guy expresses nostalgia for a pristine landscape and notes that there are two such spaces in Big Harbour and the surrounding area. The first is the section of town in which the MacAskills live. Guy implicitly contrasts this wealthy neighbourhood with his own yard. In the former, children can run through the tree-lined street, throwing chestnuts at 
one another and playing games. Guy, on the other hand, grew up in a squalid house on a dangerous highway, and had to structure his outdoor activities around cars and trucks that sped past his front yard. The second pristine space which Guy mentions is the Fleur de Lis Trail, a highway that runs through Victoria County in Cape Breton and offers tourists the opportunity to view the region's dramatic fall foliage. Although they live very close to this "attraction," Guy and his mother are unable to experience it because they do not have a vehicle. Coady implicates Cape Breton's ethnic hierarchy in Guy's sense of alienation from this landscape. She does this by contrasting Guy's community with the MacAskill's serene neighbourhood and by calling attention to the way in which Acadian symbols have been co-opted by the state, which uses them to promote a scenic drive that Guy and Marianne, two members of the Acadian community, are unable to experience.

This longing persists throughout the novel. Nowhere is Guy more happy or optimistic than when he meets Corrine for the first time. Guy fondly remembers his encounters with Corrine, as they allowed him access to the urban world of Big Harbour. In his first trip to Big Harbour, Guy immediately notices a sharp contrast between the town and the area in which he grew up. He is particularly impressed by the way in which Big Harbour's architecture mirrors natural forms, to the point where the boundary between the building and the landscape blurs:

I finish the Coke standing there by myself watching the sky cloud over and spring go away, and then I go into the school to find the library. I can't believe the school - it's enormous. It is made practically all of glass, so the cloudy grey light fills the whole place. It's like I'm still outside. ( $\underline{\mathrm{SOBH}} 29-30)$

Elsewhere, Guy talks about being overwhelmed by the fresh smell of the school: "Mostly 
there is smell. It smells new in the school. And, if possible, sunny. But I could be imagining this. I've never been in a building so full of sun" (SOBH 191). For Guy, this clean new school is unlike his house as well as most of the buildings that comprise his rural community. Guy believes that Big Harbour satisfies his desire for pleasant and unspoiled surroundings. For him, Big Harbour not only represents an escape from his suffocating and hostile home, it is also a pristine environment in which buildings and nature blend seamlessly together - a stark contrast from the garbage, industrial waste and clear-cut forests that dominate the rural landscape that surrounds Big Harbour.

In the novel's final scene, Coady returns to the image of the house, once again highlighting Guy's obsession with sanitized spaces. Coady's use of house as a metaphor for the landscape reveals her ambivalent treatment of toxicity in the novel. She presents two versions of the home place: the one Isadore has "fouled," and the hyper-sanitized and artificially pristine house created by Dan C. While, as I have mentioned, the Aucoin house was as filthy and damaged as the environment that surrounded it for most of the novel, Guy discovers that Dan C.'s renovations have made it fresh, inviting, and strangely clinical:

Finally I figured it out. There were new cupboards all along the wall coming in from the porch. I went over to check them out. On the outside, they smelled of fresh white paint, but inside was the smell of trees. Lumber so fresh, it might have been cut the day before. I stuck my head inside and breathed.

Louise was saying, "Go look out back! Dan C.'s building a patio this summer." 
The smell made me think of her. The pulp trucks interrupting us that day I skipped off school to see her, their smell of gas and sap. It seemed like every time I opened my mouth to speak to her, a truck would belch at us from the highway. (SOBH 411)

Here, the distasteful image of the noisy, exhaust-filled road accentuates the problematic relationship between Guy and Corrine, and the jarring intrusion of the pulp truck calls attention to the violence of Cape Breton's industrial economy. Coady's treatment of Dan C.'s renovations to the Aucoin family home is very similar to her depiction of Robert's

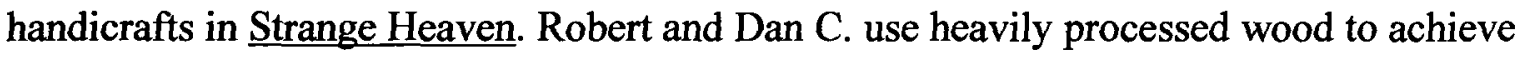
the "natural" look of their constructions. In this way, their built versions of nature serve to call attention to the absence of pristine environments in rural Cape Breton.

While Guy responds positively to the house, on the one hand, because Dan C. and Louise have stripped it of Boucher and Aucoin family photographs and possessions, he also juxtaposes its cleanliness with the ruined landscape of industrial Cape Breton. In this way, Coady adds another layer to the tentative embrace of the family found at the close of each of her texts: whereas John Jr. and Bridget, for example, find comfort solely in their emotional attachment to their families, Guy finds that his renovated home place is now physically welcoming. In much the same way as Coady spends the whole of $\underline{\text { Strange }}$ Heaven undermining and satirizing traditional portraits of the Cape Breton family only to pull back at the final moment, $\underline{\text { Saints of Big Harbour accentuates the regressive and }}$ stifling aspects of the home place; however, at the close of the text, Guy finally feels happy there. Guy ultimately finds comfort in this space only after Dan C. completely renovates the house, to the extent that he does not recognize it on sight. Coady's 
treatment of "toxic consciousness" centres on the sense of durability she attributes to the waste and pollution that marks the landscape of rural Cape Breton. Dan C. and Robert construct spaces and crafts that replicate the pristine aesthetics and olfactory senses conventionally associated with nature and present them as alternatives to the region's permanently gutted landscape.

\section{Conclusion}

Much like other contemporary Maritime writing, Coady's fiction embodies a

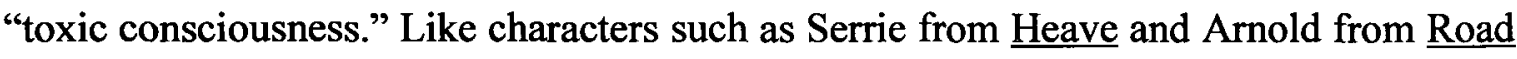
to the Stilt House, the inhabitants of Coady's Cape Breton display an ironic relationship with the industrial waste and pollution that dominates the region's natural environment. In Strange Heaven, Bridget and her friends experience the effects of Cape Breton's shift to a service-based economy on their bodies. They describe the food they eat as "trash" and "toxic." Robert's use of deformed and diseased trees to create sleek, linear, and overtly artificial animals to sell to tourists calls attention to the absence of pristine wilderness spaces in rural Cape Breton. Coady's construction of this toxic landscape is highly ambivalent in Play the Monster Blind. Although Bethany notices corporate signs on the side of the Cabot Trail in the process of decay and other characters find it impossible to escape the offensive sounds and smells of pulp trucks, Coady steps back from her emphasis on this ruined landscape in "Jesus Christ, Murdeena," where the title character and senior citizens are the only people who can see the pristine natural scenery that surrounds them. In Saints of Big Harbour, Coady links the ethnic hierarchy in Big Harbour and its surrounding rural area to characters' experience of the dangerous post- 
industrial economy. Although Guy imagines that Big Harbour is home to a pristine landscape, Pam and Corrine describe offensive encounters with its pollution. Guy is similarly alienated from the natural environment and seeks out heavily sanitized spaces such as the Big Harbour high school and the renovated Aucoin house. In Strange Heaven, Play the Monster Blind and Saints of Big Harbour, Coady depicts Cape Breton as gutted by an industrial complex that has extracted every possible natural resource from the land, leaving behind waste, both hidden and in plain view. For Coady, this is not an abstract problem; she presents post-industrial Cape Breton as a place where people live on top of and beside this toxic residue.

In her sustained and unrelenting focus on the marginalia of industrial society, both in physical and human terms, Coady's landscapes confront her audiences with the uncomfortable consequences of technological development. In this way, her work is reminiscent of T.S. Eliot's The Waste Land (1922), Alice Munro's "The Flats Road" (1971), Margaret Laurence's The Diviners (1974), Thomas Pynchon's The Crying of Lot 49 (1986), and Cormac McCarthy's The Road (2007). Cecily Brown's 2000 study of The Diviners argues that an ironic side effect of industrial society is that its "disposable" remnants such as garbage and pollution are in reality incredibly durable and serve as a highly material reminder of the class-related and ecological skeletons in its closet (22). These texts and Coady's fiction portray a landscape marked by garbage and toxic chemicals as the logical end-result of a consumer and industrial culture that discards as readily as it creates and commodifies. 


\section{CONCLUSION}

Although ecocriticism is a theoretical tool seldom used in Maritime literary criticism, recent debates in the two fields reveal a number of similarities between them. Ecocriticism and Maritime literary criticism both emerged from relatively recent political movements. In the late 1970s and early 1980s, literary critics in North America and Europe, concerned about the perceived ecological disaster, began to examine literary texts for environmental themes and lobbied for nature writing to be considered more widely in university courses and anthologies. Heavily influenced by regionalist scholarship in history and political economy in the 1970s, Maritime critics of this time period railed against a literary establishment in Canada that privileged authors from the country's urban centres and marginalized those from peripheral areas like the East Coast.

More importantly, conventional ecocritics and previous generations of Maritime literary critics share a similar definition of nature. Early ecocriticism in Canada focused on nature writing and pastoral literature that features a search for enlightenment or redemption through encounters with the pristine natural world. These studies often set nature apart from human society and romanticized empty wilderness spaces. While the tourism industry and the state appeal to a similar construction of the landscape in the Maritimes, one that naturalizes portraits of the region as serene and idyllic, much Maritime writing and literary criticism reveals an equally romantic assessment of the natural environment. Many literary critics in the Maritimes, including Janice Kulyk Keefer, maintain that a central feature of the region's writing is an idealized representation of the natural world. This appears in several ways: authors dramatize Maritimers' painful experience of outmigration and the sense of loss that accompanies 
leaving behind the picturesque region; writers like Ernest Buckler and Bliss Carman display what Keefer calls a "pastoral impulse" that sees pristine nature as a space of renewal; and Alistair MacLeod and David Adams Richards, writers who have been called "neo-pastoral," lament modern society's destruction of the natural environment even as they attach a sense of masculine pride to the region's resource economy. For this reason, critics such as Brent MacLaine and Harry Thurston claim the Maritimes as a key space for the production of nature poetry and "proto-ecocritical" writing in Canada.

Recent studies in these fields, however, have identified a new political and theoretical project: exposing and deconstructing idealized and essentialist representations of nature and the Maritime region. Contemporary ecocritics argue that "nature" should be viewed as a cultural construction and that studies on wilderness poetry and environmentalist literature objectify the natural world. Similarly, Maritime literary critics like Gwendolyn Davies, David Creelman and Lothar Honnighausen contend that contemporary writers contest romantic portraits of the region and construct the Maritime landscape as bleak and alienating.

While traditional ecocriticism in Canada and Maritime literary criticism often assume that nature is transparent and essential, Lynn Coady's fiction historicizes constructions of the natural environment and undermines corporate and artistic efforts to romanticize it. In this way, her fiction unsettles conventional ideas of what both ecocritical literature and Maritime literature might look like. It is for this reason that poststructuralist ecocriticism provides a productive method of reading Coady's texts. Coady's fiction effectively stages the conflict between conventional ecocriticism that romanticizes the environment and more contemporary approaches that deconstruct concepts like nature 
and wilderness. By acknowledging and subverting exoticized versions of the natural environment in the Maritimes, Coady provides an alternative vision of nature for both ecocriticism in Canada and Maritime literary criticism.

One of the difficulties inherent in Coady's project of contesting definitions of nature as pristine wilderness and representations of the Maritimes as a serene, polite, and welcoming playground is that on the surface, both seem harmless and perhaps even positive. It would be difficult to find someone other than Isadore Aucoin who would denigrate the idea of preserving the natural environment, and many Maritimers take pride in the notion that the region is hospitable and picturesque. As I have argued in this thesis, however, these kinds of spatial definitions serve to normalize repressive notions surrounding gender, to obscure poverty and violence by portraying the Maritimes as idyllic, and direct attention away from the fact that in regions such as rural Cape Breton, people live on top of, and alongside, pollution and industrial waste.

As I have suggested, Coady's narrative strategy makes her political stance with respect to the issues raised by this thesis difficult to pin down. While her fiction's ironic voice tends to dull its political edge and defer many of the classic social realist themes her texts approach, in her journalistic work, Coady stakes out a position on these issues and bolsters it through objectively verifiable statistics and substantiated anecdotal evidence. While the ideological bearing of her novels is often difficult to discern, Coady's views on these issues are clear throughout her newspaper and magazine articles. Coady is particularly forceful in her non-fiction writing in attacking what she sees as the harmful stereotypes often attached to the Maritimes. 
In her journalistic essays, Coady openly rejects idealized representations of the Maritimes and details their effects on the inhabitants of the region. For example, in her 1999 article, "That Rosy Image is the Pits," Coady argues that the CBC's token Maritime

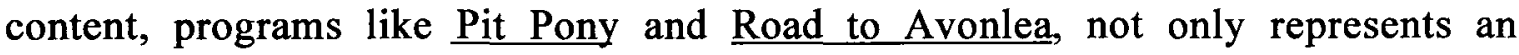
essentialized and antimodern version of life on the East Coast but also trivializes social issues that afflict the region. Coady says that cultural elites from central Canada and the East Coast effectively dehumanize Maritime culture and present it as fixed in time. She writes that in such pieces, "Maritime society consists of a basically cheerful, fresh-faced lot, suffering the occasional bout of hardship and poverty, but always bounding back with the help of friendly, supportive neighbours, a loving family, and an ever-present, gorgeously bucolic landscape that is frozen in time in the early 1900s. This is not only crap, but it's insulting crap" ("Rosy Image" E7). She also contends that the forced quaintness of "Pit Pony" makes light of the brutal labour practices of colonial-era enterprises like the National Coal Company that dominated industrial Cape Breton in the nineteenth and early twentieth centuries. While the CBC airs Pit Pony and $\underline{\text { Road to }}$ Avonlea regularly - because of their successful ratings - it infrequently broadcasts grittier films such as Life with Billy, which, in Coady's estimation, provide a more faithful rendering of the region's often violently abusive and economically downtrodden culture. Ultimately, Coady argues, "Maritime schlock is a means of trivializing and downplaying the past and present reality of all Atlantic Canadians" ("Rosy Image" E7).

In her introduction to Victory Meat: New Fiction from Atlantic Canada, Coady examines the cultural effects of stereotypes attached to Canada's East Coast. While the inhabitants of Atlantic Canada suffer from economic and social marginalization at the 
hands of the rest of the country, she also points to a less tangible but equally pressing problem: the "fetishization" of the region's culture. While poverty, deindustrialization and political alienation have direct negative effects on the people who live in Atlantic Canada, at first glance, the consequences of attempts by outsiders, the state, the tourism industry, and artists to romanticize the region are less obvious. However, Coady argues that in response to the increased demand for "traditional" music, quirky arts and crafts, and nostalgic literature, artists within the region produce merchandise to satisfy this market and inhabitants of the region often defer to outsiders by conforming to preconceived ideas about how they should live.

Coady goes on to suggest that regionalist literature has often played an important role in rejecting such definitions. While Coady mainly calls attention to contemporary Maritime literature's deconstructive use of gender, class and, ethnicity, which undermines both external stereotypes about the region and canonical literary tropes from within Atlantic Canada, she also refers to the role that the natural environment plays in this project: "Gee, I always thought Great Uncle Bob's place was a shitbox, but apparently it's been quaint all this time. My grandparents' music - the stuff that used to grate on my teenage ears - is suddenly 'haunting,' just like the landscape that was, for so many years, simply the place where I lived" ("Books that say arse" 2 ). Coady points out in this essay, as she demonstrates in all of her fiction, that romanticized definitions of nature in the Maritimes conceal what she sees as the actual experience of life in the region, which often includes economic uncertainty, domestic violence, substance abuse, and various other social problems. In this quotation, Coady notes that idealized versions 
of the landscape play as important a role as traditional music in propping up such definitions of Atlantic Canada.

In spite of the discrepancy between her literary and journalistic voices, I would like to argue that Coady also highlights in her fiction the consequences of seemingly straightforward definitions of nature as gendered, idyllic and pristine. Coady's ironic treatment of class, gender, ethnicity, regional stereotypes, the relationship between Cape Breton society and the Catholic Church, and, as this thesis has explored, depictions of the natural environment are all aimed at exposing the societal forces that undergird them. Coady's fiction points to the contradictions, hypocrisies, fabrications and affectations that prop up conventional definitions of the environment and deconstructs them with equal vigour. As discussed in Chapter 3, W.J.T. Mitchell and William Cronon argue that definitions of landscape are not innocuous, but are imbued with ideological force and deployed for specific reasons. Each construct that I have identified in Coady's fiction has direct effects on her characters.

Notions surrounding the "natural" maternal body and women as exploitable serve to regulate female sexuality and control reproduction. Coady examines and contests this construction of nature in Strange Heaven, emphasizing images of the abject in order to call attention to the regulations the health care apparatus and Bridget's family place on her. In her later texts, she satirizes educational and familial structures that encourage young men to take dangerous industrial jobs. In Play the Monster Blind, $\underline{\text { Saints of Big }}$ Harbour and Mean Boy, Coady undermines the hyper-masculine persona characters like John MacNeil, Isadore Aucoin and Jim Arsenault craft for themselves. While in Play the Monster Blind and Mean Boy, Coady's satire focuses mainly on the degree to which 
these men are petty, violent, and ultimately ridiculous in their attempts to connect themselves to a "traditional" masculine culture that harvested resources and lived off the land, in Saints of Big Harbour, the consequences are much more direct. In this novel, Coady identifies masculinity as a toxic force, one that pushes young men into industries that harm their own bodies as well as the natural environment.

As Alison Calder, Lothar Honnighausen, Ian McKay and Thomas Dunk argue, in ascribing places such as the Prairies, Northern Ontario and the Maritimes with fabricated "traditional" cultures, economic forces from within and outside those regions exploit and infantilize the people who live there. They specifically critique academic, social and literary attempts to delineate these regions based on environmental and cultural determinism. In terms of this thesis, such attempts to secure definitions of regional space serve, as Calder argues, to pass off economic problems within them as linked to cultural factors, allowing corporate and governmental elites to push environmentally and socially irresponsible industries as a cure. In her fiction, Coady specifically examines the way in which definitions of the Maritimes as idyllic and backwards emerge in the relationship between the tourism industry and the region. In these texts, the tourist gaze works to essentialize not only the landscape of the region but also the people who live in it.

Coady often satirizes the perspective of outsiders to the region, many of whom come to the Maritimes in search of an "authentic" premodern culture and dramatic scenery. In Coady's fiction, the Maritimes' invented idyllic landscape is not injurious simply because it is dishonest; the campaign by state and corporate elites to create and nurture the region's tourism industry has tangibly harmful effects on the inhabitants of the Maritimes. Several of Coady's characters attempt to conform to the tourism 
industry's version of what Cape Breton society should look like; however, many also express a sense of hostility towards visitors to the region. In Play the Monster Blind, Coady identifies other fabricated idyllic landscapes in Canada, including the West Coast and Georgian Bay, which she compares with the tourism-created definitions of Cape Breton. Although Coady's treatment of the tourism industry ranges from bitterly satirical in "Play the Monster Blind" to humorously ambivalent in Mean Boy, her texts are always attuned to the effects of the gaze of the outsider on the inhabitants of the East Coast. A constant theme in Coady's fiction is the way in which conventional portraits of the Maritimes conceal the presence of violence in the area. Coady's Maritime communities are marked by constant and often very public hostility. While conventional representations of Cape Breton and New Brunswick accentuate the safety and serenity of the region, characters such as Bridget and Guy are targeted for attack on the basis of their gender or ethnicity.

Finally, as detailed in Chapter 3, conventional ecocriticism's definition of nature as pristine wilderness has the effect of leaving polluted and toxic spaces unproblematized. As Cronon and Haraway argue, it is imperative that environmental thought acknowledge, rather than condemn, the human presence in nature, as it is too long-standing and pervasive to overlook. Coady's fiction confronts readers with a desecrated and unpleasant landscape and her characters display a "toxic consciousness" which often emphasizes the permanence of the region's waste and pollution.

The inhabitants of Coady's Cape Breton live alongside and on top of industrial waste and pollution. Her texts reveal an ironic relationship with the toxic elements of Cape Breton society: characters often crave the "trash" that corporations such as Dairy 
Queen and Sobey's serve them, incorporate things like exhaust and discarded concrete into their childhood games and commemorate the presence of mills that dump soursmelling smoke into the air and subject their workers to constant physical abuse. At the same time, Coady connects exposure to the toxic landscape to ethnicity and class status, and constructs a Cape Breton in which the waste products of mining and manufacturing constitute a permanent and integral facet of the landscape. As a result of their alienation from the natural environment, characters like Robert Murphy and Guy "fetishize" highly artificial and sanitized representations of nature.

In spite of its ironic and contingent narrative strategy, Coady's fiction points out that conventional definitions of the environment have direct consequences on the inhabitants of Maritime Canada. Just as post-structuralist ecocriticism illuminates this aspect of Coady's fiction, Strange Heaven, Play the Monster Blind, Saints of Big Harbour and Mean Boy provide ecocriticism in Canada with a vision of the natural environment that problematizes the relationship between the gendered body and nature, deconstructs romanticized portraits of the Maritimes, and reminds readers and critics that people live in and around polluted and despoiled environments like the one found in industrial Cape Breton. 


\section{WORKS CITED}

Adamson, Arthur. "Identity through Metaphor: An Approach to the Question of Regionalism in Canadian Literature." Studies in Canadian Literature 5.1 (1980): 83-99.

Alaimo, Stacey. Undomesticated Ground: Recasting Nature as Feminist Space. Ithaca: Cornell University Press, 2000.

Alexander, David. "Canadian Regionalism: A Central Problem." In Atlantic Canada and Confederation: Essays in Canadian Political Economy. Ed. Eric Sager, Lewis Fischer and Stuart Pierson. Toronto: University of Toronto Press, 1983. 44-50. ---. "New Notions of Happiness: Nationalism, Regionalism and Atlantic Canada." Atlantic Canada and Confederation: Essays in Canadian Political Economy. Ed. Eric Sager, Lewis Fischer and Stuart Pierson. Toronto: University of Toronto Press, 1983. $79-100$.

Allison, Michael David. The Individual is Everything or the World is Nothing: Morality and Regionalism in the Novels of David Adams Richards. M.A. Thesis, Acadia University, 2001.

Angus, Ian. A Border Within: National Identity, Cultural Plurality, and Wilderness. Montreal: McGill-Queen's University Press, 1997.

Armbruster, Karla,. “A Post-Structuralist Approach to Ecofeminist Criticism.” The Green Studies Reader: From Romanticism to Ecocriticism. Ed. Laurence Coupe and Jonathan Bate. New York: Routledge, 2000. 198-207.

Armbruster, Karla, and Kathleen Wallace, eds. Beyond Nature Writing. London: University of Virginia Press, 2001. 
Armstrong, Christopher. Placing Atlantic Canada. Ph.D. Dissertation, Universite de Montreal, 1998.

---. "Post-Colonial Historicity: Halifax, Region, and Empire in Barometer Rising and The Nymph and the Lamp." Downtown Canada: Writing Canadian Cities. Ed. Justin Edwards and Douglas Ivison. Toronto: University of Toronto Press, 2005. 50-64. ---. and Herb Wyile. "Firing the Regional Can(n)on: Liberal Pluralism, Social Agency, and David Adams Richards's Miramichi Trilogy." Studies in Canadian Literature 22 (1997): 1-18.

Atherton, Stanley. "Fighting Back: The Regional Renaissance in Recent Canadian Fiction." World Literature Written in English 24.1 (1984): 127-134.

Atwood, Margaret. "Last Testaments: Pat Lowther and John Thompson." Second Words: Selected Critical Prose. Toronto: Anansi, 1982. 307-312.

---. Oryx and Crake. Toronto: McLelland and Stewart, 2003.

---. Surfacing. Toronto: McLelland and Stewart, 1972.

---. Survival: A Thematic Guide to Canadian Literature. Toronto: Anansi, 1972.

---. The Journals of Susanna Moodie: Poems by Margaret Atwood. Toronto: University of Oxford Press, 1970.

Bach, Susanne. "The Geography of Perception in Hugh MacLennan's Maritime Novels." Down East: Critical Essays on Contemporary Maritime Canadian Literature. Ed. Wolfgang Hochbruck and James Taylor. Trier: Wissenschaftlicher, 1996. 81-93. Bailey, A.G. "The Literature of Nova Scotia," Dalhousie Review 29 (1949): 231-44. Bakhtin, Mikhail. "Discourse in Life and Discourse in Art (Concerning Sociological Poetics)." Freudianism: A Marxist Critique. Trans. I.R. Titunik. New York: 
Academic Press, 1976. 93-116.

--. Rabelais and His World. trans. Helene Iswolsky. Bloomington: Indiana University Press, 1984.

Balsom, Edwin. Dialogic Regional Voices: A Study of Selected Contemporary Atlantic-

Canadian Fiction. Ph.D. Thesis, Memorial University of Newfoundland, 1998.

Barry, Peter. Beginning Theory: An Introduction to Literary and Cultural Theory. New

York: Palgrave, 2002.

Bate, Jonathan. Song of the Earth. London: MacMillan Publishers Ltd., 2000.

Beneke, Timothy. Proving Manhood: Reflections on Men and Sexism. Berkeley:

University of California Press, 1997.

Bennett, Michael and David Teague (eds). The Nature of Cities: Ecocriticism and Urban Environments. Tucson: University of Arizona Press, 1999.

Bentley, DMR. "The Absence of Neoconservatism and Ecocriticism in Canadian Literary Studies." Canadian Poetry 42 (Spring/Summer 1998): 5-16.

---. The Gay/Grey Moose: Essays on the Ecologies and Mythologies of Canadian Poetry, 1690-1990. Ottawa: University of Ottawa Press, 1992.

--.. "Preface: On the Confederation Poets' Companionship with Nature: Archibald Lampman." Canadian Poetry 48 (Spring/Summer 2001): 5-12.

Berces, Frances. “Existential Maritimer: Alistair MacLeod's The Lost Salt Gift of Blood." Studies in Canadian Literature. 16. 1 (1991): 114-128.

Bezanson, Kate and Meg Luxton (eds). Social Reproduction: Feminist Political Economy

Challenges Neo-liberalism. Montreal: McGill-Queen's University Press, 2006.

Blodgett, E. D. “Intertextual Designs in Hugh MacLennan's The Watch That Ends the 
Night." Canadian Review of Comparative Literature 5 (1978): 280-88.

Bondar, Alanna. Greening the Green Space: Exploring the Emergence of Canadian

Ecological Literature Through Ecofeminist and Ecocritical Perspectives. Ph.D.

Thesis, Memorial University of Newfoundland, 2003.

---. “'that every feather is a pen, but living, // flying' Desire: The Metapoetics of Don

McKay's Birding, or desire." Studies in Canadian Literature 19.2 (1994): 14-29.

Bookchin, Murray. Essays on Social Ecology: Essays on Dialectical Naturalism.

Montreal: Black Rose Books, 1995.

Bowerbank, Sylvia. "Towards the Greening of Literary Scholarship." Canadian Review of Comparative Literature 22.3-4 (1995): 443-454.

Brodie, Janet. The Political Economy of Canadian Regionalism. 1990

Brown, Cecily. People-as-Garbage: A Metaphor We Live By. Storytelling as Composting in Six Novels: Toni Morrison's The Bluest Eye, Margaret Laurence's The Diviners, LeslieMarmon Silko's Ceremony, Marilynne Robinson's Housekeeping, Jane Smiley's A Thousand Acres and Dorothy Allison's Bastard out of Carolina. Ph.D. Thesis, University of Minnesota, 2000.

Brydon, Diana. "Landscape and Authenticity.” Dalhousie Review 61.2 (1981): 278-290.

Buckler. Ernest. The Mountain and the Valley. Toronto: McLelland and Stewart, 1989.

Buckner, Phillip. "Limited Identities Revisited: Regionalism and Nationalism in Canadian History." Acadiensis 30.1 Autumn, 4-15, 2001.

Buell, Lawrence. “Toxic Discourse.” Critical Inquiry 24 (Spring 1998): 639-665.

---. Writing for an Endangered World: Literature, Culture, and Environment in the US and Beyond. Cambridge, MA: Harvard University Press, 2001.

Bushell, Kevin. "Don McKay and Metaphor: Stretching Language Toward Wilderness." 
Studies in Canadian Literature 21.1 (1995): 37-55.

Buss, Helen. "Women and the Garrison Mentality: Pioneer Women Autobiographers and their Relation to the Land." $\underline{\operatorname{Re}(d i s) c o v e r i n g ~ O u r ~ F o r e m o t h e r s . ~ O t t a w a: ~ U n i v e r s i t y ~}$ of Ottawa Press, 1989. 123-136.

Butler, Judith. Gender Trouble: Feminism and the Subversion of Identity. New York: Routledge, 1990.

Butterbox Babies. Dir. Don McBrearty. Perf. Susan Clark, Peter MacNeill, Catherine Fitch. Canadian Broadcasting Corporation, 1995.

Calder, Alison. "Reassessing Prairie Realism.” A Sense of Place: Re-evaluating Regionalism in Canadian and American Writing. Ed. Christian Riegel and Herb Wyile. Edmonton: University of Alberta Press, 1998. 51-60.

---. "The Wilderness Plot, the Deep Map and Sharon Butala's Changing Prairie." Essays on Canadian Writing 77 (2002): 164-185.

Cameron, Donald. "The Maritime Writer and the Folks down Home." Canadian Literature 68-69 (1976): 113-21.

--- “Thomas Raddall: The Art of Historical Fiction.” Dalhousie Review 49 (1969): 54048.

Campbell, Joel. Tarcadia. Kentville, Nova Scotia: Gaspereau Press, 2004.

Campbell, Sabine (ed). Home For Christmas: Stories from the Maritimes and Newfoundland. Fredericton: Goose Lane Editions, 1999.

Careless, J.M.S. “Frontierism and Metropolitanism: Concepts Revisited." Frontier and Metropolis: Regions, Cities and Identities in Canada Before 1814. Toronto: University of Toronto Press. 35-67. 
---. "Limited Identities in Canada" Canadian Historical Review 50 (1969): 1-10.

Carruth, Mary C. “Between Abjection and Redemption: Mary Rowlandson's Subversive Corporeality." Feminist Interventions in Early American Studies. Ed. Mary

Carruth. Tuscaloosa: University of Alabama Press, 2006. 60-79.

Carson, Rachael. Silent Spring. New York: Mahoney and Rose Inc., 1962.

Chalykoff, Lisa. "Overcoming the Two Solitudes of Canadian Literary Regionalism"

Studies in Canadian Literature 23.1 (1998): 160-177.

---. Space and Identity Formation in Twentieth-century Canadian Realist Novels:

Recasting Regionalism in Canadian Literary Studies. Ph.D. Dissertation, U.B.C., 2000.

Chambers, Robert "Notes on Regionalism in Modern Canadian Fiction.” Journal of Canadian Studies 11.2 (1976): 206-25

---. "The Novels of Hugh MacLennan." Journal of Canadian Studies 2 (1967 Aug): 3-11. Cogswell, Fred. "Alden Nowlan as Regional Atavist." Studies in Canadian Literature 11.2 (1986): 206-225.

---. "Some Notes on the Development of Regional Fiction in the Maritimes." Essays on Canadian Writing 31 (Summer 1985): 192-200.

Conlin, Christy-Ann. Heave. Toronto: Doubleday Canada, 2002.

Connor, William. "The Unlikely Heroes of David Adams Richards' Second Trilogy." The International Fiction Review 25 (1998): 71-77.

--- "The River in the Blood." World Literature in English 26 (1986): 269-277.

Cook, Ramsay. “Cabbages Not Kings: Towards an Ecological Interpretation of Early Canadian History." Journal of Canadian Studies 25.4 (Winter 1990-91): 5-16. 
Cormier, Audrey. Regionalism in the Fiction of Alistair MacLeod, Alden Nowlan, and David Adams Richards. M.A. Thesis, University of New Brunswick, 2000.

Cottonland. Dir. Nance Ackerman. Documentary. National Film Board of Canada, 2006.

Coupe, Laurence and Jonathan Bate (eds). The Green Studies Reader: From Romanticism to Ecocriticism. New York: Routledge, 2000.

Creelman, David. "Conservative Solutions: The Early Historical Fiction of Thomas Raddall." Studies in Canadian Literature 20.1 (1995): 127-49.

---. "Hoping to Strike Some Sort of Solidity: The Shifting Fictions of Alistair MacLeod." Studies in Canadian Literautre 24.2 (1999): 79-99.

---. Setting in the East: Maritime Realist Fiction. Montreal: McGill-Queen's University Press, 2003.

Cresswell, T. Place: A Short Introduction. Oxford: Blackwell Publishing, 2004. Cronon, William. "The Trouble With Wilderness; or, Getting Back to the Wrong Nature." Uncommon Ground: Rethinking the Human Place in Nature. Ed. William Cronon. New York: Norton, 1996. 69-90.

Cumyn, Richard. "Susan Kerslake, at Home, Halifax, February 23, 2003." New Quarterly: New Directions in Canadian Writing 88 (2003 Fall): 118-43. Cunningham, Valerie. "Twentieth-century Fictional Satire." A Companion to Satire. Ed. Robin Quintero. Malden: Blackwell Publishing, 2007. 400-433.

Cuomo, Chris. “Still Fooling with Mother Earth.” Hypatia 16.3 (Summer 2001): 149-157. Currie, Sheldon. "David Adams Richards: The People on the Roadway." Down East: Critical Essays on Contemporary Maritime Canadian Writing. Ed. Wolfgang Hockbruck and James Taylor. Berstgrabe, Trier: Wissenschaftlicher, 1996. 133- 
144.

--.. The Glace Bay Miners' Museum. Wreck Cove: Breton Books, 1995.

Davey, Frank. "Discourse and Determinism in Nights Below Station Street." Post-

National Arguments. Toronto: University of Toronto Press, 1993. 67-80.

---. Reading Canadian Reading. Winnipeg: Turnstone Press, 1988.

---. "Towards the Ends of Regionalism." A Sense of Place: Re-evaluating Regionalism in

Canadian and American Writing. Ed. Christian Riegel. Edmonton: University of Alberta Press, 1997. 1-17.

Davies, Gwendolyn. "Literary Cultures in the Maritime Provinces." History of the Book in Canada Vol 1. Ed. Patricia Lockhart Fleming et al. Toronto: University of Toronto Press, 2004. 368-78.

--- (ed). Myth and Milieu: Atlantic Literature and Culture 1918-1939. Fredericton: Acadiensis Press, 1983.

---. Studies in Maritime Literary History, 1760-1930. Fredericton: Acadiensis Press, 1991.

---. "The West Indies \& the Literature of Maritime Canada." Canadian Literature 95 (1982 Winter): 177-181.

Davis, Richard. “Fluid Landscape/Static Land: The Traveller's Vision.” Essays on Canadian Writing 34 (1987): 140-156.

de Beauvoir, Simone. The Second Sex. trans. H.M. Parshley. New York: Knopf, 1953. Deitering, Cynthia. "The Postnatural Novel: Toxic Consciousness in Fiction of the 1980s." The Ecocriticism Reader: Landmarks in Literary Ecology. Ed. Cheryll Glotfelty and Harold Fromm. Athens: University of Georgia Press, 1996. 196- 
203.

Dickinson, Adam. Lyric Ethics: The Matter and Time of Ecopoetry. Ph.D. Thesis, University of Alberta, 2005.

Dickinson, Mark. Notes to a Poetics of Earth. Ph.D. Thesis, Trent University, 2007. Dodeman, André. “Vicissitude in Hugh MacLennan's The Watch That Ends the End." Commonwealth Essays and Studies 26:1 (2003 Autumn): 91-97.

Donawerth, Jane. Frankenstein's Daughters: Women Writing Science Fiction. Syracuse: Syracuse University Press, 1997.

Doucet, Clive. Notes From Exile: On Being Acadian. Toronto: MacLelland and Stewart, 1999.

---. The Priest's Boy. Windsor: Black Moss Press, 1992.

Doyle, James. “The Politics of Nature: Archibald Lampman's Socialism." Canadian Poetry 45 (1999): 10-30.

Dunk, Thomas. It's a Working Man's Town: Male Working Class Culture. Montreal: McGill-Queen's University Press, 2003.

Dvorak, Marta. Ernest Buckler: Rediscovery and Reassessment. Waterloo: Wilfrid Laurier UP, 2001.

---. and Coral Ann Howells. "The Literature of Atlantic Canada." Canadian Literature 189 (2006): 6-13.

Eco, Umberto. “The Frames of Comic 'Freedom." Carnival! Ed. Thomas A. Sebeok. New York: Mouton Publishers, 1984. 1-9.

Edwards, Justin and Douglas Ivison (eds). Downtown Canada: Writing Canadian Cities. Toronto: University of Toronto Press, 2005. 
Eliot, T.S. The Waste Land and Other Poems. New York: Harcourt Brace, 1962.

Empson, William. Some Versions of Pastoral. London: Chatto and Windus, 1935.

Fiamengo, Janice. "Towards a Theory of Popular Landscape in Anne of Green Gables."

Making Avonlea: L.M. Montgomery and Popular Culture Ed. Irene Gammel.

Toronto: University of Toronto Press, 2002. 225-37.

Field, Terri. “Is the Body Essential for Ecofeminism?" Organization Environment 13.1

(March 2000): 39-60.

Finnigan, Mary Francis. To Live Somewhere Else: Migration and Cultural Identity in

Alistair MacLeod's Fiction. M.A. Thesis, Saint Mary's Univeristy, 1996.

Forbes, Ernest. Challenging the Regional Stereotype. Fredericton: Acadiensis Press, 1987.

Forster, Sophia. “Don McKay’s Comic Anthropocentrism: Ecocriticism Meets ‘Mr.

Nature Poet."' Essays on Canadian Writing 77 (2002): 107-135.

Foster, Hal. “Obscene, Abject, Traumatic.” October 78 (Fall 1996). 105-124.

Foster, Janet. Working for Wildlife. Toronto: University of Toronto Press, 1978.

Foucault, Michel. "Docile Bodies.” The Foucault Reader. Ed. Paul Rabinow. New York:

Pantheon Books, 1984.

French, William. "Searing Fidelity About Grim Losers." Globe and Mail Nov. 25 1989:

35.

Friesen, G. "The Evolving Meanings of Region in Canada." Canadian Historical Review 82.3 (2001): 529-545.

Frus, Phyllis. The Politics and Poetics of Journalistic Narrative: The Timely and the Timeless. New York: Cambridge University Press, 1994. 
Frye, Northrop. Anatomy of Criticism: Four Essays. Atheneum, New York: Princeton University Press, 1957.

---. "Conclusion to A Literary History of Canada." Northrop Frye: Mythologizing

Canada. Essays on the Canadian Literary Imagination. Ed. Branko Gorjup.

Ottawa: Legas, 1996. 63-95.

---. Divisions on a Ground: Essays on Canadian Culture. Ed. James Polk. Toronto:

Anansi Press, 1982.

---. The Bush Garden. Toronto: Anansi, 1971.

Fuller, Danielle. Writing the Everyday: Women's Textual Communities in Atlantic

Canada. Montreal: McGill-Queen's University Press, 2004.

Gaffield, Chad and Pam Gaffield. Consuming Canada: Readings in Environmental History. Toronto: Copp Clark, 1995.

Garforth, Lisa. "Ideal Nature; Utopias of Landscape and Loss." Spaces of Utopia: An Electronic Journal 3 (Autumn/Winter 2006): 5-6.

Garrard, Greg. Ecocriticism. New York: Routledge, 2004.

Gifford, Terry. Pastoral. New York: Routledge, 1999.

Gilbert, Sandra and Susan Gubar. The Madwoman in the Attic: The Woman Writer and the Nineteenth-Century Literary Imagination. New Haven: Yale University Press, 1984.

Giltrow, Janet and David Stouck. “'Mute Dialogues': Michael Ondaatje's Running in the Family and the Language of Postmodern Pastoral," Postmodern Fiction in Canada. Ed. Theo D'haen and Hans Bertens. Amsterdam: Rodopi, 1992. 161-79. Gittings, Christopher. “Melodrama for the Nation: Emily of New Moon." Making 
Avonlea: L.M. Montgomery and Popular Culture Ed. Irene Gammel. Toronto: University of Toronto Press, 2002. 186-200.

Glotfelty, Cheryll and Harold Fromm (eds). The Ecocriticism Reader: Landmarks in Literary Ecology. Athens: University of Georgia Press, 1996.

Goin' Down the Road. Dir. Donald Shebib. Perf. Doug McGrath and Paul Bradley. Edvon Films Ltd., 1970.

Griffin, S. "Ecofeminism and Meaning," Ecofeminism: Women, Nature, Culture. Ed.

Karen Warren. Indianapolis: Indiana University Press, 1997. 213-226.

Gross, Elizabeth. "The Body of Signification." Abjection, Melancholia, And Love: The

Work of Julia Kristeva. London and New York: Routledge, 1990. 80-103.

Guilford, Irene, ed. Alistair MacLeod: Essays on his Works Toronto: Guernica, 2001.

Haag, Stefan. "Ecological Aurality and Silence in Margaret Atwood." Canadian Poetry 47 (2000): 14-39.

Hamming, Jeanne. Second Natures: Media, Masculinity and the Natural World in Twentieth-Century American Film and Literature. Ph.D. Thesis, West Virginia University, 2003.

Haraway, Donna. "A Cyborg Manifesto: Science, Technology, and Socialist-Feminism in the Late Twentieth Century." Simians, Cyborgs and Women: The Reinvention of Nature. New York: Routledge, 1991. 149-181.

Hart, Jonathan. “Afterward: Sense of Place: A Response to Regionalism.” A Sense of Place: Re-Evaluating Regionalism in Canadian and American Writing. Ed. Christian Riegel and Herb Wyile. Edmonton: University of Alberta Press, 1997. 113-8. 
Hartman, Simone Birgitt. "Feminist and Postcolonial Perspectives on Ecocriticism in a Canadian Context: Toward a 'Situated' Literary Theory and Practice of Ecofeminism and Environmental Justice" Nature in Literary and Cultural Studies: Transatlantic Conversations in Ecocriticism. Eds. Catrin Gersdorf and Sylvia Mayer. Amstersam: Rodopi, 2006. 87-110.

Harvey, David. "Between Space and Time: Reflections on the Geographical Imagination." Annals of the Association of American Geographers 80.3 (1990): 418-434.

Hawkins, W. J. “Thomas Raddall: The Man and His Work." Queen's Quarterly 75 (1968): 137-146.

Helms, Gabriele. "Contemporary Canadian Poetry from the Edge: An Exploration of Literary Eco-criticism." Canadian Poetry 36 (Spring/Summer 1995): 44-61. Heise, Ursula. "Toxins, Drugs, and Global Systems: Risk and Narrative in the Contemporary Novel." American Literature 74.4 (December 2002): 748-778.

Hessing, Melody, Raglon, Rebecca and Catriona Sandilands (eds). This Elusive Land: Women and the Canadian Environment. Toronto: UBC Press, 2005.

Hochbruck, Wolfgang. "Centre and Margin: Literature from the Maritimes" Down East. Critical Essays on Contemporary Maritime Canadian Writing. Ed. Wolfgang Hochbruck and James Taylor. Berstgrabe, Trier: Wissenschaftlicher, 1996. 9-21. Honnighausen, Lothar. "Defining Regionalism in North American Studies." Regionalism in the Age of Globalism. Ed. Lothar Honnighausen. Madison: Center for the Study of Upper Midwestern Cultures, 2005. 159-185.

Horrocks, Roger. Male Myths and Icons: Masculinity in Popular Culture. London: 
MacMillan, 1995.

Howells, Coral Ann. Where are the Voices Coming From? Canadian Culture and the Legacies of History. Amsterdam: Rodopi, 2004.

Hutcheon, Linda. A Theory of Parody: The Teachings of Twentieth Century Art Forms. New York: Methuen, 1985.

--.. "Eruptions of Postmodernity: the Post-Colonial and the Ecological," Essays on Canadian Writing 51-2 (Winter 1993 -Spring 1994): 146-63.

---. Irony's Edge: The Theory and Politics of Irony. New York: Routledge, 1995.

---. Splitting Images: Contemporary Canadian Ironies. Toronto: Oxford University Press, 1991.

---. "The Power of Postmodern Irony." Genre, Trope, Gender: Essays by Northrop Frye, Linda Hutcheon and Shirley Neuman. Ed. Barry Rutland. Ottawa: Carleton University Press, 1992. 35-49.

Jackson, Phoebe. “The 'Critical' Work of Edited Collections: Re-viewing the Texts of Willa Cather and Edith Wharton." College Literature 32.4 (2003), 211-216. Jaeger, Peter. “"The Land Created a Body of Lore': The Green Story in John Steffler's The Afterlife of George Cartwright." English Studies in Canada 21.1 (1995): 4154.

Johnston, Susan. "Reconstructing the Wilderness: Margaret Atwood's Reading of Susanna Moodie." Canadian Poetry 31 (1992): 28-54.

Jones, D.G. “Al Purdy's Contemporary Pastoral," Canadian Poetry 10 (1982): 32-43.

--- Butterfly on Rock. Toronto: University of Toronto Press, 1970.

Katz, Eric, Light, Andrew and David Rothenburg (eds). Beneath the Surface: Critical 
Essays in the Philosophy of Deep Ecology. Cambridge: MIT Press, 2000.

Kealey, Greg. Class, Gender and Region; Essays in Canadian Historical Sociology. St.

John's: Commmittee on Canadian Labour History, 1988.

Keefer, Janice Kulyk. "Fortunate Falls and Propitious Expulsions: Anglophone Fictions and the 'Acadian Question'.” International Journal of Canadian Studies 10 (1994 Fall): 29-45.

---. "Nova Scotia's Literary Landscape." Down East: Critical Essays on Contemporary Maritime Canadian Literature. Ed. Wolfgang Hochbruck and James Taylor. Trier: Wissenschaftlicher, 1996. 23-40.

---. "Recent Maritime Fiction: Women and Words." Studies in Canadian Literature 11:2 (1986 Fall): 168-181.

---. Under Eastern Eyes: A Critical Reading of Maritime Fiction. Toronto: University of Toronto Press, 1987.

Keith, W. J. "The Poetry of Alden Nowlan: A Critical Reassessment." Canadian Poetry: Studies, Documents, Reviews 53 (2003 Fall-Winter): 9-32.

Kern, Robert. "Ecocriticism: What is it Good For?" The Isle Reader. Ed. Michael Branch and Scott Slovic. Athens: University of Georgia Press, 258-281.

Kerridge, Richard. Writing the Environment. New York: Zed Books, 1998.

Kerslake, Susan. "White Laughter: Telling Stories at the Edge of the Abyss." New Quarterly: New Directions in Canadian Writing 88 (2003 Fall): 106-10.

Kheel, Marti. "Ecofeminism and Deep Ecology: Reflections on Identity and Difference." Re-weaving the World: The Emergence of Ecofeminism. Ed. I. Diamond and G. Orenstein. San Francisco: Sierra Book Clubs, 1995. 128-137. 
Knight, Charles. "Satire, Speech, and Genre." Comparative Literature 44.1 (1992): 22-41.

Kollin, Susan. "Toxic Subjectivity: Gender and the Ecologies of Whiteness in Todd

Haynes' Safe." Isle: Interdisciplinary Studies in Literature and Environment 9.1

(Winter 2002): 121-139.

Korte, Barbara. "English-Canadian Perspectives of Landscape." International Journal of

Canadian Studies 6 (1992), 9-24.

Kristeva, Julia. Powers of Horror: An Essay on Abjection. Trans. Leon S. Roudiez. New York: Columbia University Press, 1982.

Kristiansen, Erik. "Time, Memory and Rural Transformation: Rereading History in the Fiction of Charles Bruce and Ernest Buckler." Contested Countryside. Ed. Daniel Samson. Fredericton: Acadiensis Press, 1994: 225-257.

Lacombe, Michèle. "Carnival." Encyclopedia of Contemporary Literary Theory:

Approaches, Scholars, Terms. Ed. Irena Makaryk. Toronto: University of Toronto Press, 1993: 516-518.

Laurence, Margaret. The Diviners. Toronto: McLelland and Stewart, 1978.

Lebowitz, Andrea. "Narratives of Coming Home: Gilean Douglas and Nature Writing."

Canadian Poetry 42 (Spring/Summer 1998): 42-65.

---. "Women Write Nature" Canadian Literature 183 (Winter 2004): 124-125.

Lecker, Robert, ed. Canadian Canons: Essays in Literary Value, Toronto: University of Toronto Press, 1991.

Lee, Dennis. The Savage Fields Essays. Toronto: Anansi, 1977.

LeTourneau, Ian. Brash Postcards from the Wilderness: Don McKay's Ecopoetry. M.A. Thesis, University of New Brunswick, 2003. 
Lindsay, David. New River Strain: Locating the Author and the Narrator in David Adams

Ricards' Miramichi Trilogy. M.A. Thesis, Dalhousie University, 1997.

Lochhead, Douglas. “Atlantic Regionalism and Literature: Some Bibliographical

Comments." Essays on Canadian Writing 31 (1985): 262-66.

---. "The Literary Heritage: The Place, the Past, the Prospect." Atlantic Provinces

Literature Colloquium Papers. Ed. Kenneth MacKinnon. Saint John: Atlantic

Canada Institute, 1976. 3-12

Lousley, Cheryl. "Knowledge, Power and Place: Environmental Politics in the Fiction of Matt Cohen and David Adams Richards." Canadian Literature 195 (Winter 2007): 11-30.

Love, Glen A. Practical Ecocriticism: Literature, Biology, and the Environment. Charlottesville: University of Virginia Press, 2003.

---. "Revaluing Nature: Toward an Ecological Criticism." Western American Literature 25: 3 (1990): 201-215.

Luxton, Meg. 'Feminist Political Economy in Canada and the Politics of Social Reproduction." Social Reproduction: Feminist Political Economy Challenges Neo-liberalism. Ed. Kate Bezanson and Meg Luxton. Montreal: McGill-Queen's University Press, 2006. 11-45.

Lynes, Jeanette, and Herb Wyile. "Regionalism and Ambivalence in Canadian Literary History.” Open Letter 9.4 (1995): 117-27.

MacDonald, Ann-Marie. Fall on Your Knees. Toronto: Knopf, 1996.

MacDonald, Frances. "War of the Worlds: David Adams Richards and Modern Times." The Antigonish Review 104 (Winter 1996): 17-24. 
MacDonald, Larry. "Psychologism and the Philosophy of Progress: The Recent Fiction of MacLennan, Davies and Atwood." Studies in Canadian Literature 9:2 (1984): 121-143.

MacLaine, Brent and Hugh MacDonald, eds. Landmarks: An Anthology of New Atlantic

Canadian Poetry of the Land.Charlottetown: Acorn Press, 2001.

MacLaren, Ian. "The McGregor Syndrome." Canadian Poetry 18 (1986): 118-130.

MacLennan, Hugh. On Being a Maritime Writer. Sackville: Centre for Canadian Studies, 1984.

MacLeod, Alistair. No Great Mischief. Toronto: McLelland and Stewart, 1999.

---. "The Boat." Island: The Collected Stories. Toronto: McLelland and Stewart, 2000. 126.

---. "The Return." Island: The Collected Stories. Toronto: McLelland and Stewart, 2000. 79-98.

---. "The Closing Down of Summer" Island: The Collected Stories. Toronto: McLelland and Stewart, 2000. 180-209.

MacMillan, Carrie. "Works of Long Duration." Canadian Literature131 (1991): 207-208.

Maharaj, Rabindranath. "Bitches on All Sides." Victory Meat: New Fiction from Atlantic Canada. Ed. Lynn Coady. Toronto: Anchor Canada, 2003. 7-24.

Mandel, Eli. “The Regional Novel: Borderline Art.” Taking Stock: The Calgary Conference on the Canadian Novel. Ed. Charles Steele. Domsview, Ont.: ECW, 1982. 103-21.

Massey, Doreen. Space, Place and Gender. Cambridge: Polity, 1994.

Mazel, David (ed). A Century of Early Ecocriticism. Athens: Universty of Georgia Press, 2001. 
--- American Literary Environmentalism. Athens: The University of Georgia Press, 2000.

McCann, L.D. "Shock Waves in the Old Economy: Maritime Cities and the Great Transformation, c. 1867-1939." Shock Waves: The Maritime Urban System in the New Economy. Ed. G.J. Bendetti and R.H. Lamarche. Fredericton: Acadiensis Press, 1994. 2-44.

McCarthy, Cormac. The Road. New York: Knopf, 2007.

McCormick, Peter. "Regionalism in Canada: Disentangling the Threads." Journal of Canadian Studies 24.2 (1989): 5-21.

McGregor, Gaile. The Wacousta Syndrome: Explorations in the Canadian Langscape. Toronto: University of Toronto Press, 1985.

McKay, Ami. The Birth House. Toronto: A.A. Knopf, 2006.

McKay, Ian. Quest of the Folk: Antimodernism and Cultural Selection in TwentiethCentury Nova Scotia. Montreal: McGill - Queen's Press, 1994.

McKay, Leo. Like This: Stories. Concord: Anansi, 1996.

---. Twenty-Six. Toronto: McLelland and Stewart, 2003.

McKibben, Bill. The End of Nature. New York: Random House, 1989.

Merchant, Carolyn. The Death of Nature. New York: Harper and Row, 1980.

Milner, Phillip. "Structure in David Adams Richards' Unfinished Miramichi Saga." Essays on Canadian Writing 31 (1985): 201-210.

Mitchell, W.J.T. Landscape and Power. Chicago: University of Chicago Press, 1994. Moss, John. A Reader's Guide to the Canadian Novel. Toronto: McCelland and Stewart, 1987. 
---. "Landscape, Untitled." Essays on Canadian Writing 29 (1984): $26-47$.

---. Patterns of Isolation in English Canadian Fiction. Toronto : McClelland and Stewart, 1974.

Muise, Del. "Who Owns History Anyway? Reinventing Atlantic Canada for Pleasure and Profit." Acadiensis 27.2 (1998): 124-34.

Murray, Heather. "Women in the Wilderness." A/Mazing Space: Writing Canadian

Women Writing. Ed. Shirley Neuman and Smaro Kamboureli. Edmonton: Longspoon/NeWest, 1986. 74-83.

Namjoshi, S. "Double Landscape." Canadian Literature 67 (1976): 21-30.

New, W. H. "Beyond Nationalism: On Regionalism." World Literature Written in English 23.1 (1984): 12-18.

---. Land Sliding: Imagining Space, Presence, and Power in Canadian Writing. Toronto: University of Toronto Press, 1997.

---. "The Storm and After: Imagery and Symbolism in Hugh MacLennan's Barometer Rising." Queen's Quarterly 74 (1967): 302-313.

---. "Winter and the Night-People." Canadian Literature 36 (1968): 26-33.

Nielson, Dorothy. "Timothy Findley's Not Wanted on the Voyage: an Exemplary Ecofeminist Text." Canadian Poetry 42 (Spring/Summer 1998): 100-121.

Norgaard, K.M. "Moon Phases, Menstrual Cycles, and Mother Earth: The Construction of a Special Relationship Between Women and Nature," Ethics and the Environment 4.2 (1999): 197-209.

O'Brien, Mary. The Politics of Reproduction. Boston: Routledge and Kegan Paul, 1981. O'Brien, Susie. "Articulating a World of Difference: Ecocriticism, Postcolonialism and 
Globalization." Canadian Literature 170/171 (Autumn/Winter 2001): 140-158.

---. "Nature's Nation, National Natures? Reading Ecocriticism in a Canadian

Context." Canadian Poetry 42 (Spring/Summer 1998): 17-41.

O'dair, Sharon (2005) "'Horror or realism? Filming 'toxic discourse' in Jane Smiley's $A$

Thousand Acres" ${ }^{\text {"T }}$ Textual Practice, 19.2 (2005): 263-282.

O'Donnell, John C. (ed). The Men of the Deeps. Waterloo: Waterloo Music Company, 1975.

Oliver, Michael Brian. "Dread of the Self: Escape and Reconciliation in the Poetry of Alden Nowlan." Essays on Canadian Writing 5 (1976): 50-66.

---. "The Presence of Ice: The Early Poetry of Alden Nowlan." Studies in Canadian Literature 1 (1976): 210-22.

Omhovère, Claire. "Roots and Routes in a Selection of Stories by Alistair MacLeod." Canadian Literature 189 (2006): 50-67.

Overton, James. “'A Future in the Past'? Tourism Development, Outport Archaeology, and the Politics of Deindustrialization in Newfoundland and Labrador in the 1990s." Urban History Review 17.2 (March 2007): 60-76.

Pacey, Desmond. Creative Writing in Canada. Toronto: The Ryerson Press, 1952.

Pache, Walter. "English Canadian Fiction and the Pastoral Tradition." Canadian Literature 86 (1980): 15-28.

Palmeri, Frank. Satire in Narrative: Petronius, Swift, Gibbon, Melville, and Pynchon. Austin: University of Texas Press, 1990.

Pavlovskis-Petit, Zoja. "Irony and Satire" A Companion to Satire. Ed. Ruben Quintero. Malden: Blackwell Publishing, 2007. 510-524. 
Pynchon, Thomas. The Crying of Lot 49. New York: Harper, 1986.

Quintero, Robin. "Introduction." A Companion to Satire. Ed. Robin Quintero. Malden: Blackwell Publishing, 2007. 1-13.

Reeve, N.H. and Richard Kerridge. “Toxic Events: Postmodernism and DeLillo's White Noise." The Cambridge Quarterly 23.4 (1994): 303-323.

Relke, Diana. "Feminist Ecocritique as Forensic Archaeology: Digging in Critical Graveyards and Phyllis Webb's Gardens." Canadian Poetry 42 (Spring/Summer 1998): 66-99.

---. “The Ecological Vision of Isabella Valancy Crawford: A Reading of 'Malcolm's Katie."” ARIEL 22.3 (July 1991): 51-71.

Richards, David Adams. "Land" When the Wild Comes Leaping Up. Ed. David Suzuki. Toronto: Douglas and McIntyre, 2002. 31-44.

---. Lives of Short Duration. Ottawa: Oberon Press, 1981.

---. Mercy Among the Children. Toronto: Doubleday, 2000.

---. Nights Below Station Street. Toronto: McLelland and Stewart, 1988.

---. River of the Brokenhearted. Toronto: Doubleday, 2003.

---. Road to the Stilt House. Toronto: Harper Collins, 1985.

---. The Friends of Meager Fortune. Toronto: Doubleday, 2006.

Ricou, Laurence. "David Canaan and Buckler's Style in The Mountain and the Valley." Dalhousie Review 57 (1978): 684-96.

---. "Empty as Nightmare: Man and Landscape in Recent Canadian Prairie Fiction." Mosaic 6.2 (1973): 143-160.

---. “So Big About Green." Canadian Literature 130 (1991): 3-6.

Rimstead, Roxanne. Remnants of Nation: On Poverty Narratives by Women. Toronto: 
University of Toronto Press, 2001.

Rosendale, Steven. The Greening of Literary Scholarship. Iowa City: University of Iowa Press, 2002.

Ross, Stephen. "Authenticity and Its Discontents: The Mountain and the Valley." Canadian Literature 165 (Summer 2000): 59-75.

Rutland, Barry. "Foreward." Genre, Trope, Gender: Essays by Northrop Frye, Linda Hutcheon and Shirley Neuman. Ed. Barry Rutland. Ottawa: Carleton University Press, 1992. 35-49.

Rye, Gill. "Registering Trauma: The Body in Childbirth in Contemporary French Women's Writing." Nottingham French Studies 45.3 (Autumn 2006): 92-104.

Sacouman, James and Henry Veltmeyer (eds). From the Net to the Net: Atlantic Canada and the Global Economy. Aurora: Garamond Press, 2005.

Salleh, Ariel. ““Essentialism' and Eco-feminism.” Arena 94 (1991): 167-173.

Sandilands, Catriona. "Mother Earth, the Cyborg, and the Queer: Ecofeminism and (more) Questions of Identity," NWSA Journal 9.3 (1997): 18-40.

---. The Good-natured Feminist: Ecofeminism and the Quest for Democracy. Minneapolis: University of Minnesota Press, 1999.

Sanger, Peter. John Thompson: Collected Poems and Translations. Fredericton: Goose Lane Editions, 1995.

Savoie, Donald. “All Things Canadian are now Regional." Journal of Canadian Studies 35.1 (2000): 203-217.

Scherf, Kathleen. "David Adams Richards' Blood Ties: Essentially Women.” Room of One's Own: A Feminist Journal of Literature and Criticism 14 (1991): 23-39. 
---. "David Adams Richards: 'He Must be a Social Realist Regionalist'." Studies in Canadian Literature, 15:1 (1990): 154-170.

Scofield, Sandra. "Outpost Epic a Novel of a Troubled Immigrant Family in Early1990s." Chicago Tribune April 6 1997: C9.

Seaman, Andrew. "Fiction in Atlantic Canada." Canadian Literature 68/9 (Spring/Summer 1976): 26-39.

---. "The History of Maritime Literature." Acadiensis 8 (Spring 1979): 132-37.

Sessions, George (ed). Deep Ecology for the Twenty First Century. Boston: Shambhala Publications, 1995.

Shields, Rob. "Intersections in Cultural Policy: Geographic, Socioeconomic and Other Markers of Identity." Canadian Ethnic Studies 35 (2003): 150-164.

Spettigue, Douglas. “The Way It Was: Ernest Buckler.” Canadian Literature 32 (1967): 40-56.

Spillers, Hortense. Black, White and in Color: Essays on American Literature and Culture. Chicago: University of Chicago Press, 2003.

Stacey, Robert. "Romance, Pastoral Romance, and the Nation in History: William Kirby's The Golden Dog and Philippe-Joseph Aubert de Gaspé's Les Anciens Canadiens," $\underline{\text { Recalling Early Canada: Reading the Political in Literary and Cultural }}$ Production. Ed. Jennifer Blair et al. Edmonton: University of Alberta Press, 2005. 91-117.

Staines, David. "Mapping the Terrain." Mosaic: A Journal for the Comparative Study of Literature and Ideas 11.3 (1978): 137-51.

Stanzel, F.K. "Innocent Eyes? Canadian Landscape as Seen by Frances Brooke, Susanna 
Moodie and Others." International Journal of Canadian Studies 4 (1991): 97-110.

Stearney, Lynn. "Feminism, Ecofeminism, and the Maternal Archetype: Motherhood as

a Feminine Universal," Communication Quarterly 42.2 (1994): 145-59.

Summerby-Murray, Robert. "Interpreting Deindustrialised Landscapes of Atlantic

Canada: Memory and Industrial Heritage in Sackville, New Brunswick" The

Canadian Geographer 46 (2002): 48-62.

Surette, Leon. "Creating the Canadian Canon," Canadian Canons: Essays in Literary

Value, Ed. Robert Lecker . Toronto: University of Toronto Press, 1991. 17-29.

Sutherland, Ronald. "The Mainstream." Canadian Literature 53 (1972): 32.

Taft, Michael. "Tracking the Cheshire Cat: Ethnic Americans and American Ethnicity on

Cape Breton Island." Canadian Folklore Canadien 13.1 (1991): 35-44.

Thompson, Peter. Perceptions of the Environment in Maritime Literature. M.A. Thesis,

Saint Mary's University, 2004.

Thurston, Harry (ed). The Sea's Voice: An Anthology of Atlantic Canadian Nature

Writing. Halifax: Nimbus, 2005.

Tremblay, Tony (ed). David Adams Richards : Essays on His Works. Toronto: Guernica, 2005.

Turner, Bryan. The Body and Society: Explorations in Social Theory. London: Sage Publications, 1996.

Vare, Robert. "The State of Narrative Nonfiction Writing." Nieman Reports 54.3

(Fall 2000): 18-19.

Vaughn, R.M. "Saint Brendan's." Victory Meat: New Fiction from Atlantic Canada. Ed. Lynn Coady. Toronto: Anchor Canada, 2003. 157-172. 
Wallace, Kathleen. ““All Things Natural are Strange’: Audre Lorde, Urban Nature and Cultural Place," The Nature of Cities: Ecocriticism and Urban Environments. Ed. Michael Bennett and David Teague. Tuscon: University of Arizona Press, 1999. 55-76.

Warley, Linda, Ball, John Clement and Robert Viau. "Introduction: Mapping the Ground" Studies in Canadian Literature 23.1 (1998): 1-7.

Westfall, W. "On the Concept of Region in Canadian History and Literature." Journal of Canadian Studies 15.2 (1980): 3-15.

Williams, Raymond. The Country and the City. London: Chatto and Windus, 1973. Willmott, Glenn. "The Frontier beyond Empire: East of Everything in Thomas Raddall's The Nymph and the Lamp." Canadian Literature 157 (1998 Summer): 56-78.

Whalen, Terry. “Atlantic Possibilities." Essays on Canadian Writing 20 (Winter 198081): $32-60$.

---. "Introduction: Special Issue on the Maritime Provinces" Essays on Canadian Writing 31 (Summer 1985): 1-4.

White, Hayden. The Content of the Form: Narrative Discourse and Historical Representation. Baltimore: Johns Hopkins University Press, 1987. White, Lynn. "The Historical Roots of Our Ecologic Crisis." The Ecocriticism Reader. Eds. Cheryll Glotfelty and Harold Fromm. Athens: University of Georgia Press, 1996. 3-14.

Whitmore, Erin. Inhabiting Ecocriticism: Canadian Women Writers Write Environmentalism. M.A. Thesis, Trent University, 2003. Wilde, Alan. Horizons of Assent: Modernism, Postmodernism, and the Ironic 
Imagination. Baltimore: Johns Hopkins University Press, 1981.

Wilson, Alexander. The Culture of Nature: North American Landscape from Disney to the Exxon Valdez. Toronto: Between the Lines, 1991.

Woodcock, George. "Maritime Cadences." Canadian Literature 68/9 (Spring/Summer 1976): 3-6.

Workman, Thom. Social Torment: Globalization in Atlantic Canada. Halifax: Fernwood Publishing, 2005.

Wyile, Herb. "Regionalism, Postcolonialism and Canadian Writing: A Comparative Approach." Essays on Canadian Writing 63 (1998): 139-61.

Wylynko, David. "The Ecological Ethic: Sustainability, Ecophilosophy, and Literary Criticism" Canadian Poetry 42 (Spring/Summer 1998): 123-139.

Wynn, Graeme, "The Maritimes: The Geography of Fragmentation and Underdevelopment." Heartland and Hinterland. A Geography of Canada. Ed. L.D. McCann. Scarborough: Prentice-Hall Canada Inc., 1987.

Young, Alan R. "The Pastoral Vision of Ernest Buckler in The Mountain and the Valley" Dalhousie Review 53 (1973): 219-26.

---. Time \& Place: The Life and Works of Thomas H. Raddall. Fredericton: Acadiensis, 1991. 


\section{APPENDIX A: BIBLIOGRAPHY OF WRITINGS BY LYNN COADY}

\section{Fiction}

Strange Heaven. Fredericton: Goose Lane Editions, 1998. Toronto: Anchor Canada, 2002.

Play the Monster Blind. Toronto: Doubleday Canada, 2000.

Saints of Big Harbour. Toronto: Doubleday Canada, 2002. U.K.: Jonathan Cape, USA: Houghton-Mifflin.

Mean Boy. Toronto: Doubleday Canada, 2006.

Hyperborea. Scheduled for Fall 2009. Excerpt found at <http://www.banffcentre.ca/writing/wired/pdf/lynncoadyread.pdf $>$

\section{Theatre}

Cowboy Names, three-acts, Fredericton: Black Box Theatre, 1995.

Cold in the Morning, three-acts, staged reading, Vancouver: Theatre BC International Play Writing Competition, 1996. Also published as Coady's M.F.A. Thesis, University of British Columbia, 1997.

Monster, one-act, Kelowna Theatre Festival, 1998, Revelstoke Theatre Festival, 1998. Make Me, Vancouver: Playwright's Theatre Centre, 2005.

\section{Stories Published in Collections}

"Batter My Heart." The Day the Men Went to Town : 16 Stories by Cape Breton Women.

Ed. Ronald Caplan. Wreck Cove: Breton Books, 1999. 119-132.

"Play the Monster Blind." Turn of the Story: Canadian Short Fiction on the Eve of the Millenium. Ed. Joan Thomas and Heidi Harms. Toronto: Anansi Press, 1999. 143- 
168.

"The Three Marys." Home For Christmas: Stories from the Maritimes and

Newfoundland. Ed. Sabine Campbell. Fredericton: Goose Lane Editions, 1999. $125-141$.

"Batter My Heart." Atlantica: Stories from the Maritimes and Newfoundland. Ed. Lesley

Choyce. Fredericton: Goose Lane, 2001. 103-114.

"The Les Bird Era." The Notebooks. Ed. Michelle Berry and Natalie Caple. Toronto: Anchor Canada, 2002. 61-72.

"Play the Monster Blind." The Penguin Book of Contemporary Canadian Women's Short

Stories. Ed. Lisa Moore. Toronto: Penguin Canada, 2006. 43-68.

"Flight of the Wendybird." Great Expectations: Twenty Four True Stories About

Childbirth Ed. Lisa Moore and Dede Crane. Toronto: House of Anansi Press, 2008. 233-249.

\section{Stories Published in Periodicals}

"A Great Man's Passing." Antigonish Review 97 (Spring 1994): 13-32.

"Ice cream man." This Magazine 32.1 (July-August 1998): 36-41.

"Jesus Christ, Murdeena." Barcelona Review 19, (July-August 2000). Online at $<$ http://www.barcelonareview.com/19/e lc.htm $>$.

"Wireless." The Walrus (April 2005): 13-26.

"Clear Skies." Joyland: A Hub for Short Fiction. Website edited by Emily Schultz (June 16, 2008). Online at < http://www.joyland.ca/stories/toronto/clear_skies $>$

\section{Interviews/Profiles}

Berry, Michelle. "An Interview with the Author (Lynn Coady)." The Notebooks: 
Interviews and New Fiction from Contemporary Writers. Ed Natalee Caple and Michelle Berry. Toronto: Anchor Canada, 2002. 73-89.

Bookmunch. "Interview: Lynn Coady - Saints of Big Harbour" 2002. 28 April 2008 $<$ http://www.lynncoady.com/rev_saints_bm.htm>.

Hutchison, Lorna. "Coady, Lynn.” The Literary Encyclopedia. 16 June, 2003. Online database available at http://www.litencyc.com/

"Lynn Coady: author." Contemporary Canadian Biographies. . Thomson Gale, 1999, NA.

Lynn Coady's official website found at www.lvnncoady.com

Pyper, Andrew. "Author Profile: Lynn Coady." Quill and Quire 64.12 1-13.

Steeves, Rachel. “"Flawed splendour': a conversation with Lynn

Coady (Interview)." Studies in Canadian Literature. 32.1 (Winter 2007): 231239.

“TDR Interview Lynn Coady.” The Danforth Review, Toronto: November 2004.

\section{Critical Editions}

Urquart, Jane. The Whirlpool. Afterward by Lynn Coady. Toronto: MacLelland and

Stewart, 2002.

Victory Meat: New Fiction from Atlantic Canada. Ed. with an introduction by Lynn

Coady. Toronto: Doubleday Canada, 2003.

The Anansi Reader: 40 Years of Very Good Books. Ed. with an introduction by Lynn Coady. Toronto: Anansi, 2007.

The Journey Prize Stories 20: The Best of Canada's New Writers. Ed. Lynn Coady, Neil Smith and Heather O'Neil. Toronto: Emblem Editions, 2008. 


\section{Articles, Reviews and Essays}

"A case of made-in-Canada writer chill." The Globe and Mail. Oct 28, 2003: R1.

"A fan who's tired of being called 'ho." The Globe and Mail. Feb 3, 2004: R1.

"A few crass words about the artful poor." The Globe and Mail. May 27, 2003: R1.

“A pearl of a cultural centre." The Globe and Mail. Apr 13, 2004: R1.

“A Tragic Comedy." Quill and Quire 71.3 (March 2006): 90-1.

"Acadian drifter Clive Doucet's memoir of Acadie and its people is perceptive and absorbing, even if his glasses are sometimes rose-tinted." Globe and Mail Aug. 21, 1999: D18.

“Aficionado of R. Crumbism: Why I love libidos of comic proportions bottom cent: What's a nice Catholic feminist doing reading Heavy Metal magazine? Peering, it seems, straight into the dreams of the North American male." The Vancouver Sun May 1, 1999: E11.

"Against male vanity: From hair to eternity: This Catholic woman likes the soft and fuzzy." The Vancouver Sun. Jul 3, 1999: E2.

“All That's Holy." Event 36.1 (Summer 2007): 17-20.

"Arco Datta's shot of a woman in the throes of mourning for a relative lost in the tsunami is a beautiful, moving, brilliantly-composed work of journalistic photography, certainly worthy of having been named Photo of the Year by the non-profit foundation World Press Photo." Adbusters 13.5 (2005):1.

"Atwood and her double: The icon whose very name makes some people roll their eyes describes herself -- and her writing self." The Vancouver Sun. Mar 9, 2002: D15. 
“Avarice As An Art.” Adbusters 71 (May-Jun 2007): 1.

"Back to Backlash" Chatelaine 72.5 (May 1999): 9.

“Baltimore's Mansion (review)" Chatelaine 72.10 (Oct, 1999): 12.

"Beyond beach volleyball: Black Tights author maps a damning indictment of how woman athletes are undermined, marginalized." The Gazette. Aug 3, 2002: H2.

"Books that Say Arse," Victory Meat: New Fiction from Atlantic Canada. Ed.

Lynn Coady. Toronto: Anchor Canada, 2003. 1-6.

"By the Shore (review)." Chatelaine 72.8 (Aug 1999): 12.

“Coasting." Saturday Night. 114.6 (July-August 1999): 27-29

"Coldly compassionate Coetzee." The Globe and Mail. Dec 9, 2003: R1.

"Culture club: A country is enriched by its arts and culture, readers argue. If that requires government aid, so be it." The Vancouver Sun. Jul 31, 2001:A13.

“Deflected Nervousness." Reading Writers Reading: Canadian Authors' Reflections. Ed

Danielle Schaub. Edmonton: University of Alberta Press, 2006. 32-33.

"Epic prose: A novel set on the Miramachi will make a star of David Adams Richards,

Canada's greatest (unknown) writer." Vancouver Sun Sept. 23, 2000: D7.

"Feting a city's cultural Geist." The Globe and Mail. Mar 16, 2004: R1.

"Game, set and match: Laura Robinson convincingly argues that female athletes are second-class citizens." The Vancouver Sun. Jun 22, 2002:. H17.

"Hockey heaven, hockey hell: hockey night in Port Hawkesbury." This Magazine. 33.3 (Nov-Dec 1999): 26-7.

"Hook, Line and Stinker (review of The Drowning People)." Chatelaine 72.6 (June 1999): 8. 
"I stand revealed in all of my lady-geek glory." The Globe and Mail. Jan 6, 2004: R1.

"I think you'll like my folks." The Globe and Mail. Jul 22, 2003: R1.

"If only this trash would take me out." The Globe and Mail. Aug 5, 2003: R1.

"Irony is alive and wearing a pair of Boot Cut jeans." The Globe and Mail. Feb 17, 2004:

R1.

"Jam Session." Chatelaine 72.12 (Dec 1999): 14

"Lording it over the landlord." Canadian Geographic. 127.6 (Nov/Dec 2007): 118.

"Massive Change brought to you by: American Express and Altria." Adbusters 13.2 (2005): 1.

"More power to us all: Crossing the border between the genders." Edmonton Journal. Nov 21, 1999: E15.

"My love-hate relationship with hockey: I resent hockey for the way its overriding importance has stayed with me my entire (female) life. But I admit a wistful longing for the game that originates decades ago, when my dad took me to watch our hometown Port Hawkesbury Pirates." The Ottawa Citizen. Dec 14, 1999: A13.

"Oh right, the mythology and magic realism thing." National Post. Sep 9, 2000: B11.

"Olympic boosterism has a hollow ring." The Globe and Mail. Jul 8, 2003: R1.

"On Behaving Badly." Writing Life: Celebrated Canadian and International Authors on

Writing and Life. Ed. Constance Rooke. Toronto: McClelland and Stewart, 2006. 110-117.

"Once upon a time in the Story Seminar." The Globe and Mail. Sep 16, 2003: R1.

"Nabokov's work of dark and revolutionary genius." The Vancouver Sun. Dec 17, 2005 : 
F2.

“No Regrets." Chatelaine 72.9 (Sept 1999): 9.

"Notes from underground. (In Habitat). " Canadian Geographic. 123.1 (Jan-Feb 2003): 106 .

"Poets rush in where Atwood fears to tread." The Globe and Mail. Jun 10, 2003: R1.

“Precaution." Adbusters 13.2 (2005): 1.

“Remembrance Of Things Past: Jane Urquhart's finely crafted novel explores tangible memory." Time International 157.15 (2001): 80.

"School may not be so bad." National Post. May 25, 2002: A23.

Sixty-five women missing from Vancouver's Downtown Eastside. Fifteen bodies found,

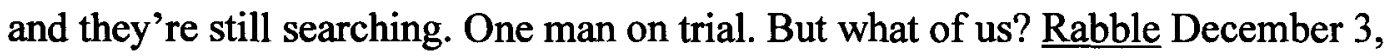
2002: 1.

"Some think this is a great defeat. It is simply a bend, nothing more, a bend in the road." Adbusters 13.3 (2005): 1 .

"Speaking for myself." The Vancouver Sun. Jul 15, 2000: E19.

"St. Georgia fights off the dragon." The Globe and Mail. Oct 15, 2003 : R4.

“Step Right In! First novelist Robert Hough offers up an amazing life under the Big Top." Time International 157.22 (2001): 60.

“Stiffed Competition." Chatelaine 72.11 (Nov 1999): 14.

"Strength in numbers: Vancouver's Seven Sisters writing collective proves that selfpublishing is more than just vanity press." The Vancouver Sun. Sep 30, 2000: E6. "Surviving Survival.: A Forum on Atwood's Survival." With Phillip Marchant and Noah 
Richler. Quill and Quire December 2007, 20-27.

"Swept away by passion: Rosemary Sullivan says it's not just the world's Carrie

Bradshaws who are fools for love. Women who should have known better, like

Simone de Beauvoir and Frida Kahlo, had the same weakness." The Vancouver

Sun May 26, 2001. E17.

"Tales of a G-G Awards juror.” The Globe and Mail. Nov 11, 2003: R3.

"That rosy image is the pits: The romanticized picture of Atlantic Canada painted in a string of CBC TV series trivializes the real lives of Maritimers." Vancouver Sun May 15, 1999: E7.

“THE ‘A' WORD.” Saturday Night. 115.1 (Feb 2000): 55.

"The backwax backlash." The Globe and Mail. Jan 20, 2004: R1.

"The dolorous Passion of Mad Max." The Globe and Mail. Aug 19, 2003: R1.

"The full read on the curse: Breaking the tampon taboo: Anyone who'd rather not discuss menstruation may now turn the page because Lynn Coady has been reading up on it." The Vancouver Sun. Aug 7, 1999: F9.

"The hot book on manliness: Feminist fatale: In a culture of Rambos, Spur Posses and Promise Keepers, Susan Faludi comes to the rescue - of men." The Vancouver Sun Oct 23, 1999: E8.

"The Importance of Being Earnest." Quill and Quire 66.9 (September 2000): 66.

"The new job reality: Many young people, who are finding it tough enough to find work, have vowed to avoid their parents' cycle of a secure future in exchange for joyless drudgery, and do not want to end up feeling that they have wasted their lives." The Vancouver Sun. Jan 2, 1999: C3. 
"The real horror of Stephen King." The Globe and Mail. Nov 25, 2003: R1.

"The smell of sour grapes." The Globe and Mail. Sep 2, 2003: R1.

"The weapons of mass distraction." The Vancouver Sun. Oct 9, 2004: D7.

"There's no place like home. The headline in the Cape Breton paper screamed "poisonous yellow ooze coming out of the ground." Transplanted Maritimer Lynn Coady wonders what the fleece-wearing, cellphone-toting denizens of Vancouver's Kitsilano would say if poisonous goo started seeping out from beneath their streets." This Magazine. Jan/Feb 1999: 32.

"They're using Viggo to sex up the book-mag trade." The Globe and Mail. Mar 2, 2004: R1.

"They've got Arnold, we've got Ashley." The Globe and Mail. Dec 23, 2003: R1.

“Two Male, British Bobbies Locked in a Lascivious Kiss.” Adbusters 13.5 (2005): 1.

"Waiting for the Whales." Canadian Georaphic (Mar 2008): 56-63.

"Western culture vultures spy eastern meat." The Globe and Mail. Jun 24, 2003: R1.

"What rhymes with scurvy?" Globe \& Mail. March 30, 2004: R1.

"Why the world needs Christopher Hitchens: A man willing to accuse Noam Chomsky of being 'soft on fascism' is someone we must hear from in times like these." The Vancouver Sun. Nov 17, 2001: D17.

"Winnipeg: the country's coolest hot zone." Globe \& Mail. Sept 30, 2003: R1. 


\section{APPENDIX B:}

JOURNAL ARTICLES AND BOOKS REVIEWS ON COADY'S WORK

\section{$\underline{\text { Articles/Chapters }}$}

Creelman, David. "Lynn Coady." Setting in the East: Maritime Realist Fiction. Montreal: McGill-Queen's University Press, 2003. 189-192.

Hutchinson, Lorna. "Lynn Coady: Strange Heaven." Strategies of the Grotesque in Canadian Fiction. Ph.D. Thesis, McGill University, 2004. 150-178.

Kelly, Tony. "A Place Called Strange Heaven." Changing English: Studies in Culture and Education 11:2 (2004): 213-222.

Wyile, Herb. "As for Me and Me Arse: Strategic Regionalism and the Home Place in Lynn Coady's Strange Heaven." Canadian Literature 189 (2006): 85-101.

\section{Reviews}

Armitage, Andrew. "Nova Scotia is the perfect setting: Trio of new novels set in Nova Scotia all worth reading." Sun Times. May 4, 2006: A5.

Atkinson, Diana. "Life's little miseries: Time after time in her new collection of stories, Lynn Coady draws attention to the kind of painful realities most of us choose to ignore." The Vancouver Sun. Mar 18, 2000: E11.

Attridge, Robert. "Living with the Vision." Event 31.3 (2002): 101-103.

Baxter, Gisele. "Mean Boy Review.” Canadian Literature. 189 (Summer 2006): 164.

Bethune, Brian. "Unforgotten Country: New Canadian fiction still draws from a past quickly fading into myth." Maclean's (July 1, 2002): 84-5.

Bigge, Ryan. "They roar, but don't rant." Globe \& Mail. (June 7, 2003): D17.

Black, Barbara. "Humour salts Coady's Cape Breton stories." The Gazette. Jan 26, 2002: 
K4.

Brook, Paula. "I like my fiction factual: It's not normal to fact-check a novel. But who said reporters are normal?" National Post. Jan 3, 2001: B1.

Butler, Tamara. "Coady, Lynn. Saints of Big Harbour." Library Journal. 127.19 (Nov 15, 2002): 99 .

Caple, Natalee. “A Mean Boy's poetic comedy." Calgary Herald. Mar 4, 2006: F3.

Carlson, Tim. "Creating a monster: Lynn Coady digs beneath the Cape Breton stereotypes in her acclaimed new book Play the Monster Blind." The Vancouver Sun Mar 23, 2000: C5.

Compton, Valerie. "Fine young writer on the mark." Edmonton Journal.. Jun 21, 1998: F7.

---. "Suffocating on The Island: A skilled look at a woman staying alive in Cape Breton." Edmonton Journal. Mar 19, 2000: E14.

Dafoe, Chris. "From unpaid phone bills to literary darling." The Globe and Mail. Mar 25, 2000: D2.

Daurio, Beverly. "Monster talent arrives." The Globe and Mail. Mar 25, 2000: D3.

---. "Saints comes marching in." The Globe and Mail. Mar 16, 2002: D9.

Donnelly, Pat. "30-something writer sees 1970s as a fascinating era." The Gazette, April 1, 2006: J3.

Drainie, Bronwyn. “I am Acadian.” Quill and Quire 67.2 (February 2002): 33.

Dunn, Lori. “Strange Heaven Review." Canadian Book Review Annual (Annual 1998): 176-177.

Fernandez, Sandy. "Homebodies: Lynn Coady's subtle mix of cramped, vital lives." Time 
International 155.14 (2000): 98.

Fuller, Danielle. "Living in Hopes - Atlantic Realities and Realisms." Canadian Literature 170/171 (Autumn/Winter 2001): 199-203.

Grainger, James. "Too subtle for Gothic; Lynn Coady has created two of the more memorable characters in recent Canadian fiction." Toronto Star. Mar 17, 2002: D13.

Grubisic, Brett Josef. "Claustrophobia in Nova Scotia." National Post. Mar 18, 2000: 7. Haggas, Carol. "Coady, Lynn. Saints of Big Harbour. " Booklist. 99.3 (Oct 1, 2002): 300 .

Halim, Nadia. "Young at Heart." Quill and Quire 64.4 (April 1998): 24.

Hamilton, Geoff. "Big Harbour, Small Life." Essays on Canadian Writing (Spring 2003): $163-169$.

Harvey, Kenneth. "Un-notable novel is a knockout The astonishing debut novel Strange Heaven, a study of the joys and frustrations of life, is both hilarious and heartbreaking, authentic and unforgettable." The Globe and Mail. Jun 20, 1998: D17.

Hepburn, Alan. "Ordure and Ornament." Canadian Literature 180 (Spring 2004): 122124.

Hodd, Tom. "A Series of Firsts: Three New Novelists from the Maritimes." Antigonish Review 119 (Autumn 1999): 89-93.

Hoefle, Harold. "Travels in Coadyland." Books in Canada 31.4 (June/July 2002): 3. Holdstock, Pauline. "Again to the well of booze, brawls and self-delusion: Hard to know whether to laugh or cry when Lynn Coady mines her rich vein of Canadian 
culture." The Vancouver Sun. Mar 9, 2002: D16.

Hollander, Malika. "Lynn Coady, Cape crusader: Saints of Big Harbour: New novel presents Coady's view of Maritime life." National Post. Apr 17, 2002: B3.

Horton, Marc. "Humour not as easy as it looks, author discovers: Pens a laugh-out- loud coming-of-age story." Edmonton Journal. Mar 5, 2006: B1.

Kavanagh, Patrick. "The Doyenne of Defeat: Lynn Coady is the Mistress of Small-Town Desperation." The Ottawa Citizen. April 7, 2002: C13.

Kemp, Arnold. "Not Such a Bleak House (review of Saints). Observer (Sunday Aug 11, 2002). Online at http://www.guardian.co.uk/books/2002/aug/11/fiction.features1

Levine, Elise. "Having scooped a G-G award nomination for her debut novel, Vancouver's Lynn Coady turns to the story form with another resounding triumph." Toronto Star Mar. 19, 2000: 1.

---. "The bright kernel of things ; Having scooped a G-G award nomination for her debut novel, Vancouver's Lynn Coady turns to the story form with another resounding triumph." Toronto Star. Mar 19, 2000: 1.

MacGowan, James. "'What if people find out I'm not as funny as Mordecai Richler?"” The Ottawa Citizen. Apr 2, 2006: C7.

MacPherson, Margaret. "Maritime watch on Lynn Coady." Edmonton Journal. Sep 20, 1998: F6.

Mandel, Charles. "Big Harbour more alluring than bleak sister." Calgary Herald. Mar 9, 2002: ES09.

---. "Home is where the writer isn't: Lynn Coady's new book is set in the place she misses - Nova Scotia." Calgary Herald. Mar 30, 2002: ES11. 
Matthews, Carol. "Saints of Big Harbour Review." Malahat Review 140 (2002): 113 114.

McGillis, Ian. "Here's why Lynn Coady is one of Canada's best." The Gazette. Mar 16, 2002: I1.

---. "Larry aspires to be a poet." The Gazette. Mar 4, 2006: J4.

---. "Small-town portrayal through its characters." Times - Colonist. May 5, 2002: D10.

Moher, Frank. Novel skewers ivory-tower absurdities." National Post. Mar 18, 2006 : WP15.

Moore, Maureen. "Blood relations: Prize-winning first novel features unwanted pregnancy ... and a 'ghastly' family life." The Vancouver Sun. Aug 22, 1998: G3.

Morash, Gordon. "Getting the good word out; Book-tour season upon us, with all the politics it takes." Edmonton Journal. Jul 5, 1998: F7.

Naves, Elaine. "Down East (accent on down)." The Gazette. Aug 15, 1998: J4.

Pyper, Andrew. "Heaven on Earth: A Surprise GG nomination adds to the honours for first-novelist Lynn Coady." Quill and Quire 64.12 (December 1998): 1-2).

Roeder Mah, Sasha. "Vivid characters create coming-of-age classic: Mean Boy hilariously skewers halls of academe." Edmonton Journal. Mar 5, 2006: E11.

Roig, Denise. "Stories peopled with originals: Coady's characters are lost, but lovable." The Gazette. Mar 18, 2000: J3.

Ross, Veronica. “Drink, drank, drunk - drab; Novel's promise drowns in sozzled poetprof's sorrows." Daily Mercury. Mar 25, 2006: C4.

Rundle, Lisa. "Debunking the mythical writer's life." The Globe and Mail. Mar 10, 2006: R31. 
Ryan, Kerry. "Saints of Big Harbour (Arts and Lit: Winter Reading)" Herizons. 16.3 (Winter 2003): 33.

Scott, Cece. “There's no place like home.” Toronto Star. Aug 29, 1998: 1.

Senna, Carl. "He's a poet and he knows it: Lynn Coady has great fun skewering an academic poseur." The Vancouver Sun. Apr 1, 2006: F16.

Simpson, Peter. "An Atlantic Canadian genre?: A new novel treads the well-worn path from Down East." The Ottawa Citizen. May 5, 2002: C11.

Sinclair, Sue. “Telling It Like It Is.” Fiddlehead 208 (Summer 2001): 158-161.

Steele, Karen. "Behind closed shutters." Times Literary Supplement 5191 (2002): 24.

Stirling, Claire. "A poet's coterie: Coady takes no prisoners with look at art and academia." Calgary Herald. Mar 4, 2006: F4.

Sutherland, Katherine. "To Plot or Not." Canadian Literature 173 (Summer 2002): 127129.

Sugars, Cynthia. "The Word I am Not." Books in Canada 35.3 (April 2006): 6-8.

Taylor, Jim. "Play the Monster Blind Review." Antigonish Review 125 (Annual 2001): 29-36.

Tihanyi, Eva. "Beware the bad boy poet." Toronto Star. Mar 5, 2006: D05.

Tong, Murray. "A devil of a place; A savage look at a Nova Scotia everyone wants to leave." The Spectator. Mar 23, 2002: M18.

---. "The trials of creative-writing school." The Spectator. Apr 8, 2006: D13.

van Herk, Aritha. "Campus poets go wild." The Globe and Mail. Mar 4, 2006: D3.

---. "Teen struggles to find truth in a riptide of lies and terror." Edmonton Journal. Mar 24, 2002: D11. 
---. "Small-minded small towns: Streets don't get any meaner than this." The Ottawa Citizen. Mar 26, 2000: C14.

Vaughn, RM. "To the lighthouse ... or maybe not." National Post. Mar 18, 2006: WP15. Venetis, Tom. "Saints of Big Harbour Review." Canadian Book Review Annual (Annual 2002): 154 .

Walker, Susan. "Coady channels unruly '70s campus-lit scene; Students embrace hardliving poet; Novelist draws on Maritimes roots." Toronto Star. Mar 28, 2006: E05.

Williams, Leigh Anne. "Portrait of the Young Poet: Lynn Coady's new novel charts the progress of a writer who is more Woody Allen than Walt Whitman." Time Canada. 167.11 (March 13, 2006): 48.

Wiersema, Robert. "A journey worth a thousand words: For writer Lynn Coady, leaving Cape Breton was probably the best thing she could have done." National Post Mar. 13, 2000: D5.

Wyman, Max. "Mining the rich vein of life's experiences: Her first novel professes to be fiction, but Lynn Coady admits that she found a wealth of literary material in her harsh upbringing in Cape Breton.” The Vancouver Sun. Sep 26, 1998: J6. 